\title{
Proposta de um modelo de capacidade de processamento de trens cargueiros em redes ferroviárias de linha singela
}

Dissertação apresentada à Escola de Engenharia de São Carlos da Universidade de São Paulo, como parte integrante dos requisitos para obtenção do título de Mestre em Ciências, Programa de Pós-Graduação em Engenharia de Transportes. Área: Planejamento e Operação de Sistemas de Transportes.

ORIENTADOR: Prof. Dr. João Alexandre Widmer 
AUTORIZO A REPRODUÇÃO E DIVULGAÇÃO TOTAL OU PARCIAL DESTE TRABALHO, POR QUALQUER MEIO CONVENCIONAL OU ELETRÔNICO, PARA FINS DE ESTUDO E PESQUISA, DESDE QUE CITADA A FONTE.

Ficha catalográfica preparada pela Seção de Tratamento da Informação do Serviço de Biblioteca - EESC/USP

Isler, Cassiano Augusto

Proposta de um modelo de capacidade de processamento de trens cargueiros em redes ferroviárias de linha singela / Cassiano Augusto Isler ; orientador: João Alexandre widmer. -- São Carlos, 2010.

Dissertação (Mestrado-Programa de Pós-Graduação em Engenharia de Transportes e Área de Concentração em Planejamento e Operação de Sistemas de Transporte) -Escola de Engenharia de São Carlos da Universidade de são Paulo, 2010

1. Capacidade ferroviária. 2. Ferrovias. 3. Linha singela. 4. Modelos de capacidade ferroviária. 5. Redes ferroviárias. I. Título. 
FOLHA DE JULGAMENTO

Candidato(a): Engenheiro CASSIANO AUGUSTO ISLER.

Dissertação defendida e julgada em 19/04/2010 perante a Comissão Julgadora:

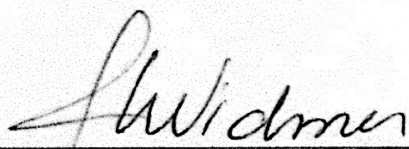

Prof. Titular JOÃO ALEXANDRE WIDMER - (Orientador) (Escola de Engenharia de São Carlos/USP)

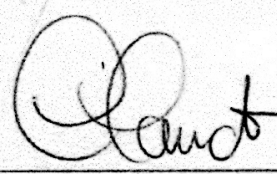

Prof. Associado CLÁUDIO BARBIERT DA CUNHA (Escola Politécnica/USP)

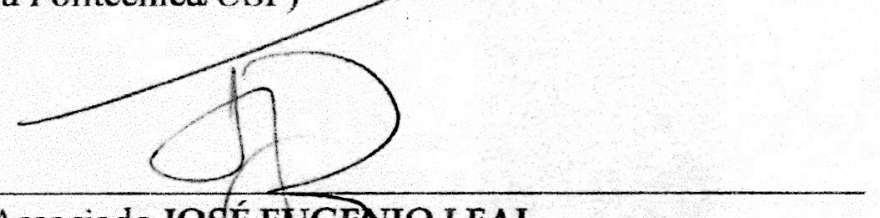

Prof. Associado JOSÉ EUGENIO LEAL

(Pontifícia Universidade Católica do Rio de Janeiro/PUC-Rio) aprovado

Aprevado

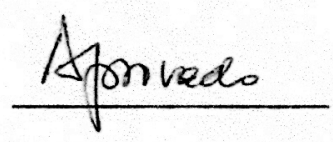

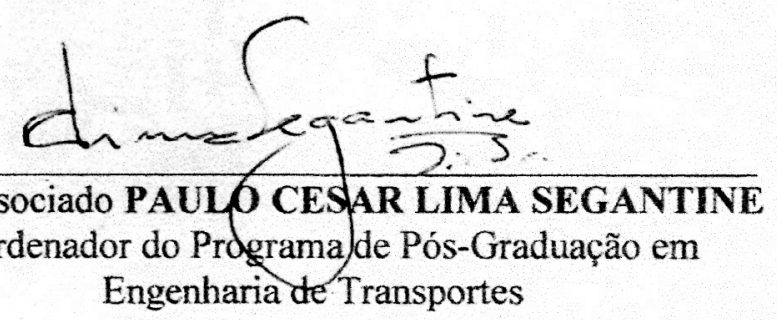

Prof. Associado PAULO CESAR LIMA SEGANTINE

Coordenador do Prdgrama de Pós-Graduação em Engenharia de Transportes

Prof. Titular GERAYDO ROBERTO MARTINS DA COSTA Presidente da Comissão da Pós-Graduação da EESC 

Aos meus pais, Sérgio e Isolina, e irmãos, Juliana e Érico.

Pela compreensão. 



\section{AGRADECIMENTOS}

Ao Prof. Dr. João Alexandre Widmer, pela atuação direta em meu desenvolvimento acadêmico e pessoal. Fico extremamente grato pelo estímulo à superação de minhas dificuldades.

Aos docentes e funcionários da Escola de Engenharia de São Carlos, cujo trabalho foi essencial para minha formação durante os anos de graduação. Aos profissionais do Departamento de Transportes dessa instituição, que viabilizaram a realização deste trabalho.

Aos meus familiares, pelo incentivo durante o desenvolvimento deste trabalho. Em especial aos meus pais, sem os quais seria impossível efetivar minhas conquistas até o presente momento.

Aos queridos amigos Aline, Erika, Ísis, Olívia, Stephanie, Tatiane e Marcelo, que estiveram próximos a mim e cujo apoio foi determinante para que atingisse meus objetivos. Aos amigos que conheci nesse período, Amilcar, Cleber, Diogo, Márcia Lika e Neto, muito obrigado pelo apoio.

Aos colegas do Departamento de Transportes, Bruno Bertoncini, Cândido, Iara, Isabela, Luciana, Mateus Araújo, Monique e Rochelle, que estiveram presentes durante a realização deste trabalho e que, de alguma forma, contribuíram para o seu melhoramento. Estendo meus agradecimentos àqueles que não foram citados, mas que certamente fizeram parte deste processo.

Aos colegas que foram orientados pelo Prof. João Alexandre Widmer, Celane, Cynthia, Karênina, Leonardo, Leandro, Serginho e Waldemiro, pelos conselhos e troca de experiências durante a minha passagem pelo Departamento de Transportes. À Dr. ${ }^{a}$ Karenina Martins Teixeira, que me auxiliou em diversas etapas desta pesquisa, fornecendo informações a que tinha acesso sem as quais seria inviável a realização deste trabalho.

Ao CNPq - Conselho Nacional de Desenvolvimento Científico e Tecnológico - pela bolsa de estudos concedida para o desenvolvimento desta pesquisa. 

Isler, C. A. (2010). Proposta de um modelo de capacidade de processamento de trens cargueiros em redes ferroviárias de linha singela. São Carlos, 2010, 215 p. Dissertação (Mestrado) - Escola de Engenharia de São Carlos, Universidade de São Paulo.

O aumento da produtividade das ferrovias, observado no período pós-concessão da operação à iniciativa privada, é decorrente da utilização de composições com grandes comprimentos e elevadas cargas por eixo, aplicação de tecnologias para o gerenciamento do sistema e investimentos na infra-estrutura. Entretanto, a intensificação do tráfego na malha ferroviária resultou no aumento do desgaste da via permanente, que aliada às restrições geométricas exigiu a imposição de limites operacionais de velocidades, comprometendo significativamente a capacidade de processamento de trens. Esta pesquisa apresenta um método de identificação dos trechos de uma rede ferroviária que necessitam de prioridade de investimentos, visando o aumento da capacidade de processamento, através de um modelo de análise da circulação dos trens com base em diagramas espaço-tempo. Os dados de entrada do modelo são os tempos de viagem nos arcos e a proporção de trens que partem de cada um dos terminais da rede, em relação ao total que converge para um terminal de concentração de cargas. O modelo fornece o número de trens diários que circulam em cada ramal da rede, o arco que restringe o aumento da capacidade do sistema e o intervalo de tempo entre trens sucessivos, no sistema. A aplicação do modelo em uma rede formada pelos ramais do sistema ferroviário do Estado de São Paulo permitiu a identificação dos $\operatorname{arcos}$ que restringem o aumento da capacidade dos trens, cujas cargas são destinadas ao Porto de Santos, e reforçou a hipótese de que a falta de conservação da infraestrutura ferroviária é o fator que impõe maiores restrições à circulação dos trens, seguido dos parâmetros geométricos (raio das curvas e rampas) da via permanente.

Palavras-chave: Capacidade ferroviária, Ferrovias, Linha singela, Modelos de capacidade ferroviária, Redes ferroviárias. 

Isler, C. A. (2010). Proposal of a freight trains processing capacity model on single line railway networks. São Carlos, 2010, 215 p. Dissertação (Mestrado) - Escola de Engenharia de São Carlos, Universidade de São Paulo.

Increasing the productivity of the railways, after the system's operation concessions, is due to usage of long trains with high loads per axis, the application of technologies to properly manage the system and investments on infrastructure. However, the intense traffic on railroad caused an increase on track's waste which, attached the geometric limitations, required the imposition of operational limits of speeds, that significantly spoiled the railway capacity. This research presents a method that identify the stretches on a railway network that need priority of investments in order to improve capacity, based on a model that analyses space-time diagrams. The input data of this model are travel times on arches and the proportion of trains that leave each terminal of the network related to all the trains that reach a terminal that concentrates the load. The model provides the number of daily trains traveling on each branch of the network, the arc that restricts the improvement on capacity and the time interval between successive trains in the system. Its application on a network of the State of São Paulo allowed identifying the arcs that restrict the improvement of system's capacity, and reinforced the hypothesis that lack of maintenance on railway infrastructure is the greatest restriction on the movement of trains, followed by geometrical parameters (radius of curves and slopes) of the track.

Keywords: Railway capacity, Railroads, Single line, Railway capacity models, Railway networks. 



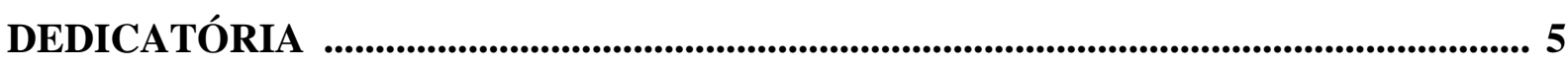

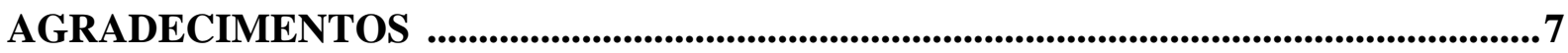

RESUMO _..............................................................................................................................................9

ABSTRACT …............................................................................................................................................11

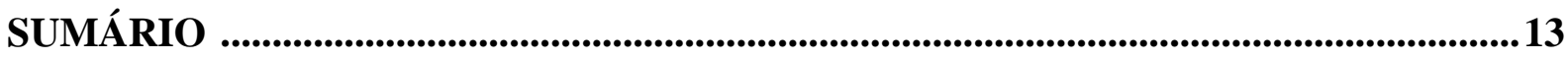

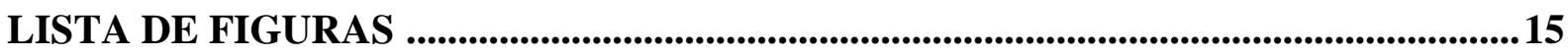

LISTA DE TABELAS ........................................................................................................................ 19

LISTA DE SIGLAS ..............................................................................................................................21

1. INTRODUÇÃO .................................................................................................................................23

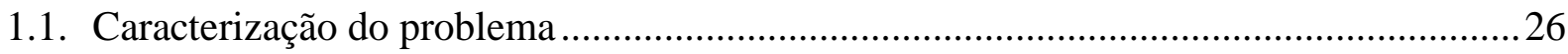

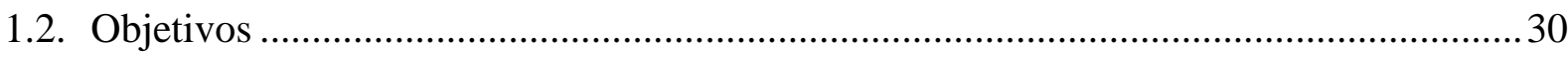

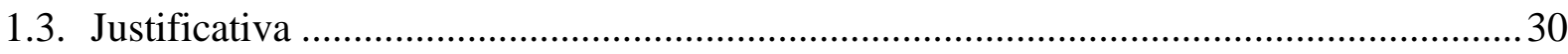

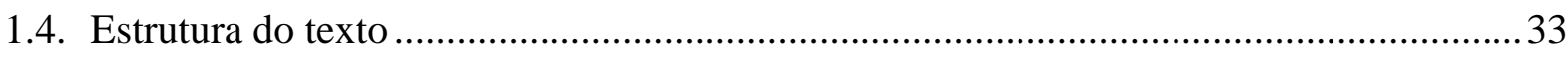

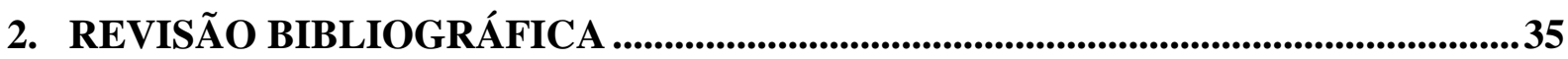

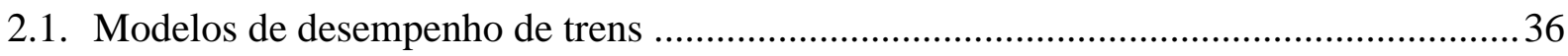

2.2. Modelos de scheduling .......................................................................................... 40

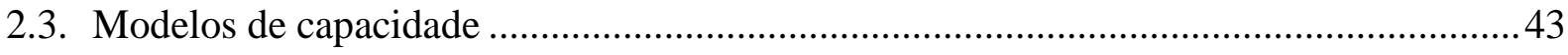

2.4. Considerações sobre a revisão bibliográfica ....................................................................52

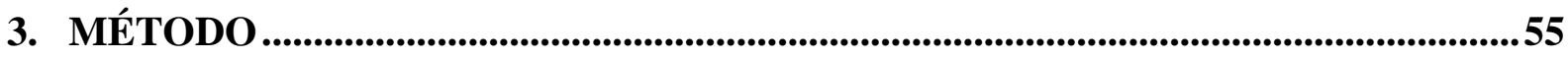

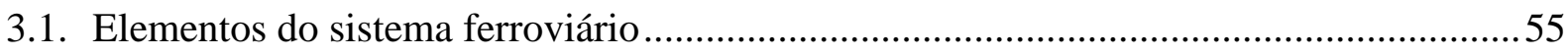

3.2. Elementos constituintes do material rodante...............................................................57

3.3. Definições sobre a operação ferroviária.........................................................................58

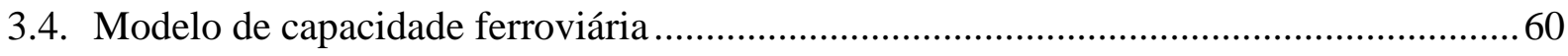

3.4.1. ETAPA 1 - Parâmetros da via e do material rodante...................................................... 60

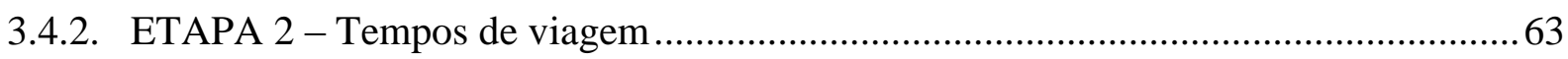

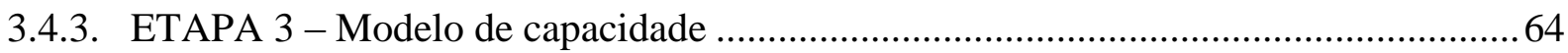

4. APLICAÇÃO DO MODELO....................................................................................81 


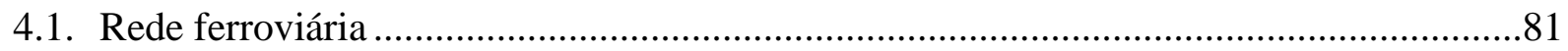

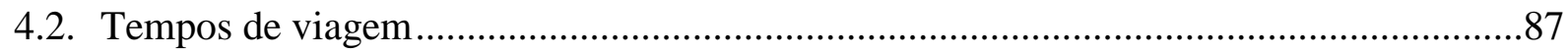

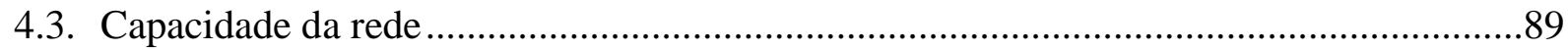

4.4. Considerações sobre a aplicação do modelo de capacidade ...........................................107

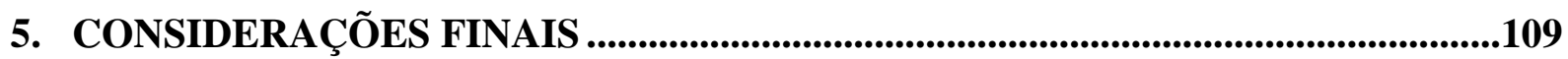

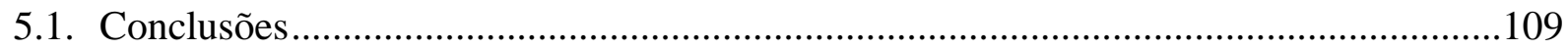

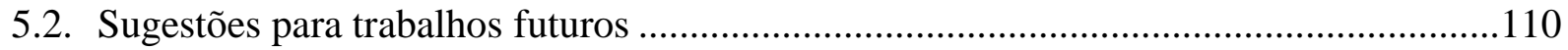

REFERÊNCIAS BIBLIOGRÁFICAS ..........................................................................113

BIBLIOGRAFIA COMPLEMENTAR ........................................................................................119

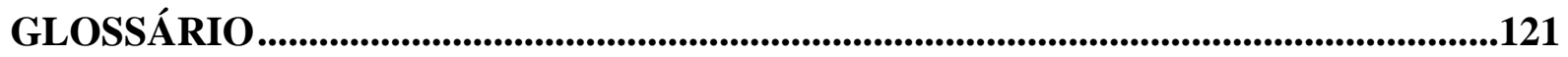

APÊNDICE A - CLASSIFICAÇÃO DA REDE..................................................125

APÊNDICE B - MODELO DE VIA PERMANENTE ....................................................133

APÊNDICE C - RAMAIS DA REDE FERROVIÁRIA ..................................................155

ANEXO A - MODELO DE LOCOMOÇÃO - TEM ................................................169

ANEXO B - MODELO DE SIMULAÇÃO - TEM .........................................................185

ANEXO C - ARQUIVOS DO SIMULADOR TEM ......................................................193

ANEXO D - EXECUTANDO O SIMULADOR - TEM ............................................215 


\section{LISTA DE FIGURAS}

Figura 1.1 - Participação das ferrovias na matriz de transporte brasileira...............................23

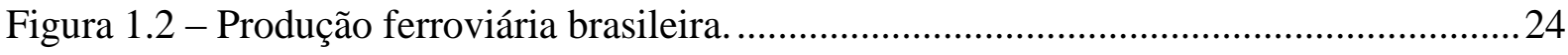

Figura 1.3 - Índice de acidentes nas ferrovias brasileiras. ............................................. 25

Figura 1.4 - Velocidades médias nos trechos operados pelas concessionárias ferroviárias. ...25

Figura 1.5 - Corredor ferroviário Brasília/Anápolis - Vitória.............................................28

Figura 1.6 - Corredor ferroviário Brasília/Anápolis - Santos............................................ 28

Figura 1.7 - Corredor ferroviário Maringá /Londrina/Cascavel - Paranaguá. ........................ 29

Figura 1.8 - Corredor ferroviário Alto Araguaia/Colômbia/Bauru - Santos. .......................... 29

Figura 1.9 - Corredor ferroviário Carajás/Estreito - São Luís................................................29

Figura 1.10 - Investimentos na malha ferroviária brasileira. .............................................. 31

Figura 1.11 - Perspectivas de investimentos na malha ferroviária por parte dos usuários do

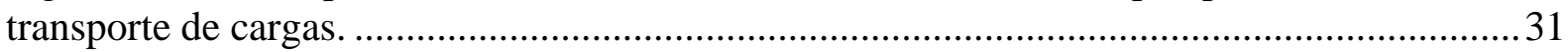

Figura 2.1 - Curva de Tração de um motor elétrico, e Resistência Total, de um trem............39

Figura 2.2 - Relação entre os tipos de capacidade ferroviária. ............................................. 45

Figura 2.3 - Diagrama espaço-tempo com movimentação de trens periódicos...................... 49

Figura 3.1 - Esquema do tipo de rede ferroviária considerada no modelo. .............................57

Figura 3.2 - Componentes de um ramal ferroviário em linha singela. ..................................57

Figura 3.3 - Velocidade instantânea e média (no espaço) entre dois nós. ..................................59

Figura 3.4 - Fluxograma das etapas para obtenção da capacidade da rede ferroviária............ 60

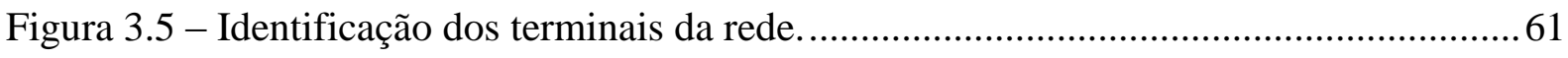

Figura 3.6 - Exemplo de Rota de Circulação (9-6-3-2-1, sentido Exportação). ....................... 62

Figura 3.7 - Fluxograma que estabelece a relação entre os módulos do algoritmo de obtenção

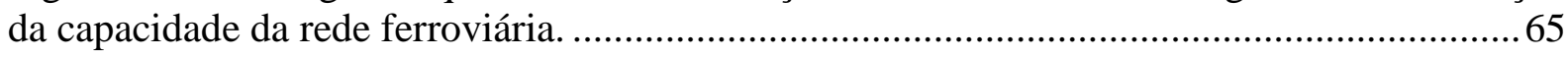

Figura 3.8 - Interface disponibilizada ao usuário para caracterização do modelo no Microsoft

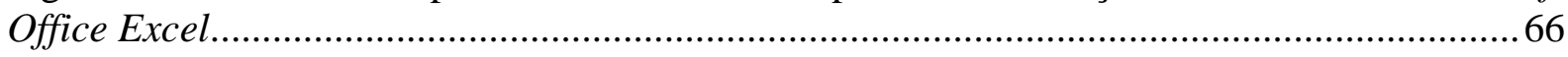

Figura 3.9 - Diagrama espaço-tempo com os dados de saída do simulador...........................67 
Figura 3.10 - Conflito entre trens em sentidos opostos em um ramal.

Figura 3.11 - Resolução do conflito no ramal pelo atraso na saída do trem no sentido Importação.

Figura 3.12 - Obtenção de headways distintos entre trens sucessivos em um ramal.

Figura 3.13 - Conflito entre trens, decorrente da diferença entre os headways nos ramais....69

Figura 3.14 - Determinação do headway crítico de cada ramal da rede. .70

Figura 3.15 - Sincronização dos trens em uma Rota de Circulação que contém o ramal " $2-1$ ".

Figura 3.16 - Sincronização dos trens em uma Rota de Circulação que contém o ramal "3-2".

Figura 3.17 - Sincronização dos trens em uma Rota de Circulação que contém o ramal "5-3". .73

Figura 3.18 - Diagrama espaço-tempo do ramal "2-1", com três nós intermediários. .74

Figura 3.19 - Estrutura condicional que verifica a compatibilidade entre headways nos ramais.

Figura 3.20 -Conflito quando hcrítico ramal é maior que hcrítico global..... .75

Figura 3.21 - Solução para o conflito quando hcrítico ramal é maior que $\mathrm{h}_{\text {crítico }}$ global. ........75

Figura 3.22 - Possíveis conflitos nos arcos que contém os terminais de um ramal. ................76

Figura 3.23 - Resolução dos conflitos nos terminais.

Figura 3.24 - Conflito no nó de um ramal dado que o intervalo entre trens sucessivos é maior que hcrítico global $(v=2)$.

Figura 3.25 - Acréscimo no tempo de espera de um trem no sentido Importação para sincronização de horários nos nós dos ramais.

Figura 3.26 - Exemplo de arquivo de saída do modelo de capacidade. . .80

Figura 4.1 - Malha ferroviária brasileira da BGTIB.

Figura 4. 2 - Perfil longitudinal do corredor ferroviário entre a estação de Santa Fé do Sul e o Porto de Santos.

Figura 4.3 - Inclinação da rampa nos pontos do corredor ferroviário entre a estação de Santa Fé do Sul e o Porto de Santos.

Figura 4.4 - Raio da curva nos pontos do corredor ferroviário entre a estação de Santa Fé do Sul e o Porto de Santos. 
Figura 4.6 - Altitudes dos pontos no arco entre o nó de Graúna e o teminal de Itirapina.

Figura 4.7 - Inclinações das rampas dos pontos no arco entre o nó de Graúna e o teminal de Itirapina.

Figura 4.8 - Arcos críticos entre os terminais de Mairinque e Itirapina (1-2), nos cenários analisados. 105

Figura 4.9 - Arcos críticos entre os terminais de Itirapina e Araraquara (2-4) nos cenários analisados.

Figura 4.10 - Arcos críticos entre os terminais de Araraquara e Santa Fé do Sul (4-6), nos cenários analisados. 106

Figura 4.11 - Pares de trens diários no Terminal Mairinque, nos cenários analisados 106

Figura 4.12 - Raios das curvas nos pontos entre os terminais de Mairinque e Santa Fé do Sul. 108

Figura 5.1 - Rede ferroviária (multigrafo) desmembrada em redes enraizadas não direcionadas. 112 

Tabela 3.1 - Coeficientes de Proporcionalidade atribuídos aos terminais da malha. 63

Tabela 4.1 - Rotas de Circulação da rede da Figura 4.5 (sentido Exportação). 86

Tabela 4.2 - Resultados do modelo de capacidade considerando todas as restrições de velocidade.

Tabela 4.3 - Resultados do modelo de capacidade com limite de velocidade de $70 \mathrm{~km} / \mathrm{h}$ entre os nós de Viracopos e Boa Vista Velha, no ramal entre os terminais de Mairinque e Itirapina. 91

Tabela 4.4 - Resultados do modelo de capacidade com limite de velocidade de $70 \mathrm{~km} / \mathrm{h}$ entre o nó de Graúna e o terminal de Itirapina, no ramal entre os terminais de Mairinque e Itirapina. .92

Tabela 4.5 - Resultados do modelo de capacidade com limite de velocidade de $70 \mathrm{~km} / \mathrm{h}$ entre os nós de Itirapina e Visconde do Rio Claro, no ramal entre os terminais de Itirapina e Araraquara.

Tabela 4.6 - Resultados do modelo de capacidade com limite de velocidade de 70km/h entre os nós de Itaici e Viracopos, no ramal entre os terminais de Mairinque e Itirapina.

Tabela 4.7 - Resultados do modelo de capacidade com limite de velocidade de $70 \mathrm{~km} / \mathrm{h}$ entre os nós de Catiguá e Uchôa, no ramal entre os terminais de Araraquara e Santa Fé do Sul. ....96

Tabela 4.8 - Resultados do modelo de capacidade com limite de velocidade de $70 \mathrm{~km} / \mathrm{h}$ entre os nós de Eng. Balduíno e Ecatu, no ramal entre os terminais de Araraquara e Santa Fé do Sul.

Tabela 4.9 - Resultados do modelo de capacidade com limite de velocidade de $70 \mathrm{~km} / \mathrm{h}$ entre os nós de Bálsamo e Eng. Balduíno, no ramal entre os terminais de Araraquara e Santa Fé do Sul.

Tabela 4.10 - Resultados do modelo de capacidade com limite de velocidade de $70 \mathrm{~km} / \mathrm{h}$ entre os nós de Ecatu e Cosmorama, no ramal entre os terminais de Araraquara e Santa Fé do Sul. .98

Tabela 4.11 - Resultados do modelo de capacidade com limite de velocidade de $70 \mathrm{~km} / \mathrm{h}$ entre os nós de Cosmorama e Simonsen, no ramal entre os terminais de Araraquara e Santa Fé do Sul.

Tabela 4.12 - Resultados do modelo de capacidade com limite de velocidade de $70 \mathrm{~km} / \mathrm{h}$ entre os nós de Uchôa e Cedral, no ramal entre os terminais de Araraquara e Santa Fé do Sul. 
Tabela 4.13 - Resultados do modelo de capacidade com limite de velocidade de $70 \mathrm{~km} / \mathrm{h}$ entre os nós de Votuporanga e Valentim Gentil, no ramal entre os terminais de Araraquara e Santa Fé do Sul. 100

Tabela 4.14 - Resultados do modelo de capacidade com limite de velocidade de $70 \mathrm{~km} / \mathrm{h}$ entre os nós de Mirassol e Bálsamo, no ramal entre os terminais de Araraquara e Santa Fé do Sul. 101

Tabela 4.15 - Resultados do modelo de capacidade nos cenários que abrangem os ramais Araraquara-Colômbia (4-5) e Itirapina-Panorama (2-3). .104 
ALL

ANTF

ANTT

AREA

AREMA

BGTIB

CNT

DNIT

EESC

EFC

EFVM

FCA

FERROBAN

FERRONORTE Ferrovia Norte Brasil S.A.

IBGE

MRS

$N A S A$

SIG

Estrada de Ferro Carajás

Ferrovia Centro-Atlântica

MRS Logística S.A.
América Latina Logística S.A.

Associação Nacional dos Transportadores Ferroviários

Agência Nacional de Transportes Terrestres

American Railway Engineering Association

American Railway Engineering and Maintenance-of-Way Association

Base Georeferenciada de Transporte Intermodal Brasileira

Confederação Nacional do Transporte

Departamento Nacional de Infraestrutura de Transportes

Escola de Engenharia de São Carlos

Estrada de Ferro Vitória-Minas

Ferrovia Bandeirantes S.A.

Instituto Brasileiro de Geografia e Estatística

National Aeronautics and Space Administration

Sistema de Informação Geográfica 
TEM

$T P C$

USP

VALEC
Train Energy Model

Train Performance Calculator (Simulador de Desempenho do Trem)

Universidade de São Paulo

VALEC Engenharia, Construções e Ferrovias 


\section{Capítulo 1}

\section{INTRODUÇÃO}

Até a primeira metade da década de 1940, o transporte de cargas e passageiros no Brasil era praticamente realizado pelo modo ferroviário. A instalação da indústria automobilística no país, a instituição do Fundo Rodoviário Nacional, a criação da Petrobrás, entre outros fatores, provocaram uma mudança significativa nesse quadro.

Em 1950, a matriz de transporte de cargas apresentava uma distribuição em que a ferrovia tinha participação em 29,2\% do mercado, a rodovia em $38 \%$ e $32,8 \%$ correspondiam ao transporte por outras modalidades (cabotagem, dutoviário etc.). Atualmente, o modo rodoviário corresponde a aproximadamente $62 \%$ das cargas transportadas no país, o ferroviário a $20 \%$ e os $18 \%$ restantes são relativos aos demais modos de transporte (SCHOPPA, 2004).

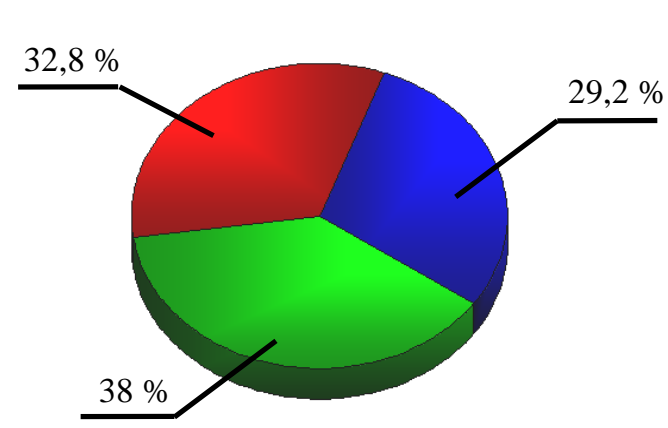

1950

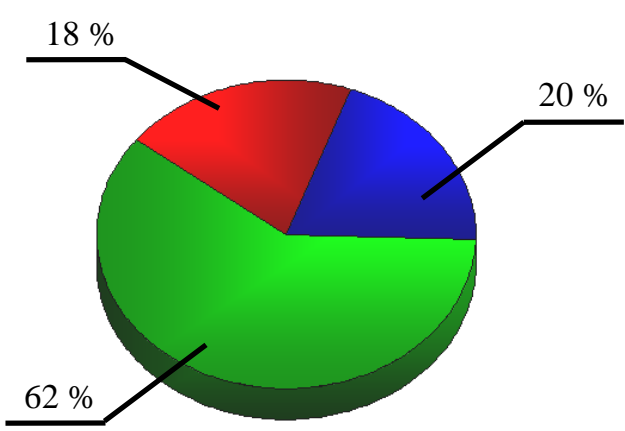

ATUAL

Ferroviário

Rodoviário

Outros

Figura 1.1 - Participação das ferrovias na matriz de transporte brasileira.

Apesar de contribuir para a expansão da fronteira agrícola e dar maior mobilidade ao transporte de cargas dos centros produtores até os consumidores, o crescimento do setor rodoviário teve como principais consequências o congestionamento do tráfego nas principais rodovias, aumento da poluição ambiental, intensificação do uso de combustíveis fósseis nãorenováveis e maiores riscos de acidentes, cujos efeitos atuam sobre os custos de transporte.

Por outro lado, a ferrovia brasileira passou, nesse período, por transformações significativas 
que envolveram a desativação de trechos e a degradação continuada da maior parcela da malha ferroviária, transferência da administração para o poder público, mudanças na política de oferecimento dos serviços de transporte ferroviário de cargas e passageiros e, posteriormente, a concessão da operação do sistema à iniciativa privada, em 1996.

Vários foram os motivos que levaram à concessão do sistema ferroviário, devido principalmente ao crescente endividamento gerado pelo déficit entre o volume de cargas transportadas e as despesas com pessoal, equipamentos e operação do sistema, dificuldade de modernizar tecnologicamente seu material rodante e as operações de embarque e desembarque de mercadorias, além da falta de uma política de marketing, informatização do sistema e qualificação de pessoal. (MARTINS et al., 1998; STEFANI, 2007).

A análise de indicadores como produção ferroviária (Figura 1.2) e número de acidentes (Figura 1.3), por exemplo, indica uma melhoria no desempenho econômico-operacional dos sistemas no período pós-concessão.

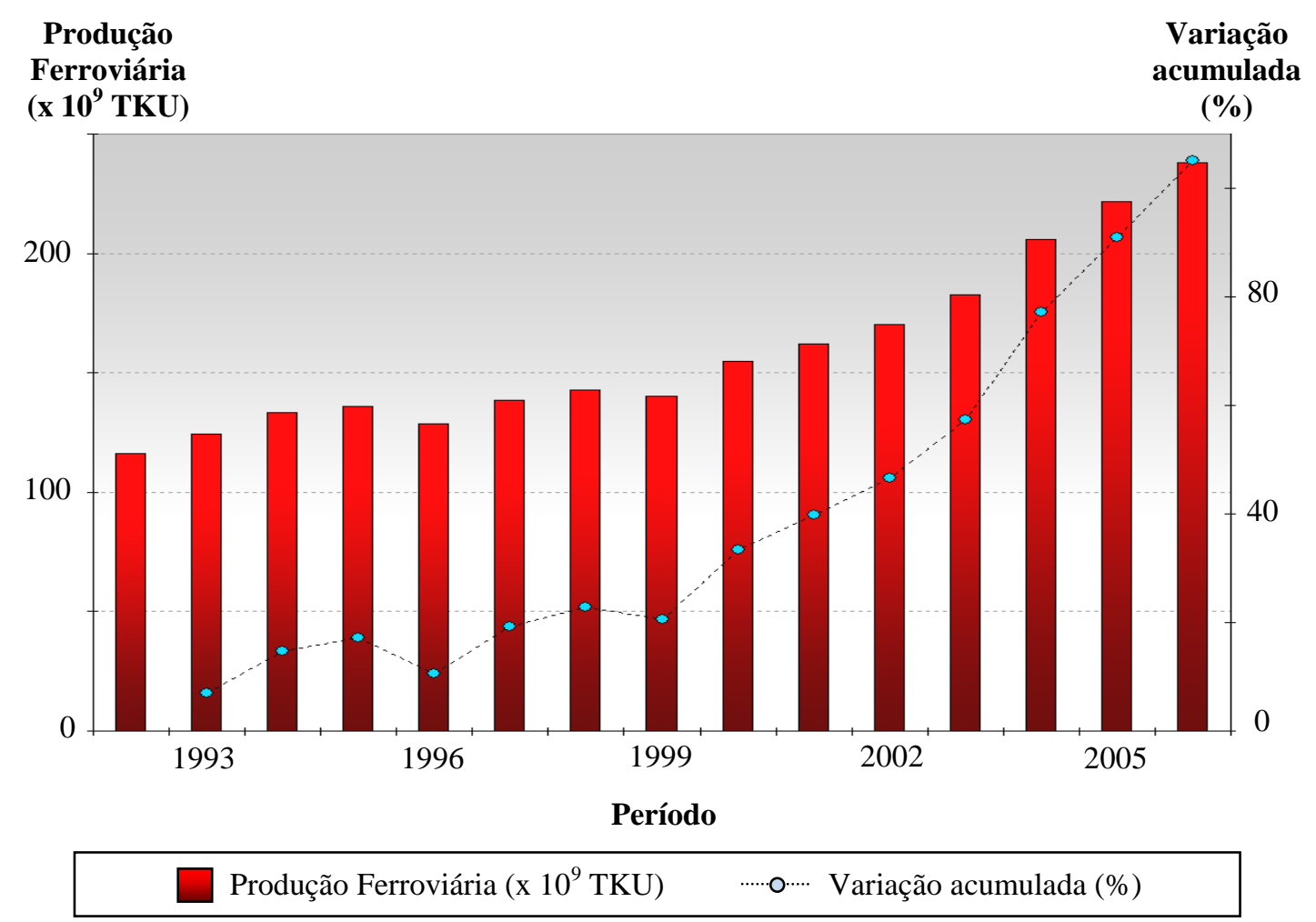

Figura 1.2 - Produção ferroviária brasileira. (Fonte:ANTT, adaptado) 


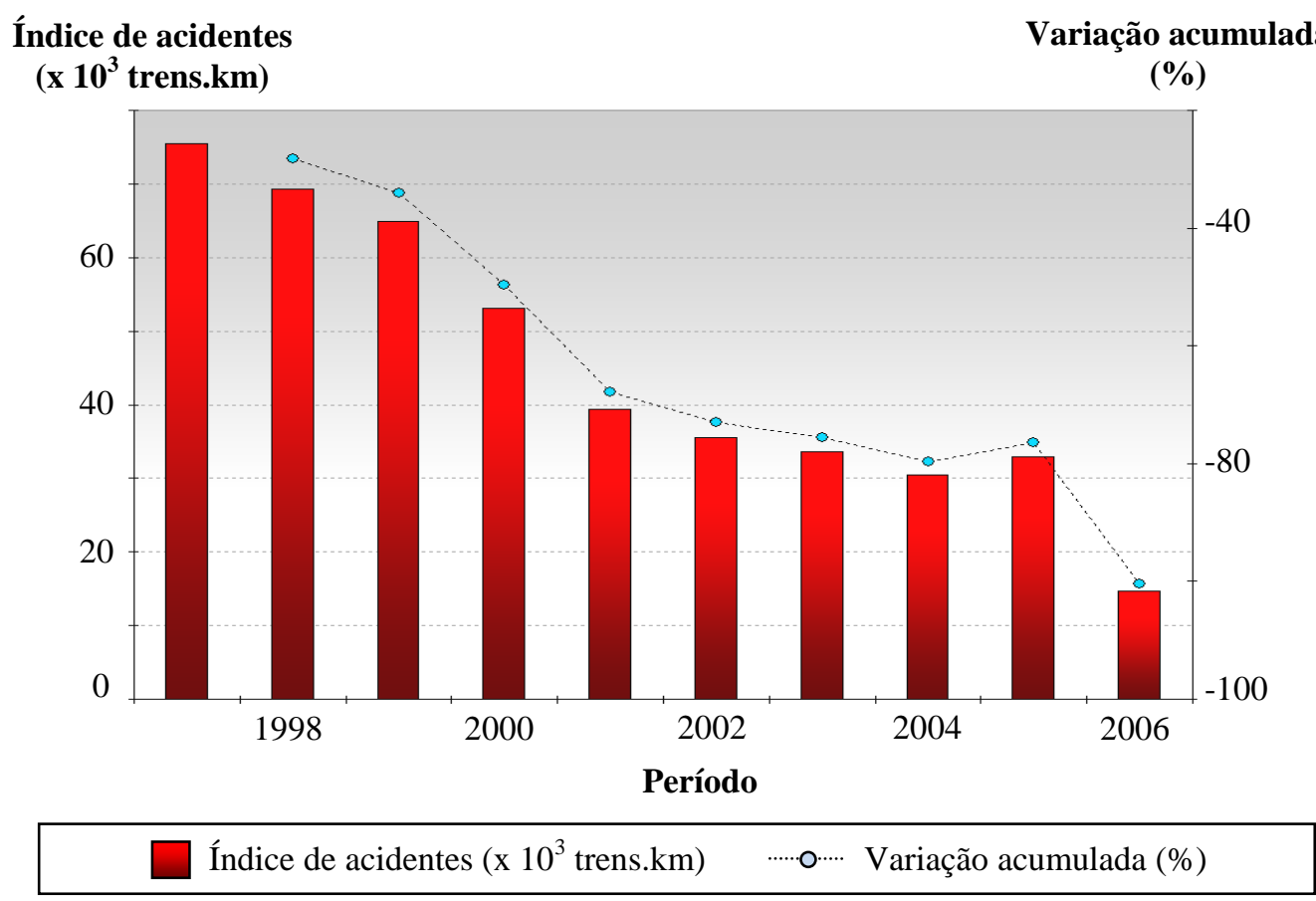

Figura 1.3 - Índice de acidentes nas ferrovias brasileiras. (Fonte: ANTF, adaptado)

Entretanto, decorrentes do processo de melhora no nível de oferta dos serviços de transporte ferroviário, diversos problemas operacionais e de infraestrutura da via permanente afetaram a produtividade das ferrovias, como pode ser observado na Figura 1.4 em relação ao declínio das velocidades médias dos trens em algumas malhas ferroviárias brasileiras.

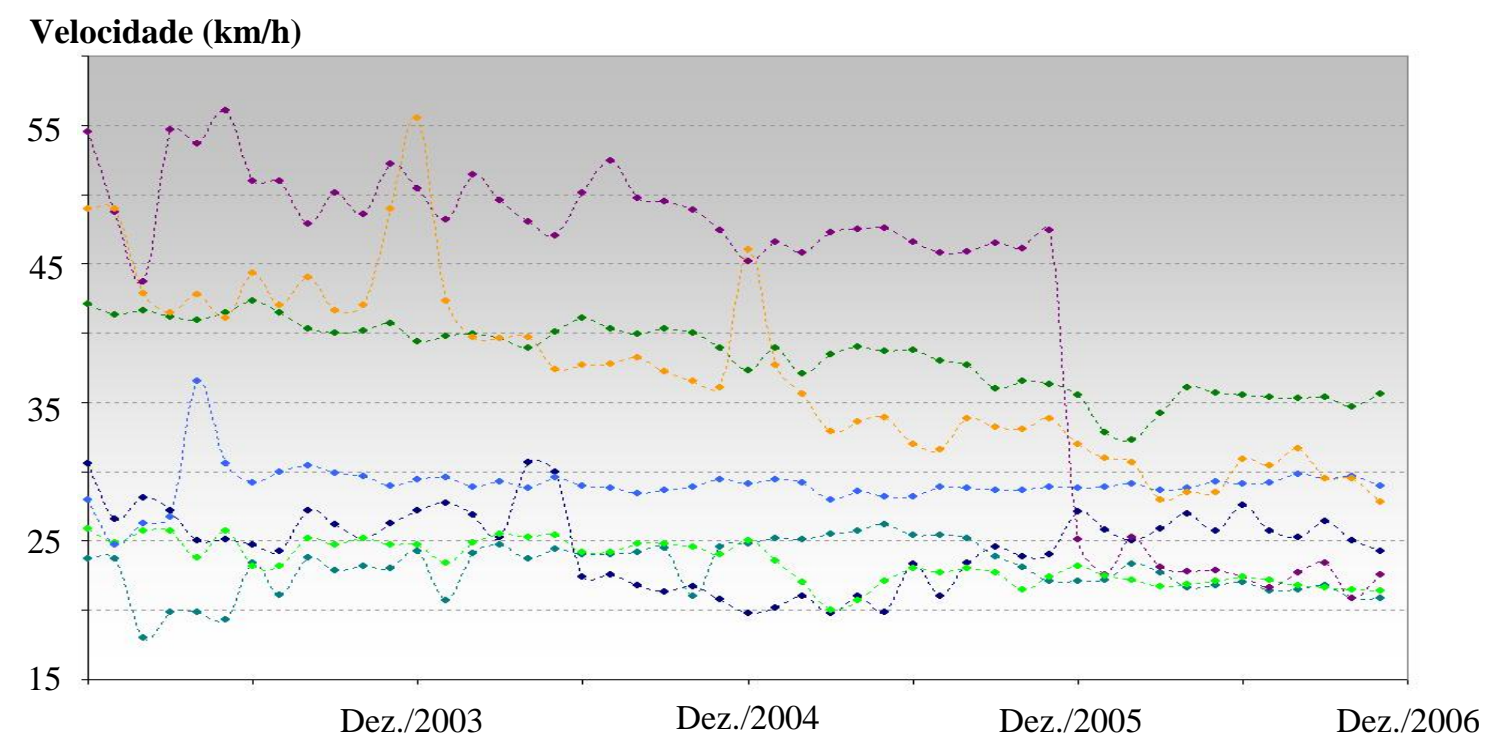

Período

\begin{tabular}{|lll|}
\hline-- FCA & -- MRS & - - ALL \\
-- EFVM & -- EFC & -- FERROBAN
\end{tabular}

Figura 1.4 - Velocidades médias nos trechos operados pelas concessionárias ferroviárias. (Fonte: ANTT, adaptado) 
Vianna (2007) apresenta como principais problemas atuais das ferrovias brasileiras a incompatibilidade entre a demanda pelos serviços e a capacidade do sistema em geral, a necessidade de modernização da via permanente, do material rodante e do sistema de gestão da malha.

O autor estabelece que o atual cenário relacionado ao transporte ferroviário de cargas exige a implantação de novos trechos e ligações estratégicas, com vistas à expansão da infraestrutura, apesar de sua extensão ser expressiva em relação aos demais países que se utilizam desse modo de transporte.

Por outro lado, o aumento da capacidade de um sistema de transporte, seja qual for a sua natureza - rodoviário, ferroviário e/ou hidroviário - não está intrinsecamente relacionado à expansão de sua estrutura física, uma vez que as políticas de intervenção e as decisões humanas envolvidas nos processos também influenciam o seu desempenho. A solução para os problemas dessa natureza é resultado da combinação do uso eficiente da infraestrutura disponível e de métodos adequados de gerenciamento. (NIJKAMP et al. ,1993)

\subsection{Caracterização do problema}

As melhorias nos sistemas de transportes são decorrentes da análise das suas atuais condições e da aplicação de ferramentas de planejamento que viabilizem a tomada de decisões sobre o direcionamento dos investimentos.

Segundo Assad (1980), as decisões administrativas variam de acordo com os investimentos requeridos, o alcance desejado das medidas, o horizonte de tempo e o nível hierárquico dos tomadores de decisões na empresa. Em relação ao horizonte temporal, essas decisões podem ser classificadas como de nível estratégico, tático ou operacional.

\section{Horizonte de Planejamento Estratégico}

As decisões nesse nível envolvem a aquisição de recursos em longo prazo (anos) e, em geral, maior investimento de capital. No contexto ferroviário, está associado aos projetos de infraestrutura e obras de melhoria como, por exemplo, construção de novas vias, duplicação das já existentes, implantação de novos pátios e desativação de linhas. 


\section{Horizonte de Planejamento Tático}

As decisões táticas estão associadas ao horizonte de tempo intermediário (trimestral ou mensal), com vistas a alocar os recursos disponíveis, e buscam responder questões sobre as políticas de classificações dos trens nos pátios, as rotas, comprimento e formação dos comboios etc.

\section{Horizonte de Planejamento Operacional}

As decisões dizem respeito às atividades cotidianas realizadas em um ambiente de elevado detalhamento e dinamismo. Estão relacionadas aos horários de chegadas e partidas dos trens, à política de prioridade entre composições, à distribuição de locomotivas com base nos comboios formados, à política de recebimento e despacho dos trens nos pátios e à definição das operações de inspeção e manutenção do material rodante, da via permanente, pátios.

O presente trabalho está inserido no contexto do planejamento estratégico pela utilização de uma ferramenta de decisão que identifica os trechos de uma rede ferroviária que exercem influência sobre a definição dos horários dos trens.

A existência de uma rede decorre da necessidade de transferência de entidades (informações, energia elétrica, água tratada, produtos etc.) do local onde são produzidas aos polos de demanda. Esses locais são conectados entre si através de equipamentos específicos (fios, dutos, estradas etc.), que geralmente possuem capacidade limitada de transferência por unidade de tempo. (AHUJA, 1993)

No caso de uma rede ferroviária, as entidades (contêineres, carga fracionada, granéis sólidos e líquidos etc.) são movimentadas por um conjunto de equipamentos (locomotivas e vagões) sobre trilhos. Os canais pelos quais essas entidades fluem entre as origens e os destinos resultam em uma rede cujos custos e tempos de percurso variam segundo as características físicas e operacionais das linhas.

Este trabalho propõe-se a responder questões sobre o problema relacionado à capacidade de processamento de trens em uma rede ferroviária, através da determinação do número de trens que podem ser alocados na rede, segundo condições operacionais pré-estabelecidas.

A partir disso pretende-se identificar as causas que limitam a capacidade de processamento de cargas no sistema ferroviário (condições de conservação da via e equipamentos, características 
geométricas etc.) e os trechos em que ocorrem.

Para a construção de um modelo que representa o problema investigado utilizar-se-á o conceito de rede matemática estabelecido pela Teoria dos Grafos (ver Apêndice A). Nesta pesquisa será empregado o termo "rede enraizada não-direcionada" para definir o tipo de malha ferroviária que é objeto de estudo de capacidade neste trabalho.

Esta configuração de rede foi estabelecida pelo fato de ser recorrente nos vários corredores ferroviários de exportação/importação de cargas no Brasil, como pode ser observado no conjunto de ilustrações da Figura 1.5 à Figura 1.9.

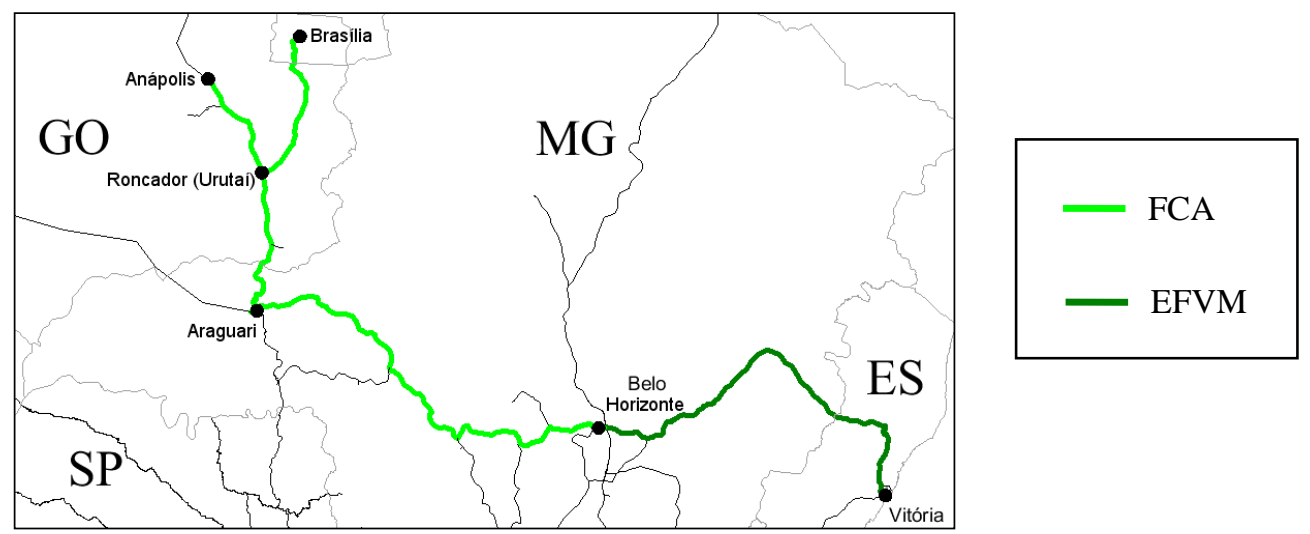

Figura 1.5 - Corredor ferroviário Brasília/Anápolis - Vitória. (Fonte: CNT, 2007 - adaptado)

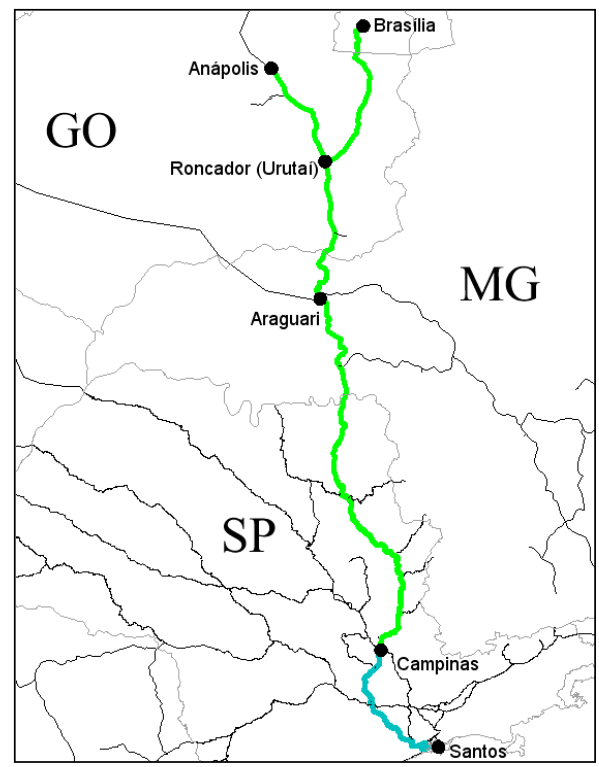

- FCA

FERROBAN

Figura 1.6 - Corredor ferroviário Brasília/Anápolis - Santos. (Fonte: CNT, 2007 - adaptado) 


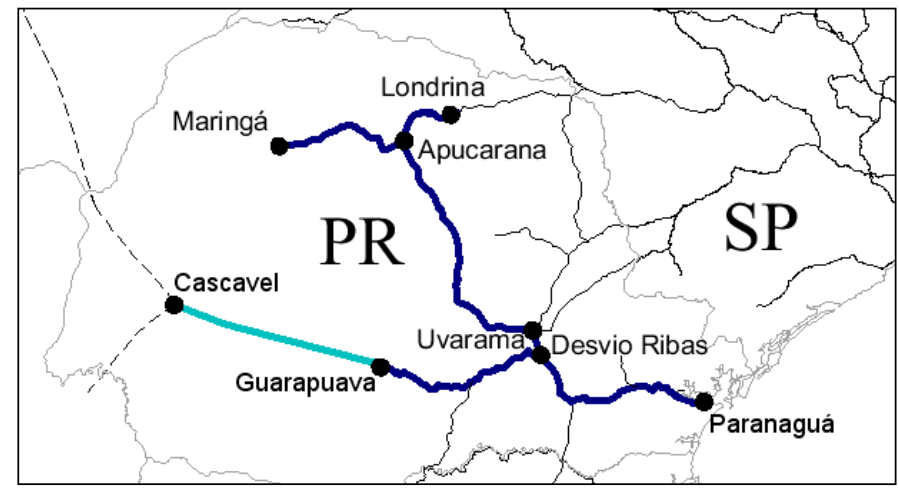

FERROBAN

ALL

Figura 1.7 - Corredor ferroviário Maringá /Londrina/Cascavel - Paranaguá. (Fonte: CNT, 2007 adaptado)
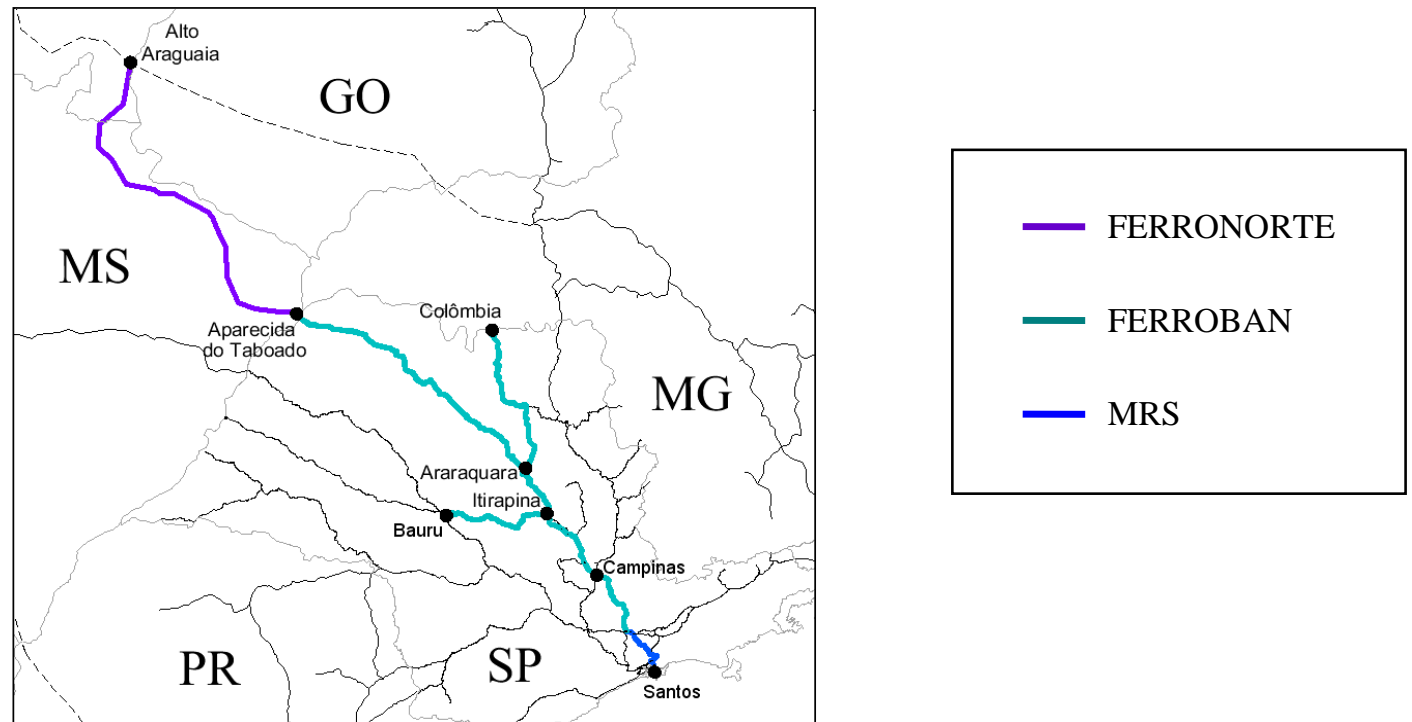

Figura 1.8 - Corredor ferroviário Alto Araguaia/Colômbia/Bauru - Santos. (Fonte: CNT, 2007 adaptado)

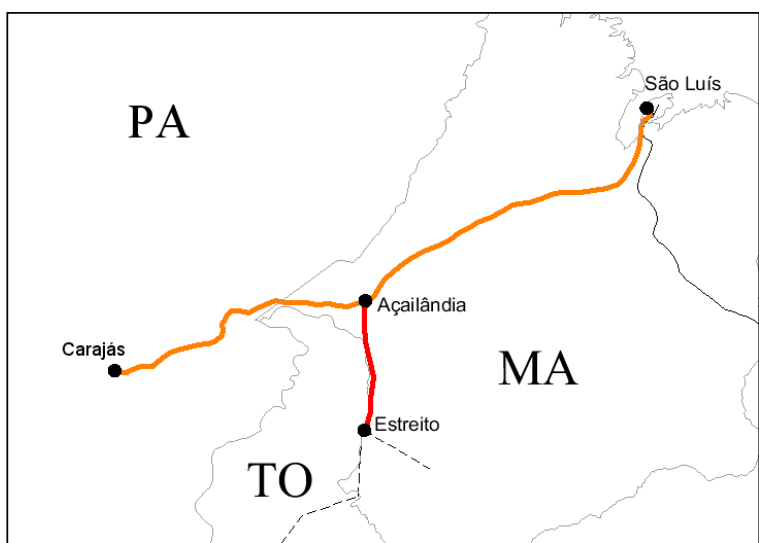

EFC

Figura 1.9 - Corredor ferroviário Carajás/Estreito - São Luís. (Fonte: CNT, 2007 - adaptado) 


\subsection{Objetivos}

Esta pesquisa tem o objetivo de propor um método que auxilie no direcionamento de investimentos na superestrutura ferroviária com horizonte de planejamento estratégico através da identificação dos arcos que limitam a capacidade de processamento de trens unitários de cargas por dia-sentido em uma rede ferroviária enraizada não-direcionada.

Para atingir o objetivo estabelecido são definidos os seguintes objetivos específicos:

1. Criar um modelo de geração de diagramas espaço-tempo para determinação do número de trens diários que circulam na rede, considerando:

(i) a configuração da malha ferroviária quanto ao modo como os ramais são conectados entre si e a influência que cada local de geração e recebimento de cargas exerce sobre o número total de trens no sistema;

(ii) o desempenho dos trens, definido pelos tempos de viagem entre estações;

(iii) a existência de conflitos entre trens em direções opostas, em consequência da definição dos horários de chegadas e partidas das estações.

2. Estabelecer cenários para análise do desempenho do modelo de capacidade e dos fatores que restringem a movimentação dos trens, considerando:

(i) a geometria da via permanente (rampas e raios de curvas horizontais e verticais) e os limites de velocidade nos arcos;

(ii) as dimensões e cargas dos veículos ferroviários que circulam na rede.

\subsection{Justificativa}

Uma das consequências da concessão da operação do sistema ferroviário à iniciativa privada foi o aumento dos investimentos em infraestrutura e equipamentos associados a esse modo de transporte, como pode ser observado no gráfico da Figura 1.10, em que é possível constatar a escassez de investimentos estatais, inclusive no período pré-concessão. 


\section{Investimentos $\left(\mathbf{R} \$ \mathbf{x} 10^{8}\right)$}

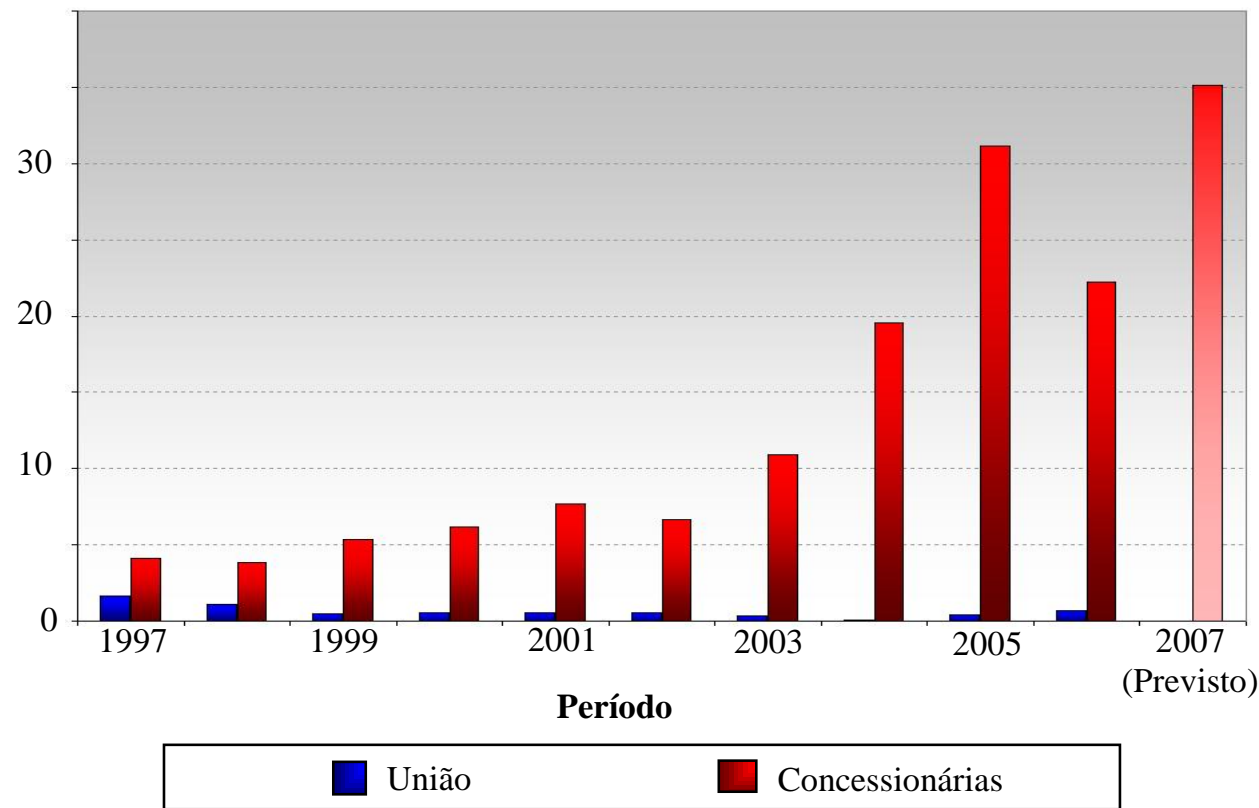

Figura 1.10 - Investimentos na malha ferroviária brasileira. (Fonte:ANTF, adaptado)

Ainda sob o ponto de vista de investimentos, contata-se que a maioria dos clientes que utilizam a ferrovia não pretende investir nos ramais de que fazem uso, como pode ser observado na Figura 1.11, que apresenta as respostas dessas empresas quando questionadas sobre a pretensão de alocar recursos nos ramais em que transportam seus produtos.

Diante disso, infere-se que as melhorias necessárias para o aumento da produtividade das ferrovias estão sujeitas à alocação de recursos das empresas que administram a operação desses sistemas. Entretanto, o aumento dos investimentos indicados na Figura 1.10 pode ser associado à intensificação do tráfego, que demanda a aplicação de recursos para manutenção de um nível de serviço satisfatório de atendimento aos clientes.

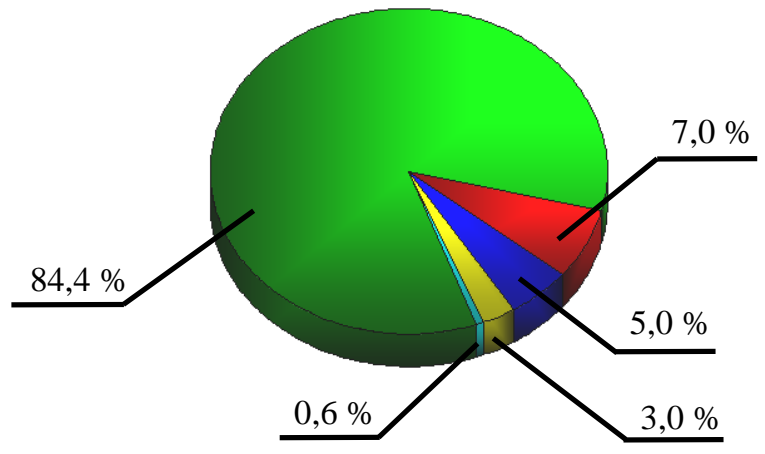

\begin{tabular}{|c|c|c|}
\hline Não & $\begin{array}{l}\text { Sim, ramal particular } \\
\text { Sim, terminais intermodais }\end{array}$ & $\begin{array}{l}\text { Sim, outros } \\
\text { Não sabe / Não respondeu }\end{array}$ \\
\hline
\end{tabular}

Figura 1.11 - Perspectivas de investimentos na malha ferroviária por parte dos usuários do transporte de cargas. (Fonte: CNT, 2007 - adaptado) 
Outro fator que implica em afirmar que a maior parte desses investimentos é destinada à manutenção das linhas ferroviárias decorre do modelo de concessão estabelecido para o transporte de cargas, em que os órgãos privados são responsáveis apenas pela operação e aplicação de investimentos para manutenção do nível de serviço referente ao período que receberem o direito de administração do serviço.

Além disso, o modelo de concessão das ferrovias estabelece que a via permanente e o material rodante permanecem sob a jurisdição do poder público e que a responsabilidade pelos serviços de transporte será devolvida a ele após o final do contrato, como pode ser constatado nos contratos de concessão da malha ferroviária brasileira, no website da Agência Nacional de Transportes Terrestres (ANTT).

Desse modo, para o adequado direcionamento dos recursos para melhoria da operação, por parte das concessionárias, enquanto estas detiverem o direito de utilização do sistema, e a correta intervenção sobre a infraestrutura das ferrovias, pelos órgãos públicos, é preciso a realização de estudos para tornar conhecidas as atuais condições da infraestrutura existente no país.

Nesse contexto, este projeto de pesquisa se insere em uma linha de pesquisa sob orientação do Prof. Dr. João Alexandre Widmer, de investigação dos fatores limitantes da capacidade de transporte ferroviário de cargas no Brasil e possíveis contribuições para o direcionamento dos investimentos a serem realizados nas ferrovias nos próximos anos.

A motivação para a realização deste trabalho surgiu dos resultados obtidos por Batista (2006), que estudou as variáveis que restringem a capacidade de um trecho ferroviário em linha singela, dotado de várias nós que permitem o cruzamento de trens que trafegam em sentidos opostos.

As conclusões obtidas permitiram identificar os principais fatores que impedem o aumento do número de trens diários no sistema, sendo as condições de conservação da superestrutura ferroviária o principal fator limitante da sua capacidade.

Entretanto, o modelo empregado naquela pesquisa determina a capacidade em trechos contendo apenas dois nós intermediários, o que torna excessivamente trabalhosa a análise de trechos extensos com vários dispositivos de cruzamentos entre trens. Além disso, o modelo não considera a interação entre as arestas de uma rede ferroviária enraizada não-direcionada, 
estabelecida pela relação entres os seus vértices.

Este trabalho apresenta uma continuidade dos resultados obtidos por Batista (2006) para disponibilizar uma ferramenta de planejamento estratégico que inclua fatores não considerados na pesquisa anterior, através de um método de identificação dos arcos críticos de uma rede.

\subsection{Estrutura do texto}

Este trabalho está dividido em cinco capítulos, sendo o primeiro esta Introdução.

O Capítulo 2 apresenta a revisão da literatura que abrange os conceitos sobre modelos de desempenho de veículos ferroviários, modelos de programação de horários de trens (modelos de scheduling) e modelos de capacidade ferroviária.

O Capítulo 3 contém a descrição dos elementos envolvidos no processo de movimentação dos trens no sistema ferroviário e a descrição do algoritmo de capacidade.

No Capítulo 4 são apresentados os resultados da aplicação do modelo de capacidade em uma rede ferroviária existente.

O Capítulo 5 traz as considerações sobre o modelo de capacidade proposto neste trabalho, os resultados de sua aplicação e sugestões para trabalhos futuros. 


\section{Capítulo 2}

\section{REVISÃO BIBLIOGRÁFICA}

Nesta revisão bibliográfica são abordados os modelos de representação do movimento dos trens na via, os modelos de alocação e programação de horários de trens (modelos de scheduling) e os conceitos e modelos existentes sobre capacidade ferroviária.

Além dos três níveis de planejamento (estratégico, tático e operacional) estabelecidos para a tomada de decisões, os modelos utilizados para representação de problemas nas diversas áreas do conhecimento podem ser classificados em analíticos, de simulação e de otimização, os quais muitas vezes se interpõem na abordagem de um problema específico.

\section{Modelos Analíticos}

Segundo Petersen e Taylor (1982), estes modelos utilizam expressões algébricas para caracterizar a circulação de trens de diferentes tipos, com prioridades distintas, em função de suas características operacionais e da configuração da via ferroviária.

Abril et al. (2005) afirmam que, em geral, esses modelos são bastante simples, permitem a obtenção de soluções preliminares aos problemas e podem ser tomados como parâmetro de referência ou comparação em relação às soluções obtidas através de outros métodos.

\section{Modelos de Simulação}

Assad (1980) afirma que estes modelos descrevem o movimento dos trens de modo mais realista, através da criação de entidades que circulam em um sistema que se aproxima do movimento real do trem. Assim, são estabelecidos os itinerários e a série de decisões que representam as políticas de movimentação nas linhas e estações, incluindo-se nos dados de saída informações sobre os custos de operação (movimentação e classificação dos trens) e os tempos de movimentação.

Com isso o usuário é capaz de refletir sobre a política de decisão a ser adotada no sistema e buscar uma solução razoável para o problema, dentre várias alternativas disponibilizadas pela execução de repetidas simulações, ou definir o modelo mais próximo da realidade, utilizado 
para validar uma tabela de horários.

Petersen e Taylor (1982) apresentam como limitação dos modelos de simulação o fato de, em geral, apresentarem uma estrutura pouco flexível, muitas vezes aplicável a ferrovias específicas, com necessidade de grande quantidade de dados para produzir resultados satisfatórios, e apresentarem restrições ao tratamento de dados em sistemas com intenso volume de tráfego.

\section{Modelos de Otimização}

Estes modelos, segundo Petersen e Taylor (1982), tratam do problema de alocação dos trens na via com vistas a melhorar alguma medida de desempenho do sistema, como maximizar o volume de tráfego, minimizar o atraso total etc.

Nesse contexto, Ahuja et al. (1993) classifica os modelos de otimização com fluxos em redes em três grupos distintos. Os problemas de caminho mínimo (shortest path problem) têm como objetivo básico a definição de rotas adequadas entre os nós da rede, com vistas à obtenção do menor custo financeiro, de tempo etc. Assad (1980) afirma que os seus dados de entrada são basicamente as demandas previstas para os fluxos de tráfego nos arcos da rede ferroviária, para definição de uma rota em relação a uma função objetivo definida.

Os problemas de fluxo máximo (maximum flow problem) são utilizados na determinação do maior volume de tráfego entre nós da rede, segundo limites de capacidade pré-definidos. Por outro lado, os problemas de fluxo de mínimo custo (minimum cost flow problem) são tais que as restrições de custos e de capacidades associadas às ligações devem satisfazer a demanda dos nós de destino, em função da capacidade de produção dos nós de origem, com o objetivo de identificar o fluxo de custo mínimo que pode ser alocado nas rotas.

\subsection{Modelos de desempenho de trens}

O movimento dos trens nas linhas é a atividade básica que caracteriza um sistema de transporte ferroviário. Os modelos de desempenho são aqueles capazes de representar matematicamente as forças envolvidas no processo de movimentação das locomotivas e vagões. Esses modelos consideram as forças de propulsão fornecidas pelas locomotivas e as de resistência ao movimento, e permitem a determinação das velocidades nos arcos da rede, bem como acelerações instantâneas, consumo de combustível etc. 
Um modelo de desempenho é utilizado neste trabalho para obtenção dos tempos médios de viagem entre as estações, destinadas ao cruzamento de trens que circulam em sentidos opostos na linha, definidos como parâmetros de entrada do modelo de capacidade de uma rede ferroviária.

O desenvolvimento de modelos analíticos, capazes de expressar com precisão o equilíbrio entre as forças envolvidas no processo de movimentação de um trem, mostra que as expressões matemáticas são difíceis de serem determinadas devido à complexidade do sistema. As expressões derivadas de formulações empíricas obtidas em campo e através de observações em laboratório mostram-se mais adequadas para representar o movimento do trem na via. (HAY, 1982)

Morlok (1978) descreve os tipos de resistência ao movimento dos trens associados aos modelos de locomoção de veículos ferroviários, que somados resultam na Resistência Total. A parcela associada ao peso e atrito entre os componentes mecânicos (eixos e mancais) dos veículos é denominada Resistência Inerente ao Movimento, aquela relativa à declividade da via é denominada Força de Rampa - sendo usado esse termo por ser ora favorável ao movimento, ora contrário a ele - e a força associada à pressão do ar exercida sobre o veículo em movimento é caracterizada como Resistência Aerodinâmica.

Outro tipo de resistência, característico das composições ferroviárias, está associado ao atrito lateral entre as suas rodas e o trilho da via permanente quando se movimenta em uma curva horizontal, denominada Resistência de Curva.

A força propulsora disponibilizada pelas locomotivas é dada em termos da potência dos motores elétricos acionados pelos geradores a diesel, no caso das locomotivas diesel-elétricas, e tem a velocidade como parâmetro em comum com as equações de resistência. A velocidade de um trem é calculada basicamente pelo equilíbrio - igualdade - entre as fórmulas matemáticas que representam a força de resistência total imposta aos veículos e a força de propulsão disponibilizada pelas locomotivas, como indicado na Equação (2.1).

$$
\mathrm{R}_{\mathrm{T}}=\mathrm{F}_{\mathrm{t}}
$$

em que $\quad \mathrm{R}_{\mathrm{T}}=f\left(\mathrm{~V}, \mathrm{M}_{\mathrm{loc}}, \mathrm{M}_{\mathrm{vag}}, \mathrm{n}_{\mathrm{loc}}, \mathrm{n}_{\mathrm{vag}}, \alpha_{1}, \alpha_{2}, \ldots, \alpha_{\mathrm{n}}\right)=$ Resistência Total

$$
\mathrm{F}_{\mathrm{t}}=f\left(\mathrm{~V}, \mathrm{P}, \mathrm{n}_{\mathrm{loc}}\right)=\text { Força motriz }
$$


e $\quad \mathrm{V}=$ velocidade do trem

$$
\begin{aligned}
& \mathrm{M}_{\mathrm{loc}}=\text { massa das locomotivas } \\
& \mathrm{M}_{\mathrm{vag}}=\text { massa dos vagões } \\
& \mathrm{n}_{\mathrm{loc}}=\text { número de locomotivas do trem } \\
& \mathrm{n}_{\mathrm{vag}}=\text { número de vagões do trem } \\
& \mathrm{P}=\text { potência das locomotivas }
\end{aligned}
$$

$\alpha_{1}, \alpha_{2}, \ldots, \alpha_{\mathrm{n}}=$ coeficientes relacionados aos componentes mecânicos dos veículos, pressão do ar, atrito roda-trilho, elevações, raios de curvas etc.

Os modelos analíticos podem considerar, ainda, fatores como aderência entre os eixos motrizes e os trilhos da ferrovia, de modo a limitar a força aplicada pelos motores para evitar escorregamento, a força limite de frenagem - máxima permitida para parar o trem com segurança, e a força máxima que pode ser suportada pelos engates entre os veículos.

Graficamente, o conjunto de soluções que satisfaz a condição de equilíbrio entre a força de tração fornecida pelas locomotivas e as de resistência que atuam sobre o trem é dado pela envoltória delimitada pela curva de Resistência Total do trem, pela velocidade máxima permitida no arco analisado e a curva de força motriz de um motor elétrico.

A Figura 2.1 ilustra o método gráfico de obtenção da velocidade de equilíbrio. A curva de resistência contida na área delimitada pela Curva de Tração corresponde ao conjunto de pares ordenados (Velocidade, Força Motriz), que satisfazem o equilíbrio entre as forças atuantes sobre o trem. A velocidade máxima possível é definida pelo cruzamento entre a curva de Resistência Total e o limite da curva de força tratora. 


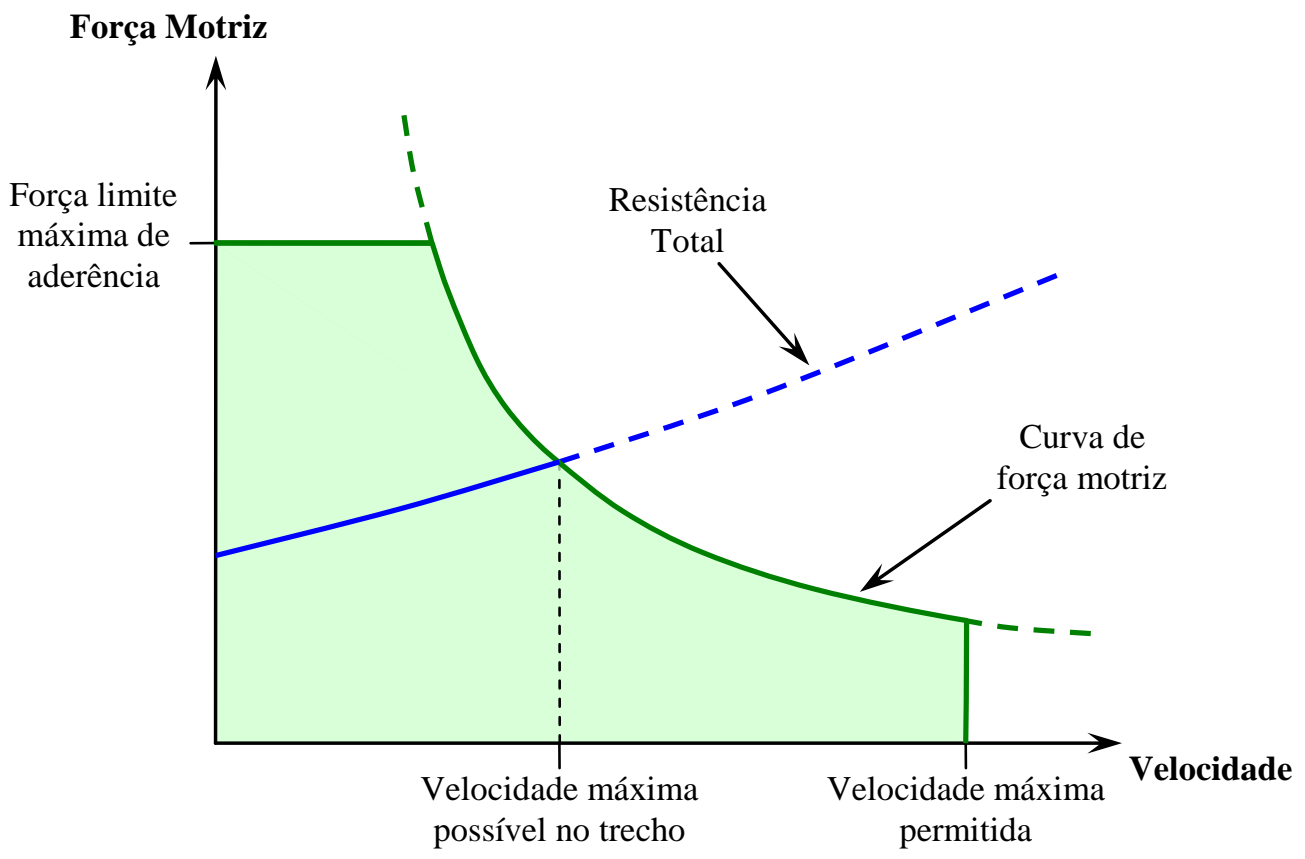

Figura 2.1 - Curva de Tração de um motor elétrico, e Resistência Total, de um trem.

Para utilização prática, os modelos analíticos de desempenho de trens, com frequência, são integrados aos de simulação, que permitem tratar maior quantidade de dados com análise do comportamento transitório dos entes envolvidos no processo e da interação veículo-via no sistema (PETERSEN \& TAYLOR, 1982).

Esses programas são desenvolvidos devido à dificuldade de se determinarem, com precisão, as velocidades nos arcos através de operações algébricas, e à grande quantidade de dados envolvidos no processo de cálculo das forças de resistência, tratora, de aceleração, de desaceleração etc. (HAY, 1982). No algoritmo dos simuladores são inseridas as equações de resistência e força motriz, com os devidos coeficientes, e realizado um processo de cálculo iterativo para intervalos de tempo definidos a priori (MORLOK, 1978).

Nesses programas, os valores de velocidade são calculados através de um Simulador de Desempenho do Trem (Train Performance Calculator - TPC). Concomitante aos cálculos do tempo de percurso e consumo de combustível que realiza, o SDT exibe a trajetória do trem no espaço e no tempo, a partir das características do trem-tipo e da geometria da via, definidas pelo usuário.

Martin (1999) define um conjunto de conceitos e variáveis envolvidos na simulação de um trem circulando em um sistema ferroviário, complementando-o com os aspectos relacionados à simulação de trens múltiplos em uma rede. $\mathrm{O}$ autor mostra que as simulações auxiliam os 
operadores do sistema na tomada de decisões e apresenta uma ferramenta de simulação, o RailPlan $^{\circledR}$, um SDT capaz de modelar o desempenho de uma composição durante operação de múltiplos trens, que utiliza o Animator ${ }^{\circledR}$ como ferramenta de visualização das operações realizadas pelo programa.

Apesar de existirem outros simuladores que podem ser aplicados à análise do desempenho de trens: Truper ${ }^{\circledR}$, criado pela Universidade Estadual de Londrina, ROMAN ${ }^{\circledR}$ - ROute MANagement - utilizado na Alemanha e Áustria (BARBER et al., 2007), neste trabalho é utilizado o software desenvolvido pela Association of American Railroads (AAR), denominado Train Energy Model (TEM), na versão 2.5, cujos resultados mostraram-se adequados às necessidades do estudo proposto.

Esse simulador reproduz o movimento dos trens segundo as características do conjunto de vagões (número de eixos, carga transportada, peso por eixo) e locomotivas (número de eixos, peso total, potência), os parâmetros da infraestrutura (raio das curvas em planta e perfil longitudinal, elevação das rampas), os equipamentos existentes na linha ferroviária (pontes, túneis, passagens em nível, limites operacionais de velocidade, localização dos pátios de cruzamento e manobra) e outros parâmetros, como velocidade e direção do vento, condições de frenagem etc.

As simulações são precedidas do preparo de arquivos, que são configurados com o auxílio de uma interface disponibilizada pelo software TEM. A definição dos parâmetros de entrada é ambientada no sistema operacional $M S$-DOS e resulta em um conjunto de arquivos utilizados durante a execução de uma simulação.

O Anexo A apresenta as equações de locomoção de veículos ferroviários, utilizadas no simulador TEM versão 2.5 , provenientes dos modelos analíticos de desempenho de trens. $\mathrm{O}$ Anexo B apresenta os programas que fazem parte do simulador e a relação entre eles. $\mathrm{O}$ Anexo C apresenta os arquivos gerados - e a relação entre eles - durante a preparação dos dados de entrada do simulador e o Anexo D fornece um roteiro para execução de uma simulação no software especificado.

\subsection{Modelos de scheduling}

No contexto associado às ferrovias, scheduling é o processo no qual a um vagão - quando se torna disponível para movimentação - é associado um plano de viagem, executado quando 
este vagão deve se movimentar em um comboio até o seu destino (MISSOURI PACIFIC, 1977, apud KWON et al., 1998)

Petersen e Taylor (1982) abordam o problema alocação dos trens na via em uma linha ferroviária singela através de um modelo analítico. Os autores definem uma sequência de expressões algébricas que caracterizam a circulação dos trens sob condições de segurança, que podem ser inseridas em pacotes de simulação ou otimização.

O modelo considera os segmentos em linha dupla, destinados ao cruzamento de trens em sentidos opostos, a separação temporal entre trens, as velocidades nos arcos, as características e prioridades das composições etc. A rotina computacional para definição dos tempos de parada e circulação dos trens na via é definida por uma função de múltiplas variáveis e o algoritmo resolve os conflitos na ordem em que surgem durante sua execução.

Ainda no âmbito dos modelos analíticos, Jovanovic e Harker (1991) propuseram um modelo de scheduling de trens com horizonte de planejamento tático, através da utilização de um sistema denominado SCAN (Scheduling Analysis), cuja metodologia baseia-se em um algoritmo de programação inteira mista, sendo seus conceitos similares aos problemas de flow-shop scheduling em linhas de manufatura.

Essa ferramenta opera a partir de uma tabela pré-definida de horários de circulação de trens em um segmento de via singela, caracterizado segundo algumas premissas. Sua consistência é verificada e, caso seja constatado um cruzamento entre trens em sentidos opostos, em locais inadequados, uma heurística interna é acionada de modo a torná-la factível. A seguir inicia-se a análise da nova tabela de horários em busca de outros conflitos entre trens, em um processo iterativo até que todas as inconsistências sejam solucionadas.

Martin (1999) apresenta uma ferramenta baseada em um modelo analítico, para geração de tabelas de horários de trens em linhas ferroviárias singelas, cujos dados de entradas consistem nos resultados apresentados pelo simulador de desempenho de trens, o RailPlan ${ }^{\circledR}$. Além das tabelas de horários, o software TrainPlan ${ }^{\circledR}$ produz gráficos de circulação de trens com base nos tempos de percurso entre estações e permite a aquisição de dados para o sistema de sinalização da linha ferroviária.

Szpigel (1972, apud ABRIL et al., 2008) foi o primeiro a propor um algoritmo branch-andbound para resolver o problema de scheduling de trens em linha singelas, dados os seus 
horários de partida das estações. Abril et al. (2008) afirmam que apenas a partir da década de 1990 esse tipo de problema passou a atrair a atenção para estudos voltados à área de pesquisa operacional.

Higgins et al. (1996) propõem um modelo que pode ser utilizado como uma ferramenta de decisão para estabelecer os horários de trens em tempo real, de maneira otimizada, e um planejamento em nível operacional, para avaliar os impactos na mudança dos horários de chegadas e saídas das composições nas estações.

Entretanto, nas aplicações práticas, Higgins et al. (1997) afirmam que a solução ótima para o problema de scheduling nem sempre é prioritária, pelo fato de necessitar de um tempo de processamento computacional geralmente longo e de, em alguns casos, a solução não poder ser encontrada devido ao caráter qualitativo de algumas variáveis e restrições.

Nesse trabalho são apresentadas heurísticas para definição dos horários de trens que circulam em uma linha singela, com trechos em linha dupla, para cruzamentos ou ultrapassagens, de modo a auxiliar os controladores do sistema na solução dos conflitos nos desvios, satisfazendo as condições de segurança e obtendo os mínimos atrasos - ou tempos totais de viagens possíveis.

Os autores definem alguns conceitos sobre o sistema ferroviário, suas variáveis, premissas e dados de entrada, a função objetivo e as condições de contorno do modelo. A partir disso aplicam quatro técnicas para solução do problema, capazes de determinar uma solução próxima da ótima, em um intervalo de tempo relativamente curto: Heurística de Busca Local (Local Search Heuristic - LSH), Algoritmo Genético (Genetic Algorithms - GA), Algoritmo de Busca Tabu (Tabu Search - TS) e dois Algoritmos Híbridos (Hybrid Algorithms - HAl e HA2).

Caprara et al. (2002) apresentam um modelo de definição de tabelas de horários, a fim de que os trens respeitem a capacidade de circulação da via, e algumas restrições operacionais préestabelecidas. O problema denominado Train Timetabling Problem (TTP), ou "Problema de Tabelas de Horários de Trens", considera como trecho ferroviário em linha singela, com um número de estações intermediárias, aquele que faz a ligação entre duas estações principais.

Os autores fazem uma abordagem baseada na Teoria de Grafos, utilizando um multigrafo direcionado em que os nós correspondem às saídas/chegadas a uma estação em um horário 
definido. A formulação considera uma heurística de programação linear inteira associada à relaxação Lagrangiana, com as restrições relativas aos nós do grafo, resultando na obtenção de uma solução em menor tempo computacional.

Liu e Kozan (2009) modelaram um sistema ferroviário em que os trens, as seções em linha singela e seções em linha dupla de uma rede ferroviária, divididas em trechos independentes são considerados como atividades, máquinas individuais e máquinas paralelas, respectivamente, analogamente a um processo de manufatura.

No modelo, o movimento dos trens é associado ao problema de "Job-shop-scheduling com máquinas paralelas" (Parallel-machine job-shop-scheduling - PMJSS), cujo objetivo é minimizar o makespan. Os autores utilizam o conceito de grafos para expor o problema de bloqueio de máquinas e propõem uma heurística para o problema de "Job-shop-scheduling, aplicado a máquinas paralelas com bloqueio permitido" (Blocking parallel-machine job-shopscheduling - BPMJSS), que não admite a utilização simultânea de uma mesma máquina (seção de linha singela) para realização de duas atividades distintas (circulação de trens).

Barber et al. (2007) apresentam ferramentas de gerenciamento de tabelas de horários de circulação de trens em linhas e redes ferroviárias, com aplicação de modelos de simulação e otimização: $\quad$ RAILSYS ${ }^{\circledR}, \quad$ ROMAN $^{\circledR}, \quad$ CAPRAS $^{\circledR}, \quad$ FASTA $^{\circledR}, \quad$ OPENTRACK ${ }^{\circledR}$, OPENTIMETABLE ${ }^{\circledR}$, MULTIRAIL $^{\circledR}$ etc.

\subsection{Modelos de capacidade}

Dependendo do contexto em que está inserido, o termo "capacidade" pode ser interpretado de várias maneiras, uma vez que possui diferentes significados e aplicações. Em relação à atividade ferroviária, é o máximo volume (trens diários) que pode ser movimentado em uma linha segundo um plano de horários e atividades (de tráfego e operacional) sem, no entanto, desrespeitar restrições pré-estabelecidas. (KRUEGER, 1999).

Assim, o conceito de capacidade de uma linha ferroviária pode ser entendido como o número de trens que podem trafegar em uma dada infraestrutura ferroviária, em um intervalo de tempo, sob certas condições operacionais pré-estabelecidas.

Krueger (1999) utiliza diferentes definições para classificar os tipos de capacidade empregados na avaliação do desempenho de um sistema ferroviário, a saber: 


\section{Capacidade Teórica}

É o número de trens que trafegam em uma rota, em um período de tempo definido, em condições ideais, caracterizado por um cenário virtual em que os comboios apresentam movimento constante com headway mínimo entre eles.

Este parâmetro expressa o limite máximo da capacidade de tráfego, considerando que o movimento dos trens é homogêneo ao longo do dia, que estes são espaçados uniformemente e não há interrupções no sistema. Por ser um valor obtido através de fórmulas empíricas e não considerar os efeitos da variação do tráfego e das operações, é impossível que seja praticado em condições reais.

\section{Capacidade Prática}

É o limite prático do número de unidades que podem se movimentar na linha ferroviária com certo nível de confiabilidade. Pelo fato de refletir as condições de circulação de diferentes tipos de trens - cargueiros e de passageiros, com prioridades distintas, segundo o acúmulo de tráfego e outras condições do sistema, representa uma medida mais realista de capacidade.

Como representa a combinação específica de infraestrutura, tráfego e operações para movimentar o volume máximo de produtos, com um nível de serviço e confiabilidade prédeterminados, é a medida mais significativa de capacidade do sistema ferroviário.

Este parâmetro representa a capacidade que pode ser permanentemente fornecida sob condições normais de operação e, segundo o autor, representa aproximadamente $2 / 3$ da capacidade teórica, valor este obtido através da execução de inúmeras simulações de eventos discretos.

\section{Capacidade Utilizada}

Representa o volume de tráfego e as operações realizadas, de fato, na linha ou rede ferroviária e, em geral, é menor que o valor da capacidade prática por diversos motivos, como o tempo mínimo de viagem entre nós nos ramais, atrasos no despacho dos trens nos terminais e pátios, atrasos decorrentes do volume de tráfego na via, devido à eficiência dos equipamentos utilizados na operação, às restrições impostas pelas condições climáticas etc.

\section{Capacidade Disponível}

Representa a diferença entre a Capacidade Prática e a Capacidade Utilizada e corresponde ao 
volume de tráfego adicional, que pode ser inserido na rota de circulação dos trens. Se for permitida a inserção de novos trens é considerada capacidade excedente, caso contrário é considerada capacidade perdida.

A Figura 2.2 apresenta graficamente a relação entre os tipos de capacidade associados à operação ferroviária.

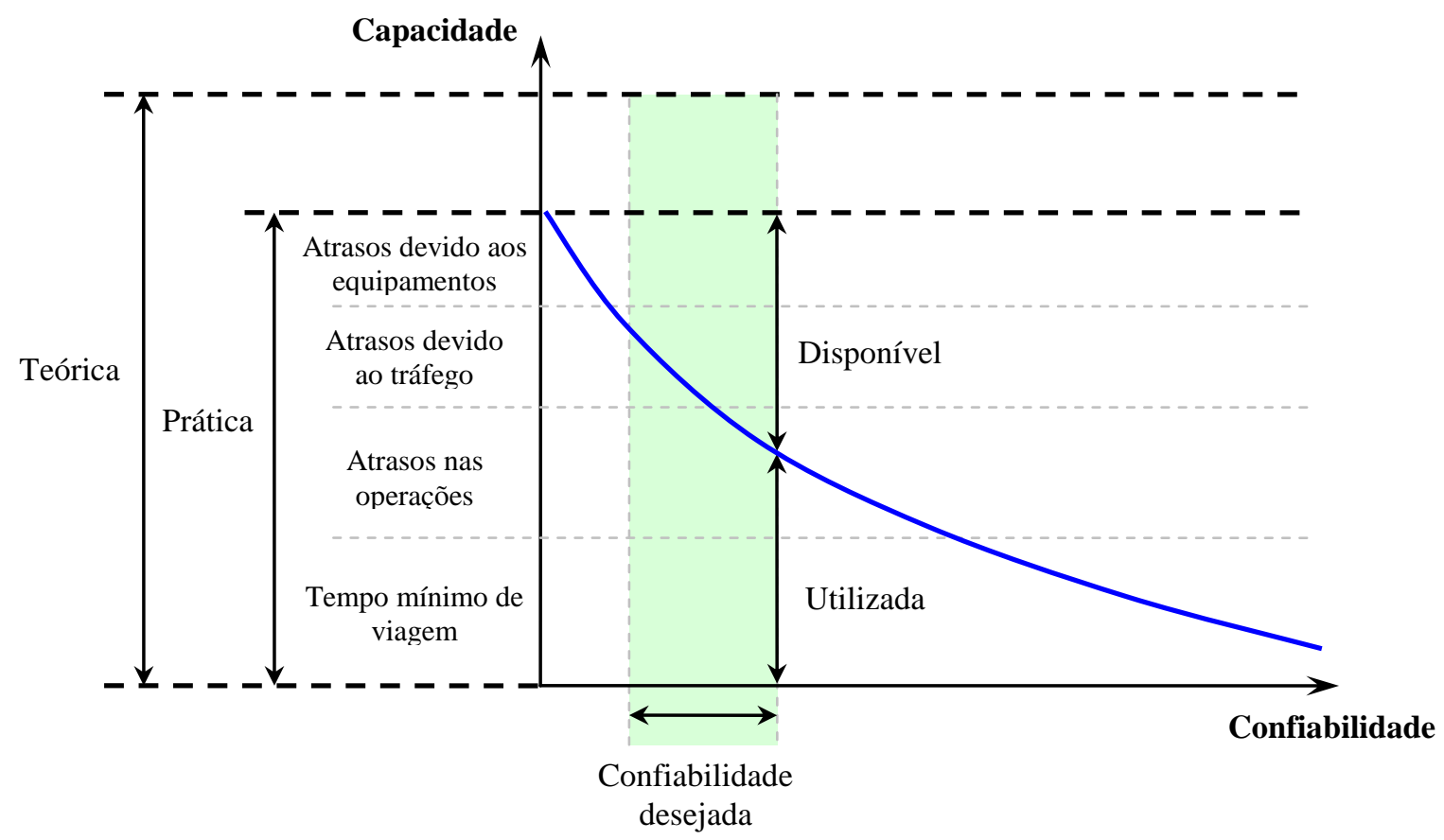

Figura 2.2 - Relação entre os tipos de capacidade ferroviária. (Fonte: KRUEGER, 1999 - adaptado)

A modelagem de sistemas ferroviários tem como objetivo analisar o movimento dos trens e as atividades de despacho nas seções das linhas. Esses modelos permitem investigar a capacidade de circulação, identificar os pontos de restrição à movimentação e avaliar as prioridades definidas no cruzamento de trens em sentidos opostos. A capacidade de uma linha ferroviária pode ser avaliada segundo os atrasos dos trens, sob diferentes regras operacionais (ASSAD, 1980).

Devido à possibilidade de ocorrência de choque entre trens que circulam em sentidos opostos em uma via singela, podem ser utilizadas técnicas de programação como ferramentas auxiliares para estabelecer os horários dos trens de modo a evitar acidentes e prejuízos de ordem econômica e social.

Abril et al. (2008) realizaram uma revisão sobre os métodos de obtenção da capacidade de processamento de trens, tanto em linhas singelas quanto em redes ferroviárias complexas, e afirmam que a capacidade ferroviária é uma variável dinâmica que depende das características 
dos trens, das condições operacionais e da infraestrutura do sistema.

Em relação à infraestrutura ferroviária, os autores consideram os seguintes fatores: sistema de sinalização e blocos, número de vias, definição de rotas, efeitos da rede, condições da via, limites de velocidade e comprimento das seções. Em relação aos parâmetros de tráfego que interferem no número de trens que circulam no sistema: novas linhas ou linhas existentes, mistura de trens, regularidade na execução das tabelas de horários, fator de tráfego pico (medida de concentração de tráfego em um intervalo de tempo) e prioridades dos trens.

Relacionados aos fatores operacionais, consideram-se as interrupções do tráfego, o tempo de parada dos trens, o tempo máximo de viagem, a unidade de tempo de referência para o cálculo da capacidade, o nível de serviço desejado, a confiabilidade do sistema e a robustez das tabelas de horários.

Apesar de todos esses fatores serem relevantes na análise de um sistema, a velocidade dos trens nas seções entre estações constitui um elemento fundamental na elaboração dos modelos que envolvem as atividades ferroviárias (capacidade, scheduling, roteamento etc.) e exerce influência considerável sobre os seus resultados (BRINA, 1982).

Vários estudos têm sido realizados para determinar a capacidade de um sistema ferroviário através da aplicação de modelos analíticos, com o emprego de ferramentas computacionais. Abril et al. (2008) esclarecem que esses modelos geralmente fornecem como resultado a capacidade teórica de um trecho ferroviário - ou rede - e a capacidade prática é definida como uma porcentagem deste valor ou pela inclusão de restrições no processo de cálculo da capacidade teórica.

A seguir, são apresentados alguns trabalhos considerados relevantes, que envolvem modelos de capacidade de ferrovias, os quais podem ser tomados como ferramentas de decisão para investimentos com horizonte de planejamento estratégico.

Janic (1984) propõe um modelo probabilístico de análise de capacidade de um ramal ferroviário em linha singela, com múltiplos nós, dadas as suas características geométricas, de circulação de trens e as regras de controle do tráfego. A partir da inserção do comprimento das seções entre estações, dos tipos, velocidades e regras de separação dos trens, e da distribuição do tráfego nas duas direções de circulação, o modelo fornece a capacidade teórica da linha e a probabilidade que dois trens terão de se cruzar, independentemente do sentido em que circulam. 
Em extensão a esse trabalho, Janic (1988) apresenta um estudo da capacidade prática de linhas ferroviárias, com características semelhantes ao anterior, em que calcula o atraso médio de cada categoria de trens com base na Teoria de Filas, associada a modelos com distribuições estocásticas.

Alguns conceitos apresentados por Abril et al. (2008), sobre os fatores que exercem influência sobre a capacidade de um sistema ferroviário, já haviam sido utilizados por Krueger (1999), que desenvolveu um modelo paramétrico de capacidade para planejamento ferroviário, capaz de preencher a lacuna existente entre as formulações empíricas e os modelos de simulação existentes.

Esse autor apresenta formulações que quantificam os fatores que afetam a capacidade de um trecho ferroviário e compara a capacidade das linhas que integram a rede ferroviária, possibilitando a identificação dos gargalos para aplicação de investimentos, com o objetivo de aumentar o volume de tráfego do sistema.

Por analisar a rede ferroviária como um conjunto de seções em linha singela, dotadas de trechos em linha dupla, destinados ao cruzamento/ultrapassagem de trens, o modelo não considera a relação entre os trechos interconectados entre si e a interferência dos horários dos trens que se cruzam nos pátios, conectando-se entre si para formar a rede.

Ainda sob o ponto de vista dos modelos analíticos, Kozan e Burdett (2005) apresentam um método determinístico para obtenção da capacidade teórica de um corredor ferroviário em linha singela e estimativa dos custos totais ferroviários em um período. Os autores afirmam que uma aproximação típica para determinar a capacidade é encontrar o número de trens que circulam em uma seção crítica (CS - Critical Section), em um intervalo de tempo.

A partir disso, o modelo estima o número de trens em um trecho, com base no tempo de movimentação e com maior valor entre os calculados nas seções que interligam as estações de cruzamento da linha.

O cálculo desses tempos é função da quantidade e da distribuição direcional de cada tipo de trem, e de um coeficiente denominado Tempo de Movimentação na Seção (SRT - Section Running Time), obtido a partir das velocidades, acelerações e desacelerações dos trens e de regras de circulação no sistema.

Nos modelos analíticos que envolvem a circulação de trens periódicos, a capacidade de um nó 
pode ser calculada de maneira simplificada (Equação 2.2), levando em consideração as distâncias entre pontos de paradas, as velocidades nas seções entre estações e os atrasos decorrentes dos cruzamentos entre trens em sentidos opostos (BRINA, 1982).

$$
\mathrm{C}_{\mathrm{T}}=\frac{\mathrm{I}}{\sum_{\mathrm{i}=1}^{\mathrm{n}} \frac{\mathrm{d}_{\mathrm{i}}}{\mathrm{v}_{\mathrm{mi}_{\mathrm{i}}}}+\Delta \mathrm{t}}
$$

onde: $\mathrm{C}_{\mathrm{T}}=$ capacidade utilizada da linha (trens/unidade de tempo)

I = intervalo de tempo para análise da capacidade, em geral, 24 horas

$\mathrm{d}_{\mathrm{i}}=$ distância entre desvios/pátios de manobra consecutivos

$\mathrm{v}_{\mathrm{m}_{\mathrm{i}}}=$ velocidade média entre dois desvios/pátios de manobra consecutivos

$\Delta \mathrm{t}=$ atraso total dos trens devido aos cruzamentos e ultrapassagens

O autor afirma que as fórmulas para cálculo da capacidade são aproximadas e que uma maneira mais adequada para obtenção do número de trens em uma linha é através do diagrama espaço-tempo, encaixando-se o máximo de trens possíveis em um período de 24 horas, segundo regras de tráfego pré-estabelecidas.

A representação gráfica das operações dos trens, através de diagramas espaço-tempo, é uma ferramenta de decisão para o planejamento ferroviário (determinação da capacidade) e controle da operação (análise da movimentação das composições ferroviárias).

Neste tipo de gráfico, o espaço é definido no eixo vertical, com a localização dos desvios destinados ao cruzamento de trens em sentidos opostos, as estações e os pátios de manobra, e o tempo no eixo horizontal, com intervalo dependente da capacidade que se deseja avaliar (diária, semanal, mensal etc.). Nele pode ser representada a movimentação de vários tipos de trens que circulam em sistema ferroviário que, segundo o padrão de formação, de movimentação (periódicos ou não) e carga transportada, podem ser classificados como diretos, de ciclo, de auxílio, de passageiros e outros destinados a testes e reparos na linha.

A separação temporal entre os trens, em um dado instante, afeta diretamente a possibilidade de alocação destes na linha, com influência sobre o número de conflitos, o tempo total de percurso e, assim, sobre a capacidade do trecho ferroviário. A Figura 2.3 ilustra um diagrama espaço-tempo, com trens periódicos circulando em um trecho com 4 nós intermediários. 


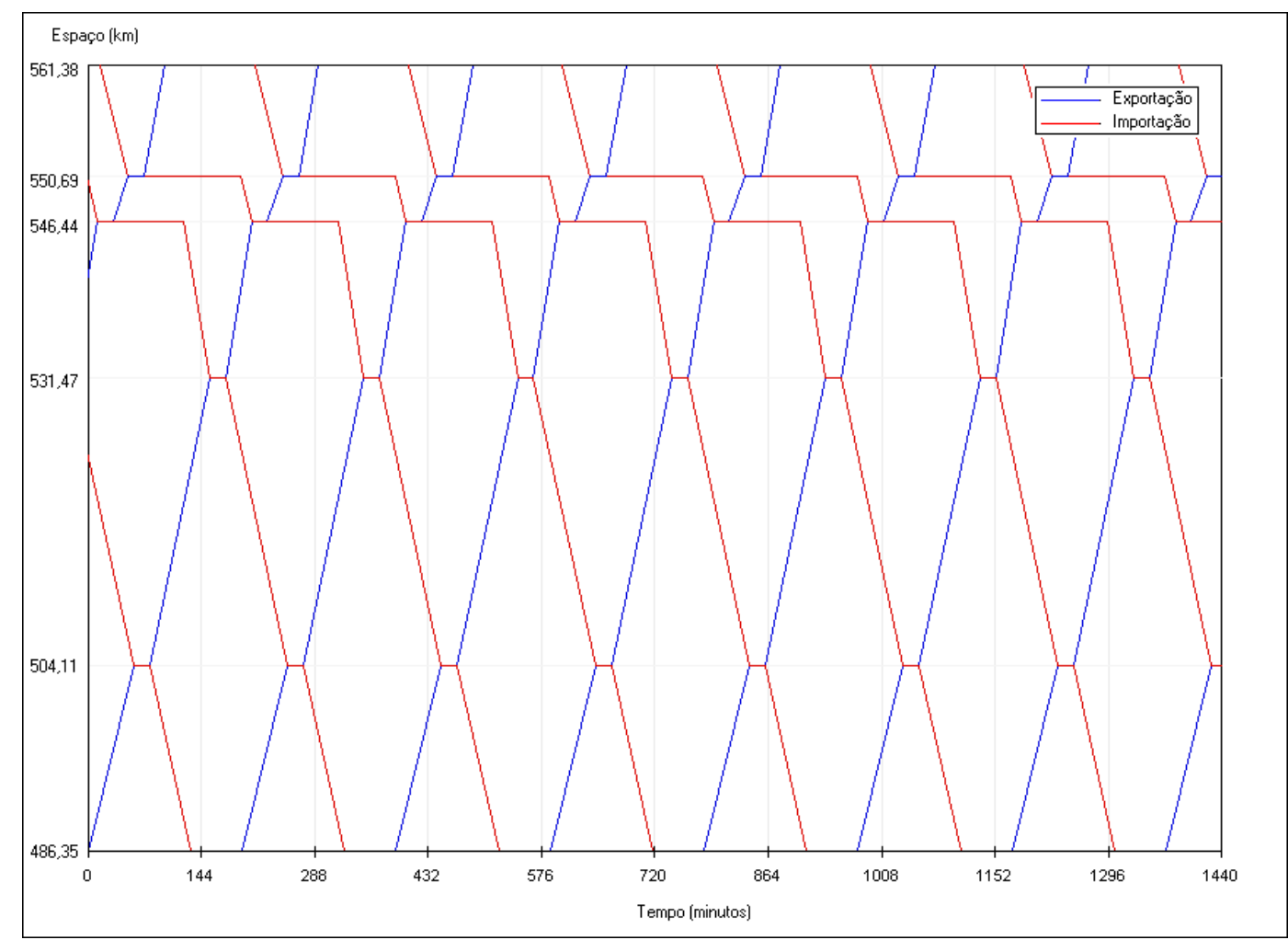

Figura 2.3 - Diagrama espaço-tempo com movimentação de trens periódicos. (Fonte: próprio autor)

Brina (1982) afirma que medidas para a melhoria da circulação podem ser tomadas através da análise do gráfico que caracteriza o percurso dos trens, e que através dessa ferramenta é possível verificar qual estação é a mais conveniente para que ocorram os cruzamentos e se estes acontecerão nos locais programados.

O modelo de capacidade elaborado por Abril et al. (2005) considera trens periódicos circulando em um ramal em via singela, com várias seções separadas por pátios de cruzamento. As premissas do método, que definem as regras de tráfego e de operação, consideram que existe apenas um tipo de trem e que o fluxo é igual em ambas as direções de circulação.

Kozan e Burdett (2005) afirmam que os modelos de identificação dos gargalos de sistemas ferroviários consideram que o fluxo total é limitado por uma seção crítica, cujos investimentos em infraestrutura devem ser direcionados. Baseado nisso, Abril et al. (2005) desenvolveram um procedimento denominado "Técnica Fracional” (Fractional Technique), que localiza essa seção e, com base no tempo de circulação dos trens, calcula a sua capacidade teórica.

No âmbito dos modelos de simulação aplicados ao estudo da capacidade, Leilich (1998) apresenta um roteiro para modelagem de um sistema real, que abrange desde a definição dos 
objetivos de estudo até a análise das variáveis de desempenho. O autor apresenta exemplos de aplicação dos simuladores no planejamento das atividades ferroviárias e expõe os tipos de abordagem matemática utilizadas neste tipo de pesquisa.

São apresentadas relações paramétricas que permitem analisar a janela de tempo disponível para manutenção da via (track maintenace window) e monitorar o nível de utilização da capacidade do sistema (line capacity monitoring system), baseadas em uma estimativa da capacidade da via, cujos parâmetros consideram o espaçamento entre estações, velocidade média de tráfego, proporção de linha dupla, prioridade dos trens etc., valores esses resultantes das simulações.

Krueger et al. (2000) apresentam o posicionamento de especialistas a respeito das vantagens de aplicação de simulações para planejamento estratégico de investimentos em ferrovias, e também algumas possíveis áreas de desenvolvimento daquele tipo de modelagem. Os autores afirmam que esses modelos podem ser utilizados para analisar a capacidade de uma rede ou terminal, pela determinação dos atrasos associados aos trens, e avaliar o impacto das variáveis no nível de serviço e confiabilidade do sistema.

Em relação às redes ferroviárias, esse tipo de modelagem é útil para ajustar adequadamente as tabelas de horários, para que representem as condições reais de circulação; localizar os gargalos da rede, tal que seus efeitos sejam minimizados, e prever os efeitos sobre os custos relativos à operação da via. Sobre os terminais, as análises dizem respeito às necessidades das instalações físicas em relação ao gerenciamento do fluxo de entrada e saída de veículos.

Middelkoop e Bouwman (2001) elaboraram um ambiente de simulação de suporte à decisão sobre os investimentos em infraestrutura e adequação das empresas operadoras do sistema à capacidade de uma rede ferroviária, considerando a circulação de diferentes tipos de trens.

A ferramenta computacional apresentada - SIMONE - constitui-se de módulos que abrangem uma biblioteca de simulação para inserção das estruturas que fazem parte de uma ferrovia, uma interface que conecta a base de dados de infraestrutura, um modelo gerador de tabelas de horários e um gerador de dados de saída, que permite o tratamento dos resultados obtidos.

A utilização do software resulta em indicadores de desempenho, como atraso nos ramais da rede, headways entre trens, pontualidade nos horários de chegadas e saídas das estações, e gráficos que relacionam os parâmetros avaliados pelos módulos. 
Como mencionado anteriormente, os modelos de simulação apresentam pouca flexibilidade em relação à aplicação em ferrovias com diferentes configurações. Devido a isso, várias pesquisas e ferramentas foram desenvolvidas para análise da capacidade de processamento e definição de prioridades de investimentos em ferrovias específicas. Entre estas podemos destacar os trabalhos de Peter e Teunisse (1997), Lewellen e Tumay (1998) e Rangaraj et al. (2003).

Os modelos de otimização, em geral, apresentam soluções melhores na avaliação da capacidade ferroviária em relação aos demais métodos, por utilizarem técnicas de programação matemática - Algoritmo de Programação Linear Inteira Mista, por exemplo, cujo objetivo é preencher tabelas de horários a partir de uma tabela inicial vazia ou que apresente utilização parcial do sistema.

Assim, é possível afirmar que a capacidade de um trecho ou rede ferroviária pode ser obtida a partir dos conceitos de otimização aplicados aos modelos de scheduling, abordados em alguns trabalhos descritos no item 2.2 deste capítulo.

Nesse contexto, Salido et al. (2004) elaboraram um modelo de capacidade cuja função é minimizar a soma dos tempos de viagem dos trens, considerando a topologia da infraestrutura (distância entre estações, características da via etc.), os parâmetros das composições ferroviárias (número e tipos de trens, velocidades, tempos de parada) e as regras de tráfego (frequência, headway entre trens etc.).

O modelo matemático formal é dividido em dois problemas distintos, um de programação inteira e outro de programação linear, com as variáveis definidas pelo anterior. A capacidade foi estudada em termos da distância mínima de segurança entre trens na mesma seção, com a circulação de trens periódicos em linhas singelas.

A partir desse modelo, Barber et al. (2004) construíram uma ferramenta computacional de gerenciamento da infraestrutura e operação do sistema ferroviário, que permite a interação do usuário. O trabalho mostra que, através da inserção dos dados de entrada e posterior análise da tabela de horários apresentada na forma de diagrama espaço-tempo, o algoritmo é capaz de resolver o problema de circulação de trens periódicos distintos - com demandas diferentes - e determinar a capacidade de processamento em um trecho de via singela.

Barber et al. (2006) apresentam um Sistema de Suporte a Decisões (DSS - Decision Support 
System) com características semelhantes à ferramenta descrita anteriormente, porém o modelo matemático é complementado com dois módulos de otimização, o de "Otimização Padrão" (Standard Optimization), cujos resultados devem necessariamente satisfazer as restrições impostas pelo operador, tráfego e infraestrutura, e o de "Otimização Flexível" (Flexible Optimization), com a relaxação das restrições se a tabela de horários resultante for considerada melhor que a fornecida como dado de entrada.

Kozan e Burdett (2006) apresentam uma revisão sobre o método analítico de obtenção da capacidade em um trecho ferroviário em linha singela, exposto em Kozan e Burdett (2005), incorporando ao modelo os atrasos nos cruzamentos e ultrapassagens dos trens, e com isso determinam a capacidade de processamento para cada tipo de composição que circula nas linhas.

Como complemento a esse trabalho, os autores elaboraram um modelo de cálculo do número de trens que trafegam entre as origens e destinos de uma rede ferroviária, com aplicação em um exemplo teórico. Devido à interação entre os corredores, à inserção de desvios nos trechos e aos atrasos nesses locais, a modelagem mostra-se mais complexa e demanda a utilização de um modelo de otimização para a resolução dos conflitos.

Analogamente aos modelos de scheduling, Barber et al. (2007) apresentam algumas ferramentas que utilizam métodos analíticos, de simulação e otimização, para análise da capacidade de trechos e redes ferroviárias, dentre eles o CAPRES ${ }^{\circledR}$, DEMIURGE $^{\circledR}$, RAILCAP $^{\circledR}, \mathrm{CMS}^{\circledR}$ e MOM-DALLAS $^{\circledR}$.

\subsection{Considerações sobre a revisão bibliográfica}

Os trabalhos apresentados nesta revisão bibliográfica e aqueles apresentados como referências complementares indicam que, apesar de ser objeto de estudo há vários anos, a atividade ferroviária não possui um modelo ou método unificado capaz de responder todas as questões que a abrangem, devido principalmente à grande quantidade de variáveis envolvidas no delineamento dos problemas e o modo como são mensuradas, e às diferentes abordagens em relação à movimentação e alocação dos trens na linha férrea.

A proposta de um modelo de capacidade que abranja o tipo de malha ferroviária apresentada neste trabalho - enraizada não direcionada - justifica-se pelo fato de que os modelos existentes não consideram todas as premissas necessárias para representação do movimento dos trens na rede, apresentam pouca flexibilidade em relação à aplicação em diferentes 
ferrovias e não fornecem os dados de saída necessários para as análises pretendidas.

No trabalho apresentado por Abril et al. (2005), é possível identificar um estudo semelhante ao abordado nesta dissertação, com a determinação da capacidade de um ramal ferroviário em linha singela, no qual circulam trens em sentidos opostos. Entretanto, esse modelo não pode ser empregado para identificação dos arcos que restringem o aumento do número de trens diários em redes enraizadas não direcionadas, sendo aplicável somente para determinação da capacidade em linhas com múltiplos nós.

Kozan e Burdett (2005) apresentam um modelo de capacidade com características semelhantes às do anterior, porém a extensão do método a redes ferroviárias, apresentado em Kozan e Burdett (2006), necessita de ferramentas específicas para solução de problemas de otimização e apresenta uma formulação complexa para representação do problema, o que torna inviável a sua utilização neste trabalho.

Os artigos e publicações nacionais evidenciaram uma carência de estudos direcionados ao planejamento de longo prazo, segundo as características e necessidades da malha ferroviária brasileira, em termos de investimentos na infraestrutura. Pelo caráter estratégico, a utilização de um simulador de desempenho de trens, para obtenção dos tempos de viagem nos arcos, justifica-se pelo fato destes valores corresponderem aos máximos valores possíveis de serem praticados sob as condições de carregamento, força tratora disponível, geometria da via e limites operacionais de velocidade.

Essa premissa permite afirmar que o modelo de capacidade utiliza o máximo aproveitamento da via em termos de velocidade desenvolvida pelos trens, pois se esse valor fosse relativo à velocidade operacional praticada atualmente, a capacidade determinada não corresponderia ao limite que determina a necessidade de investimentos em infraestrutura.

Entretanto, durante a realização desta pesquisa foi possível constatar que os tempos reais de viagem dos trens nos arcos são difíceis de serem obtidos junto ao operador do sistema e que a obtenção destes na prática demanda tempo e recursos financeiros que inviabilizam a sua determinação.

O modelo de capacidade proposto neste trabalho é classificado como uma heurística que apresenta um procedimento de resolução dos conflitos entre trens em sentidos opostos, em uma rede ferroviária, baseado no diagrama espaço-tempo, respeitando as condições mínimas 
de tempos de espera nos cruzamentos, os tempos de viagem obtidos através de um simulador de desempenho de trens e demais parâmetros considerados relevantes.

Desse modo, o modelo proposto neste trabalho viabiliza a determinação do número de trens na rede ferroviária relativo à capacidade teórica do sistema, pois considera que o tráfego de trens é homogêneo, que estes são espaçados uniformemente e não há interrupções aleatórias na operação do sistema. Entretanto, é necessário ressaltar que as premissas adotadas no modelo apresentado no próximo capítulo não fornecem necessariamente resultados ótimos para o problema abordado. 


\section{Capítulo 3}

\section{MÉTODO}

O movimento de trens é possível devido à existência de uma infraestrutura compatível com o material rodante que circula sobre ela. A construção de um modelo que represente esse processo exige a caracterização dos elementos ferroviários para que a relação entre eles possa ser definida convenientemente em uma linguagem computacional.

A seguir são apresentados os conceitos relacionados ao sistema ferroviário, à sua operação e ao material rodante utilizado no transporte de cargas, e as etapas que devem ser cumpridas para obtenção da capacidade de uma rede ferroviária enraizada não-direcionada.

\subsection{Elementos do sistema ferroviário}

A nomenclatura dos elementos da malha ferroviária está associada aos termos utilizados para definição do tipo de rede a que se aplica o modelo proposto neste trabalho. Os terminais são análogos aos vértices, a partir dos quais os trens são criados, e têm como destino um terminal específico identificado como polo de concentração de cargas, equivalente à raiz do sistema.

Para cada trem criado em um terminal existe uma composição equivalente em sentido oposto, com origem no polo de concentração de cargas e destino no respectivo terminal a que está associado. A modelagem proposta admite que os terminais possuem capacidade ilimitada de geração e processamento de trens e podem também ser utilizados como pátios de triagem, de classificação, dentre outras funções.

No modelo, o polo de concentração de cargas - para onde os trens convergem no sentido Exportação e de onde partem no sentido Importação em direção aos demais terminais da rede - também não apresenta restrições de capacidade de processamento que possam existir, por exemplo, nos casos em que este estiver situado em uma região portuária cujas operações dependem dos tempos de descarregamento dos vagões, recebimento e despachos do trens etc.

A posição de um terminal não é necessariamente na extremidade de um ramal, pois como característica de um grafo bipartido, associado a uma malha ferroviária, um terminal (ou 
vértice) pode ser criado em um ramal (ou aresta) a partir da definição de um local que viabiliza o cruzamento entre trens que trafegam em sentidos opostos e estabelece um centro de geração e processamento de cargas.

Os ramais são equivalentes às arestas dos grafos, e caracterizados como trechos em linha singela, com a possibilidade de circulação de trens nos dois sentidos. O modelo admite que mais de um trem em mesmo sentido, ou em sentidos opostos, circule em um ramal no mesmo instante. Os ramais podem conter trechos duplicados denominados nós, que viabilizam o cruzamento desses trens, de modo que os trechos em linha singela existentes entre dois nós consecutivos são definidos como $\operatorname{arcos}$.

Por ser em via singela, a circulação das composições nos arcos é restrita a um trem por sentido, para evitar colisões, de modo que a entrada de uma composição em um sentido é condicionada à saída de outro em sentido contrário. Desse modo, um arco tem capacidade limitada a um único trem em um determinado instante " $t$ " independente do sentido de circulação.

Cada arco da rede possui condições de tráfego em seu entorno (passagens em nível, perímetro urbano etc.) e estado de conservação que impõem limites de velocidade aos trens que neles circulam sendo que as suas características geométricas (seção transversal e perfil longitudinal) foram definidas, na época de construção, segundo a topografia do local e a configuração dos trens que circulariam nas linhas ferroviárias para os propósitos previstos.

Os nós dos ramais estão associados aos "pátios de cruzamento", caracterizados pela existência de duas ou mais linhas paralelas à principal, destinadas apenas ao cruzamento dos trens que circulam em sentidos opostos em um trecho de via singela (BRINA, 1979). O autor afirma que esses trechos devem ser suficientemente extensos para que contenham o trem de maior comprimento que se movimenta na linha, entretanto, devido aos grandes comprimentos das composições ferroviárias atuais, estas podem não parar ou serem fracionadas para poderem ser inseridas nos nós.

Durante o processo de construção das ferrovias, no Brasil, foram implantados trechos em linha singela com diferentes bitolas (1,00 metros, 1,60 metros e 1,435 metros), fato que atualmente resulta em problemas operacionais devido à incompatibilidade do material rodante com a via permanente. O modelo de capacidade exige a compatibilidade entre bitolas nos ramais da rede, estabelecida pela existência de trilhos paralelos fixados a uma mesma distância em 
ramais subsequentes ou pela instalação de um terceiro trilho, que permite a circulação de trens com distâncias entre rodas distintas.

A Figura 3.1 ilustra os elementos do tipo de rede ferroviária abordada no modelo de capacidade, análoga a uma rede enraizada não-direcionada, com os componentes descritos neste item.

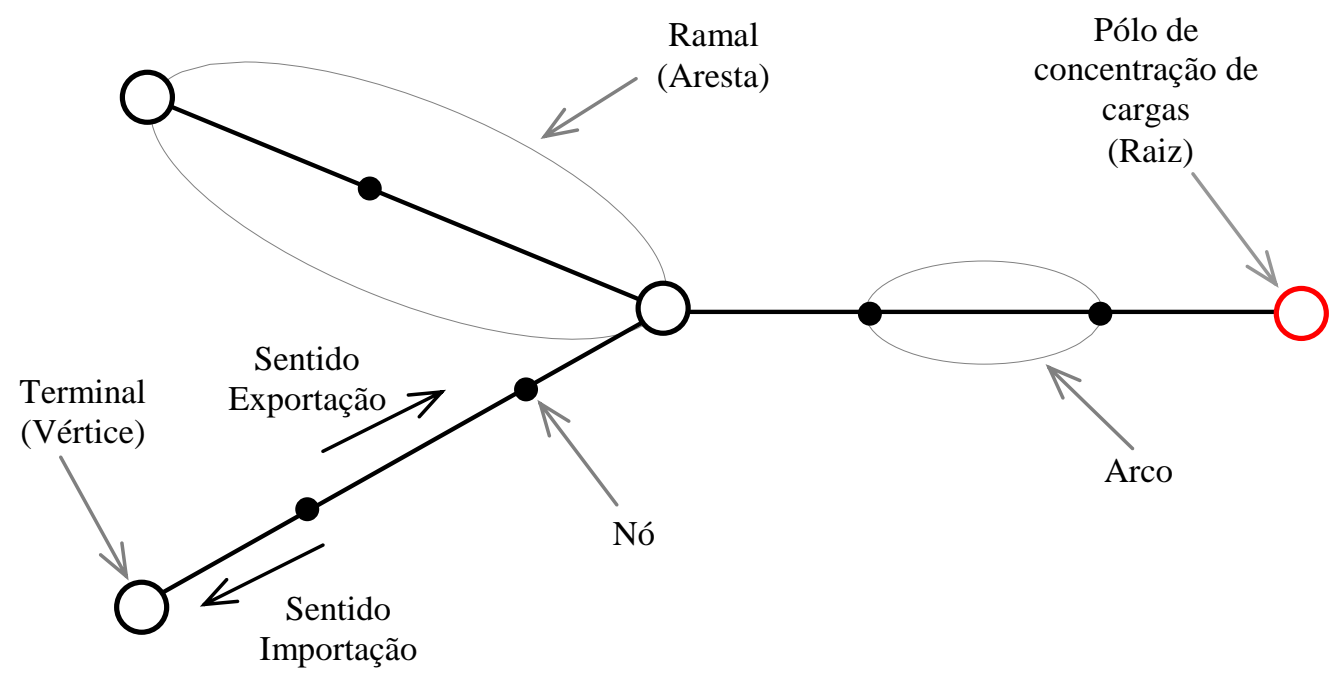

Figura 3.1 - Esquema do tipo de rede ferroviária considerada no modelo.

A Figura 3.2 apresenta o esquema de um ramal da rede em que são indicados os sentidos de movimentação dos trens e os nós de um ramal ferroviário em linha singela.

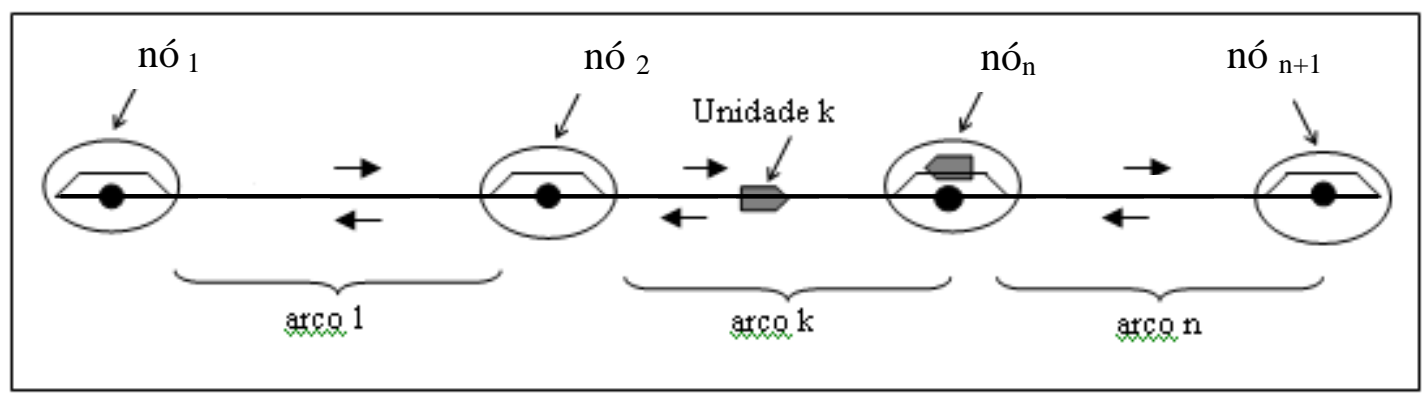

Figura 3.2 - Componentes de um ramal ferroviário em linha singela.

\subsection{Elementos constituintes do material rodante}

O trem-tipo é o conjunto de locomotivas e vagões que circulam pela rede e transportam as cargas entre os terminais. A composição é caracterizada segundo o tipo de locomotiva adotada no sistema de tração, a localização destas no comboio, os tipos de vagões e suas configurações de carregamento, e demais características associadas ao material rodante.

No método de modelagem, o trem se origina em um terminal e percorre os ramais sem que sua 
configuração inicial seja alterada, em relação ao número de locomotivas e vagões e a localização destes no comboio. Uma vez concluído o percurso, os trens são desfeitos no terminal de destino e uma composição correspondente é criada e despachada no sentido oposto, segundo as regras definidas no algoritmo do modelo de capacidade.

A tração decorrente da transferência da força motriz gerada pelo motor elétrico das locomotivas diesel-elétricas é função da sua potência, definida pelo fabricante e utilizada como dado de entrada no simulador de desempenho de trens, para obtenção dos tempos de viagem nos arcos.

O comprimento total do trem é a somatória do comprimento dos vagões e locomotivas, limitado pelo comprimento dos desvios, força tratora das locomotivas, capacidade de carga nos engates e a capacidade dos trens de reiniciarem o seu movimento em um aclive. Como o transporte a longas distâncias é uma das principais características do modo ferroviário, sendo estas da ordem de centenas de quilômetros, a relação entre o tamanho do trem-tipo e as distâncias percorridas permite afirmar que os comboios são vistos no sistema como uma partícula que descreve um movimento na linha.

A carga transportada depende da limitação por peso, ou volume, dos vagões utilizados. Este parâmetro está diretamente relacionado à potência das locomotivas empregadas e aos custos de manutenção, devido às solicitações de carga sobre a linha férrea. Apesar de ser permitido aos trens terem configurações diferentes quando partem de um terminal, a relação peso/potência destes nos ramais é admitida constante no método proposto, estabelecendo-se uma condição teórica de mesma velocidade em um arco para trens provenientes de terminais distintos.

\subsection{Definições sobre a operação ferroviária}

Em uma linha ferroviária singela, os trens podem circular em dois sentidos, o que resulta em conflitos provocados pela impossibilidade de tráfego das composições em um arco no mesmo intervalo de tempo. Para elaboração do modelo é considerada a circulação dos trens em dois sentidos, denominados "Exportação" e "Importação", em que o primeiro é atribuído às composições que partem dos terminais da rede em direção ao polo de concentração de cargas e o outro é atribuído às que saem desse local e retornam aos respectivos terminais.

O desempenho dos trens é influenciado pelo seu sentido de circulação na via, pois os arcos 
com rampas ascendentes em um sentido impõem fornecimento maior de tração por parte das locomotivas, mas, por outro lado, em sentido contrário auxiliam o movimento.

O tempo de viagem dos trens nos arcos depende das condições topográficas da via (relevo, superelevação etc.), comprimento dos arcos, velocidade máxima permitida, condições climáticas de operação, estado de conservação da superestrutura ferroviária etc. O movimento dos trens no diagrama espaço-tempo é baseado no tempo de viagem entre nós, pela aproximação das velocidades instantâneas no arco através da velocidade média no espaço (Equação 3.1), representado graficamente pelas ilustrações da Figura 3.3.

$$
\overline{\mathrm{u}}_{\mathrm{s}}=\frac{\mathrm{S}_{\mathrm{i}}}{\mathrm{t}_{\mathrm{i}}}
$$

em que $\quad \overline{\mathrm{u}}_{\mathrm{s}}=$ velocidade média no espaço no arco i $(\mathrm{km} / \mathrm{hora})$

$$
\begin{aligned}
& \mathrm{s}_{\mathrm{n}}=\text { espaço percorrido no arco } \mathrm{i}(\mathrm{km}) \\
& \mathrm{t}_{\mathrm{i}}=\text { tempo gasto pelo trem para percorrer o arco } \mathrm{i} \text { (horas) }
\end{aligned}
$$
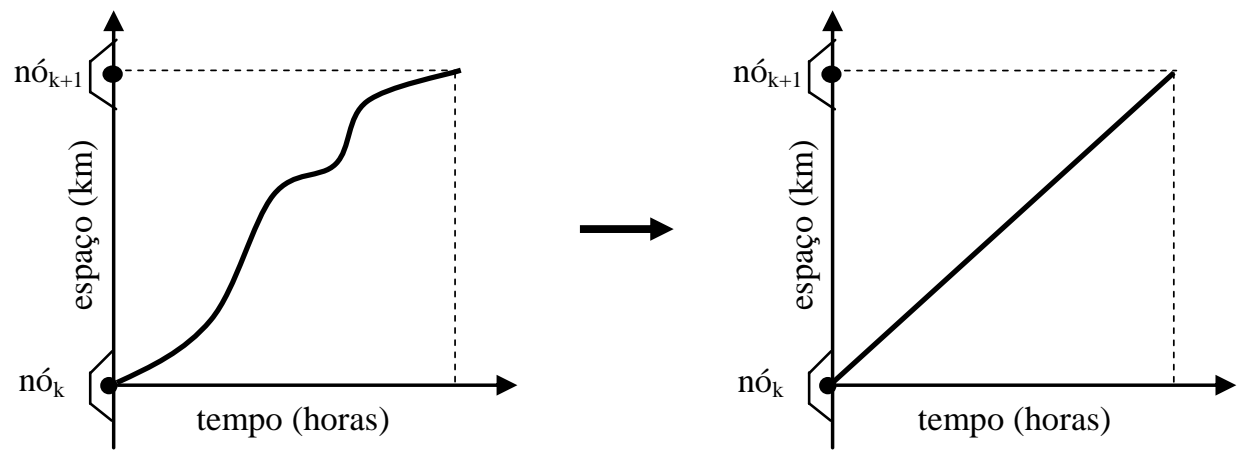

Figura 3.3 - Velocidade instantânea e média (no espaço) entre dois nós.

Em relação aos horários de circulação dos trens no sistema, existe a incompatibilidade entre os diversos tipos de serviços disponibilizados por uma mesma infraestrutura ferroviária transporte de passageiros e cargas - cujas características são distintas em termos de velocidade operacional e nível de serviço desejado.

Entretanto, o modelo apresentado neste trabalho admite a circulação dos trens de carga em todos os horários do dia, não sendo consideradas as restrições impostas aos operadores, pelo fato de ser um modelo de planejamento estratégico com vistas à identificação dos gargalos da via. 
Outro parâmetro relacionado à operação ferroviária é o headway entre trens, que corresponde ao intervalo de tempo entre composições sucessivas que circulam no mesmo sentido em um ramal. O headway é influenciado pela diferença de velocidade dos trens, pois as composições mais lentas tendem a ocupar os arcos entre nós adjacentes por um período mais longo e, por isso, aumentam o tempo entre as saídas sucessivas de trens no mesmo sentido.

Desse modo, esse intervalo de tempo exerce influência direta sobre o número de trens na linha, pois define os horários dos cruzamentos nos nós e, consequentemente, a capacidade de processamento do sistema.

\subsection{Modelo de capacidade ferroviária}

Para obtenção da capacidade da rede ferroviária é necessário que sejam executadas três etapas distintas, relacionadas entre si pela sequência apresentada no fluxograma da Figura 3.4, detalhada nos itens a seguir.

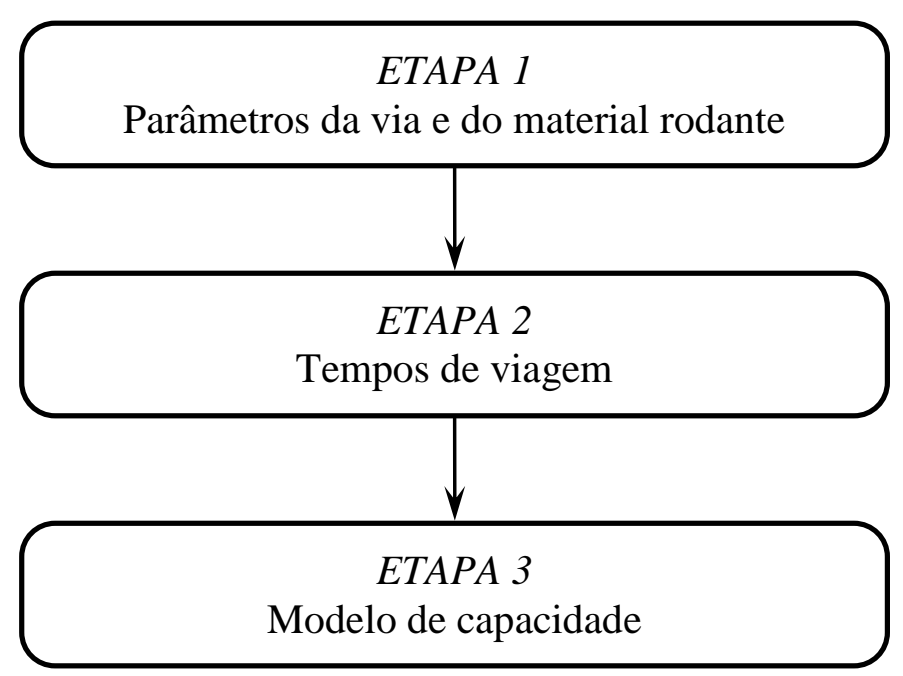

Figura 3.4 - Fluxograma das etapas para obtenção da capacidade da rede ferroviária.

\subsubsection{ETAPA 1 - Parâmetros da via e do material rodante}

Esta etapa tem início com a definição da rede através da identificação dos terminais, dos ramais que fazem a ligação entre esses elementos, através da identificação dos nós e caracterização dos arcos.

Para viabilizar a construção dos arquivos do simulador TEM (ver página 38 - item “2.1 Modelos de desempenho de trens"), devem ser obtidos os parâmetros relativos à via permanente (altitudes, raio das curvas horizontais e verticais e inclinação das rampas), 
estabelecidos os limites de velocidade nos arcos e definidos o tipo e número de locomotivas e vagões que circularão no sistema em função da carga transportada.

A seguir devem ser executados procedimentos que permitam representar as relações entre os elementos do sistema ferroviário e o reconhecimento deste formato pela linguagem computacional adotada. Inicialmente, o polo de concentração de cargas (ou raiz) da rede ferroviária deve ser identificado e a ele atribuído um índice (rótulo) igual a um valor inteiro, diferente de zero (preferencialmente o valor " 1 ").

Os demais terminais devem ser identificados e a eles atribuídos índices tal que o valor inteiro atribuído a um terminal seja sempre maior que o do terminal precedente no sentido Importação, e que um mesmo índice não seja utilizado para identificar terminais distintos.

A Figura 3.5 ilustra um exemplo de rede ferroviária em linha singela enraizada nãodirecionada, cujos índices dos terminais foram definidos segundo as condições estabelecidas anteriormente.

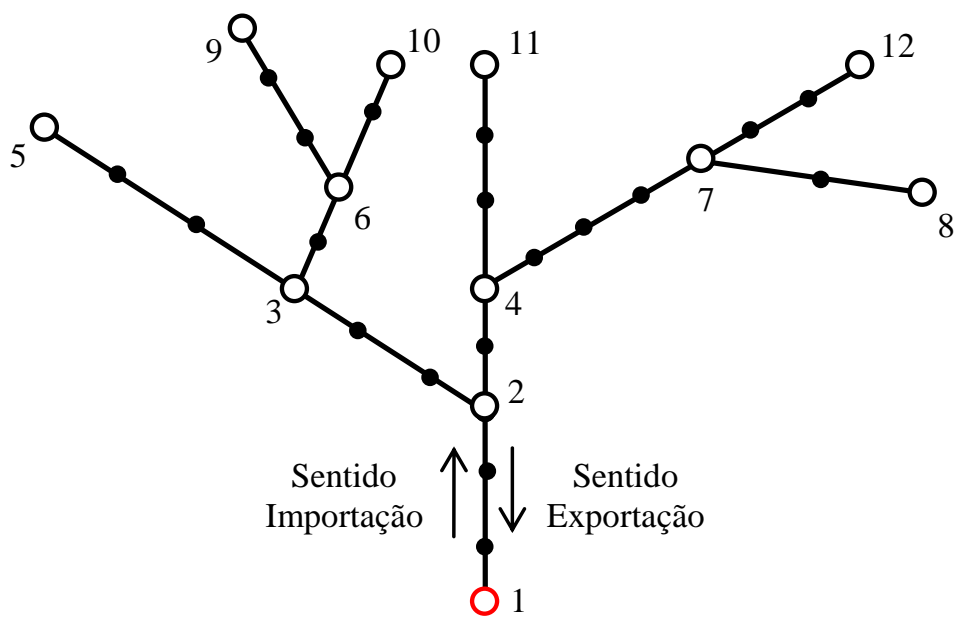

Figura 3.5 - Identificação dos terminais da rede.

Apesar de ser possível aos trens movimentarem-se entre quaisquer pares de terminais, o modelo proposto não admite transporte de carga interna na rede, ou seja, a circulação dos trens dar-se-á apenas entre locais cuja origem ou destino final sejam necessariamente o polo de concentração de cargas.

Assim, para todos os terminais da rede, exceto o polo de concentração de cargas, é definido um caminho denominado "Rota de Circulação", correspondente à trajetória que um trem descreve no sentido Exportação, desses locais até a raiz da rede. O percurso é definido pela 
sequência de índices dos terminais que o trem atravessa a partir de sua origem até atingir o polo de concentração de cargas. A Figura 3.6 ilustra uma Rota de Circulação da rede da Figura 3.5 para um trem criado no terminal "9", que passa pelos terminais "6", "3" e "2", e chega ao terminal "1" quando no sentido Exportação.

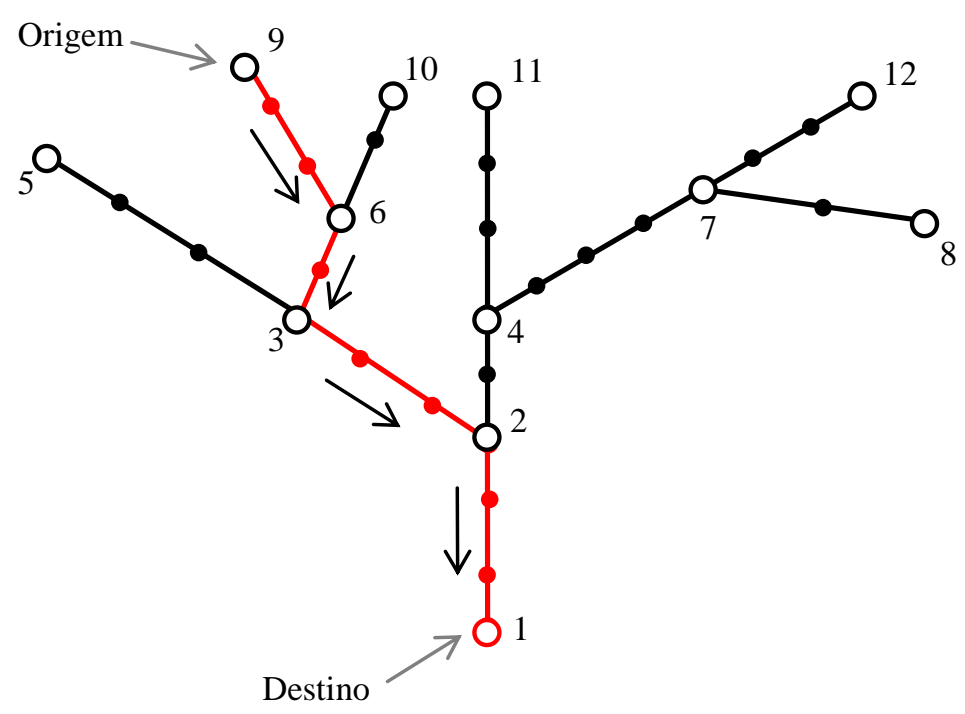

Figura 3.6 - Exemplo de Rota de Circulação (9-6-3-2-1, sentido Exportação).

Em uma rede de transporte ferroviário podem existir terminais geradores e receptores de cargas com diferentes volumes de tráfego diário, cuja representatividade em relação ao sistema pode variar de acordo com a importância dos produtos oriundos de sua região de abrangência ou da capacidade de absorção de cargas provenientes de outros polos.

Para representar numericamente a influência de cada terminal, através de uma ponderação préestabelecida, foi definida a variável "Coeficiente de Proporcionalidade". A sua finalidade é caracterizar a proporção de trens que partem de cada um dos terminais em relação ao número total de composições que chegam ao polo de concentração de cargas no sentido Exportação, no período de 24 horas.

Assim, para cada terminal que define o início de uma Rota de Circulação é atribuído um valor de Coeficiente de Proporcionalidade, que varia no intervalo fechado entre $0 \%$ e $100 \%$. A soma dos Coeficientes de Proporcionalidade relativos a cada terminal deve resultar em 100\%, que corresponde a toda a carga transportada no sistema no sentido Exportação ou Importação.

A representação da malha ferroviária no modelo é feita através de uma tabela semelhante à estrutura de adjacência utilizada para definição de um grafo. Apesar de ser uma rede não- 
direcionada, essa representação é equivalente à de um grafo direcionado com arestas orientadas no sentido Exportação a partir de cada um dos terminais da malha, exceto o polo de concentração de cargas.

A Tabela 3.1 apresenta uma possível combinação dos Coeficientes de Proporcionalidade em cada uma das Rotas de Circulação definidas pelos terminais de origem dos trens no sentido Exportação, na malha ferroviária da Figura 3.5.

Tabela 3.1 - Coeficientes de Proporcionalidade atribuídos aos terminais da malha.

\begin{tabular}{cccccc}
\hline $\begin{array}{c}\text { Coeficiente de } \\
\text { Proporcionalidade }\end{array}$ & $\begin{array}{c}\text { Terminal de } \\
\text { origem }\end{array}$ & \multicolumn{4}{c}{$\begin{array}{c}\text { Terminais subsequentes } \\
\text { (sentido Exportação) }\end{array}$} \\
\hline $10 \%$ & $\mathbf{2}$ & 1 & & & \\
\hline $0 \%$ & $\mathbf{3}$ & 2 & 1 & & \\
\hline $0 \%$ & $\mathbf{4}$ & 2 & 1 & & \\
\hline $20 \%$ & $\mathbf{5}$ & 3 & 2 & 1 & \\
\hline $10 \%$ & $\mathbf{6}$ & 3 & 2 & 1 & \\
\hline $0 \%$ & $\mathbf{7}$ & 4 & 2 & 1 & \\
\hline $10 \%$ & $\mathbf{8}$ & 7 & 4 & 2 & 1 \\
\hline $20 \%$ & $\mathbf{9}$ & 6 & 3 & 2 & 1 \\
\hline $10 \%$ & $\mathbf{1 0}$ & 6 & 3 & 2 & 1 \\
\hline $0 \%$ & $\mathbf{1 1}$ & 4 & 2 & 1 & \\
\hline $20 \%$ & $\mathbf{1 2}$ & 7 & 4 & 2 & 1 \\
\hline
\end{tabular}

Como os Coeficientes de Proporcionalidade são uma variável de entrada do modelo, podem ser estabelecidos manualmente pelo usuário, segundo o volume de carga atual que se origina nos terminais da rede ou através de um algoritmo vinculado ao modelo de capacidade, que varia esses valores no intervalo de $0 \%$ a $100 \%$ a um incremento pré-definido, o que permite analisar o efeito de cada combinação sobre o número de trens que circulam nos ramais da malha ferroviária.

\subsubsection{ETAPA 2 - Tempos de viagem}

Para cada ramal da rede são executadas simulações com o TEM, para obtenção dos tempos de viagem nos arcos, nos dois sentidos de circulação. O modelo de locomoção, os programas que constituem o simulador, o formato dos arquivos e o procedimento para execução das simulações são descritos no Anexo A, Anexo B, Anexo C e Anexo D, respectivamente.

No modelo de capacidade descrito na ETAPA 3 considera-se que todos os trens apresentam o 
mesmo tempo de parada (maior que zero) nos nós da rede, os quais são definidos nessa etapa de inserção de dados no simulador de desempenho de trens através do arquivo com extensão “.STP”, descrito no Anexo C. Essa generalização permite que sejam estabelecidos tempos de parada distintos nos nós, a partir de critérios definidos pelo usuário, inclusive com a atribuição do valor nulo, que caracteriza a passagem direta dos trens nos nós.

Os dados resultantes das simulações são disponibilizados ao usuário em arquivos de texto com extensão “.OUT”, no formato de colunas, conforme exposto no item C.2.6 (Arquivo de saída do simulador) do Anexo C.

Esses arquivos devem ser agrupados no diretório que contém o arquivo do modelo de capacidade, e devem ser nomeados com os índices dos terminais a que se referem em relação ao sentido de circulação. Por exemplo, os arquivos do ramal "3-2" da Figura 3.5 devem ser nomeados como "32" e "23", para estabelecer os tempos de viagem nos seus arcos no sentido Exportação e Importação, respectivamente.

\subsubsection{ETAPA 3 - Modelo de capacidade}

Essa etapa corresponde à execução do algoritmo que resulta na capacidade de processamento de trens da rede, pela definição de uma tabela de horário viável com análise do movimento dos trens através de diagramas espaço-tempo. O Microsoft Office Excel foi o software definido para execução do modelo, por permitir a caracterização da rede ferroviária de modo simples e pela facilidade de criação e edição de gráficos.

Apesar de possuir diversas funções pré-definidas para tratamento de dados, a geração dos diagramas espaço-tempo nesse programa foi viabilizada pela elaboração de procedimentos específicos, com o uso de um pacote de programação computacional nele inserido, denominado Visual Basic for Applications - versão orientada a objetos do Visual Basic integrado ao pacote de aplicativos do Microsoft Office.

Essa ferramenta complementar - permite a criação de módulos independentes que interagem entre si e com as planilhas do Microsoft Office Excel. (JELEN e SYRSTAD, 2004). Os softwares de programação que utilizam a linguagem orientada a objetos consideram as variáveis (matrizes, vetores, etc.) estruturadas como uma coleção de entidades discretas e distintas, cujos atributos lhes são conferidos através de comandos denominados métodos, além de permitir a criação de uma interface para que o usuário possa interagir com o 
sistema (RUMBAUGH et al., 1994).

Os passos executados pelo algoritmo transcrito na linguagem de programação característica do Visual Basic for Applications baseiam-se nos módulos do fluxograma da Figura 3.7.

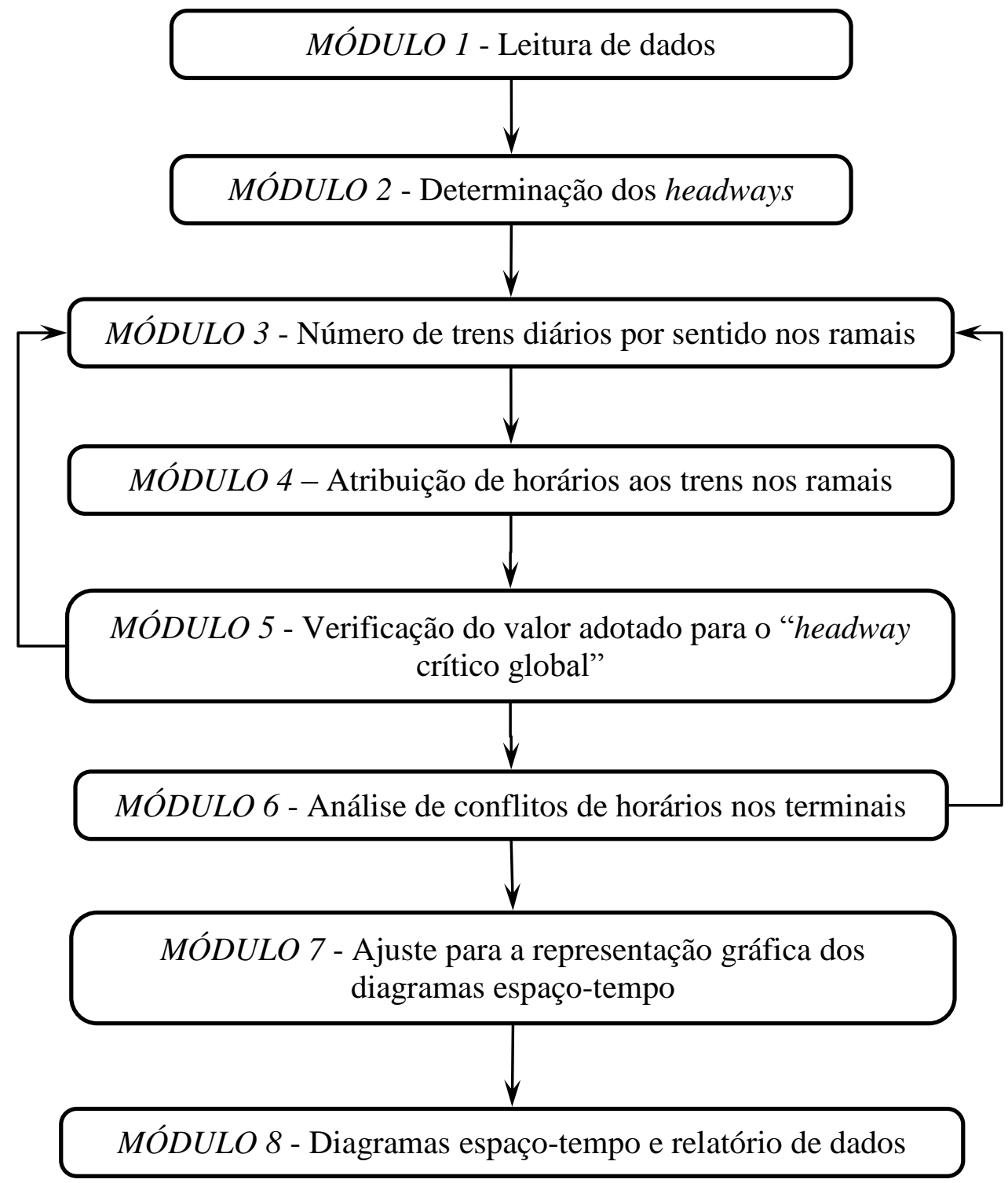

Figura 3.7 - Fluxograma que estabelece a relação entre os módulos do algoritmo de obtenção da capacidade da rede ferroviária.

A seguir são apresentadas as operações lógicas e matemáticas dos procedimentos relativos a cada um dos módulos do fluxograma acima, que resultam na representação gráfica do movimento dos trens e no número de composições que circulam nos ramais da rede.

\section{MÓDULO 1 - Leitura de dados}

O primeiro passo que precede a execução do algoritmo é relativo à caracterização da via, 
através da identificação dos terminais de geração e recebimento de trens, definição das Rotas de Circulação e atribuição dos Coeficientes de Proporcionalidade aos terminais (item 3.4.1).

Além da definição desse conjunto de variáveis, é necessário estabelecer o valor de um parâmetro correspondente ao tempo de espera mínimo entre a chegada de um trem no terminal de um ramal e a sua saída no ramal subjacente, denominado "Tempo de espera mínimo nos terminais", expresso em minutos.

A Figura 3.8 apresenta a tela exibida ao usuário para caracterização da via e dos parâmetros do modelo na malha da Figura 3.5.

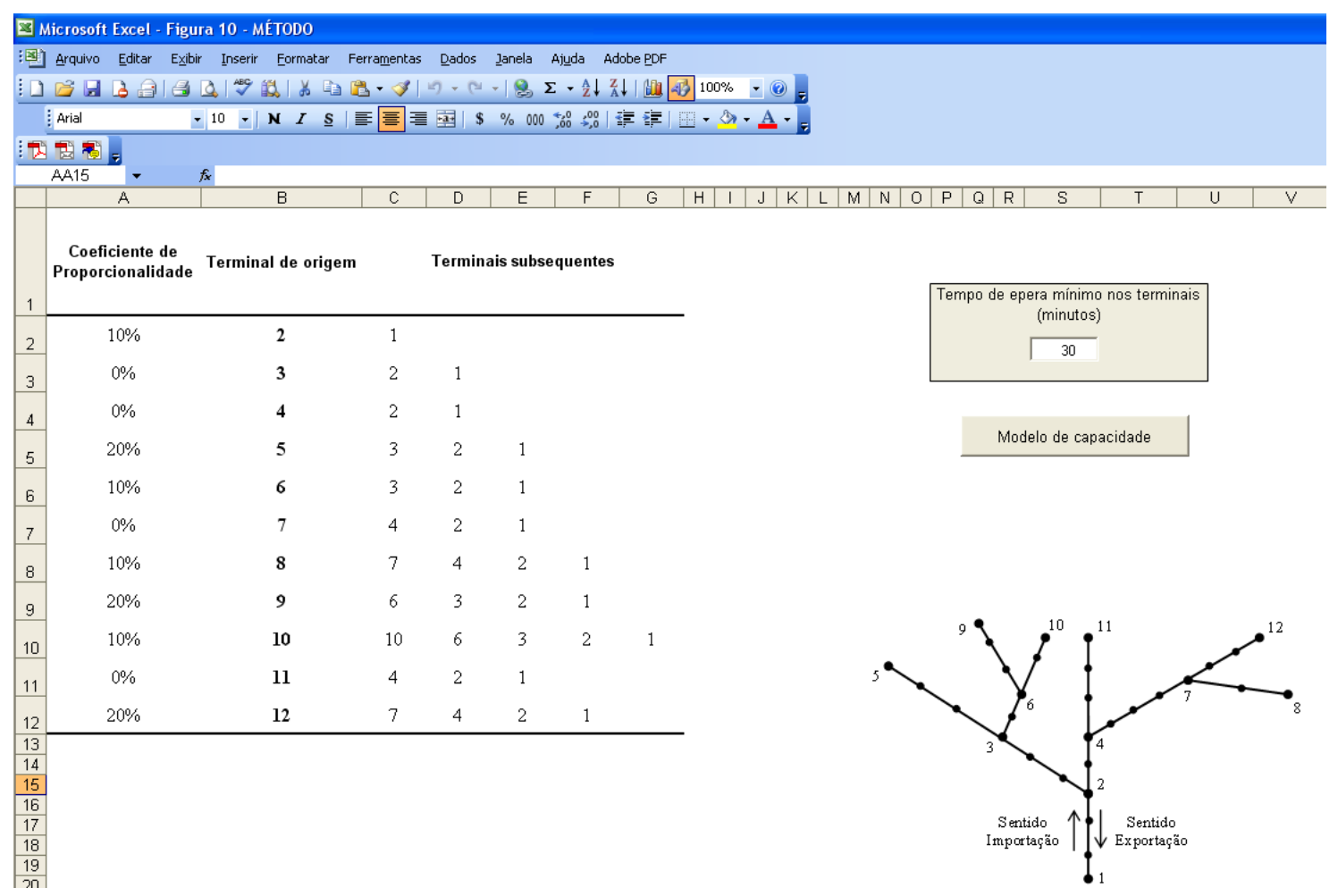

Figura 3.8 - Interface disponibilizada ao usuário para caracterização do modelo no Microsoft Office Excel.

Após a caracterização do sistema ferroviário, os parâmetros referentes à geometria da via, ao material rodante e às condições operacionais são inseridos nos arquivos de entrada de dados do simulador, descritos no Anexo C. As simulações do movimento dos trens nos ramais são executadas para os dois sentidos de circulação (Exportação e Importação) e os arquivos contendo os tempos de viagem, resultantes desse procedimento, são nomeados conforme exposto no item 3.4.2.

O algoritmo realiza a leitura dos arquivos com a descrição do desempenho dos trens durante as simulações e são efetuadas as devidas conversões de unidades - Equação (3.2) e Equação 
(3.3), uma vez que o TEM opera com o sistema inglês de unidades. Desse modo, o espaço percorrido passa a ser expresso em quilômetros e os tempos de percurso nos arcos em horas, para representação satisfatória do movimento dos trens nos diagramas espaço-tempo.

$$
\text { Tempo (horas) }=\text { Tempo (horas) }+\underline{\text { Tempo }(\text { minutos })}+\underline{\text { Tempo (segundos) }}
$$

$$
\text { Espaço }(\mathrm{km})=1,609344 \cdot \text { Espaço }(\text { milhas })+0,000309 \cdot \text { Espaço }(\text { pés })
$$

Como especificado anteriormente, o modelo considera a velocidade média dos trens no espaço associada a um tempo de viagem, entre nós consecutivos. Assim, para todos os ramais da rede é criado um trem em cada sentido de circulação, com início da operação no tempo (t) igual a zero hora, que resulta em horários fixos de entrada e saída das composições nos respectivos nós e terminais, como ilustrado na Figura 3.9.

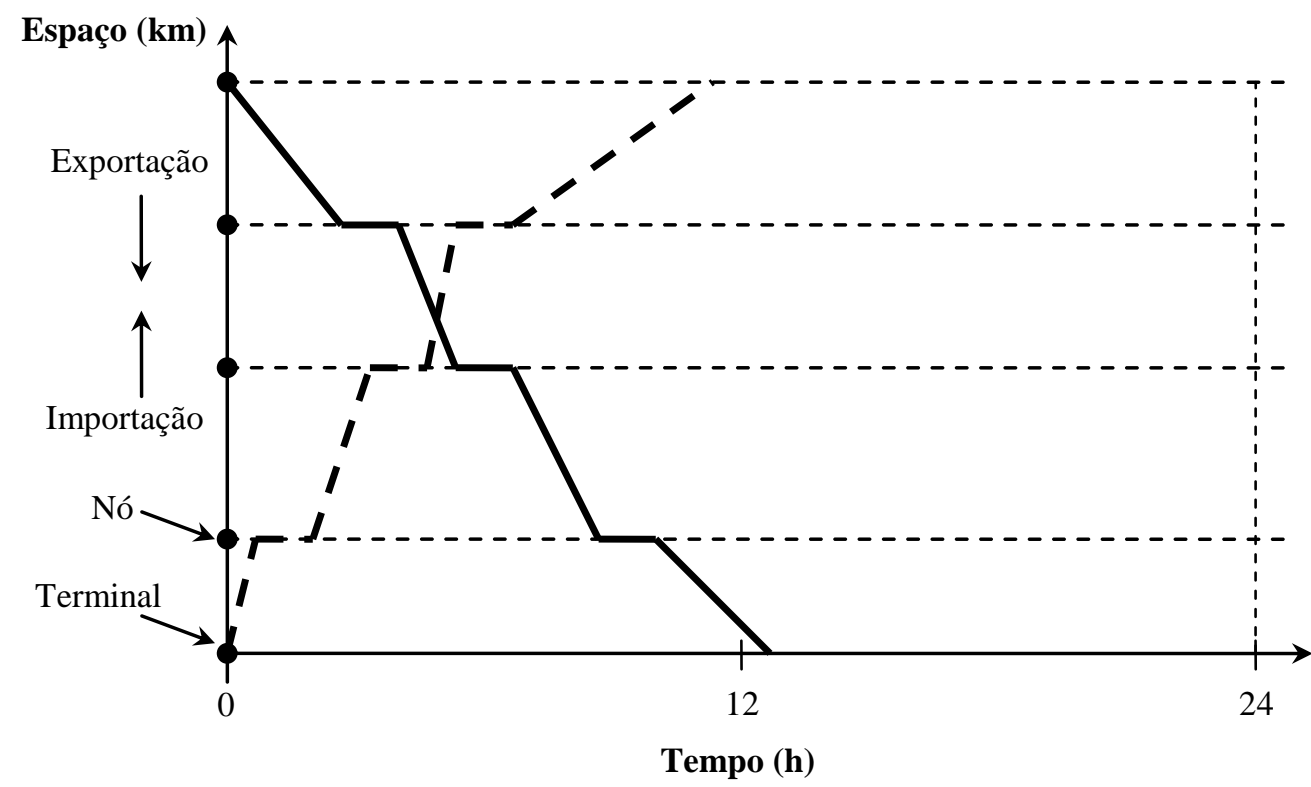

Figura 3.9 - Diagrama espaço-tempo com os dados de saída do simulador.

\section{MÓDULO 2 - Determinação dos headways}

Os passos descritos a seguir são necessários para eliminação do conflito entre trens em sentidos opostos, que se cruzam em locais que não são caracterizados como nó ou terminal (Figura 3.10), e para determinar os valores de um headway que viabiliza a inserção do maior número de trens em cada um dos ramais da rede. Assim, para todos os ramais: 


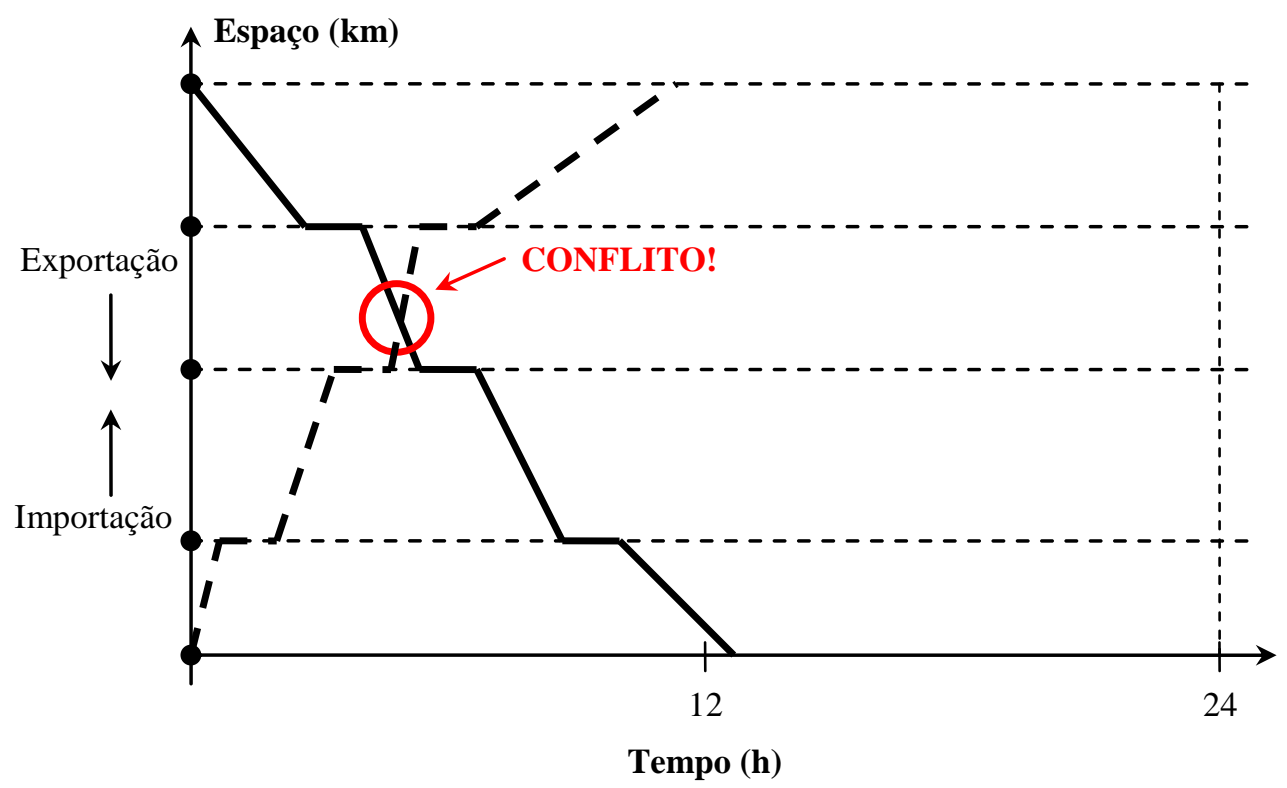

Figura 3.10 - Conflito entre trens em sentidos opostos em um ramal.

Passo 1: Impor um atraso ao horário de entrada do trem no sentido Importação, de modo que o horário de entrada deste no primeiro nó do ramal, nesse sentido, coincida com o de entrada do trem no sentido oposto no mesmo local (Figura 3.11);

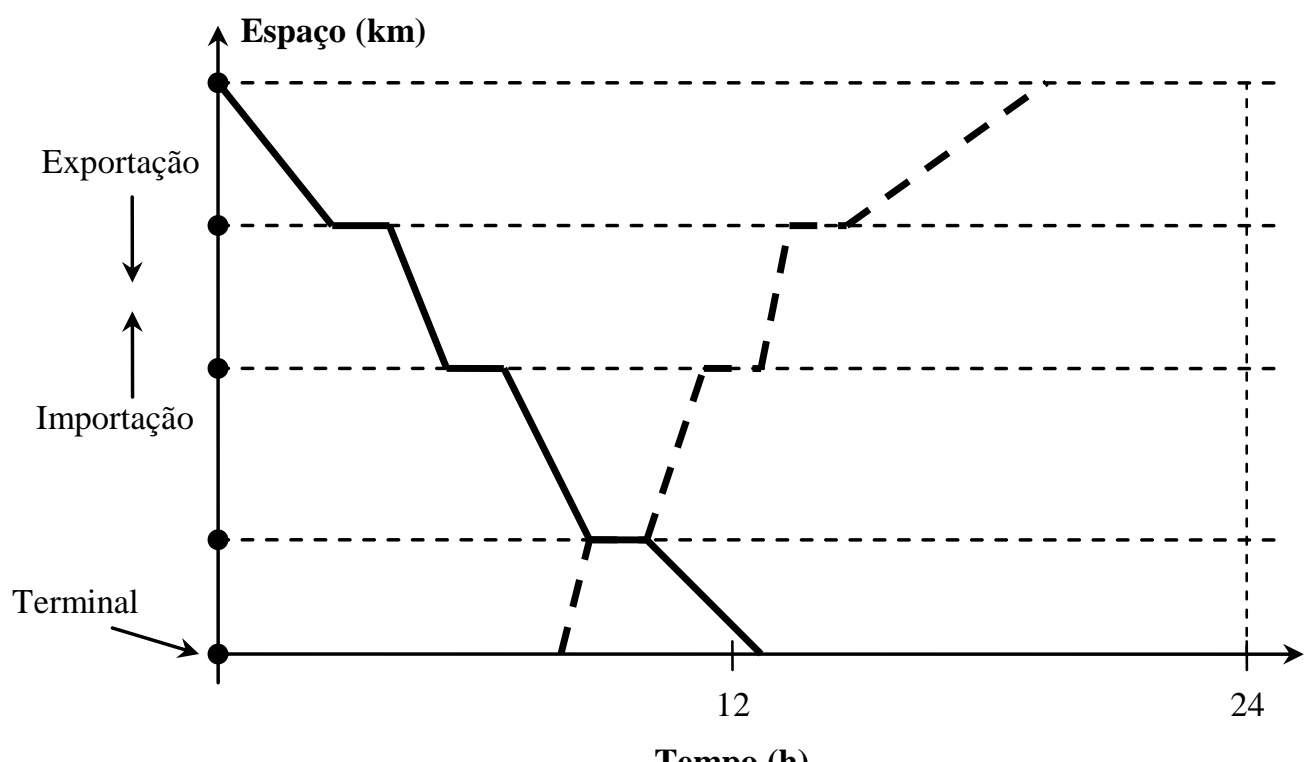

Figura 3.11 - Resolução do conflito no ramal pelo atraso na saída do trem no sentido Importação.

Passo 2: Criar trens no sentido Exportação em número igual ao de nós no ramal, menos uma unidade, separados por headways $\left(\mathrm{h}_{\mathrm{i}}\right)$ distintos, e estabelecer a sincronização dos horários de entrada nos demais nós com o trem de sentido Importação. O procedimento é ilustrado na Figura 3.12, em que os trens inseridos em um ramal genérico partem do terminal no sentido Exportação, com headways distintos $\left(\mathrm{h}_{1} \mathrm{e} \mathrm{h}_{2}\right)$; 


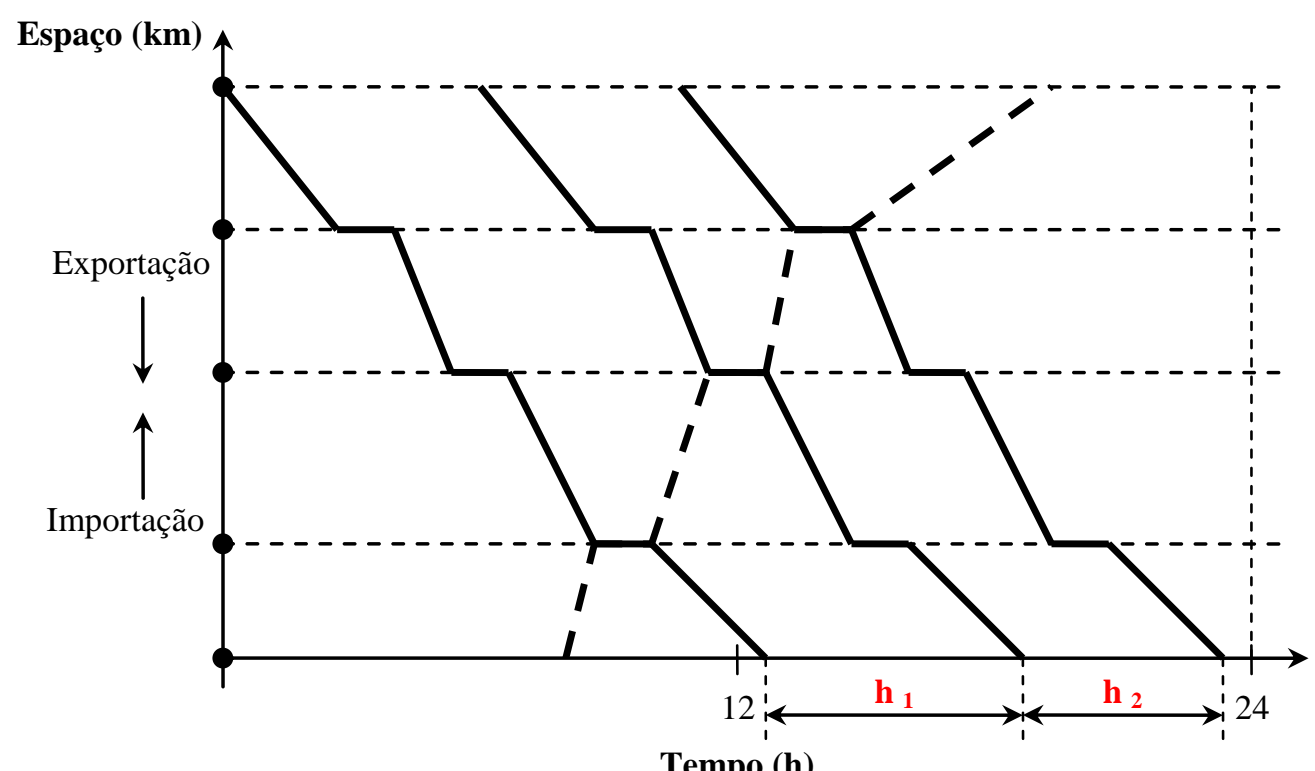

Tempo (h)

Figura 3.12 - Obtenção de headways distintos entre trens sucessivos em um ramal..

Passo 3: Criar trens no sentido Importação em número igual ao de nós no ramal menos uma unidade, e estabelecer a sincronização destes com os trens no sentido Exportação criados no passo anterior, na entrada do primeiro nó em relação àquele sentido. O procedimento pode resultar em novos conflitos como os apresentados na Figura 3.13, resolvidos pelo procedimento estabelecido no próximo passo.

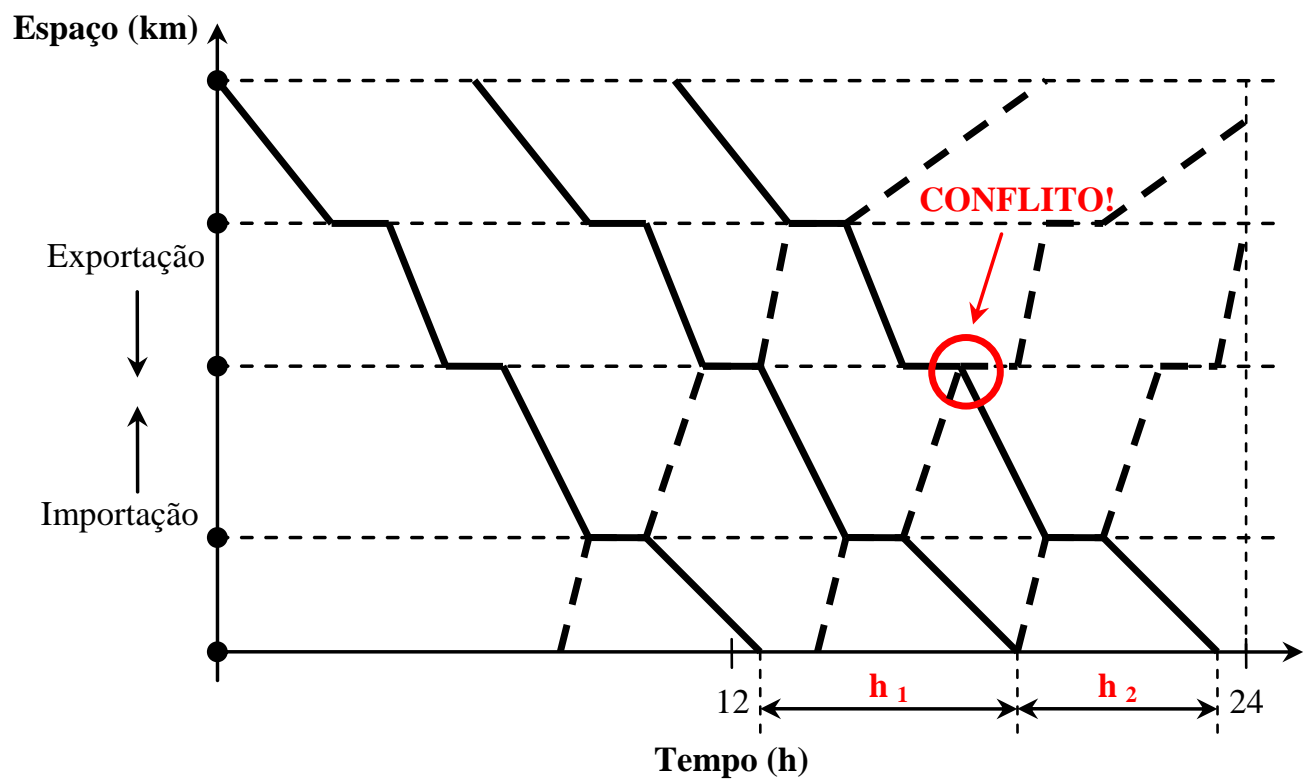

Figura 3.13 - Conflito entre trens, decorrente da diferença entre os headways nos ramais.

Passo 4: Atribuir o maior $\mathrm{h}_{\mathrm{i}}\left(\mathrm{h}_{1}\right.$ no exemplo da Figura 3.12) a uma variável denominada "headway crítico", associada a cada um dos ramais da rede. A uniformização do intervalo entre trens sucessivos, pela imposição do "headway crítico" em um ramal e inserção de 
atrasos nos tempos de parada dos trens de sentido Importação nos nós, resulta em um diagrama espaço-tempo factível, como exemplificado na Figura 3.14;

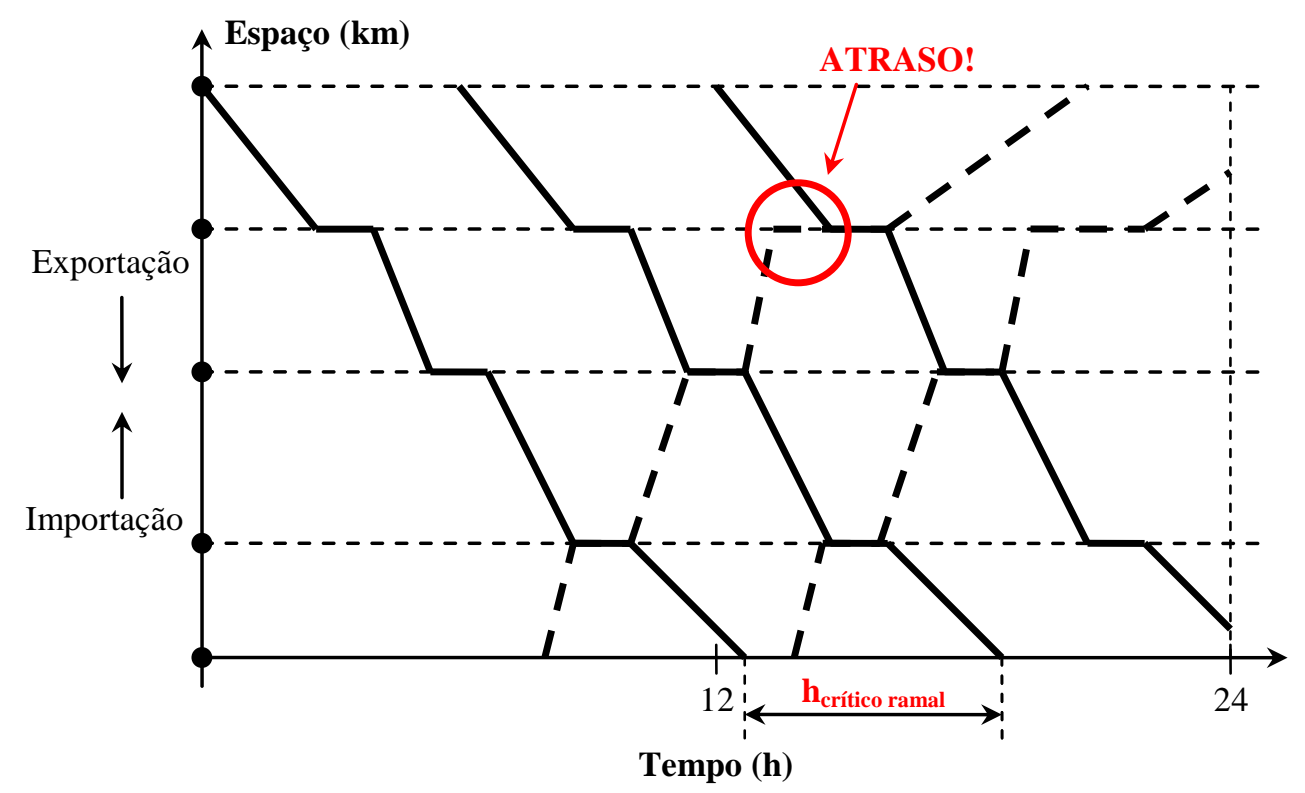

Figura 3.14 - Determinação do headway crítico de cada ramal da rede.

A definição do "headway crítico" de um ramal viabiliza a alocação do maior número possível de trens em um ramal sem que ocorram cruzamentos nos arcos, e a identificação do arco que restringe a capacidade do ramal.

A análise da Figura 3.12 permite constatar que o segundo arco no sentido Importação é o que restringe a capacidade, pois se a velocidade nesse segmento fosse maior que a indicada, o "headway crítico" do ramal teria um valor menor e, como consequência, os horários de entrada dos trens no sentido Exportação seriam antecipados, com aumento da capacidade diária de processamento no ramal.

Passo 5: Estabelecer o valor inicial da variável "headway crítico global” ( $\mathrm{h}_{\text {crítico global }}$ headway mínimo entre trens sucessivos, atribuído a todos os ramais da rede - igual ao "headway crítico" do ramal que contém o polo de concentração de cargas da rede.

\section{MÓDULO 3 - Número de trens diários por sentido nos ramais}

O número de trens que circulam em cada ramal da rede é calculado pelos procedimentos apresentados a seguir.

Passo 1: Determinação do número de trens no ramal que contém o polo de concentração de cargas dado pelo maior inteiro menor que o resultado do quociente entre o período de 
operação ferroviária (24 horas) e o "headway crítico global", com os ajustes indicados na Equação (3.4);

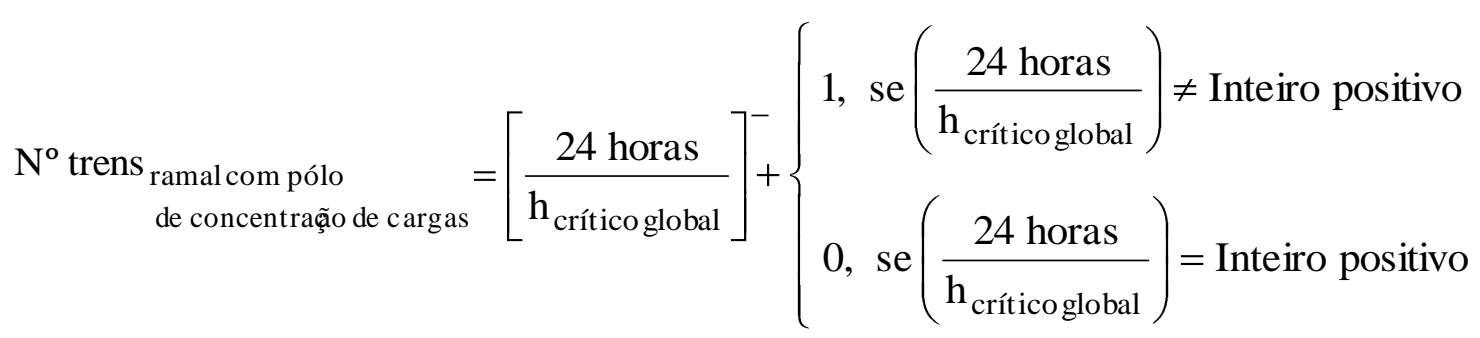

Passo 2: Determinação do número de trens que circulam nos demais ramais da rede, pelo produto do número de trens no ramal que contém o polo de concentração de cargas calculado anteriormente - e os respectivos Coeficientes de Proporcionalidade, segundo a Equação (3.5). Como o movimento dos trens ocorre nos dois sentidos, para cada composição ferroviária no sentido Exportação existe uma correspondente no sentido Importação.

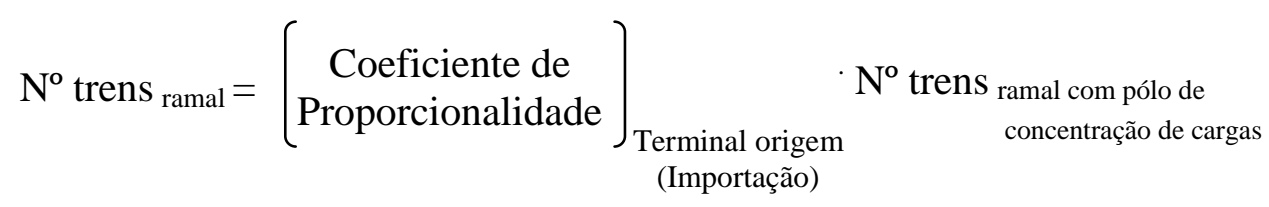

Como os Coeficientes de Proporcionalidade são expressos em porcentagens, os resultados da Equação (3.5) são aproximados para valores inteiros, de modo que o número de trens em um ramal seja igual à soma dos trens nos seus ramais precedentes no sentido Exportação, e que a soma das composições geradas nos terminais seja igual ao número de trens diários no polo de concentração de cargas.

\section{MÓDULO 4 - Atribuição de horários aos trens nos ramais}

Uma vez determinado o número de trens que circulam nos ramais da rede, por dia, são definidos os horários de chegadas e saídas destes nos terminais, segundo a sequência de passos apresentados a seguir.

Passo 1: As matrizes que definem os horários dos trens nos ramais são zeradas e em todos os ramais é criada uma composição com horário de entrada no sentido Exportação, fixado à zero hora, com uma respectiva composição no sentido oposto.

Passo 2: Efetua-se a sincronização dos trens no sentido Importação, no primeiro nó desse sentido, com os de Exportação para cada um dos ramais da Rota. 
Passo 3: Assumindo inicialmente que o tempo de permanência em todos os terminais é igual a zero, para toda Rota de Circulação, o horário de entrada em um ramal no sentido Importação do trem sentido Exportação é sincronizado com o de saída no ramal precedente naquele sentido, a partir do ramal com o polo de concentração de cargas. O procedimento é executado até que o terminal de saída no sentido Importação seja o primeiro de cada Rota de Circulação;

Na sequência de ilustrações da Figura 3.15, Figura 3.16 e Figura 3.17, são exemplificados os procedimentos do Passo 1, Passo 2 e Passo 3 deste módulo, com a definição hipotética dos horários de um trem na Rota de Circulação "5-3-2-1" da rede definida na Figura 3.5;

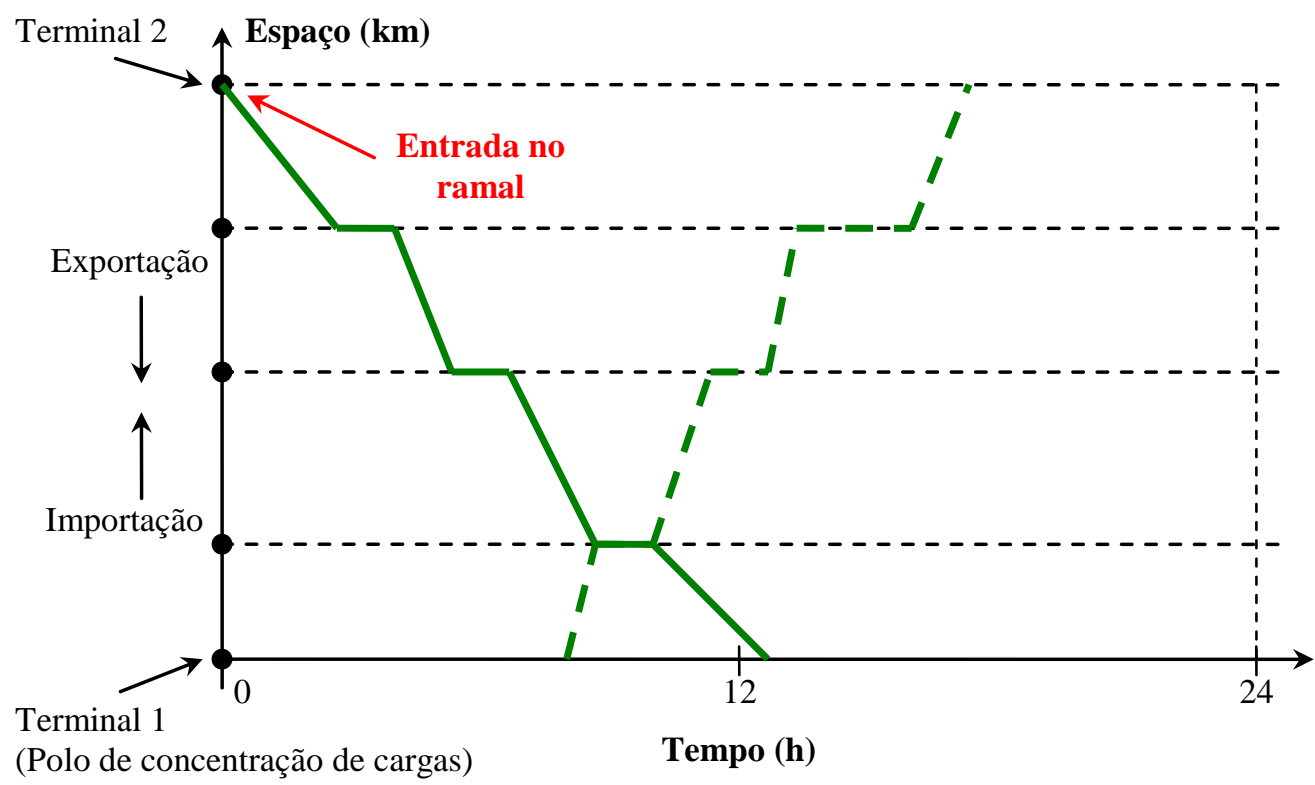

Figura 3.15 - Sincronização dos trens em uma Rota de Circulação que contém o ramal "2-1".

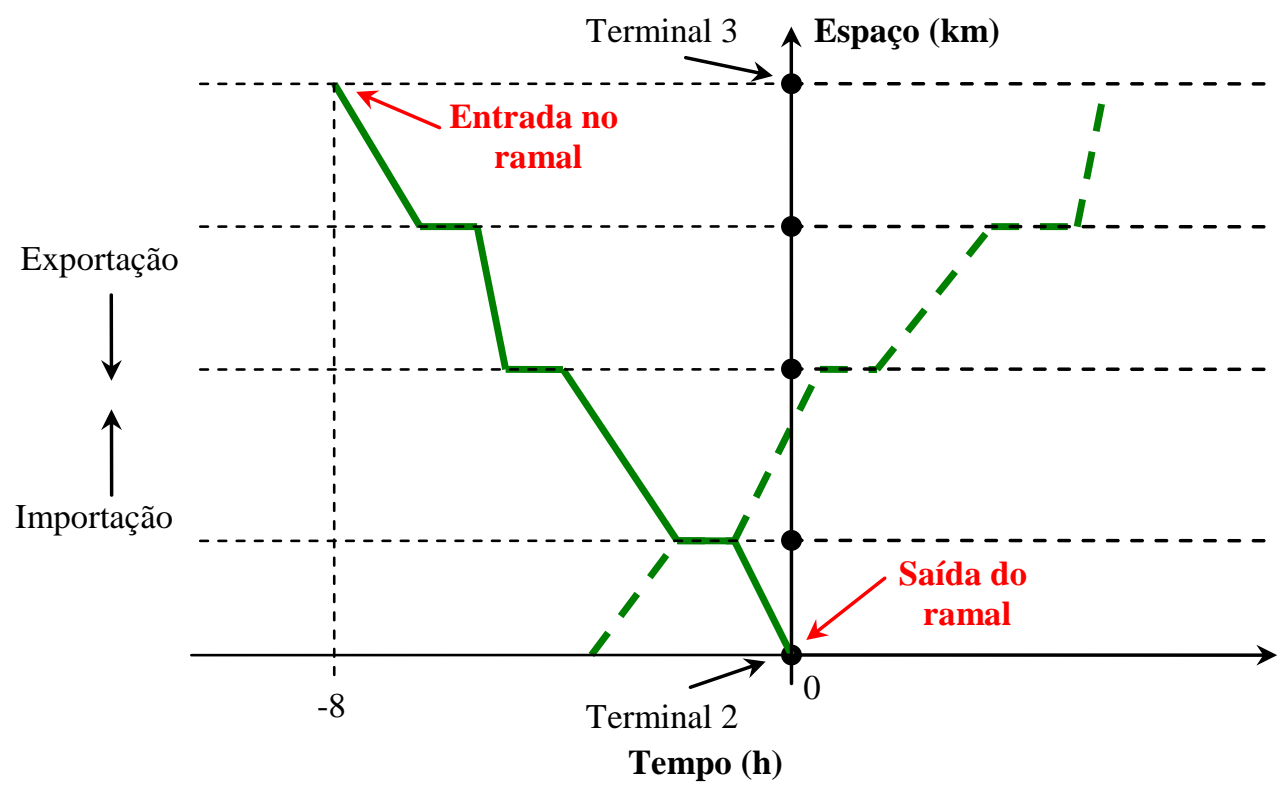

Figura 3.16 - Sincronização dos trens em uma Rota de Circulação que contém o ramal "3-2". 


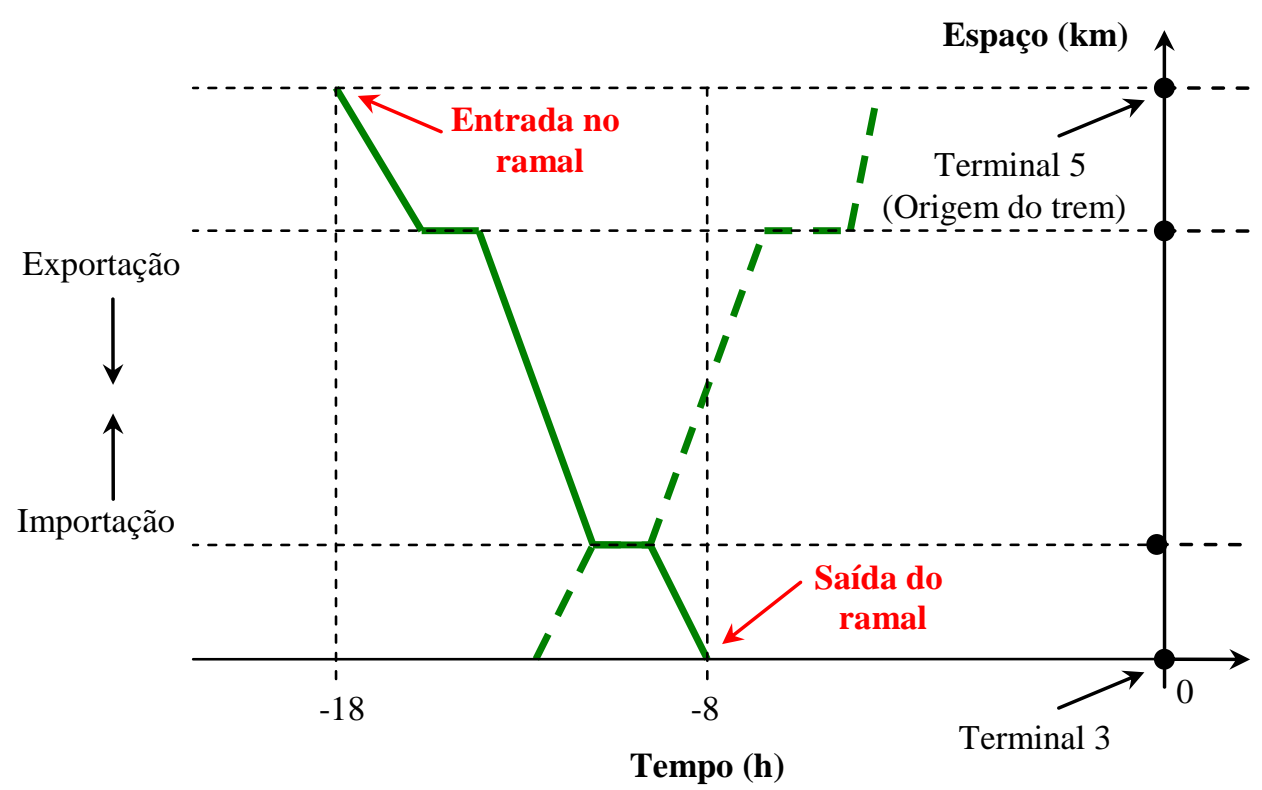

Figura 3.17 - Sincronização dos trens em uma Rota de Circulação que contém o ramal "5-3".

Passo 3: Os índices dos terminais de origem das Rotas de Circulação que possuem trens circulando por elas são ordenados em uma sequência crescente;

Passo 4: O trem de sentido Exportação, com origem no primeiro terminal dessa sequência, tem horário de entrada no ramal que contém o polo de concentração de cargas fixado à zero hora. Ao trem de sentido Exportação, que se origina no segundo terminal da sequência de índices, atribui-se um horário de entrada nesse ramal igual ao do trem anterior somado ao "headway crítico global", repetindo-se o processo para os demais trens com origem nos terminais correspondentes à sequência definida. Nesse primeiro passo deslocam-se os horários dos respectivos trens nos ramais precedentes de cada Rota desse mesmo "headway crítico global";

Passo 5: Repete-se o passo anterior até que todos os trens das Rotas de Circulação calculados no Módulo 3 tenham seus horários de circulação nos ramais definidos, de modo que, quando o número de trens por dia de uma Rota de Circulação for atingido, o índice do terminal de origem que a define é excluído da sequência em ordem crescente definida no Passo 3.

Para a rede da Figura 3.5, um exemplo de alocação dos trens no ramal que contém o polo de concentração de cargas pode ser visualizado no diagrama espaço-tempo da Figura 3.18, com a definição dos horários dos respectivos trens nos ramais precedentes, segundo os passos descritos anteriormente. 


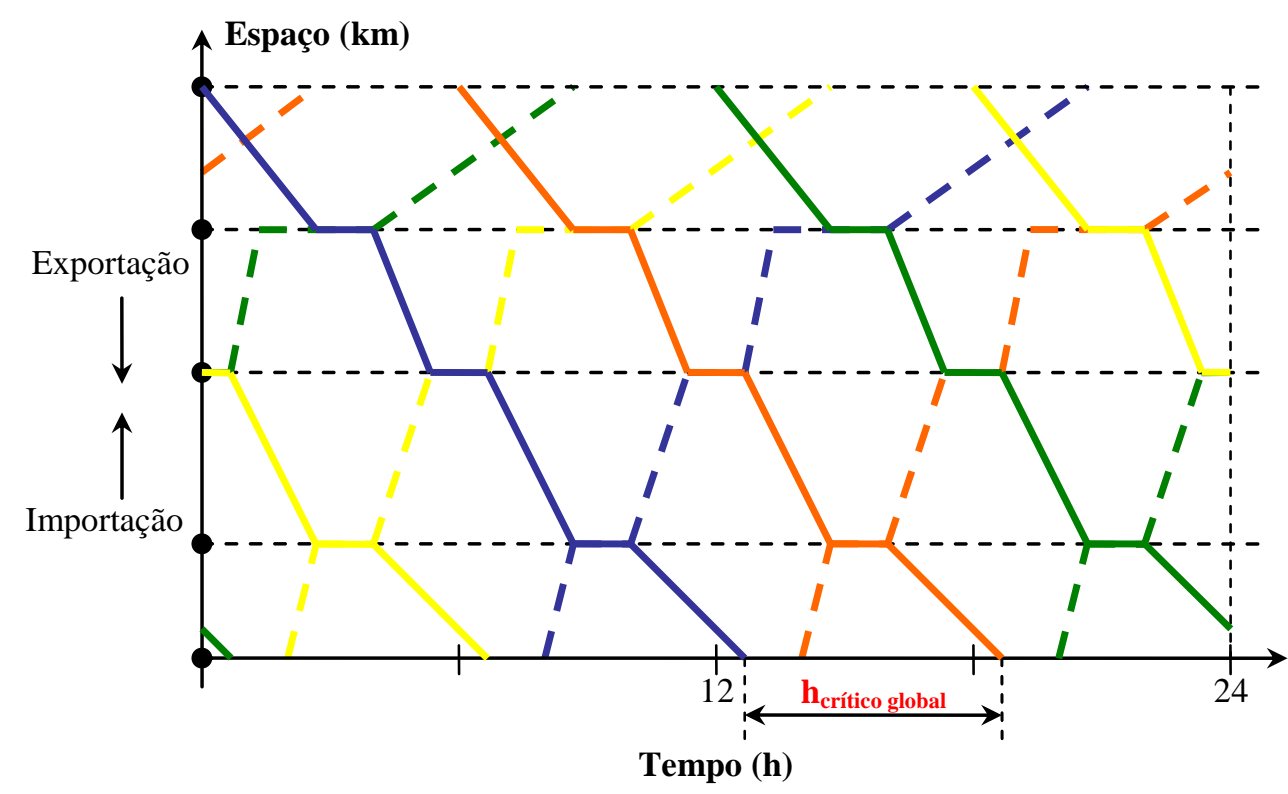

Figura 3.18 - Diagrama espaço-tempo do ramal “2-1", com três nós intermediários.

\section{MÓDULO 5 - Verificação do valor definido como "headway crítico global"}

Neste módulo, verifica-se a compatibilidade de tráfego de trens sucessivos gerados no $M O ́ D U L O 4$, nos ramais que precedem aquele que contém o polo de concentração de cargas, de acordo com a sequência de procedimentos apresentada a seguir.

Passo 1: Verificação da existência de pares de trens sucessivos gerados no MÓDULO 4, separados por um intervalo de tempo igual ao "headway crítico global" em um mesmo ramal;

Passo 2: Para aqueles pares que satisfazem a condição do Passo 1 , verifica-se a condição do "headway crítico" desse ramal ser maior que o "headway crítico global";

Passo 3: Adoção de um novo "headway crítico global" definido como o maior entre os valores identificados no Passo 2, caso existam.

O fluxograma da Figura 3.19 sintetiza o procedimento.

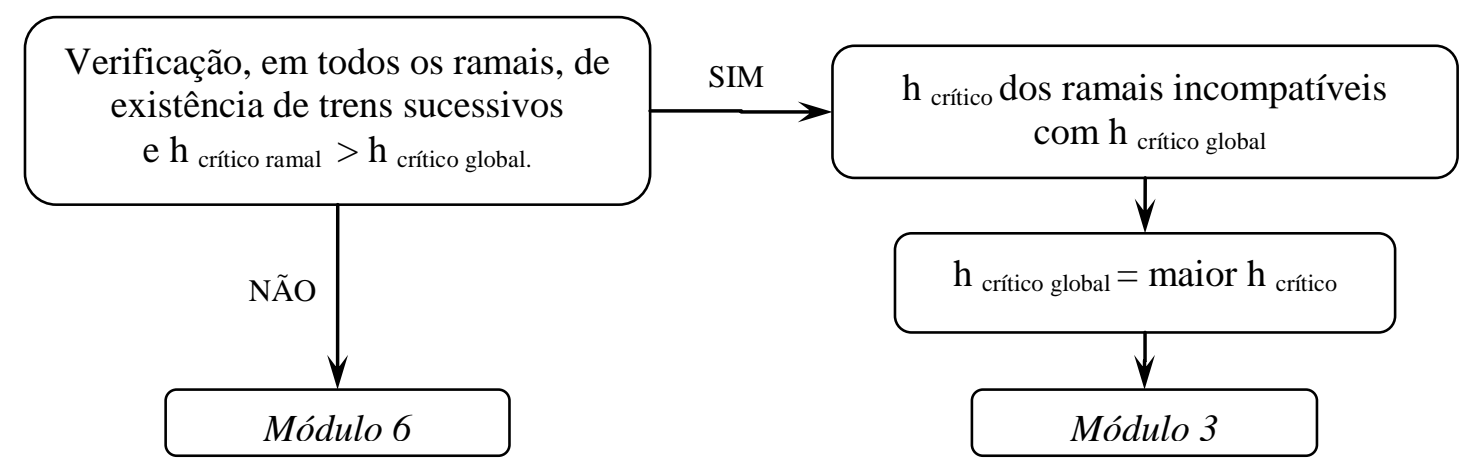

Figura 3.19 - Estrutura condicional que verifica a compatibilidade entre headways nos ramais. 
Os diagramas espaço-tempo, a seguir, ilustram o processo de identificação de pares de trens sucessivos realizado no Passo 2 (Figura 3.20) e a solução do conflito proposta no Passo 3 (Figura 3.21), em relação aos horários hipotéticos no ramal “3-2”.

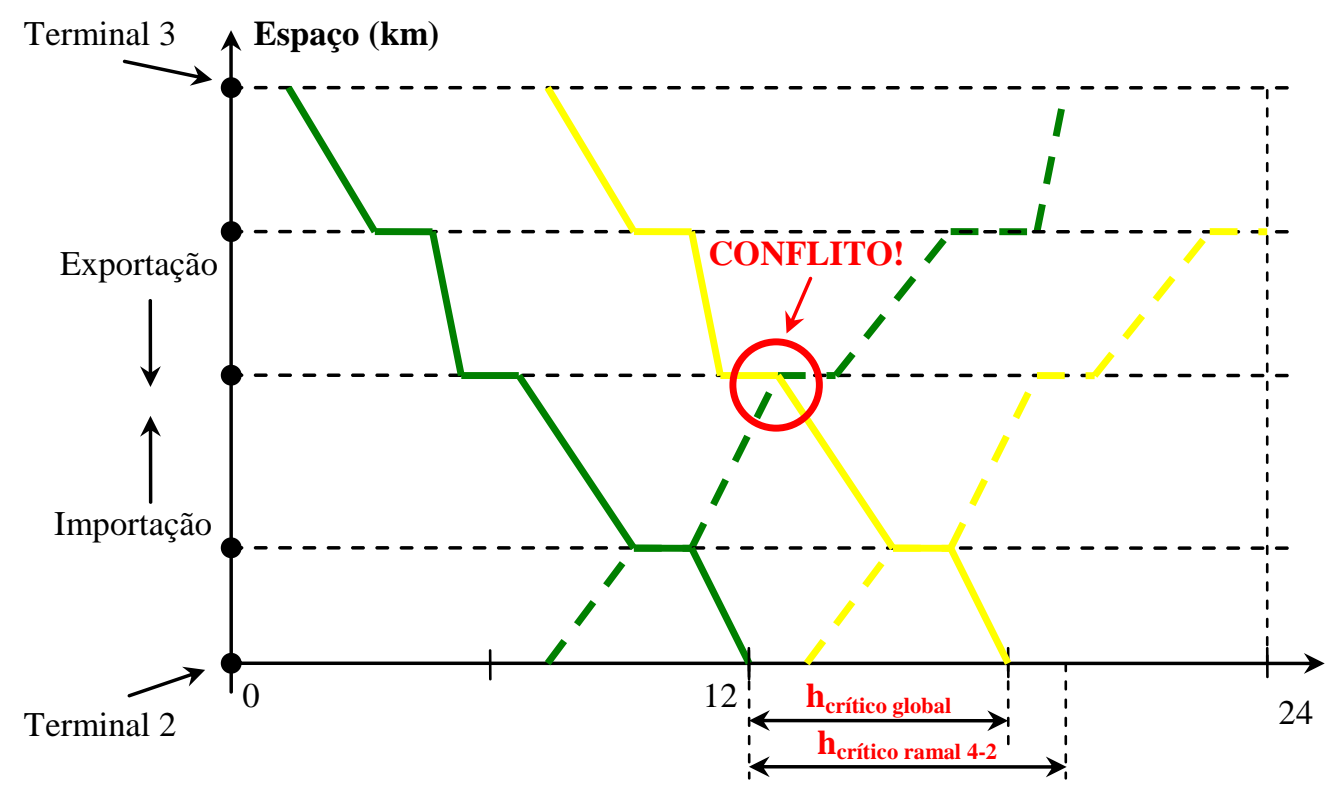

Tempo (h)

Figura 3.20 -Conflito quando $\mathrm{h}_{\text {crítico ramal }}$ é maior que $\mathrm{h}_{\text {crítico global }}$.

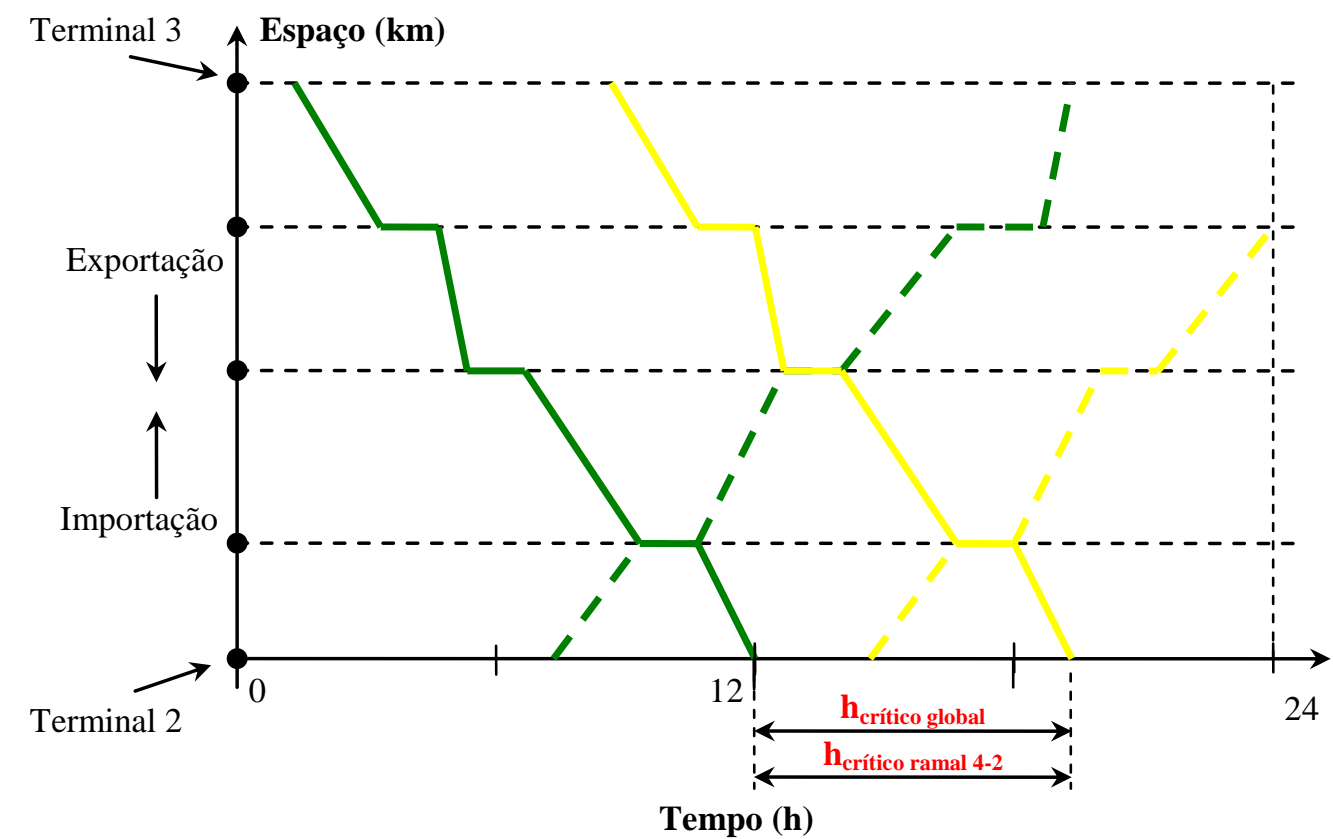

Figura 3.21 - Solução para o conflito quando $h_{\text {crítico ramal }}$ é maior que $h_{\text {crítico global. }}$.

Como o número de trens no polo de concentração de cargas é inversamente proporcional ao valor do "headway crítico global" do sistema (Equação 3.4), o aumento desse tempo resulta na diminuição da capacidade de processamento de trens na rede e, como pode ser constatado nos 
passos descritos neste módulo, a alteração desse parâmetro indica que o modelo considera a interação entre os ramais da malha ferroviária para cálculo do número de trens no sistema.

\section{MÓDULO 6 - Análise de conflitos de horários nos terminais}

Solucionado o problema de verificação da compatibilidade entre headways no sistema, o algoritmo passa à análise do problema de cruzamento de composições em sentidos opostos, nos arcos que contêm um terminal, conforme ilustrado na Figura 3.22.

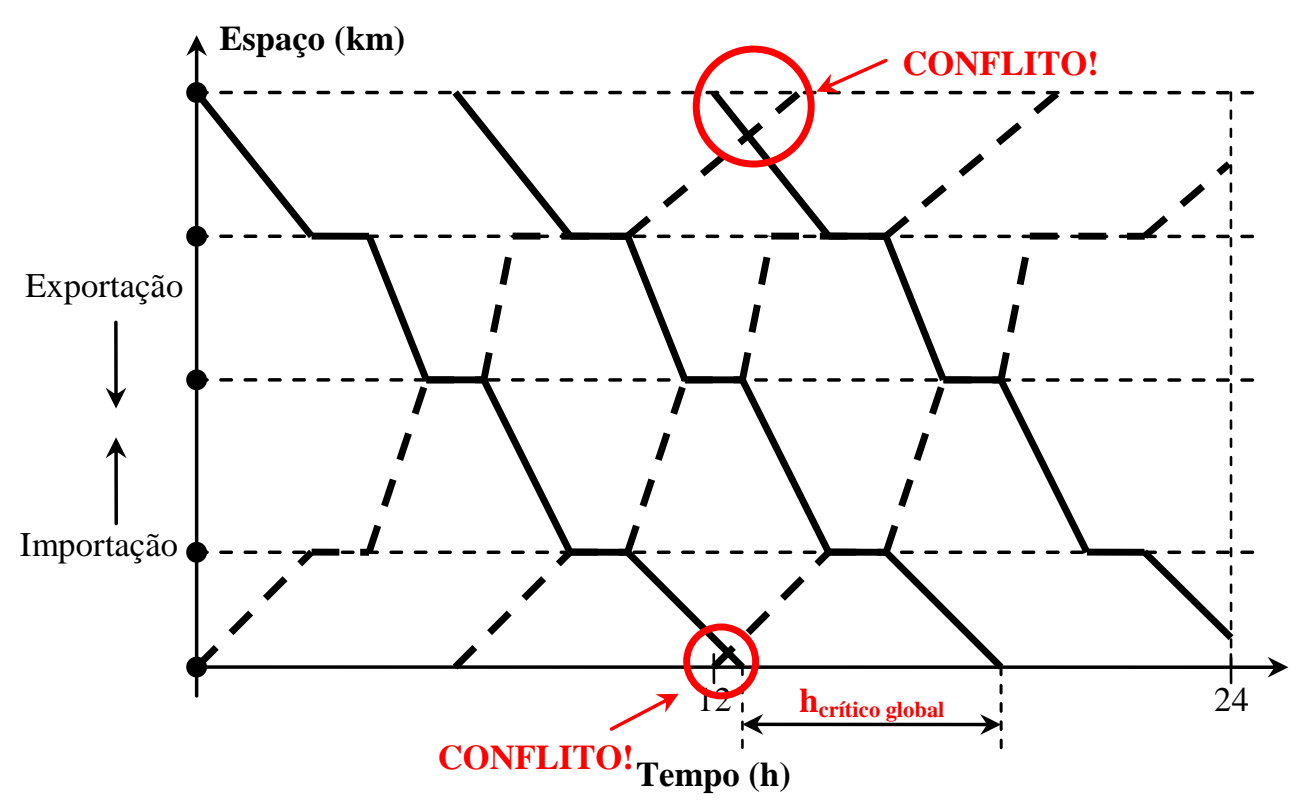

Figura 3.22 - Possíveis conflitos nos arcos que contém os terminais de um ramal.

Para resolver esse tipo de conflito, para cada ramal da rede o algoritmo realiza os passos descritos a seguir.

Passo 1: Identificar os arcos que contém um terminal em uma de suas extremidades, e os ramais em que estão situados;

Passo 2: Calcular, em cada um desses arcos, a diferença entre o horário de saída do k-ésimo trem do ramal no respectivo terminal no sentido Exportação e o horário de entrada do primeiro trem no sentido Importação nesse terminal, com " $k$ " igual ao número de nós do ramal em que está contido o arco analisado.

Passo 3: Calcular, em cada um desses arcos, a diferença entre o horário de saída do k-ésimo trem no respectivo terminal no sentido Importação e o horário de entrada do primeiro trem no sentido Exportação nesse terminal. 
Após realização desses procedimentos, o algoritmo procede à execução dos seguintes passos:

Passo 4: Identificar os valores positivos maiores ou iguais que a variável "Tempo de espera mínimo nos terminais" calculados no Passo 2 e Passo 3 e atribuir o maior deles à variável denominada $\Delta_{\text {conflito ramal }}$.

Passo 5: Agrupar os valores de $\Delta_{\text {conflito ramal }}$ identificados no Passo 4 e atribuir o maior deles à variável denominada $\Delta_{\text {conflito global }}$.

Passo 6: Se o valor do parâmetro do Passo 5 for diferente de zero, um novo valor de "headway crítico global” para o sistema é calculado segundo a Equação (3.6).

$$
\left(\mathrm{h}_{\text {crítico global }}\right)=\left(\mathrm{h}_{\text {crítico global }}\right)+\Delta_{\text {conflito global }}+\begin{aligned}
& \text { "Tempo de espera } \\
& \text { mínimo nos terminais" }
\end{aligned}
$$

Passo 7: Se o "headway crítico global" for alterado o algoritmo é redirecionado para o MÓDULO 3.

Graficamente, a alteração do valor do "headway crítico global" possibilita a resolução do conflito apresentado na Figura 3.22, que resulta no diagrama espaço-tempo da Figura 3.23.

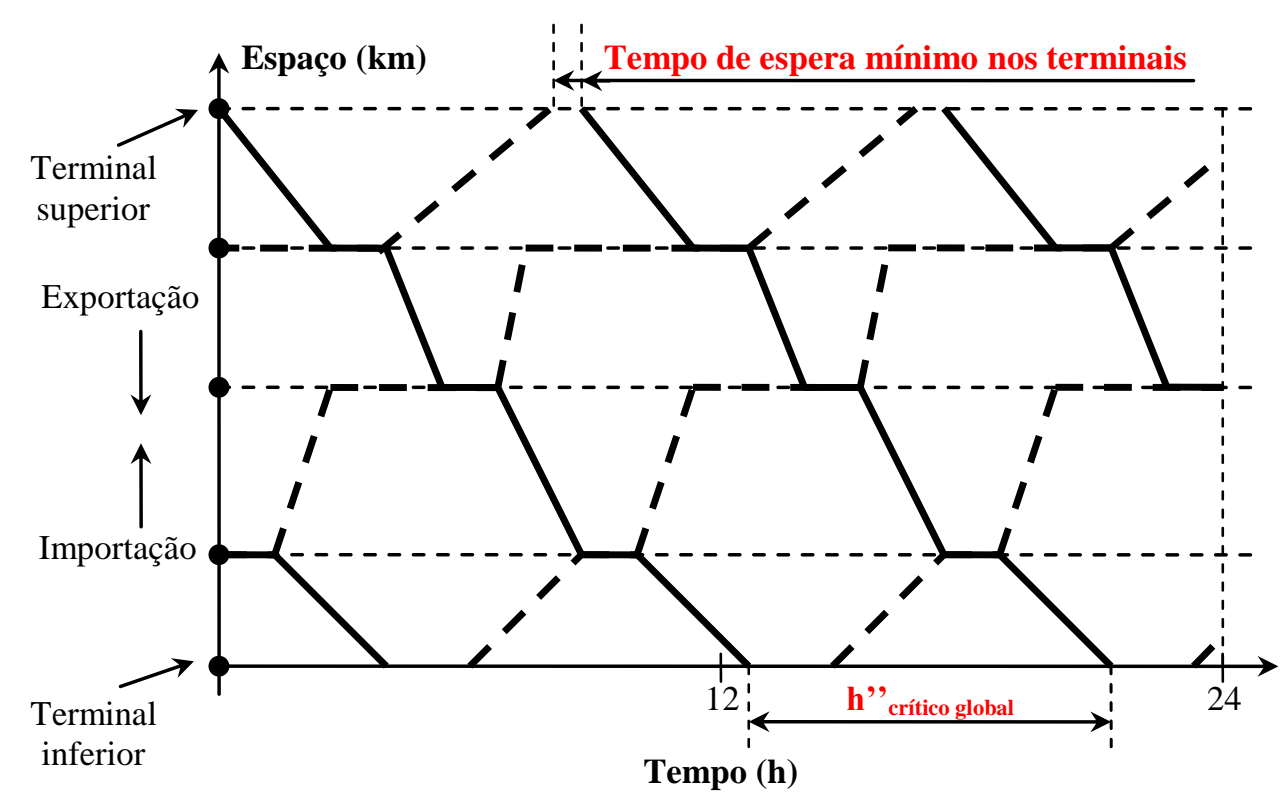

Figura 3.23 - Resolução dos conflitos nos terminais.

Se o valor do "headway crítico global" for alterado, o arco crítico da rede deixa de ser aquele definido pelo "headway crítico" do ramal (no Passo 5 do MÓDULO 2 ou Passo 3 do $M O ́ D U L O 5$ ) e passa a ser o que define o maior valor do parâmetro $\Delta_{\text {conflito global }}$. 


\section{MÓDULO 7 - Ajuste para a representação gráfica dos diagramas espaço-tempo}

O MÓDULO 5 tratou da análise da compatibilidade entre o "headway crítico" dos ramais e o "headway crítico global", nos casos em que aquele valor é maior que esse parâmetro e existiam trens sucessivos no mesmo sentido de circulação, separados por esse intervalo de tempo.

Entretanto, para a adequada representação da circulação dos trens nos ramais, através dos diagramas espaço-tempo, é necessário resolver o conflito gerado nas situações em que o "headway crítico" de um ramal é menor que o "headway crítico global" ou aquele valor é maior que esse, porém com separação temporal entre trens sucessivos no ramal menor que um múltiplo (maior ou igual a 2) do "headway crítico global”.

Este módulo do algoritmo é executado apenas para permitir a adequada representação da circulação dos trens no diagrama espaço-tempo, pois não há influência dos procedimentos sobre o "headway crítico global" e, consequentemente, sobre a capacidade de processamento de trens na malha.

Assim, os passos descritos a seguir são executados para todos os ramais da rede, exceto aquele cujo "headway crítico" foi atribuído ao "headway crítico global".

Passo 1: Calcular o intervalo entre pares de trens sucessivos que circulam no ramal no sentido Exportação;

Passo 2: Para cada intervalo de tempo obtido no Passo 1, calcular o valor (inteiro positivo) da variável $v$ dado pelo resultado da divisão entre esse valor e o "headway crítico global" (Equação 3.7);

$$
v=\frac{\text { Intervaloentre trens sucessivos }}{\mathrm{h}_{\text {crítico global }}}
$$

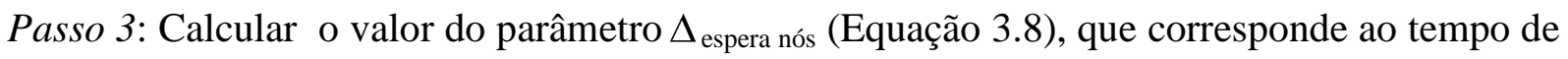
espera a ser adicionado ao trem no sentido Importação, no nó em que ocorre o conflito ilustrado na Figura 3.24;

$$
\Delta_{\text {espera nós }}=\left(v \cdot \mathrm{h}_{\text {crítico global }}\right)-\mathrm{h}_{\text {crítico ramal }}
$$




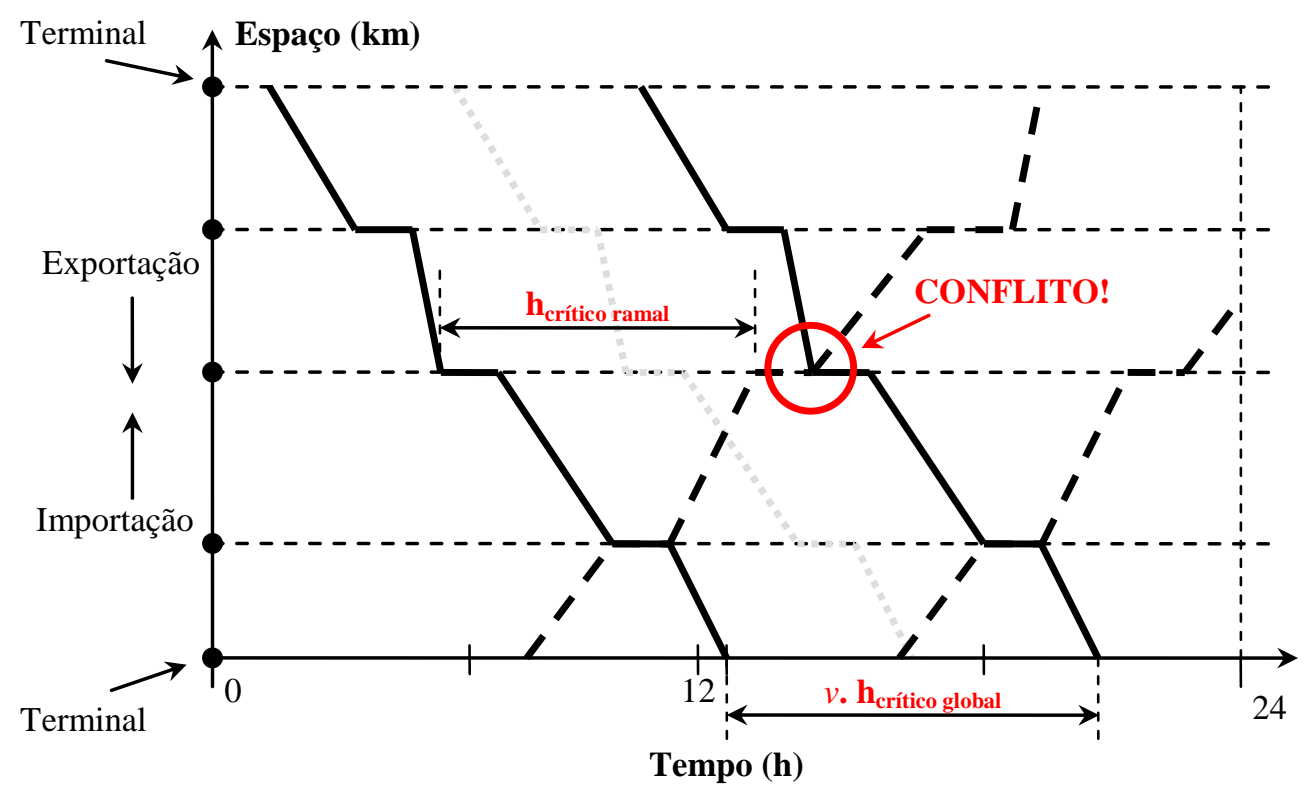

Figura 3.24 - Conflito no nó de um ramal dado que o intervalo entre trens sucessivos é maior que hcrítico global $(v=2)$

Passo 4: Adicionar o tempo de espera ( $\left.\Delta_{\text {espera nós }}\right)$ ao trem no sentido Importação, que cruza com outro no sentido Exportação, no v-ésimo nó do ramal naquele sentido. A Figura 3.25 apresenta graficamente o procedimento executado pelo algoritmo para ajuste dos tempos de entrada e saída dos trens nos nós dos ramais.

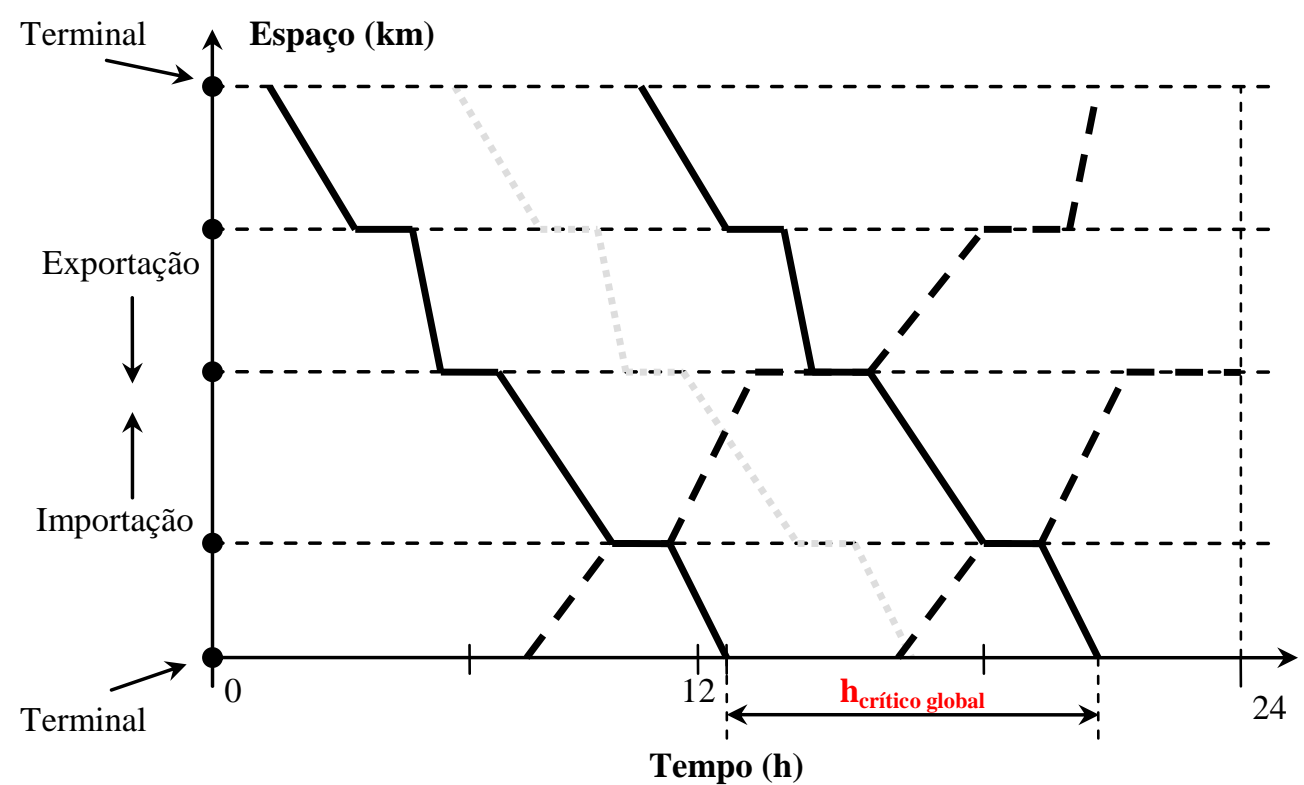

Figura 3.25 - Acréscimo no tempo de espera de um trem no sentido Importação para sincronização de horários nos nós dos ramais. 


\section{MÓDULO 8 - Diagramas espaço-tempo e relatório de dados}

Esse módulo gera um diagrama espaço-tempo para cada ramal da rede, para visualização dos gráficos dos horários relativos ao movimento dos trens no período de 24 horas, através do Visual Basic for Applications em uma planilha do software Microsoft Office Excel,.

Além da exibição dos gráficos, é criado um arquivo de texto no qual são impressos os headways, o "headway crítico" e o número de composições de cada ramal, o "headway crítico global" e o arco crítico da rede ferroviária, como ilustrado na Figura 3.26.

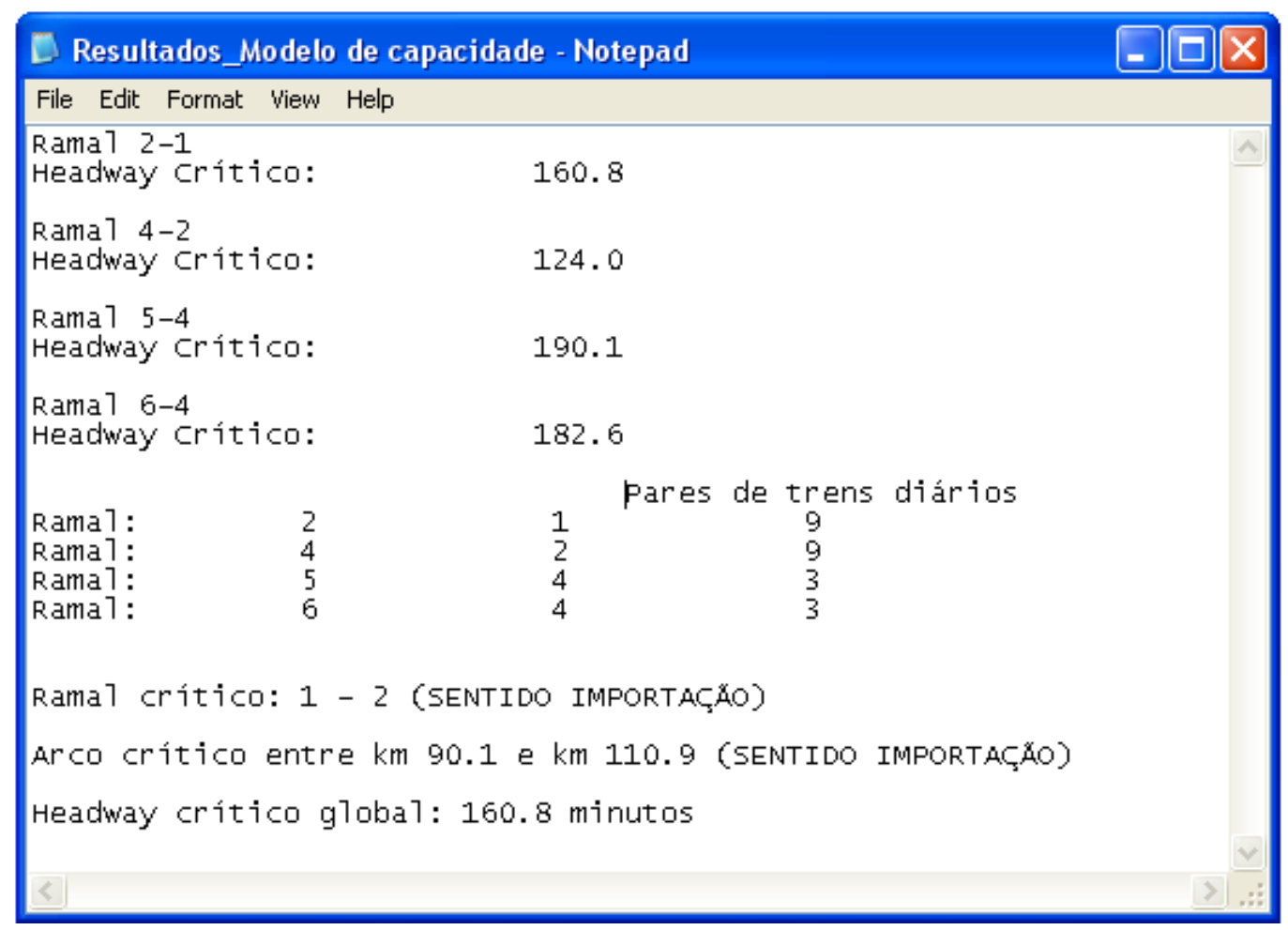

Figura 3.26 - Exemplo de arquivo de saída do modelo de capacidade. 


\section{Capítulo 4}

\section{APLICAÇÃO DO MODELO}

Este capítulo apresenta um exemplo de aplicação do modelo de capacidade de processamento de trens em uma rede ferroviária em linha singela, com análise dos gargalos de um sistema real, com o objetivo de identificar os arcos que necessitam de prioridade de investimentos em manutenção da via permanente.

Os itens que se seguem dizem respeito à caracterização da rede ferroviária, definição dos parâmetros relativos à via permanente e material rodante para obtenção dos tempos de viagem nos arcos, e os resultados da aplicação do modelo de capacidade sob diferentes condições estabelecidas no formato de cenários.

\subsection{Rede ferroviária}

A escolha da rede ferroviária para análise da capacidade teve início com a identificação dos sistemas adequados às condições estabelecidas pelo modelo e que apresentam necessidade de melhorias nas condições de tráfego para aumento do volume de carga transportada.

Para isso, foi utilizada uma base de dados denominada "Base Georeferenciada de Transporte Intermodal Brasileira" (BGTIB), que integra as bases geográficas de rodovias, ferrovias, hidrovias e rota oceânica, disponibilizadas individualmente pelo Programa de Engenharia de Transportes da Universidade Federal do Rio de Janeiro (PET-UFRJ) ao Departamento de Transportes da Escola de Engenharia de São Carlos da Universidade de São Paulo (USP), e atualizadas por Karênina Martins Teixeira (TEIXEIRA, 2007), durante a elaboração de sua tese de doutorado nessa instituiçãa ${ }^{1}$.

A Figura 4.1 apresenta a malha ferroviária que constitui o BGTIB, cujos dados georeferenciados são apresentados sob a forma de um arquivo de linhas no software Transcad.

\footnotetext{
${ }^{1}$ TEIXEIRA, K. M. Publicação eletrônica [mensagem pessoal]. Mensagem recebida por <cassiano.isler@usp.br> em 26 jun. 2009.
} 


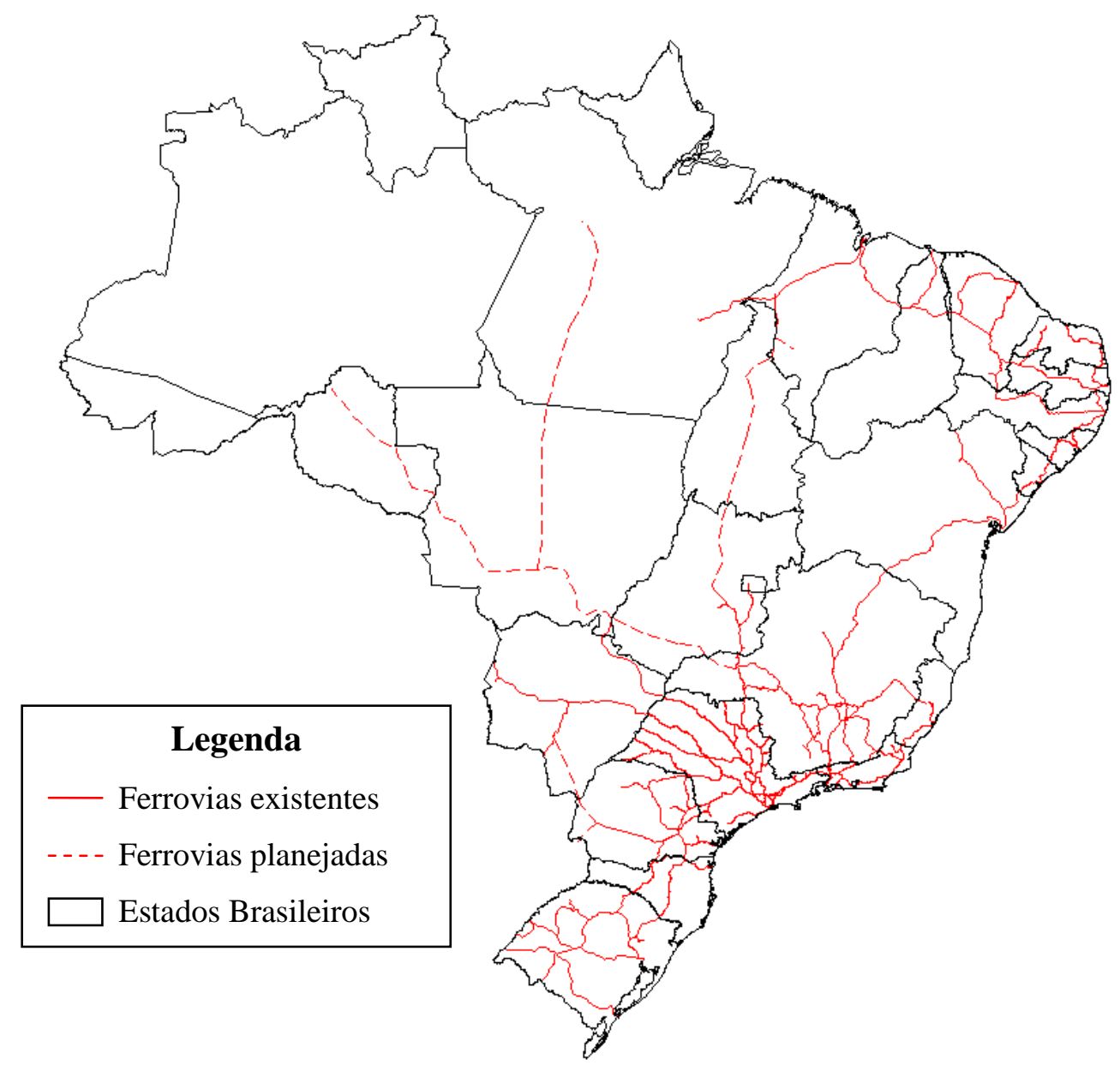

Figura 4.1 - Malha ferroviária brasileira da BGTIB. (Fonte: TEIXEIRA, 2007)

Este estudo de capacidade deu ênfase à malha ferroviária do Estado de São Paulo, por ser mais densa do que em outros estados brasileiros e pelo expressivo volume de carga que circula no sistema devido aos trens provenientes de regiões no interior do país em direção ao Porto de Santos, que possui terminal rodo-ferroviário com expressiva capacidade de processamento e viabiliza o transporte marítimo e de cabotagem (CNT, 2007).

A análise da referida malha mostra que os ramais que a constituem foram construídos em diferentes períodos e circunstâncias econômicas e políticas distintas, que culminaram na implantação de linhas com bitolas distintas, o que restringe a circulação de um mesmo trem na malha (SCHOPPA, 2004). Devido a isso, e pelo fato de alguns ramais apresentarem pouca demanda de transporte pelo modo ferroviário, foram estabelecidos trechos específicos para definição da rede que foi objeto de estudo.

O corredor ferroviário com maior volume de tráfego no Estado de São Paulo, utilizado para escoamento da produção da região Centro-Oeste do Brasil, essencialmente granéis sólidos, é definido pelas estações de Santa Fé do Sul, Araraquara, Itirapina, Boa Vista, Mairinque, 
Evangelista de Souza e, após a transposição da Serra do Mar, Paratinga até atingir o Porto de Santos.

Segundo Lacerda (2005), o trecho entre a estação de Santa Fé do Sul e Boa Vista (próxima à cidade de Campinas) foi construído em bitola larga $(1,60 \mathrm{~m})$, entre esta estação e a de Evangelista de Souza possui terceiro trilho que possibilita a circulação de trens com bitola métrica (1,00 m). Entre o nó de Evangelista de Souza e Paratinga, que compreende o trecho da Serra do Mar, a ferrovia é duplicada com distância entre trilhos de 1,60 m, e deste local até o Porto de Santos a linha é de mesma bitola com trechos dotados de terceiro trilho.

A duplicação da via em parte do corredor caracterizado foi devida às restrições impostas pelas elevadas rampas íngremes existentes no trecho da Serra do Mar (ver Figura 4. 2), tanto para os trens de sentido Importação, que necessitam de força de tração adicional para percorrer o trecho, quanto para os de Exportação, que exigem a aplicação de uma força de frenagem considerável para controle da velocidade nas rampas descendentes.

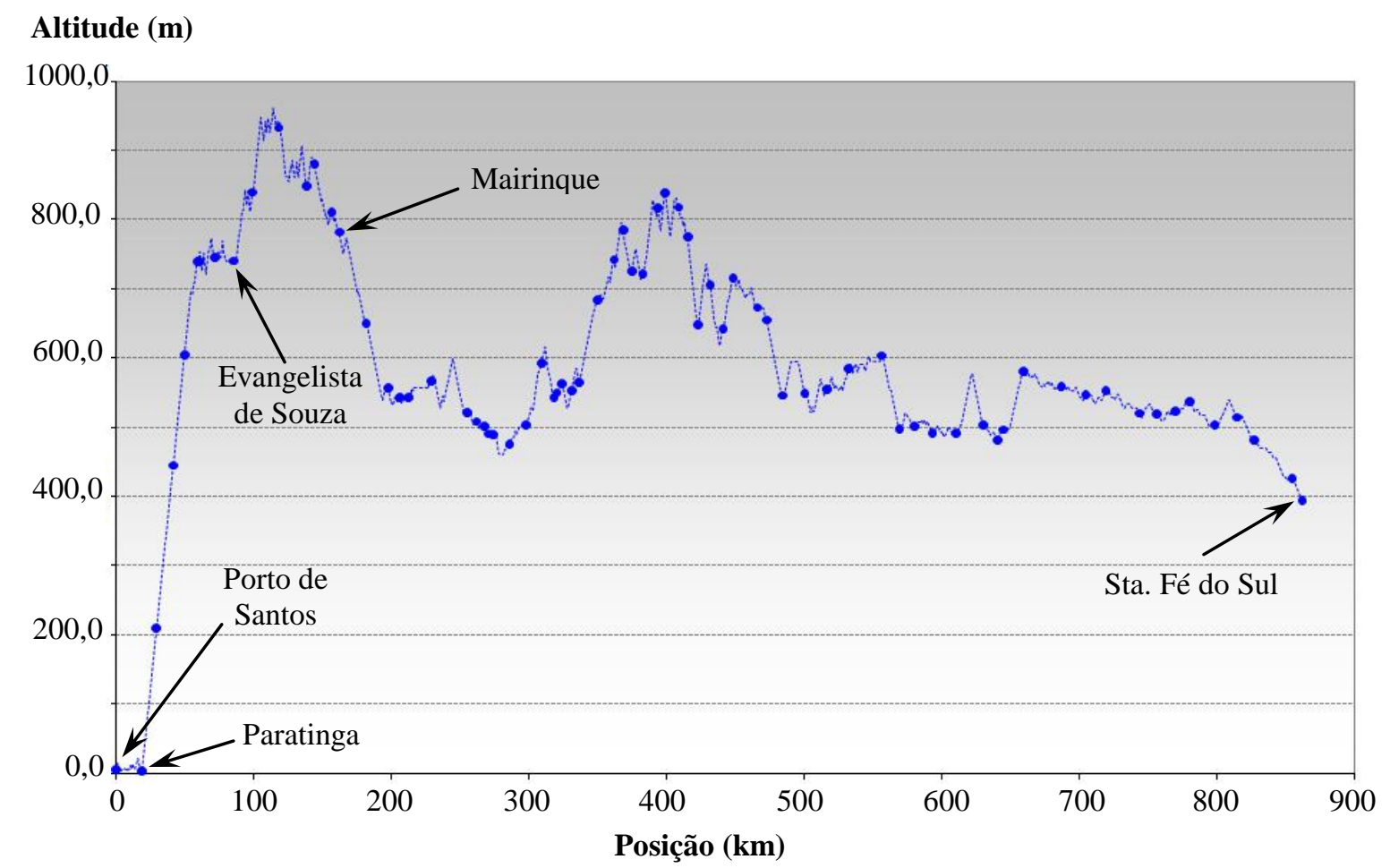

Figura 4. 2 - Perfil longitudinal do corredor ferroviário entre a estação de Santa Fé do Sul e o Porto de Santos.

A premissa de que um trecho ferroviário duplicado apresenta capacidade de processamento de trens expressivamente maior que a de um trecho de via singela permite excluir do escopo 
desta investigação o trecho entre as estações de Evangelista de Souza e Paratinga, que compreeende a Serra do Mar.

Considerou-se, ainda, que a capacidade de movimentação dos trens entre a estação de Paratinga e o Porto de Santos está sujeita a interferências de outros modos de transporte e depende também da capacidade de processamento de cargas da região portuária, condições essas não contempladas no modelo de capacidade proposto neste trabalho.

Desse modo, foi definida a priori a estação de Evangelista de Souza como o polo de concentração de cargas da rede para aplicação do modelo de capacidade. Entretanto, após a realização de simulações no simulador TEM verificou-se que as velocidades dos trens no trecho entre essa estação e a de Mairinque, em ambos os sentidos de circulação, são expressivamente menores que os limites operacionais impostos pelas condições de conservação da superestrutra e demais elementos da linha ferroviária (pontes, viadutos, passagens em nível etc.).

Os resultados das simulações demonstram que a velocidade dos veículos ferroviários nesse trecho é limitada pela geometria da via, caracterizada pela alternância entre aclives e declives acentuados e raios de curvas com orientações opostas, ambos com pequenas distâncias, como pode ser observado nos gráficos da Figura 4.3 e Figura 4.4.

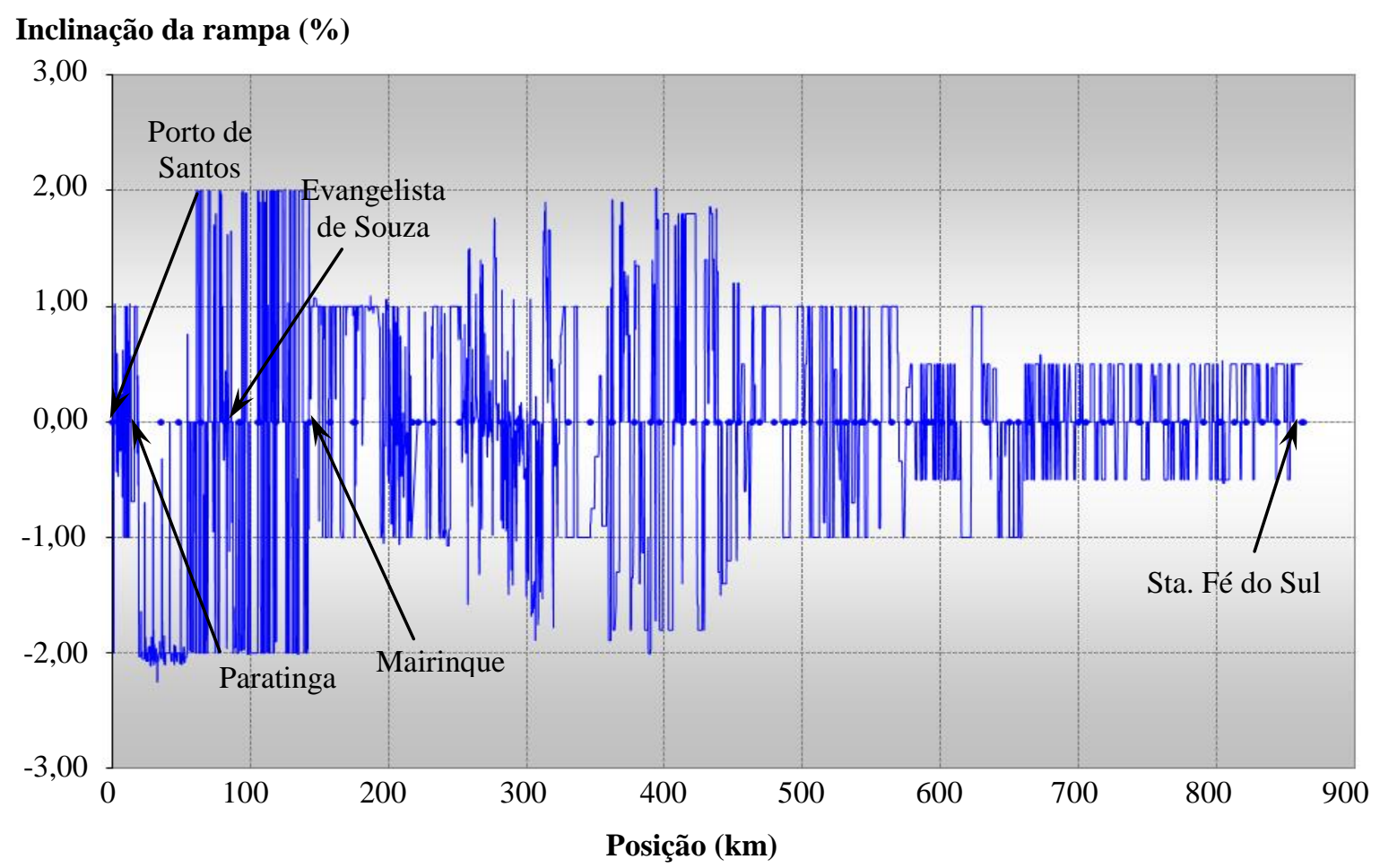

Figura 4.3 - Inclinação da rampa nos pontos do corredor ferroviário entre a estação de Santa Fé do Sul e o Porto de Santos. 


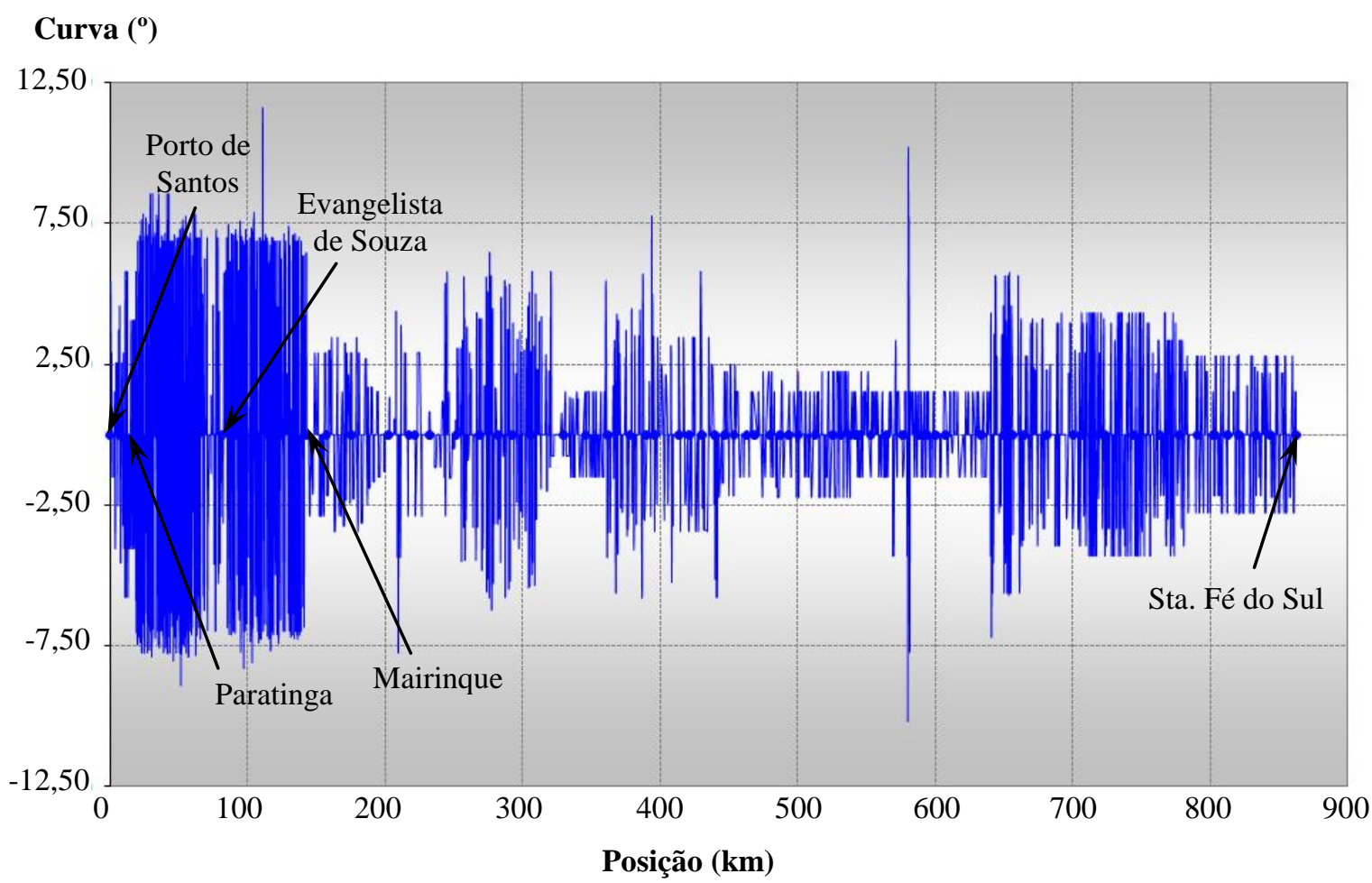

Figura 4.4 - Raio da curva nos pontos do corredor ferroviário entre a estação de Santa Fé do Sul e o Porto de Santos.

Diante dessas condições e do fato de que este trabalho não tem o objetivo de propor alterações nas características geométricas da via, estabeleceu-se que o modelo de capacidade fosse aplicado no trecho entre as estações de Santa Fé do Sul e Mairinque, definindo-os como terminais da rede, sendo este último o polo de concentração de cargas.

Para definir a rede enraizada não-direcionada foram incluídos os terminais de Panorama e Colômbia, cujos ramais - também construídos em bitola larga - ligam esses polos de geração e recebimento de trens ao corredor posicionado entre Santa Fé do Sul e Mairinque. Assim, os terminais da malha ferroviária e os índices a eles atribuídos são: Mairinque (1), Itirapina (2), Panorama (3), Araraquara (4), Colômbia (5) e Santa Fé do Sul (6).

Desse modo, os ramais da rede ferroviária em análise são definidos pela conexão entre os seguintes terminais: Mairinque-Itirapina (1-2), Itirapina-Panorama (2-3), Itirapina-Araraquara (2-4), Araraquara-Colômbia (4-5) e Araraquara-Santa Fé do Sul (4-6), ), como indicado na Figura 4.5. 


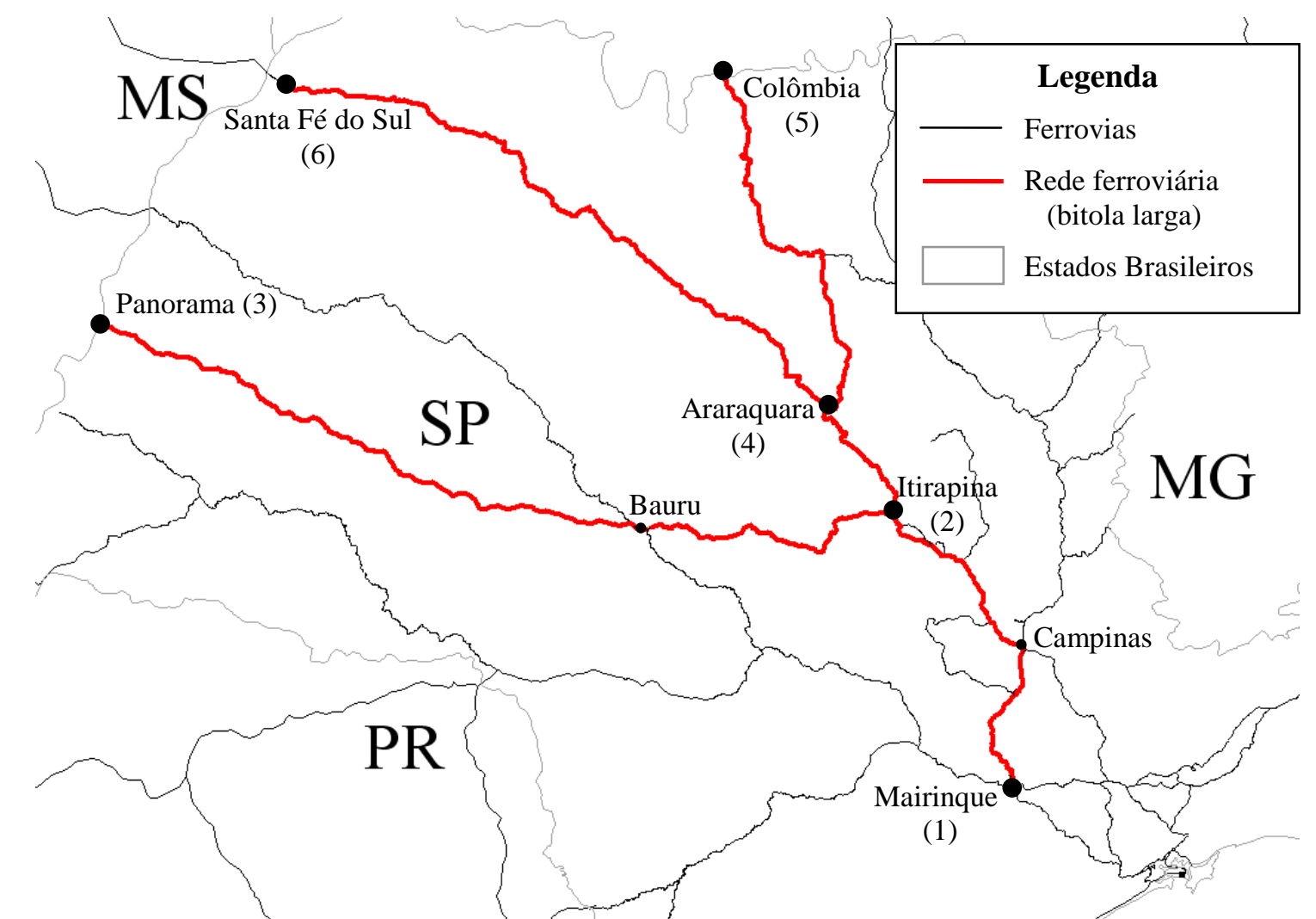

Figura 4.5 - Rede ferroviária utilizada no modelo de capacidade. (Fonte: TEIXEIRA, 2007 adaptado)

Para identificação da posição dos nós nos ramais foi atribuído o "km 0" (zero) à cada terminal de entrada dos trens nos ramais no sentido Importação e, partir destes, definidos os marcos quilométricos dos nós subsequentes nesse sentido, dados pela distância entre esses locais e o terminal do respectivo ramal.

A Tabela 4.1 a seguir define as Rotas de Circulação dos trens provenientes dos terminais, que se movimentam em direção ao polo de concentração de cargas (Terminal Mairinque) no sentido Exportação.

Tabela 4.1 - Rotas de Circulação da rede da Figura 4.5 (sentido Exportação).

\begin{tabular}{cccc}
\hline Terminal de origem & \multicolumn{3}{c}{ Terminais subsequentes } \\
\hline Itirapina (2) & Mairinque (1) & & \\
\hline Panorama (3) & Itirapina (2) & Mairinque (1) & \\
\hline Araraquara (4) & Itirapina (2) & Mairinque (1) & \\
\hline Colômbia (5) & Araraquara (4) & Itirapina (2) & Mairinque (1) \\
\hline Santa Fé do Sul (6) & Araraquara (4) & Itirapina (2) & Mairinque (1) \\
\hline
\end{tabular}




\subsection{Tempos de viagem}

Esta etapa está relacionada à obtenção dos tempos de viagem dos trens nos arcos dos ramais, determinados através da utilização do simulador de desempenho de trens TEM versão 2.5. Para isso, é necessário que sejam conhecidas as configurações do trem que circulará no sistema; a geometria da via, caracterizada pelas inclinações das rampas e raios das curvas, e os limites de velocidade nos arcos, definidos pelas condições de conservação da superestrutura.

Em relação ao material rodante, o usuário do modelo caracteriza-o através de parâmetros como o volume de carga disponível nos terminais, comprimento dos nós, número de vagões e locomotivas disponíveis para a operação etc. Entretanto, os parâmetros relacionados à via permanente são mais difíceis de serem estabelecidos, uma vez que dependem das condições estabelecidas no período de construção da linha ferroviária.

Os dados reais sobre a via permanente do trecho entre os terminais de Santa Fé do Sul e Mairinque são conhecidos devido ao trabalho realizado por Celane Néry de Oliveira Batista (BATISTA, 2006) no Departamento de Transportes da Escola de Engenharia de São Carlos, que adquiriu os valores das inclinações das rampas, raios de curvas e limites de velocidade no trecho, na época da realização da pesquisa, os quais, entretanto, não puderam ser complementados atualmente com os parâmetros referentes aos demais ramais da rede em estudo.

Foi constatado durante a pesquisa que essa dificuldade é decorrente da inexistência ou falta de gerência dos projetos que datam da época da construção dessas linhas, uma vez que órgãos públicos (ANTT, Departamento Nacional de Infraestrutura de Transportes - DNIT, Instituto Brasileiro de Geografia e Estatística - IBGE) e privados (América Latina Logística S.A., ALL, operador do sistema em análise) foram consultados e nenhum deles mostrou-se apto a fornecer adequadamente as informações requisitadas.

Diante disso e da necessidade de ser apresentada uma aplicação para o modelo de capacidade proposto, foi elaborado um método de geração de dados relativos à via permanente dos ramais entre os terminais de Itirapina-Panorama (2-3) e Araraquara-Colômbia (4-5), cujos procedimentos estão descritos no Apêndice B. Os valores resultantes da aplicação desse método nos ramais indicados foram aplicados ao simulador TEM para obtenção dos tempos de 
viagem nos arcos desses ramais, os quais foram aplicados ao modelo de capacidade proposto neste trabalho.

Em relação ao trem-tipo utilizado no transporte de cargas nos ramais da rede, foi considerada uma composição com o mesmo comprimento e relação peso/potência, partindo dos terminais em direção ao polo de concentração de cargas e vice-versa, de modo a permitir que a análise feita neste trabalho levasse em consideração apenas as características da via permanente, uma vez que o objetivo deste trabalho é obter resultados que auxiliem no planejamento estratégico de investimentos na superestrutura ferroviária.

Esse trem é composto de uma locomotiva principal do tipo DASH9, com massa de 160 toneladas, uma locomotiva auxiliar do tipo U20 - para os arcos que necessitam de força de tração adicional - com massa de 108 toneladas, e 45 vagões do tipo HOOPER, carregados com massa total de 100 toneladas cada um.

Para execução do modelo de capacidade foi estabelecido o tempo de parada mínimo dos trens nos nós dos ramais, e terminais, igual a 30 minutos - este último definido pela variável “Tempo de espera mínimo nos terminais" - de modo que esses valores estão sujeitos a alteração após a execução do modelo de capacidade segundo os procedimentos do algoritmo descrito no Capítulo 3.

Após a preparação dos arquivos do simulador apresentados no Anexo C, formatados com base nos dados sobre a via permanente e o trem-tipo, foram executadas as simulações nos dois sentidos de circulação (Exportação e Importação) nos ramais da rede, seguindo os passos indicados no Anexo D, com a execução do movimento dos trens baseada no modelo de simulação apresentado no Anexo B que, por sua vez, está fundamentado nas equações do modelo de locomoção do Anexo A.

O Apêndice C apresenta a descrição detalhada dos ramais, com a localização dos nós segundo as regras estabelecidas para definição dos marcos quilométricos nos ramais, e apresentação dos tempos de viagem dos trens nos arcos nos dois sentidos de circulação (Exportação e Importação), com e sem as restrições impostas pelos limites operacionais de velocidade. 


\subsection{Capacidade da rede}

Após a determinação dos tempos de viagem entre as estações, nos ramais da rede caracterizada, é possível obter a capacidade de processamento de trens no sistema através da aplicação do modelo apresentado no Capítulo 3.

A análise da capacidade da rede foi realizada através da construção dos cenários apresentados neste item. No primeiro cenário são consideradas as características reais de movimentação dos trens nos arcos dos ramais rede, admitindo todas as restrições de velocidade impostas aos trens.

Nos cenários subsequentes são retiradas as restrições impostas pelos limites operacionais de velocidade nos arcos que restringem o aumento do número de trens no terminal de concentração de cargas, identificados no cenário anterior ao analisado.

Essa medida equivale a afirmar que as condições de conservação da superestrutura ferroviária foram melhoradas através da intervenção direta sobre os componentes da via permanente (trilhos, dormentes, lastro etc.), o que resultou no aumento da velocidade média das composições nos arcos e, consequentemente, diminuição dos tempos médios de viagem nos arcos críticos.

O método de análise dos cenários é tal que em cada um deles o modelo de capacidade de processamento de trens na rede é executado sucessivas vezes, variando-se os Coeficientes de Proporcionalidade atribuídos aos terminais.

Essa variação é definida através de um algoritmo associado ao modelo, de modo que são definidas combinações dos Coeficientes de Proporcionalidade de cada um dos terminais da rede com esses valores variando no intervalo fechado de 0 a $100 \%$ a incrementos de $10 \%$. Para cada combinação cuja soma dos Coeficientes seja igual a 100\% o modelo que calcula a capacidade de processamento de trens na rede é executado e os resultados são impressos em um arquivo de texto.

Nesse arquivo é apresentado o valor do "headway crítico global" em minutos, os Coeficientes de Proporcionalidade dos terminais, o número de pares de trens que circulam nos ramais da rede no período de 24 horas, o ramal crítico e a posição do nó inicial e final do arco crítico nesse trecho, para cada combinação dos Coeficientes de Proporcionalidade dos terminais que satisfaça a condição estabelecida anteriormente. 
Ao final desse processo, a frequência de ocorrência de um mesmo arco crítico é calculada em relação ao total de combinações dos Coeficientes de Proporcionalidade, que viabilizaram a aplicação do algoritmo de capacidade. Em relação a cada uma das frequências calculadas são registrados o respectivo ramal crítico, o número de pares de trens diários no polo de concentração de cargas e a identificação (nome e posição) do nó inicial e final do arco crítico.

A identificação do arco que apresenta maior restrição sobre o número máximo de trens que chegam ao polo de concentração de cargas, no período de 24 horas, é dada pelo arco crítico com a maior frequência de ocorrência no conjunto obtido pela execução do modelo de capacidade no respectivo cenário.

A partir disso, um novo cenário é configurado pela retirada das restrições operacionais de velocidade no arco crítico e definição do limite de velocidade de 43 mph (aproximadamente $70 \mathrm{~km} / \mathrm{h}$ ), correspondente à intervenção sobre os elementos da superestrutura ferroviária, que viabilizam o aumento da velocidade média dos trens.

O modelo de capacidade é novamente executado e as frequências de ocorrência são computadas para identificação do novo arco crítico da rede, considerando os novos tempos de viagem no arco crítico do cenário anterior (ver Apêndice C), que corresponde à alteração dos arquivos do simulador e execução de novas simulações com o TEM, empregando o mesmo trem-tipo utilizado nos procedimentos anteriores.

A seguir, são apresentados os resultados da aplicação dos procedimentos descritos para a rede em análise, com a descrição do cenário, apresentação dos valores obtidos pela aplicação do modelo de capacidade e considerações sobre a construção do próximo cenário.

\section{Cenário 1}

O movimento dos trens nos arcos está sujeito às condições reais da via, sem alteração das restrições de velocidade devido às rampas, raios de curvas e limites operacionais decorrentes da conservação da superestrutura ferroviária.

Tabela 4.2 (continua) - Resultados do modelo de capacidade considerando todas as restrições de velocidade.

\begin{tabular}{ccccc}
\hline $\begin{array}{c}\text { Ramal } \\
\text { Crítico }\end{array}$ & $\begin{array}{c}\text { Nó } \\
\text { Inicial* }^{*}\end{array}$ & $\begin{array}{c}\text { Nó } \\
\text { Final* }\end{array}$ & $\begin{array}{c}\text { Pares de } \\
\text { trens/dia** }\end{array}$ & $\begin{array}{c}\text { Frequência } \\
(\%)\end{array}$ \\
\hline $1-2$ & $\begin{array}{c}\text { km 90,2 } \\
\text { Viracopos (ZVK) }\end{array}$ & $\begin{array}{c}\text { km 110,9 } \\
\text { Boa Vista Velha (ZBV) }\end{array}$ & 9 & 59,5 \\
\hline
\end{tabular}


Tabela 4.2 (conclusão) - Resultados do modelo de capacidade considerando todas as restrições de velocidade.

\begin{tabular}{ccccc}
\hline $\begin{array}{c}\text { Ramal } \\
\text { Crítico }\end{array}$ & $\begin{array}{c}\text { Nó } \\
\text { Inicial* }\end{array}$ & $\begin{array}{c}\text { Nó } \\
\text { Final* }\end{array}$ & $\begin{array}{c}\text { Pares de } \\
\text { trens/dia*** }\end{array}$ & $\begin{array}{c}\text { Frequência } \\
\text { (\%) }\end{array}$ \\
\hline $4-6$ & $\begin{array}{c}\text { km 152,2 } \\
\text { Catiguá (ZCT) }\end{array}$ & $\begin{array}{c}\text { km 169,3 } \\
\text { Uchôa (ZUC) }\end{array}$ & 8 & 17,2 \\
\hline $4-5$ & $\begin{array}{c}\text { km 173,3 } \\
\text { Barretos (ZBR) }\end{array}$ & $\begin{array}{c}\text { km 199,1 } \\
\text { Adolfo Pinto (ZWH) }\end{array}$ & 8 & 13,7 \\
\hline $2-3$ & $\begin{array}{c}\text { km 131,9 } \\
\text { Bauru (ZBU) }\end{array}$ & \begin{tabular}{c} 
Garça (ZGR) \\
\hline
\end{tabular}
\end{tabular}

* Relativo ao arco crítico no sentido Importação.

** No polo de concentração de cargas

A partir da Tabela 4.2, é possível afirmar que arco entre os nós situados no km 90,2 (Viracopos) e km 110,9 (Boa Vista Velha), no sentido Importação, do ramal entre os terminais de Mairinque e Itirapina, restringe em 9 pares de trens por dia no polo de concentração de cargas em 59,5\% das combinações dos Coeficientes de Proporcionalidade dos terminais.

\section{Cenário 2}

Com os resultados do cenário anterior foi realizada uma intervenção no arquivo da via do simulador TEM no arco crítico identificado, alterando o limite operacional de velocidade para $70 \mathrm{~km} / \mathrm{h}$, o que equivale a melhorar as condições gerais de conservação da superestrutura sem alteração no traçado da via, permitindo aos trens percorrerem o trajeto com maior velocidade sem comprometer a segurança da operação. Os valores de capacidade do sistema, obtidos pela aplicação do procedimento descrito anteriormente, são apresentados na Tabela 4.3.

Tabela 4.3 - Resultados do modelo de capacidade com limite de velocidade de 70km/h entre os nós de Viracopos e Boa Vista Velha, no ramal entre os terminais de Mairinque e Itirapina.

\begin{tabular}{ccccc}
\hline $\begin{array}{c}\text { Ramal } \\
\text { Crítico }\end{array}$ & $\begin{array}{c}\text { Nó } \\
\text { Inicial* }\end{array}$ & $\begin{array}{c}\text { Nó } \\
\text { Final* }\end{array}$ & $\begin{array}{c}\text { Pares de } \\
\text { trens/dia** }\end{array}$ & $\begin{array}{c}\text { Frequência } \\
(\%)\end{array}$ \\
\hline $1-2$ & $\begin{array}{c}\text { km 210,9 } \\
\text { Graúna (ZOX) }\end{array}$ & $\begin{array}{c}\text { km 223,2 } \\
\text { Itirapina (ZIQ) }\end{array}$ & 10 & 53,7 \\
\hline $4-6$ & $\begin{array}{c}\text { km 152,2 } \\
\text { Catiguá (ZCT) }\end{array}$ & $\begin{array}{c}\text { km 169,3 } \\
\text { Uchôa (ZUC) }\end{array}$ & 8 & 17,5 \\
\hline $4-5$ & $\begin{array}{c}\text { km 173,3 } \\
\text { Barretos (ZBR) }\end{array}$ & $\begin{array}{c}\text { km 199,1 } \\
\text { Adolfo Pinto (ZWH) }\end{array}$ & 8 & 15,7 \\
\hline $2-3$ & $\begin{array}{c}\text { km 131,9 } \\
\text { Bauru (ZBU) }\end{array}$ & Garça (ZGR) & 5 & 13,1 \\
\hline
\end{tabular}

* Relativo ao arco crítico no sentido Importação.

** No polo de concentração de cargas

A modificação do limite de velocidade no arco indicado acarreta o aumento de 9 para 10 pares de trens por dia no polo de concentração de cargas e o arco que define esse cenário está 
situado entre os nós do km 210,9 (Graúna) e o km 223,2 (Itirapina), no sentido Importação, do ramal entre os terminais de Mairinque e Itirapina, em 53,7\% das combinações dos Coeficientes de Proporcionalidade dos terminais.

\section{Cenário 3}

De modo análogo ao cenário anterior, foi realizada uma intervenção no arquivo da via permanente entre o nó do km 210,9 (Graúna) e o km 223,2 (Itirapina), no sentido Importação, do ramal entre os terminais de Mairinque e Itirapina, com aumento do limite de velocidade para $70 \mathrm{~km} / \mathrm{h}$ no arco. A aplicação do modelo de capacidade resultou nos valores apresentados na Tabela 4.4 .

Tabela 4.4 - Resultados do modelo de capacidade com limite de velocidade de 70km/h entre o nó de Graúna e o terminal de Itirapina, no ramal entre os terminais de Mairinque e Itirapina.

\begin{tabular}{|c|c|c|c|c|}
\hline $\begin{array}{l}\text { Ramal } \\
\text { Crítico }\end{array}$ & $\begin{array}{c}\text { Nó } \\
\text { Inicial* }\end{array}$ & $\begin{array}{l}\text { Nó } \\
\text { Final* }\end{array}$ & $\begin{array}{c}\text { Pares de } \\
\text { trens/dia** }\end{array}$ & $\begin{array}{c}\text { Frequência } \\
(\%)\end{array}$ \\
\hline $2-4$ & $\begin{array}{c}\mathrm{km} 0 \\
\text { Itirapina (ZIQ) }\end{array}$ & $\begin{array}{c}\mathrm{km} \mathrm{13,0} \\
\text { Visconde do Rio Claro (ZVI) }\end{array}$ & 10 & 35,9 \\
\hline $1-2$ & $\begin{array}{c}\mathrm{km} 77,7 \\
\text { Itaici (ZIC) }\end{array}$ & $\begin{array}{c}\mathrm{km} 90,2 \\
\text { Viracopos }(\mathrm{ZVK})\end{array}$ & 11 & 18,2 \\
\hline $4-6$ & $\begin{array}{c}\text { km 152,2 } \\
\text { Catiguá (ZCT) }\end{array}$ & $\begin{array}{c}\text { km 169,3 } \\
\text { Uchôa (ZUC) }\end{array}$ & 8 & 17,5 \\
\hline $4-5$ & $\begin{array}{c}\mathrm{km} 173,3 \\
\text { Barretos (ZBR) }\end{array}$ & $\begin{array}{c}\text { km 199,1 } \\
\text { Adolfo Pinto (ZWH) }\end{array}$ & 8 & 15,7 \\
\hline $2-3$ & $\begin{array}{c}\text { km 131,9 } \\
\text { Bauru (ZBU) }\end{array}$ & $\begin{array}{c}\mathrm{km} \mathrm{206,0} \\
\text { Garça (ZGR) }\end{array}$ & 5 & 12,8 \\
\hline
\end{tabular}

* Relativo ao arco crítico no sentido Importação.

** No polo de concentração de cargas

A alteração no limite de velocidade no arco não modifica o número máximo de trens por dia no polo de concentração de cargas (10 pares), entretanto, o arco que restringe a capacidade com maior frequência de ocorrência $(35,9 \%)$ é o que conecta o nó do km 0 (Itirapina) e o do km 13,0 (Visconde do Rio Claro), no sentido Importação do ramal, entre os terminais de Itirapina e Araraquara.

\section{Cenário 4}

Esse cenário considera o aumento do limite de velocidade para $70 \mathrm{~km} / \mathrm{h}$ e aplicação do modelo de capacidade no arco entre o nó do km 0 (Itirapina) e o do km 13,0 (Visconde do Rio Claro), no sentido Importação do ramal, entre os terminais de Itirapina e Araraquara, uma vez que a 
maior porcentagem de ocorrência do arco crítico apresentada nos resultados do cenário anterior é nesse trecho.

Tabela 4.5 - Resultados do modelo de capacidade com limite de velocidade de 70km/h entre os nós de Itirapina e Visconde do Rio Claro, no ramal entre os terminais de Itirapina e Araraquara.

\begin{tabular}{ccccc}
\hline $\begin{array}{c}\text { Ramal } \\
\text { Crítico }\end{array}$ & $\begin{array}{c}\text { Nó } \\
\text { Inicial* }^{*}\end{array}$ & $\begin{array}{c}\text { Nó } \\
\text { Final* }\end{array}$ & $\begin{array}{c}\text { Pares de } \\
\text { trens/dia** }\end{array}$ & $\begin{array}{c}\text { Frequência } \\
(\%)\end{array}$ \\
\hline $1-2$ & $\begin{array}{c}\text { km 77,7 } \\
\text { Itaici (ZIC) }\end{array}$ & $\begin{array}{c}\text { km 90,2 } \\
\text { Viracopos (ZVK) }\end{array}$ & 11 & 55,8 \\
\hline $4-6$ & $\begin{array}{c}\text { km 152,2 } \\
\text { Catiguá (ZCT) }\end{array}$ & $\begin{array}{c}\text { km 169,3 } \\
\text { Uchôa (ZUC) }\end{array}$ & 8 & 16,9 \\
\hline $4-5$ & $\begin{array}{c}\text { km 173,3 } \\
\text { Barretos (ZBR) }\end{array}$ & $\begin{array}{c}\text { km 199, } \\
\text { Adolfo Pinto (ZWH) }\end{array}$ & 8 & 14,9 \\
\hline $2-3$ & $\begin{array}{c}\text { km 131,9 } \\
\text { Bauru (ZBU) }\end{array}$ & $\begin{array}{c}\text { karça (ZGR) } \\
\text { Gato }\end{array}$ & 5 & 12,4 \\
\hline
\end{tabular}

* Relativo ao arco crítico no sentido Importação.

** No polo de concentração de cargas

Os menores tempos de viagem naquele arco mostram que o trecho entre o nó do $\mathrm{km} \mathrm{77,7}$ (Itaici) e o do km 90,2 (Viracopos), no sentido Importação do ramal entre os terminais de Mairinque e Itirapina, passa a ser o que restringe a capacidade no sistema com maior porcentagem de ocorrência $(55,8 \%)$, novamente com a capacidade de 11 pares de trens diários no Terminal Mairinque.

\section{Cenário 5}

Foi atribuído o valor de $70 \mathrm{~km} / \mathrm{h}$ aos limites de velocidade no arquivo de caracterização da via permanente, no arco crítico identificado no cenário anterior. Após a obtenção dos novos tempos de viagem no arco e execução do modelo de capacidade com as combinações dos Coeficientes de Proporcionalidade dos terminais foram obtidos os resultados apresentados na Tabela 4.6.

Tabela 4.6 (continua) - Resultados do modelo de capacidade com limite de velocidade de $70 \mathrm{~km} / \mathrm{h}$ entre os nós de Itaici e Viracopos, no ramal entre os terminais de Mairinque e Itirapina.

\begin{tabular}{ccccc}
\hline $\begin{array}{c}\text { Ramal } \\
\text { Crítico }\end{array}$ & $\begin{array}{c}\text { Nó } \\
\text { Inicial* }\end{array}$ & $\begin{array}{c}\text { Nó } \\
\text { Final* }\end{array}$ & $\begin{array}{c}\text { Pares de } \\
\text { trens/dia** }\end{array}$ & $\begin{array}{c}\text { Frequência } \\
(\%)\end{array}$ \\
\hline $1-2$ & $\begin{array}{c}\text { km 210,9 } \\
\text { Graúna (ZOX) }\end{array}$ & $\begin{array}{c}\text { km 223,2 } \\
\text { Itirapina (ZIQ) }\end{array}$ & 11 & 50,0 \\
\hline $4-6$ & $\begin{array}{c}\text { km 152,2 } \\
\text { Catiguá (ZCT) }\end{array}$ & $\begin{array}{c}\text { km 169,3 } \\
\text { Uchôa (ZUC) }\end{array}$ & 8 & 19,3 \\
\hline
\end{tabular}


Tabela 4.6 (conclusão) - Resultados do modelo de capacidade com limite de velocidade de $70 \mathrm{~km} / \mathrm{h}$ entre os nós de Itaici e Viracopos, no ramal entre os terminais de Mairinque e Itirapina.

\begin{tabular}{ccccc}
\hline $\begin{array}{c}\text { Ramal } \\
\text { Crítico }\end{array}$ & $\begin{array}{c}\text { Nó } \\
\text { Inicial* }\end{array}$ & $\begin{array}{c}\text { Nó } \\
\text { Final* }\end{array}$ & $\begin{array}{c}\text { Pares de } \\
\text { trens/dia** }\end{array}$ & $\begin{array}{c}\text { Frequência } \\
(\%)\end{array}$ \\
\hline $4-5$ & $\begin{array}{c}\text { km 173,3 } \\
\text { Barretos (ZBR) }\end{array}$ & $\begin{array}{c}\text { km 199,1 } \\
\text { Adolfo Pinto (ZWH) }\end{array}$ & 8 & 16,8 \\
\hline $2-3$ & $\begin{array}{c}\text { km 131,9 } \\
\text { Bauru (ZBU) }\end{array}$ & $\begin{array}{c}\text { km 206,0 } \\
\text { Garça (ZGR) }\end{array}$ & 5 & 13,9 \\
\hline
\end{tabular}

* Relativo ao arco crítico no sentido Importação.

** No polo de concentração de cargas

$\mathrm{O}$ arco que restringe a capacidade em 50,0\% das combinações dos Coeficientes de Proporcionalidade dos terminais é novamente aquele situado entre as estações de Graúna e Itirapina, no km 210,9 e km 223,2, respectivamente, no sentido Importação do ramal entre os terminais de Mairinque e Itirapina, sem alteração do número de trens diários no Terminal Mairinque, em relação ao cenário anterior. Esse resultado mostra que o aumento da capacidade de processamento de trens no arco crítico não está condicionado apenas à retirada das restrições impostas pelos limites de velocidade dados pelas condições de conservação da superestrutura da linha.

O gráfico da Figura 4.6 mostra que a expressiva declividade das rampas exige elevada força de tração por parte das locomotivas para o trem transpor o trecho no sentido Importação (Mairinque - Santa Fé do Sul), o que resulta em baixas velocidades instantâneas arco, resultando em maior tempo de viagem nesse sentido.

Aliada a isso, a grande variação na amplitude dos raios das curvas no arco (Figura 4.7) faz com que o trem alterne entre pontos de aceleração e desaceleração em ambos os sentidos de circulação, fator este que também exerce influência sobre os tempos de viagem.

Esses fatores, juntamente com o parâmetro associado ao comprimento entre nós (GraúnaItirapina), que se mostra extenso em relação aos demais arcos do sistema e também exerce influência sobre os tempos de viagem no arco, indicam que a geometria da via é o limitante do número máximo de trens, no período de 24 horas, no arco crítico identificado neste cenário em detrimento das condições de conservação da via. 


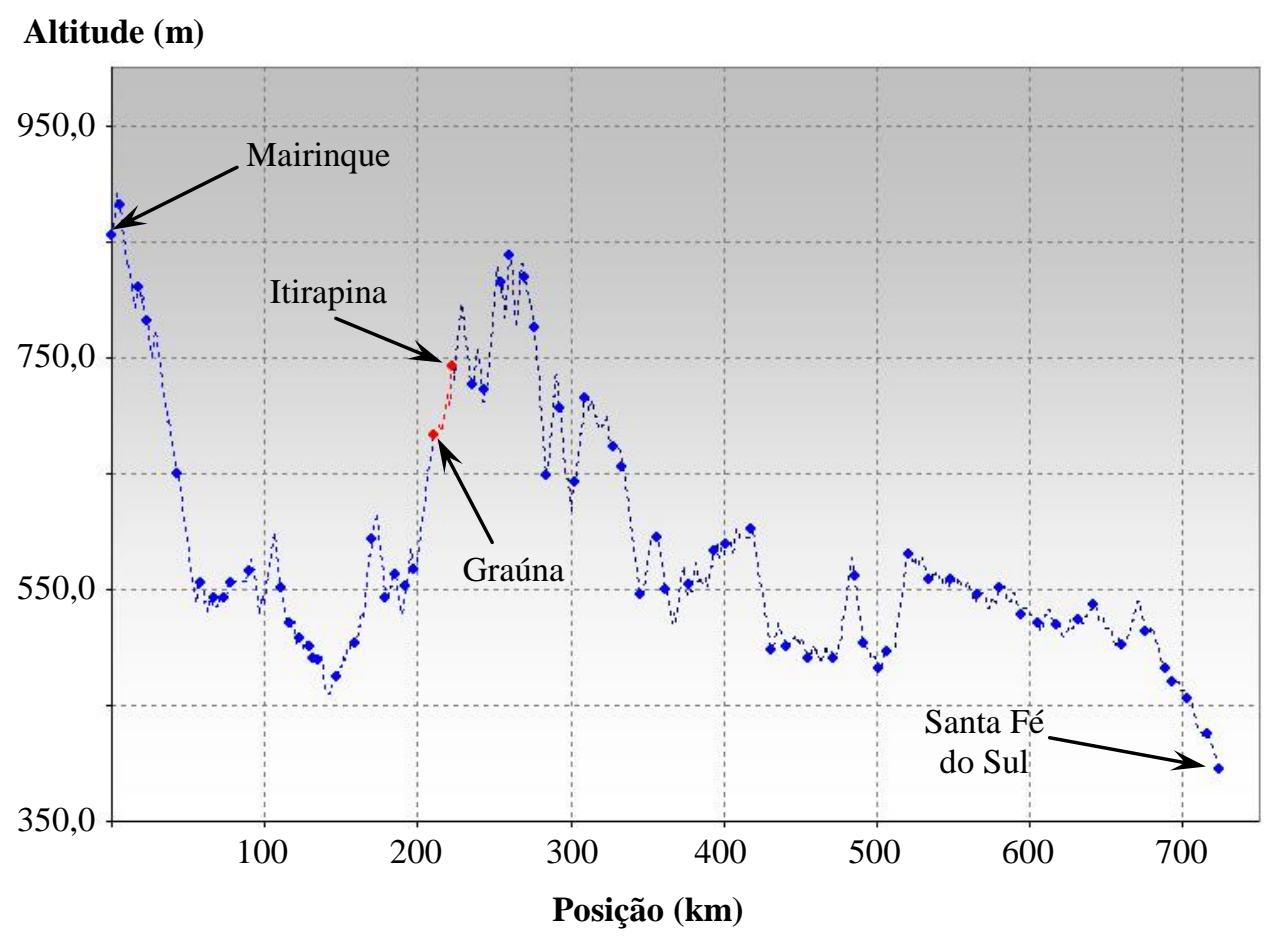

Figura 4.6 - Altitudes dos pontos no arco entre o nó de Graúna e o teminal de Itirapina.

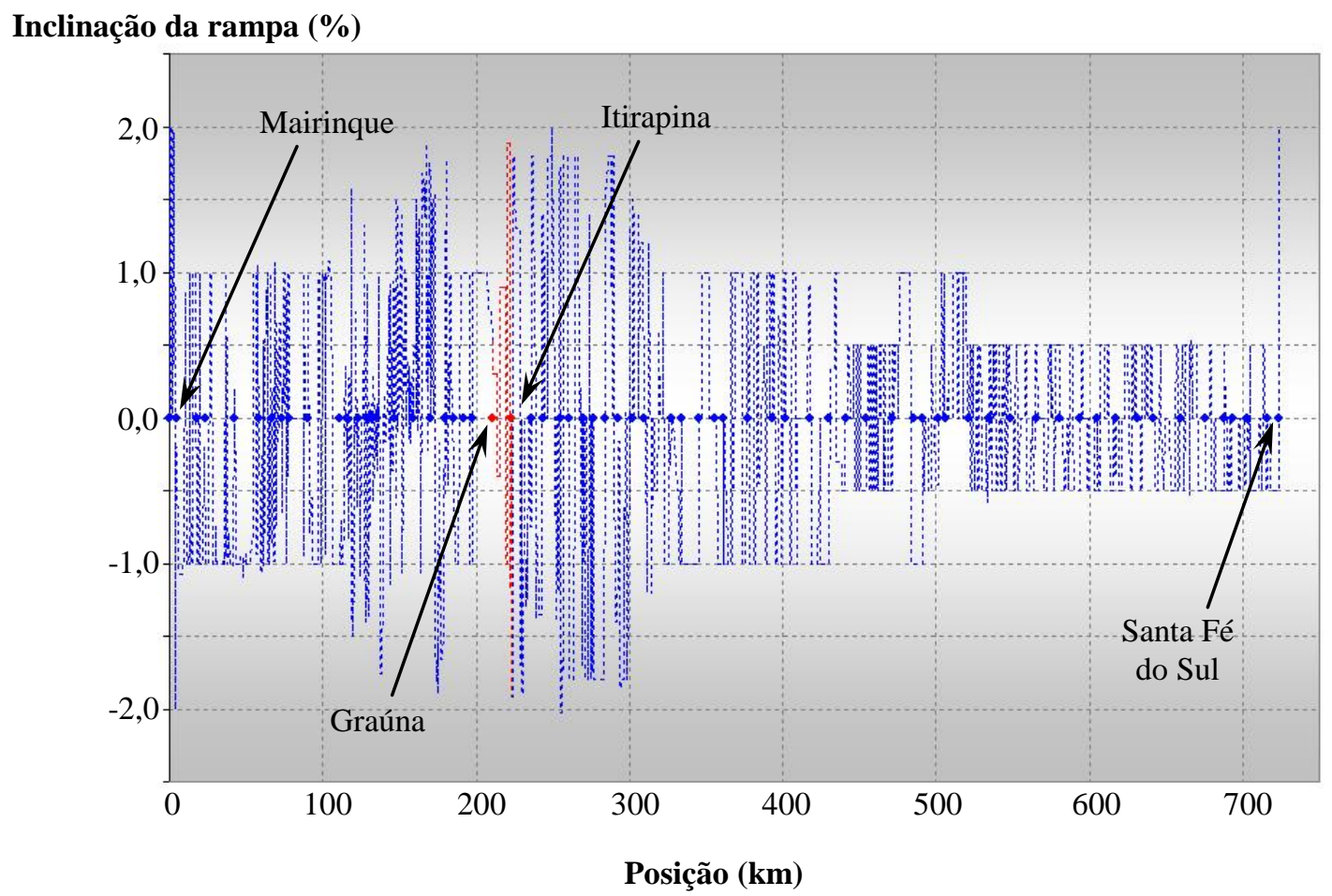

Figura 4.7 - Inclinações das rampas dos pontos no arco entre o nó de Graúna e o teminal de Itirapina.

Do ponto de vista das restrições impostas pela geometria da via, o aumento da capacidade de processamento no arco crítico identificado neste cenário pode ser obtido pela modificação do traçado da linha ferroviária, optando-se por um percurso com rampas de menor declividade e, consequentemente, aumento da velocidade dos trens no arco. No âmbito operacional pode ser 
considerada a alternativa de aumento do número de locomotivas dos trens que circulam no arco no sentido Importação, uma vez que as rampas nesse sentido apresentam elevada declividade.

Entretanto, como a análise proposta neste trabalho está direcionada à verificação dos gargalos da rede atribuídos às condições de conservação da via permanente, e não em propor alterações no traçado da via, que necessitaria de estudos sobre perfis mais adequados, ou alteração da configuração do trem para aumento da força de tração necessária ao seu movimento, o que compromete uma das premissas do modelo de capacidade proposto, os próximos cenários foram caracterizados pela alteração dos limites de velocidade no arco crítico dos ramais, com a segunda maior frequência de ocorrência em relação às combinações dos Coeficientes de Proporcionalidade dos terminais.

\section{Cenário 6}

Este cenário foi definido pela alteração dos limites de velocidade no arco entre as estações de Catiguá e Uchôa, situadas no km 152,2 e km 169,3, respectivamente, em relação ao sentido Importação do ramal, entre os terminais de Araraquara e Santa Fé do Sul, que restringe a capacidade da rede em 19,3\% dos casos, com 8 pares de trens por dia no Terminal Mairinque.

A definição da velocidade máxima permitida no arco para $70 \mathrm{~km} / \mathrm{h}$ resulta nos valores apresentados na Tabela 4.7, obtidos após a execução do modelo de capacidade.

Tabela 4.7 - Resultados do modelo de capacidade com limite de velocidade de 70km/h entre os nós de Catiguá e Uchôa, no ramal entre os terminais de Araraquara e Santa Fé do Sul.

\begin{tabular}{|c|c|c|c|c|}
\hline $\begin{array}{l}\text { Ramal } \\
\text { Crítico }\end{array}$ & $\begin{array}{c}\text { Nó } \\
\text { Inicial* }\end{array}$ & $\begin{array}{c}\text { Nó } \\
\text { Final* }\end{array}$ & $\begin{array}{c}\text { Pares de } \\
\text { trens/dia** }\end{array}$ & $\begin{array}{c}\text { Frequência } \\
(\%)\end{array}$ \\
\hline $1-2$ & $\begin{array}{c}\text { km 210,9 } \\
\text { Graúna (ZOX) }\end{array}$ & $\begin{array}{c}\text { km 223,2 } \\
\text { Itirapina (ZIQ) }\end{array}$ & 11 & 50,0 \\
\hline 4-6 & $\begin{array}{c}\mathrm{km} 245,9 \\
\text { Eng. Balduíno (ZEB) }\end{array}$ & $\begin{array}{c}\mathrm{km} 263,7 \\
\text { Ecatu (ZEC) }\end{array}$ & 9 & 19,3 \\
\hline $4-5$ & $\begin{array}{c}\mathrm{km} 173,3 \\
\text { Barretos (ZBR) }\end{array}$ & $\begin{array}{c}\mathrm{km} \mathrm{199,1} \\
\text { Adolfo Pinto (ZWH) }\end{array}$ & 8 & 16,8 \\
\hline $2-3$ & $\begin{array}{c}\text { km 131,9 } \\
\text { Bauru (ZBU) }\end{array}$ & $\begin{array}{c}\mathrm{km} \mathrm{206,0} \\
\text { Garça (ZGR) }\end{array}$ & 5 & 13,9 \\
\hline
\end{tabular}

* Relativo ao arco crítico no sentido Importação.

** No polo de concentração de cargas

Os resultados indicam um aumento para 9 trens/dia no terminal de concentração de cargas da rede, na mesma proporção das combinações dos Coeficientes de Proporcionalidade do cenário 
anterior, com permanência do arco crítico entre os nós do km 245,9 (Eng. Balduíno) e km 263,7 (Ecatu), em relação ao sentido Importação do ramal 4-6 (Araraquara-Santa Fé do $\mathrm{Sul})$.

\section{Cenário 7}

Este cenário resulta da alteração do limite de velocidade para $70 \mathrm{~km} / \mathrm{h}$ no arco crítico, identificado no cenário anterior, com obtenção dos resultados apresentados na Tabela 4.8, após determinação dos novos tempos de viagem e execução do modelo de capacidade para as combinações das porcentagens dos Coeficientes de Proporcionalidade dos terminais.

Tabela 4.8 - Resultados do modelo de capacidade com limite de velocidade de 70km/h entre os nós de Eng. Balduíno e Ecatu, no ramal entre os terminais de Araraquara e Santa Fé do Sul.

\begin{tabular}{ccccc}
\hline $\begin{array}{c}\text { Ramal } \\
\text { Crítico }\end{array}$ & $\begin{array}{c}\text { Nó } \\
\text { Inicial* }\end{array}$ & $\begin{array}{c}\text { Nó } \\
\text { Final* }\end{array}$ & $\begin{array}{c}\text { Pares de } \\
\text { trens/dia** }\end{array}$ & $\begin{array}{c}\text { Frequência } \\
(\%)\end{array}$ \\
\hline $1-2$ & $\begin{array}{c}\text { km 210,9 } \\
\text { Graúna (ZOX) }\end{array}$ & $\begin{array}{c}\text { km 223,2 } \\
\text { Itirapina (ZIQ) }\end{array}$ & 11 & 50,0 \\
\hline $4-6$ & $\begin{array}{c}\text { km 231,9 } \\
\text { Bálsamo (ZVU) }\end{array}$ & $\begin{array}{c}\text { km 245,9 } \\
\text { Eng. Balduíno (ZEB) }\end{array}$ & 9 & 19,3 \\
\hline $4-5$ & $\begin{array}{c}\text { km 173,3 } \\
\text { Barretos (ZBR) }\end{array}$ & $\begin{array}{c}\text { kdolfo Pinto (ZWH) } \\
\text { Adint }\end{array}$ & 8 & 16,8 \\
\hline $2-3$ & $\begin{array}{c}\text { km 131,9 } \\
\text { Bauru (ZBU) }\end{array}$ & Garça (ZGR) & 5 & 13,9 \\
\hline \hline
\end{tabular}

* Relativo ao arco crítico no sentido Importação.

** No polo de concentração de cargas

Nesse caso, o arco crítico passa a ser o situado entre os nós de Bálsamo e Eng. Balduíno, no km 231,9 e km 245,9, respectivamente, em relação ao sentido Importação do ramal, entre os terminais de Araraquara e Santa Fé do Sul. O número de trens no terminal Mairinque (9 pares/dia) permanece inalterado em relação ao cenário anterior, em 19,3\% das combinações.

\section{Cenário 8}

Os resultados indicados na Tabela 4.9 foram obtidos após a alteração do limite de velocidade para $70 \mathrm{~km} / \mathrm{h}$ no arco crítico entre os nós indicados no Cenário 7, execução de novas simulações e aplicação do modelo de capacidade da rede feroviária. 
Tabela 4.9 - Resultados do modelo de capacidade com limite de velocidade de 70km/h entre os nós de Bálsamo e Eng. Balduíno, no ramal entre os terminais de Araraquara e Santa Fé do Sul.

\begin{tabular}{ccccc}
\hline $\begin{array}{c}\text { Ramal } \\
\text { Crítico }\end{array}$ & $\begin{array}{c}\text { Nó } \\
\text { Inicial* }\end{array}$ & $\begin{array}{c}\text { Nó } \\
\text { Final* }\end{array}$ & $\begin{array}{c}\text { Pares de } \\
\text { trens/dia** }\end{array}$ & $\begin{array}{c}\text { Frequência } \\
(\%)\end{array}$ \\
\hline $1-2$ & $\begin{array}{c}\text { km 210,9 } \\
\text { Graúna (ZOX) }\end{array}$ & $\begin{array}{c}\text { km 223,2 } \\
\text { Itirapina (ZIQ) }\end{array}$ & 11 & 50,0 \\
\hline $4-6$ & $\begin{array}{c}\text { km 263,7 } \\
\text { Ecatu (ZEC) }\end{array}$ & $\begin{array}{c}\text { km 278,2 } \\
\text { Cosmorama (ZKY) }\end{array}$ & 10 & 19,3 \\
\hline $4-5$ & $\begin{array}{c}\text { km 173,3 } \\
\text { Barretos (ZBR) }\end{array}$ & $\begin{array}{c}\text { km 199,1 } \\
\text { Adolfo Pinto (ZWH) }\end{array}$ & 8 & 16,8 \\
\hline $2-3$ & $\begin{array}{c}\text { km 131,9 } 206,0 \\
\text { Gaurça (ZGR) }\end{array}$ & 5 & 13,9 \\
\hline
\end{tabular}

* Relativo ao arco crítico no sentido Importação.

** No polo de concentração de cargas

O novo gargalo, identificado em $19,3 \%$ das combinações dos Coeficientes de Proporcionalidade, está situado no arco entre os nós do km 263,7 (Ecatu) e o km 278,2 (Cosmorama), no sentido Importação do ramal, entre os terminais de Araraquara e Santa Fé do Sul, com aumento para 10 pares de trens diários no polo de concentração de cargas da rede.

\section{Cenário 9}

O aumento da velocidade limite para $70 \mathrm{~km} / \mathrm{h}$ no arco crítico do cenário anterior, a execução de novas simulações para obtenção dos tempos de viagem sem os limites operacionais de velocidade e a aplicação do modelo de capacidade considerando as combinações dos Coeficientes de Proporcionalidade dos terminais têm como resultado os dados apresentados na Tabela 4.10.

Tabela 4.10 - Resultados do modelo de capacidade com limite de velocidade de 70km/h entre os nós de Ecatu e Cosmorama, no ramal entre os terminais de Araraquara e Santa Fé do Sul.

\begin{tabular}{ccccc}
\hline $\begin{array}{c}\text { Ramal } \\
\text { Crítico }\end{array}$ & $\begin{array}{c}\text { Nó } \\
\text { Inicial* }\end{array}$ & $\begin{array}{c}\text { Nó } \\
\text { Final* }\end{array}$ & $\begin{array}{c}\text { Pares de } \\
\text { trens/dia** }\end{array}$ & $\begin{array}{c}\text { Frequência } \\
(\%)\end{array}$ \\
\hline $1-2$ & $\begin{array}{c}\text { km 210,9 } \\
\text { Graúna (ZOX) }\end{array}$ & $\begin{array}{c}\text { km 223,2 } \\
\text { Itirapina (ZIQ) }\end{array}$ & 11 & 50,0 \\
\hline $4-6$ & $\begin{array}{c}\text { km 278,2 } \\
\text { Cosmorama (ZKY) }\end{array}$ & $\begin{array}{c}\text { km 292,0 } \\
\text { Simonsen (ZZM) }\end{array}$ & 10 & 19,3 \\
\hline $4-5$ & $\begin{array}{c}\text { km 173,3 } \\
\text { Barretos (ZBR) }\end{array}$ & $\begin{array}{c}\text { km 199,1 } \\
\text { Adolfo Pinto (ZWH) }\end{array}$ & 8 & 16,8 \\
\hline $2-3$ & $\begin{array}{c}\text { km 131,9 } \\
\text { Bauru (ZBU) }\end{array}$ & $\begin{array}{c}\text { Garça (ZGR) } \\
\text { Gaura }\end{array}$ & 5 & 13,9 \\
\hline
\end{tabular}

* Relativo ao arco crítico no sentido Importação.

** No polo de concentração de cargas 
$\mathrm{O}$ arco que restringe o aumento do número de trens diários no polo de concentração de cargas em 19,3\% das combinações, com permanência de 10 pares de trens diários nesse local, é o situado entre as estações de Cosmorama e Simonsen, no km 278,2 e km 292,0, respectivamente, no sentido Importação do ramal, entre os terminais de Araraquara e Santa Fé do Sul.

\section{Cenário 10}

A alteração do limite de velocidade no arco crítico identificado no cenário anterior, a execução de simulações com essas características da via permanente e a aplicação do modelo de capacidade têm como resultado os dados indicados na Tabela 4.11.

Tabela 4.11 - Resultados do modelo de capacidade com limite de velocidade de 70km/h entre os nós de Cosmorama e Simonsen, no ramal entre os terminais de Araraquara e Santa Fé do Sul.

\begin{tabular}{|c|c|c|c|c|}
\hline $\begin{array}{l}\text { Ramal } \\
\text { Crítico }\end{array}$ & $\begin{array}{c}\text { Nó } \\
\text { Inicial* }\end{array}$ & $\begin{array}{c}\text { Nó } \\
\text { Final* }\end{array}$ & $\begin{array}{c}\text { Pares de } \\
\text { trens/dia*** }\end{array}$ & $\begin{array}{c}\text { Frequência } \\
(\%)\end{array}$ \\
\hline $1-2$ & $\begin{array}{c}\text { km 210,9 } \\
\text { Graúna (ZOX) }\end{array}$ & $\begin{array}{c}\text { km 223,2 } \\
\text { Itirapina (ZIQ) }\end{array}$ & 11 & 50,0 \\
\hline $4-6$ & $\begin{array}{c}\text { km 169,3 } \\
\text { Uchôa (ZUC) }\end{array}$ & $\begin{array}{c}\text { km 182,9 } \\
\text { Cedral (ZCG) }\end{array}$ & 10 & 19,3 \\
\hline $4-5$ & $\begin{array}{c}\text { km 173,3 } \\
\text { Barretos (ZBR) }\end{array}$ & $\begin{array}{c}\text { km 199,1 } \\
\text { Adolfo Pinto (ZWH) }\end{array}$ & 8 & 16,8 \\
\hline $2-3$ & $\begin{array}{c}\text { km 131,9 } \\
\text { Bauru (ZBU) }\end{array}$ & $\begin{array}{c}\mathrm{km} \mathrm{206,0} \\
\text { Garça (ZGR) }\end{array}$ & 5 & 13,9 \\
\hline
\end{tabular}

* Relativo ao arco crítico no sentido Importação.

** No polo de concentração de cargas

Novamente o gargalo da rede está situado no ramal definido pelos terminais de Araraquara e Santa Fé do Sul, com a segunda maior frequência de ocorrência das combinações dos Coeficientes de Proporcionalidade (19,3\%) entre as estações de Uchôa (km 169,3) e Cedral (km 182,9), em relação ao sentido Importação, com 10 pares de trens diários no polo de concentração de cargas.

\section{Cenário 11}

A retirada da restrição de velocidade, devido à condição de conservação da superestrutura ferroviária pelo aumento da velocidade para $70 \mathrm{~km} / \mathrm{h}$ no arco crítico entre os nós de Uchôa e Cedral, a realização das simulações para obtenção dos tempos de viagem e a aplicação do modelo de capacidade da rede geram os resultados apresentados na Tabela 4.12. 
Tabela 4.12 - Resultados do modelo de capacidade com limite de velocidade de 70km/h entre os nós de Uchôa e Cedral, no ramal entre os terminais de Araraquara e Santa Fé do Sul.

\begin{tabular}{ccccc}
\hline $\begin{array}{c}\text { Ramal } \\
\text { Crítico }\end{array}$ & $\begin{array}{c}\text { Nó } \\
\text { Inicial* }\end{array}$ & $\begin{array}{c}\text { Nó } \\
\text { Final* }\end{array}$ & $\begin{array}{c}\text { Pares de } \\
\text { trens/dia** }\end{array}$ & $\begin{array}{c}\text { Frequência } \\
(\%)\end{array}$ \\
\hline $1-2$ & $\begin{array}{c}\text { km 210,9 } \\
\text { Graúna (ZOX) }\end{array}$ & $\begin{array}{c}\text { km 223,2 } \\
\text { Itirapina (ZIQ) }\end{array}$ & 11 & 50,0 \\
\hline $4-6$ & $\begin{array}{c}\text { km 302,7 } \\
\text { Votuporanga (ZVP) }\end{array}$ & $\begin{array}{c}\text { km 315,4 } \\
\text { Valentim Gentil (ZVG) }\end{array}$ & 11 & 19,3 \\
\hline $4-5$ & $\begin{array}{c}\text { km 173,3 } \\
\text { Barretos (ZBR) }\end{array}$ & $\begin{array}{c}\text { km 199,1 } \\
\text { Adolfo Pinto (ZWH) }\end{array}$ & 8 & 16,8 \\
\hline $2-3$ & $\begin{array}{c}\text { km 131,9 } \\
\text { Bauru (ZBU) }\end{array}$ & $\begin{array}{c}\text { km 206,0 } \\
\text { Garça (ZGR) }\end{array}$ & 5 & 13,9 \\
\hline
\end{tabular}

* Relativo ao arco crítico no sentido Importação.

** No polo de concentração de cargas

Com o aumento da capacidade da rede para 11 pares de trens diários no polo de concentração de cargas, em 19,3\% das combinações dos Coeficientes de Proporcionalidade dos terminais com soma igual a 100\%, o arco crítico deste cenário está situado entre os nós de Votuporanga e Valentim Gentil, no km 302,7 e km 315,4, respectivamente, no sentido Importação, do ramal definido pelos terminais de Araraquara e Santa Fé do Sul.

\section{Cenário 12}

A alteração do limite de velocidade no arco crítico do cenário anterior, entre as estações de Votuporanga e Valentim Gentil, no ramal que conecta os terminais de Araraquara e Santa Fé do Sul, resulta nos valores apresentados na Tabela 4.13.

Tabela 4.13 - Resultados do modelo de capacidade com limite de velocidade de 70km/h entre os nós de Votuporanga e Valentim Gentil, no ramal entre os terminais de Araraquara e Santa Fé do Sul.

\begin{tabular}{ccccc}
\hline $\begin{array}{c}\text { Ramal } \\
\text { Crítico }\end{array}$ & $\begin{array}{c}\text { Nó } \\
\text { Inicial* }\end{array}$ & $\begin{array}{c}\text { Nó } \\
\text { Final* }\end{array}$ & $\begin{array}{c}\text { Pares de } \\
\text { trens/dia** }\end{array}$ & $\begin{array}{c}\text { Frequência } \\
(\%)\end{array}$ \\
\hline $1-2$ & $\begin{array}{c}\text { km 210,9 } \\
\text { Graúna (ZOX) }\end{array}$ & $\begin{array}{c}\text { km 223,2 } \\
\text { Itirapina (ZIQ) }\end{array}$ & 11 & 50,0 \\
\hline $4-6$ & $\begin{array}{c}\text { km 218,7 } \\
\text { Mirassol (ZMO) }\end{array}$ & $\begin{array}{c}\text { km 231,9 } \\
\text { Bálsamo (ZVU) }\end{array}$ & 11 & 19,3 \\
\hline $4-5$ & $\begin{array}{c}\text { km 173,3 } \\
\text { Barretos (ZBR) }\end{array}$ & $\begin{array}{c}\text { Adolfo Pinto (ZWH) } \\
\text { Adom }\end{array}$ & 8 & 16,8 \\
\hline $2-3$ & $\begin{array}{c}\text { km 131,9 } \\
\text { Bauru (ZBU) }\end{array}$ & Garça (ZGR) & 5 & 13,9 \\
\hline
\end{tabular}

* Relativo ao arco crítico no sentido Importação.

** No polo de concentração de cargas

O arco crítico deste cenário está situado entre as estações de Mirassol e Bálsamo, no km 218,7 e km 231,9, respectivamente, em relação ao sentido Importação do ramal Araraquara-Santa Fé 
do Sul, em 19,3\% das combinações dos Coeficientes de Proporcionalidade, sem aumento do número de pares de trens diários no polo de concentração de cargas em relação ao cenário anterior.

\section{Cenário 13}

A alteração do limite de velocidade do arco crítico identificado no Cenário 12, a obtenção dos tempos de viagem sem essa restrição ao movimento dos trens e a execução do modelo de capacidade resultam nos valores indicados na Tabela 4.14.

Tabela 4.14 - Resultados do modelo de capacidade com limite de velocidade de 70km/h entre os nós de Mirassol e Bálsamo, no ramal entre os terminais de Araraquara e Santa Fé do Sul.

\begin{tabular}{ccccc}
\hline $\begin{array}{c}\text { Ramal } \\
\text { Crítico }\end{array}$ & $\begin{array}{c}\text { Nó } \\
\text { Inicial* }\end{array}$ & $\begin{array}{c}\text { Nó } \\
\text { Final* }\end{array}$ & $\begin{array}{c}\text { Pares de } \\
\text { trens/dia** }\end{array}$ & $\begin{array}{c}\text { Frequência } \\
(\%)\end{array}$ \\
\hline $1-2$ & $\begin{array}{c}\text { km 210,9 } \\
\text { Graúna (ZOX) }\end{array}$ & $\begin{array}{c}\text { km 223,2 } \\
\text { Itirapina (ZIQ) }\end{array}$ & 11 & 69,3 \\
\hline $4-5$ & $\begin{array}{c}\text { km 173,3 } \\
\text { Barretos (ZBR) }\end{array}$ & $\begin{array}{c}\text { km 199,1 } \\
\text { Adolfo Pinto (ZWH) }\end{array}$ & 8 & 16,8 \\
\hline $2-3$ & $\begin{array}{c}\text { km 131,9 } \\
\text { Bauru (ZBU) }\end{array}$ & Garça (ZGR) & 5 & 13,9 \\
\hline \hline
\end{tabular}

* Relativo ao arco crítico no sentido Importação.

** No polo de concentração de cargas

Os resultados do modelo indicam que o arco que restringe o aumento da capacidade da rede em 69,3\% dessas combinações é, novamente, o situado entre o nó de Graúna e o terminal de Itirapina. Conforme esclarecido nas conclusões sobre os resultados do Cenário 5, o aumento da capacidade teórica desse arco requer intervenções na geometria da via, duplicação por exemplo, ou adoção de uma política de operação com locomotivas adicionais, hipóteses estas não incluídas no escopo desta investigação.

Desse modo, o arco que restringe a capacidade da rede sob as condições estabelecidas neste cenário é o situado entre os nós de Barretos e Adolfo Pinto, no km 173,3 e km199,1, respectivamente, no sentido Importação, no ramal entre os terminais de Araraquara e Colômbia, com 8 pares de trens diários no polo de concentração de cargas da rede, em 16,8\% das combinações dos Coeficientes de Proporcionalidade dos terminais com soma igual a $100 \%$.

A partir dos resultados obtidos no Cenário 13, foram executados procedimentos semelhantes para os ramais críticos identificados em cenários subsequentes. Entretanto, optou-se por 
apresentar um resumo sobre os resultados obtidos após execução do modelo de capacidade sobre a rede com as alterações dos limites de velocidade nos arcos críticos.

O detalhamento dos resultados da aplicação do modelo de capacidade até este cenário justifica-se por duas razões. A primeira está relacionada com a questão da geração dos dados relativos à geometria da via permanente (inclinações das rampas e raios das curvas), através do procedimento descrito no Apêndice $B$, que resultou na criação de um modelo virtual dos ramais 2-3 e 4-5, sem garantia de que os tempos de viagem obtidos pelo simulador TEM correspondam à realidade, como exposto naquele item.

A segunda relaciona-se com o fato de que as análises efetuadas até este cenário abrangem o corredor da rede com maior volume de circulação de cargas, como citado anteriormente, entre os terminais de Santa Fé do Sul e Mairinque, cujos dados sobre a geometria e limites operacionais de velocidade utilizados nas simulações correspondem aos parâmetros reais da via, ou seja, os arcos críticos apresentados são os que realmente necessitam de investimentos para aumento do número de trens diários no polo de concentração de cargas da rede.

\section{Cenários 14 a 22}

As caracterizações do Cenário 14 até o Cenário 22 são dadas pela alteração do limite de velocidade nos arcos críticos, com posterior execução das simulações para determinação dos tempos de viagem sem as restrições operacionais de velocidade e execução do modelo de capacidade, alternando-se os valores dos Coeficientes de Proporcionalidade dos terminais.

A Tabela 4.15 apresenta o ramal e o arco crítico dos cenários subsequentes ao Cenário 13, o número de pares de trens diários no polo de concentração de cargas (Terminal Mairinque) e a proporção de ocorrência de um arco crítico, cujas combinações dos Coeficientes de Proporcionalidade apresentam a segunda maior frequência de ocorrência, uma vez que a maior porcentagem nessas condições apresenta o arco crítico entre o nó de Graúna e o terminal de Itirapina.

Os resultados do Cenário 14 ao Cenário 17 indicam que os arcos críticos da rede situam-se no ramal entre os terminais de Araraquara e Colômbia, os quais foram identificados pela execução de procedimento análogo aos cenários anteriores.

A partir do Cenário 18 os arcos críticos identificados situam-se entre os terminais de Itirapina e Panorama. A alteração do limite de velocidade no arco crítico do Cenário 18 (Bauru-Garça) 
resulta no nó crítico entre os nós de Dracena e Marrequinhas (Cenário 19) como aquele que restringe o aumento da capacidade da rede.

A alteração do limite de velocidade no arco desse cenário e aplicação do modelo de capacidade resulta na recorrência do arco crítico entre os nós de Bauru e Garça (Cenário 20), como pode ser observada na Tabela 4.15. Apesar de neste trabalho não serem propostas soluções baseadas na alteração do traçado da via permanente, considerou-se a divisão do arco entre os nós de Bauru e Garça em dois segmentos de igual comprimento para verificação do efeito dessa intervenção sobre a capacidade do sistema.

A divisão do arco crítico identificado anteriormente resultou novamente no arco entre os nós de Dracena e Marrequinhas, observado nos resultados do Cenário 21. Para verificar o efeito da divisão de um arco em dois segmentos sobre a capacidade do sistema, esse arco também foi dividido ao meio, sendo obtidos os resultados do Cenário 22 após aplicação do modelo de capacidade.

A identificação do próximo arco crítico implica na divisão daquele identificado no Cenário 22 em dois arcos distintos. Entretanto, essa divisão pode ser realizada de inúmeras maneiras (não apenas em dois arcos de mesmo comprimento como no Cenário 20 e Cenário 21), influenciada, entre outros fatores, pela geometria da via, elementos existentes na faixa de domínio da ferrovia, e implica na realização de um estudo sobre a localização mais adequada dos nós nesses arcos, o que está fora do contexto da investigação proposta neste trabalho.

Foi constatado que a causa que estabelece a recorrência de um arco crítico é a expressiva diferença entre o comprimento deste em relação ao comprimento médio dos demais arcos da rede. Essa afirmação baseia-se no fato de que o tempo de viagem em um arco é diretamente proporcional ao comprimento entre os nós que o define, que por sua vez é o fator preponderante na definição do headway crítico de um ramal, dado que esse parâmetro é igual ao maior valor entre os de headways (soma do tempo de viagem no Sentido Exportação, no Sentido Importação e tempo de espera no nó). 
Tabela 4.15 - Resultados do modelo de capacidade nos cenários que abrangem os ramais AraraquaraColômbia (4-5) e Itirapina-Panorama (2-3).

\begin{tabular}{|c|c|c|c|c|c|}
\hline Cenário & $\begin{array}{l}\text { Ramal } \\
\text { Crítico }\end{array}$ & $\begin{array}{c}\text { Nó } \\
\text { Inicial* }\end{array}$ & $\begin{array}{c}\text { Nó } \\
\text { Final* }\end{array}$ & $\begin{array}{c}\text { Pares de } \\
\text { trens/dia*** }\end{array}$ & $\begin{array}{c}\text { Ocorrência } \\
(\%)\end{array}$ \\
\hline 14 & $4-5$ & $\begin{array}{l}\mathrm{km} 125,5 \\
\text { Bebedouro } \\
\text { (ZBD) }\end{array}$ & $\begin{array}{c}\mathrm{km} 151,5 \\
\text { Colina } \\
(\mathrm{ZCJ})\end{array}$ & 10 & 16,8 \\
\hline 15 & $4-5$ & $\begin{array}{c}\mathrm{km} 71,0 \\
\text { Barrinha } \\
(\mathrm{ZBH})\end{array}$ & $\begin{array}{c}\mathrm{km} \mathrm{90,2} \\
\text { Passagem } \\
\text { (ZPL) }\end{array}$ & 11 & 16,8 \\
\hline 16 & $4-5$ & $\begin{array}{l}\text { km 108,0 } \\
\text { Ibitiuva } \\
\text { (ZIB) }\end{array}$ & $\begin{array}{c}\mathrm{km} \mathrm{125,5} \\
\text { Bebedouro } \\
\text { (ZBD) }\end{array}$ & 11 & 16,8 \\
\hline 17 & $4-5$ & $\begin{array}{c}\mathrm{km} \mathrm{45,9} \\
\text { Guarani } \\
\text { (ZGK) }\end{array}$ & $\begin{array}{l}\mathrm{km} 58,5 \\
\text { Pradopolis } \\
\text { (ZXE) }\end{array}$ & 11 & 15,9 \\
\hline 18 & $2-3$ & $\begin{array}{c}\text { km 131,9 } \\
\text { Bauru } \\
(\mathrm{ZBU})\end{array}$ & $\begin{array}{c}\mathrm{km} 206,0 \\
\text { Garça } \\
\text { (ZGR) }\end{array}$ & 5 & 13,9 \\
\hline 19 & $2-3$ & $\begin{array}{c}\mathrm{km} \mathrm{396,1} \\
\text { Dracena } \\
(\mathrm{ZDN})\end{array}$ & $\begin{array}{c}\mathrm{km} \mathrm{448,2} \\
\text { Marrequinhas } \\
\text { (ZNQ) }\end{array}$ & 6 & 13,9 \\
\hline 20 & $2-3$ & $\begin{array}{c}\mathrm{km} 131,9 \\
\text { Bauru } \\
(\mathrm{ZBU})\end{array}$ & $\begin{array}{c}\mathrm{km} 206,0 \\
\text { Garça } \\
\text { (ZGR) }\end{array}$ & 7 & 13,9 \\
\hline 21 & $2-3$ & $\begin{array}{c}\mathrm{km} 396,1 \\
\text { Dracena } \\
(\mathrm{ZDN})\end{array}$ & $\begin{array}{c}\mathrm{km} 448,2 \\
\text { Marrequinhas } \\
\text { (ZNQ) }\end{array}$ & 7 & 13,9 \\
\hline 22 & $2-3$ & $\begin{array}{c}\text { km 169,0 } \\
\text { Intermediária }\end{array}$ & $\begin{array}{c}\mathrm{km} \mathrm{206,0} \\
\text { Garça } \\
\text { (ZGR) }\end{array}$ & 8 & 13,9 \\
\hline
\end{tabular}

* Relativo ao arco crítico no sentido Importação.

** No polo de concentração de cargas

Os arcos críticos identificados nos resultados do Cenário 1 ao Cenário 12 são apresentados na Figura 4.8, Figura 4.9 e Figura 4.10, referentes aos ramais "1-2", "2-4" e "4-6", respectivamente. 


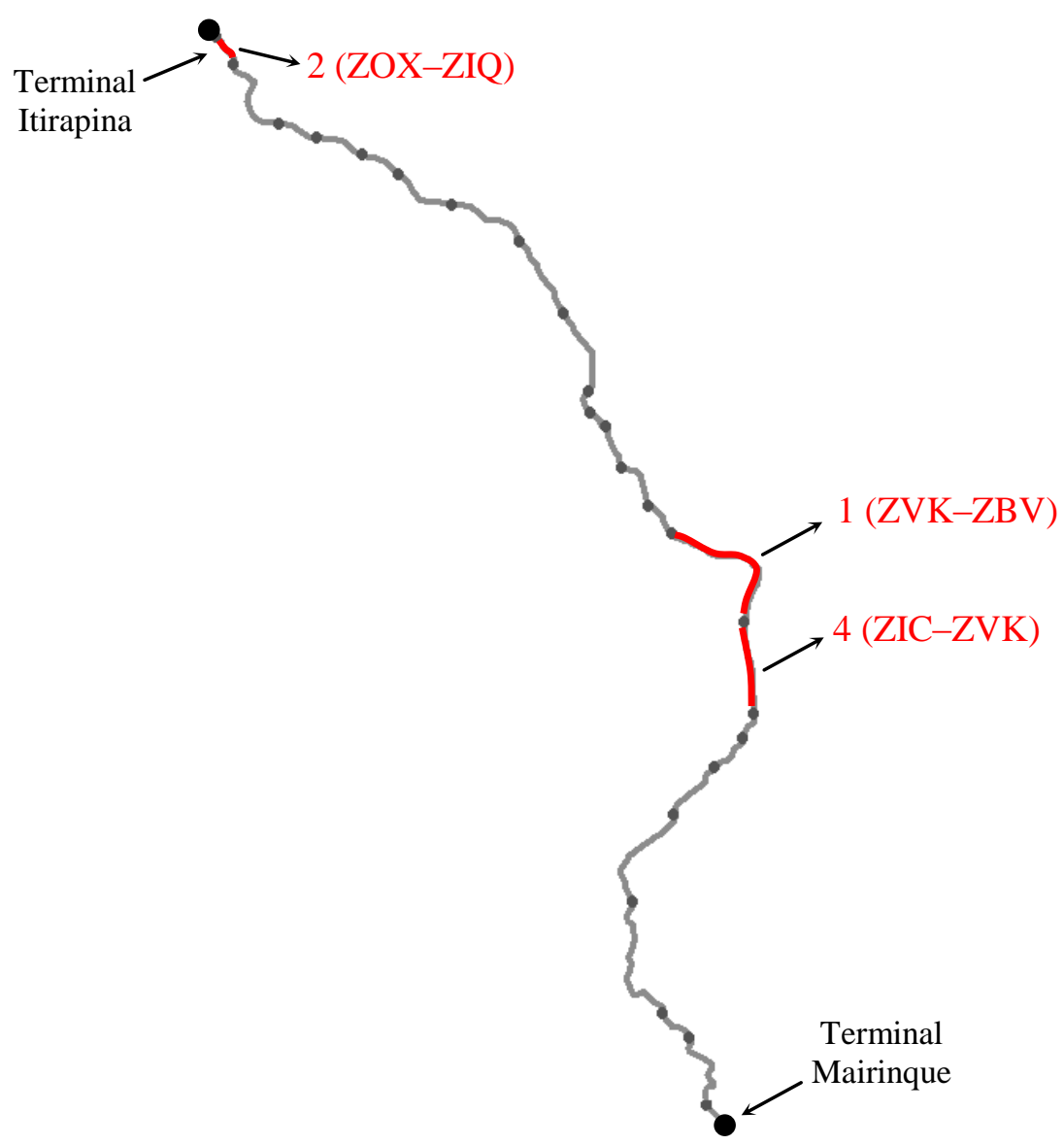

Figura 4.8 - Arcos críticos entre os terminais de Mairinque e Itirapina (1-2), nos cenários analisados.

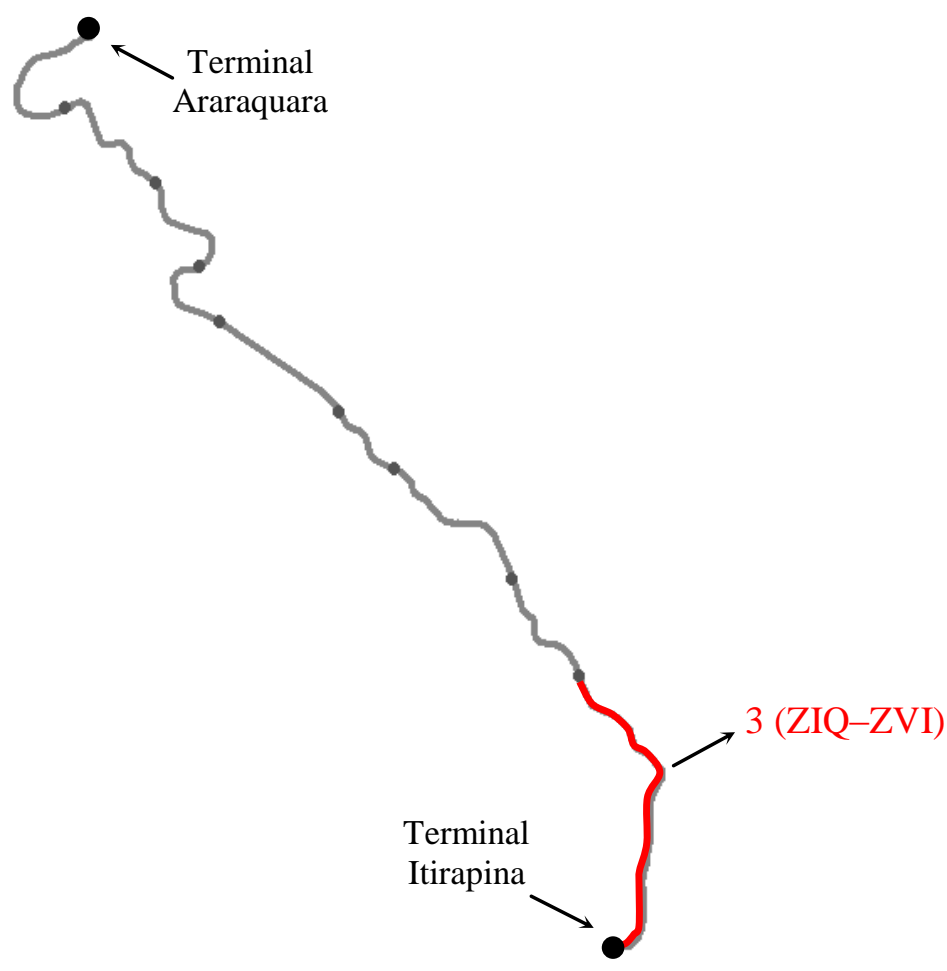

Figura 4.9 - Arcos críticos entre os terminais de Itirapina e Araraquara (2-4) nos cenários analisados. 


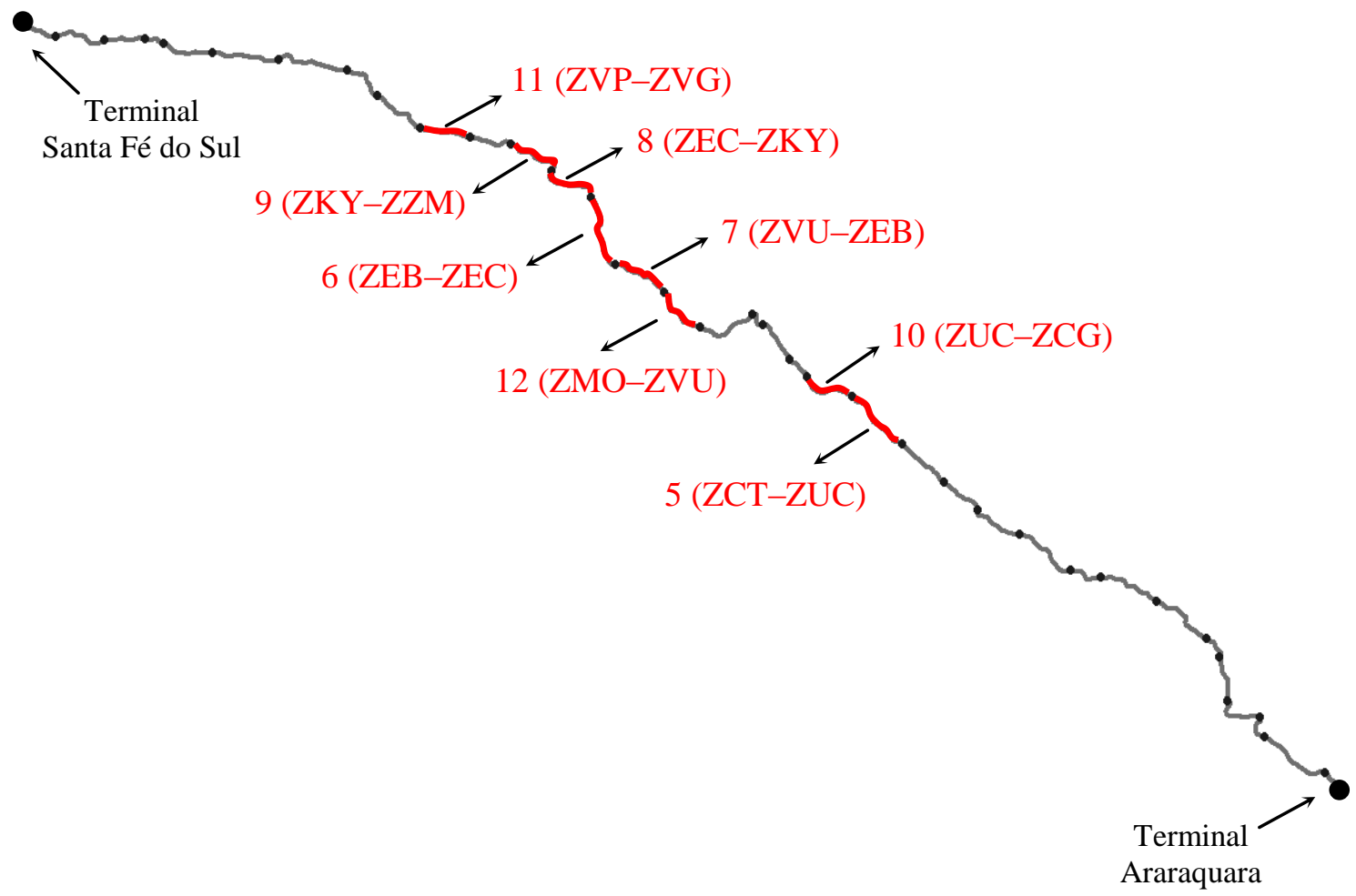

Figura 4.10 - Arcos críticos entre os terminais de Araraquara e Santa Fé do Sul (4-6), nos cenários analisados.

O gráfico da Figura 4.11 apresenta o número de pares de trens, por dia, que circulam nos ramais da rede em cada cenário analisado.

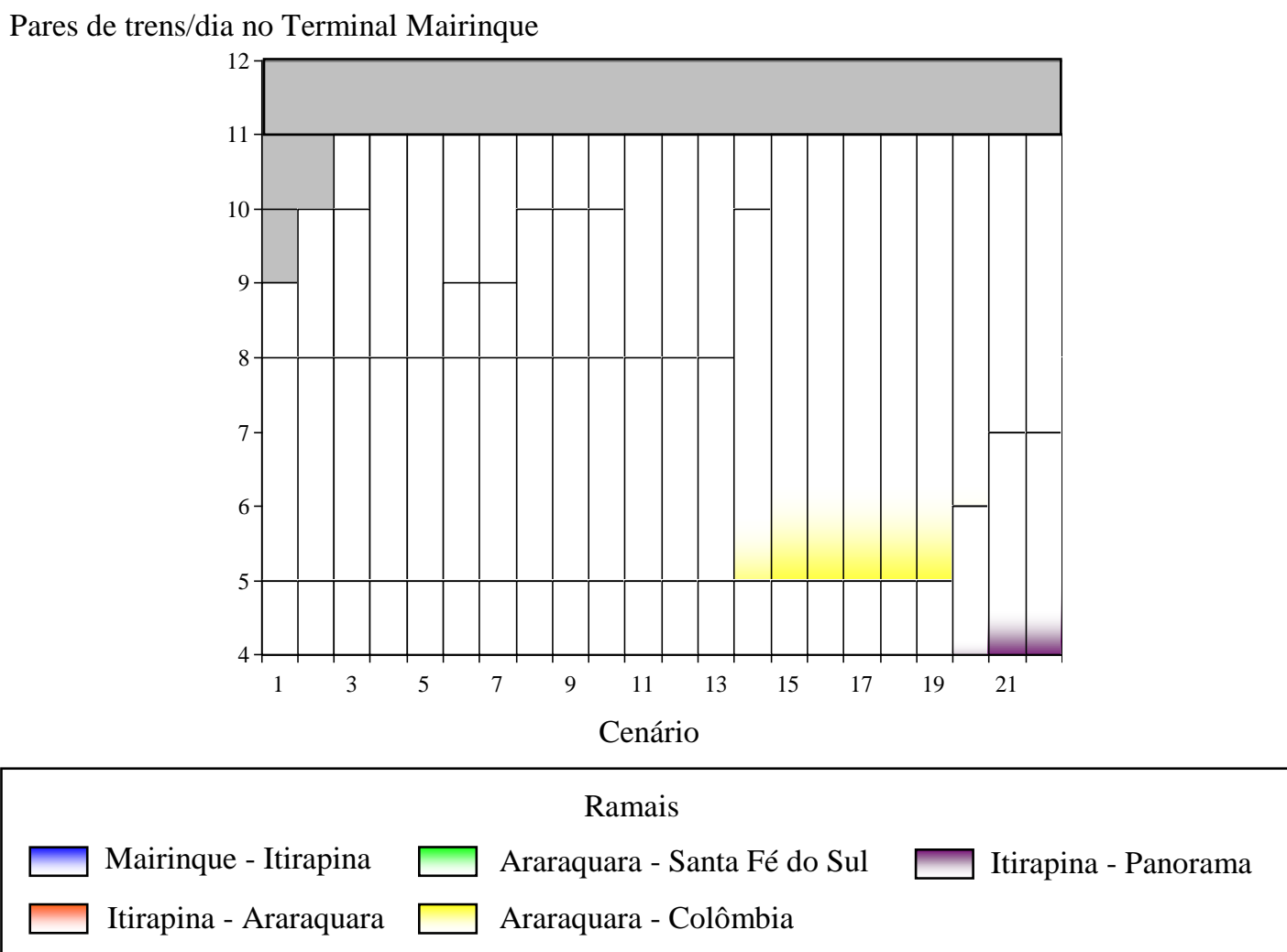

Figura 4.11 - Pares de trens diários no Terminal Mairinque, nos cenários analisados. 


\subsection{Considerações sobre a aplicação do modelo de capacidade}

Apesar da dificuldade de obtenção dos dados reais sobre os parâmetros relacionados com a geometria e limites de velocidade nos arcos dos ramais Itirapina-Panorama e AraraquaraColômbia, os resultados obtidos na aplicação do modelo são válidos em relação ao corredor de transporte entre os terminais de Santa Fé do Sul e Mairinque, apresentados entre o Cenário 1 e o Cenário 13, uma vez que utilizaram-se as restrições reais da via fornecidas pela diretoria da extinta Ferrovia Bandeirantes S.A. (Ferroban) por ocasião da pesquisa de Batista (2006).

Nos resultados dos demais cenários caracterizados não há garantia de que os arcos críticos identificados correspondam à situação real quanto às restrições de capacidade dos trens, uma vez que os tempos de viagem nos arcos entre os terminais de Panorama-Itirapina e ColômbiaAraraquara foram obtidos através de um método de inferência estatística que fornece valores aproximados desse parâmetro de entrada do modelo de capacidade (ver Apêndice B).

O recurso de construir um cenário virtual para esses ramais da rede ferroviária foi devido à impossibilidade de obter os dados reais que caracterizam os arcos, tanto por parte da concessionária ALL (informação verbal) ${ }^{2}$ quanto de órgãos públicos como a ANTT (informação pessoal) $)^{3}$.

Além de conhecer os arcos que restringem o aumento da capacidade de circulação de trens no sistema considerado, constatou-se que as inclinações das rampas exercem maior influência sobre a velocidade média dos trens nos arcos do que os raios das curvas, como pode ser observado nos resultados apresentados na Tabela B.2 do Apêndice B, e confirmados na análise do Cenário 5.

Isso pode ser justificado pela observação da variação do grau da curva em cada ponto do trecho entre os terminais de Mairinque e Santa Fé do Sul, ilustrado no gráfico da Figura 4.12. Nele é possível observar que no arco entre o nó de Graúna e o terminal de Itirapina (arco crítico identificado no Cenário 5) esse parâmetro apresenta variações menos expressivas que nos arcos não identificados como restritivo ao movimento dos trens na rede (entre o $\mathrm{km} 500 \mathrm{e}$

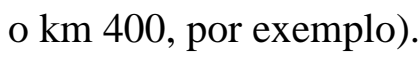

\footnotetext{
${ }^{2}$ Informação fornecida por ALL S.A. através de contato telefônico em São Carlos, em 2009.

3 Mensagem recebida por cassiano.isler@usp.brem 17 abr. 2009
} 


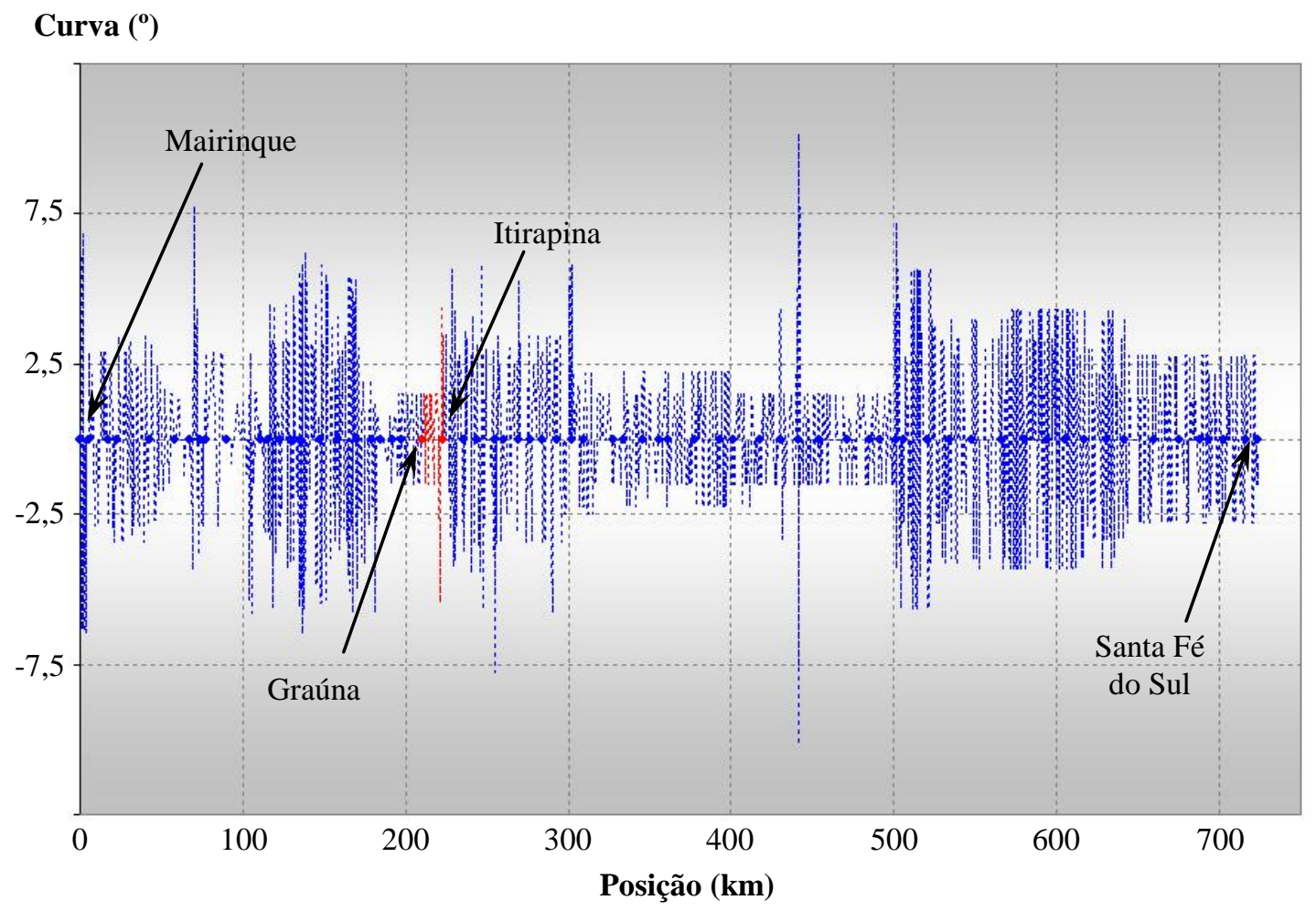

Figura 4.12 - Raios das curvas nos pontos entre os terminais de Mairinque e Santa Fé do Sul.

Na prática, o operador do sistema poderia aumentar a capacidade de tração dos trens no arco crítico do Cenário 5, para redução dos tempos médios de viagem. Entretanto, a aplicação desse procedimento, sobre as análises propostas neste trabalho, afeta diretamente a premissa que diz respeito à utilização de um mesmo trem-tipo circulando nos ramais da rede, que viabiliza a identificação do arco que necessita de reparos nas condições de conservação da superestrutura ferroviária, independentemente da configuração do trem-tipo. 


\section{Capítulo 5}

\section{CONSIDERAÇÕES FINAIS}

Neste capítulo é apresentada uma análise sobre o desempenho do modelo de capacidade elaborado e do método de caracterização da via permanente. Também são apresentadas as conclusões sobre os resultados da aplicação do modelo, sugeridas possíveis alterações no seu algoritmo e apresentadas propostas para trabalhos futuros.

\subsection{Conclusões}

Este trabalho cumpre com o objetivo de contribuir para o estudo sobre a capacidade instalada das linhas ferroviárias singelas no Brasil, com a configuração específica de redes enraizadas não-direcionadas, recorrentes no sistema ferroviário do país.

O modelo apresentado permite identificar as causas que impedem o aumento da velocidade dos trens nos arcos - limites operacionais de velocidade ou características geométricas - que têm relação direta com a capacidade de processamento de trens na rede, e definir os arcos prioritários que necessitam de investimentos para melhoria do desempenho do sistema.

Apesar das limitações encontradas na obtenção dos dados para a aplicação prática, o modelo proposto apresentou resultados consistentes com as informações obtidas em investigações anteriores em relação ao eixo principal da rede abordada no capítulo anterior.

Esse argumento tem por base a verificação de que os resultados sobre os arcos que restringem a capacidade de processamento de trens, no ramal entre os terminais de Santa Fé do Sul e Araraquara, foram iguais aos obtidos por Batista (2006).

Com isso, fica disponibilizada uma ferramenta de apoio à tomada de decisões com horizonte de planejamento de longo prazo (estratégico), capaz de identificar os gargalos de uma rede com as características específicas apresentadas nos capítulos precedentes.

A necessidade de validação do modelo e a dificuldade de obtenção dos dados sobre as características geométricas e os limites de velocidade em dois ramais da rede apresentada no Capítulo 4 foram os fatores determinantes para a elaboração do modelo de caracterização da 
via permanente, apresentado no Apêndice B. Esse método de inferência de dados sobre a via permanente viabiliza a utilização de um simulador de desempenho de trens, que tem como resultado valores pseudo-realistas dos tempos de viagem entre os nós dos ramais da rede ferroviária, os quais, por sua vez, são utilizados como dados de entrada do modelo de capacidade proposto nesta pesquisa.

Entretanto, esse método de caracterização da via permanente apresenta restrições de aplicação prática dos resultados devido à impossibilidade de identificação dos arcos com limites de velocidade reais, dados pela condição de conservação da superestrutura ferroviária e pela imprecisão na obtenção das altitudes dos pontos que determinam o traçado da via para cálculo das rampas, nesses locais.

Em relação aos resultados da aplicação do modelo de capacidade à rede existente no Estado de São Paulo, é possível afirmar que as restrições de capacidade nos arcos estão associadas, em geral, às condições de conservação da superestrutura ferroviária, que determinam a velocidade máxima que pode ser praticada pelos trens nos arcos.

Sob essas condições, a redução dos tempos médios de viagem em 12 dos 66 arcos da malha ferroviária, pela melhoria das condições de conservação da superestrutura ferroviária, resulta em um aumento de 37,5 \% no número de trens no polo de concentração de cargas da rede - de 8 para 11 trens diários no terminal Mairinque, em 69,3\% das combinações dos Coeficientes de Proporcionalidade dos terminais.

O modelo mostra claramente que a restrição de velocidade imposta aos trens no arco entre o nó de Graúna e o terminal de Itirapina é devido à configuração geométrica da via permanente, definido pelas rampas e raios das curvas horizontais, em detrimento dos limites operacionais de velocidade, dados pela condição de conservação da superestrutura ferroviária e demais elementos existentes no arco (pontes, viadutos, passagens em nível etc.).

Mesmo não tendo sido realizados estudos econômicos sobre o custo de manutenção desses arcos, melhoria do lastro, troca de trilhos desgastados etc., o modelo de capacidade mostra-se útil por permitir a identificação dos arcos que necessitam de prioridade de investimentos para aumento da produtividade do sistema.

\subsection{Sugestões para trabalhos futuros}

A seguir, são apresentadas possíveis melhorias que podem ser aplicadas ao algoritmo do 
modelo de capacidade de processamento de trens na rede ferroviária em linha singela e sugestões de estudos posteriores, que podem ser realizados com o uso dessa ferramenta.

O modelo de capacidade pode ser complementado através da atribuição de prioridades aos trens, segundo os seus terminais de origem no sentido Exportação, uma vez que existem locais de geração de trens com cargas de maior relevância no sistema e cuja chegada no destino (polo de concentração de cargas) apresenta maiores vantagens em relação às demais composições ferroviárias.

Essas prioridades podem ser utilizadas para definir o padrão de ordenação da sequência de chegada dos trens no polo de concentração de cargas da rede definida no MÓDULO 4, no Capítulo 3 deste texto.

Além desse método de definição de prioridades, podem ser testadas outras formas de ordenação da chegada dos trens ao terminal de concentração de cargas, para que seja verificada a possibilidade de existência de uma sequência diferente da utilizada neste trabalho (ordem crescente dos índices dos terminais de origem no sentido Exportação), o que pode levar a diferentes resultados de capacidade em relação aos obtidos atualmente.

O modelo de capacidade proposto pode, ainda, ser complementado considerando-se a existência de seções de bloqueio nos arcos, que permitem a inserção de trens consecutivos em um mesmo arco separados por um intervalo de tempo menor que o headway crítico global e, consequentemente, afetam a capacidade do sistema.

Como proposta para um futuro trabalho, sugere-se a execução do modelo de capacidade com inserção dos tempos de viagem nos arcos obtidos através de simulações que considerem a geometria da via permanente e limites de velocidade reais nos ramais de Panorama-Itirapina e Colômbia-Araraquara.

Os resultados provenientes dessa análise permitiriam a comparação com os apresentados neste trabalho, em relação aos arcos críticos identificados e ao número de trens que circulam nos ramais em cada cenário estabelecido. Seria possível, ainda, comparar o desempenho do modelo de caracterização da via permanente do Apêndice B em relação aos tempos de viagem dos trens nos arcos e como as aproximações desse modelo afetam a capacidade do sistema.

O modelo pode ainda ser aplicado a outras redes ferroviárias existentes no Brasil, para verificação de sua validade e análise dos resultados em relação ao número de trens que 
circulam nos seus ramais e aos arcos críticos que necessitam de investimentos para redução das restrições de velocidade.

Apesar de este trabalho apresentar a análise da capacidade de uma rede ferroviária enraizada não direcionada, constatou-se a possibilidade de aplicação do modelo em uma rede fechada, para verificação dos ramais com menor restrição quanto ao número de trens no sistema. Isso pode ser realizado através da divisão da rede fechada em diversas redes ramificadas e posterior aplicação do modelo de capacidade sobre cada uma delas, segundo as suas premissas, como ilustrado na rede hipotética da Figura 5.1.

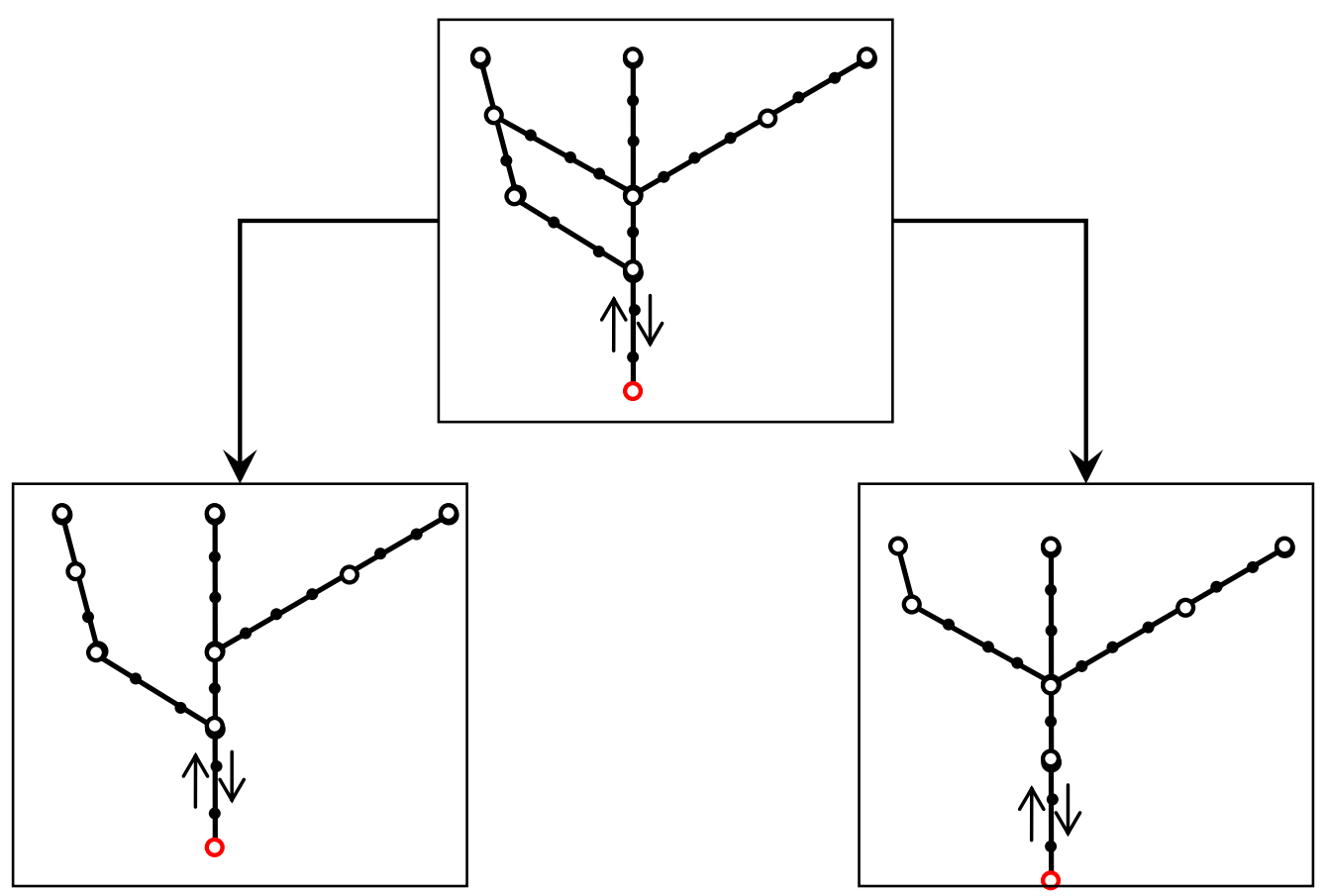

Figura 5.1 - Rede ferroviária (multigrafo) desmembrada em redes enraizadas não direcionadas.

Ainda em relação à aplicação dos modelos em ouros tipos de redes ferroviárias, podem ser ser abordadas as redes que possuem arcos ou ramais em linha dupla, reduzindo esses trechos a terminais, uma vez que apresentam as mesmas características que esses dispostivos, como capacidade ilimitada de processamento de cargas.

Estudos podem ainda ser realizados para análise das consequências das alterações sobre o traçado da via permanente e avaliação da viabilidade de implantação de novos ramais. Esses trabalhos podem incluir análises de custos de manutenção em relação à capacidade de processamento, para compará-los com os custos de construção de novos ramais e sua capacidade, o que permite a identifcação da relação "custo x benefício" entre a implantação de novos trechos e a manutenção dos existentes. 


\section{REFERÊNCIAS BIBLIOGRÁFICAS}

ABRIL, M. et al. A heuristic technique for the capacity assessment of periodic trains. Frontiers in Artificial Intelligence and Applications, v. 131 , p. 339-346, 2005.

ABRIL, M. et al. An assessment of railway capacity. Transportation Research Part E, v. 44, p. 774-806, 2008.

AHUJA, R.K.; MAGNANTI, T.L.; ORLIN, J. B. Network Flows: Theory, Algorithms, and Applications. 1st edition. New Jersey: Prentice-Hall, 1993. 864 p.

ALL - AMÉRICA LATINA LOGÍTICA S.A. Disponível em <http://www.alllogistica.com.br>. Acesso em: 16 set. 2008.

AMERICAN RAILWAY ENGINEERING AND MAINTENACE-OF-WAY ASSOCIATION. Disponível em <http://www.arema.org/>. Acesso em: 18 jul. 2008.

ASSAD, A. A. Models for rail transportation. Transportation Research Part A, v. 14, p. 205-220, 1980.

ASSOCIAÇÃO NACIONAL DE TRANSPORTES TERRESTRES. Disponível em <http://www.antt.gov.br>. Acesso em: 14 jun. 2008.

Publicação eletrônica [mensagem pessoal]. Mensagem recebida por <cassaino.isler@sc.usp.br> em 13 abr. 2009.

ASSOCIAÇÃO NACIONAL DOS TRANSPORTADORES FERROVIÁRIOS. Disponível em <http://www.antf.org.br>. Acesso em: 19 jun. 2008.

BARBER, F. et al. A decision support system for railway timetabling (MOM): the Spanish case. In: Computers in Railways X: Computer System Design and Operation in the Railway and Other Transit Systems, Prague, 2006. Proceedings of 10th International Conference on Computers in Railways. Prague: 2006. p. 235-244.

BARBER, F. et al. An interactive train scheduling tool for solving and plotting running maps. In: 10th Conference of the Spanish Association for Artificial Intelligence, San Sebastian, 
Spain, 2003. Proceedings of 10th Conference of the Spanish Association for Artificial Intelligence. San Sebastian, Spain: 2003. p. 646-655.

BARBER, F. et al. Survey of automated Systems for Railway Management. Valencia: Technical University, 2007. 65 p.

BATISTA, C.N.O. Contribuição à análise da capacidade de processamento de trens cargueiros em linhas ferroviárias singelas no Brasil. Dissertação (Mestrando em Engenharia Civil) - Escola de Engenharia de São Carlos, Universidade de São Paulo, São Carlos, 2006.

BAZARAA, M. S.; JARVIS, J. J.; SHERALI, H. D. Linear Programming and network flows. 2nd. Ed. New York: John Wiley \& Sons, 1990. 684 p.

BRINA, H. L. Estradas de ferro. Rio de Janeiro: LTC - Livros Técnicos e Científicos Editora S.A., 1979. v. 1: Via permanente. 276 p.

BRINA, H. L. Estradas de ferro. Rio de Janeiro: LTC - Livros Técnicos e Científicos Editora S.A., 1982. v. 2: Operação. 232 p.

CAPRARA, A.; FISCHETTI, M.; TOTH, P. Modeling and solving the train timetabling problem. Operations Research, v. 50, n. 5, p. 851-861, 2002.

CONFEDERAÇÃO NACIONAL DO TRANSPORTE, CNT. Pesquisa Ferroviária CNT 2006. Brasília, DF, 2007.

DRISH, W.F. Train Energy Model version 2.0 user's manual (version 2.5 supplement): AAR Report SD-39 Supp. Chicago: AAR Research and Test Department - Technical Center, 1992. $137 \mathrm{p}$.

HAY, W.W. Railroad Engineering. 2nd edition. New York : John Wiley, 1982. 784 p.

HIGGINS, A.; KOZAN, E.; FERREIRA, L. Heuristic techniques for single line train scheduling. Journal of Heuristics, v. 3, p. 43-62, 1997.

HIGGINS, A.; KOZAN, E.; FERREIRA, L. Optimal scheduling of trains on a single line track. Transportation Research Part B, v. 30, p. 147-161, 1996. 
JANIC, M. A practical capacity model of a single track line. Transportation Planning and Technology, v. 12, p. 301-318, 1988.

JANIC, M. Single track line capacity model. Transportation Planning and Technology, v. 9, p. 135-151, 1984.

JELEN, B.; SYRSTAD, T. (2004). Macros e VBA para Microsoft Excel. 1.ed. Rio de Janeiro: Elsevier, 2004. 576 p.

JOVANOVIC, D.; HARKER, P. Tactical scheduling of rail operations: the SCAN I system. Transportation Science, v. 25, p. 46-64, 1991.

KOZAN, E.; BURDETT, R. A railway capacity determination model and rail access charging methodologies. Transportation Planning and Technology, v. 28, p. 27-45, 2005.

KOZAN, E.; BURDETT, R. L. Techniques for absolute capacity determination in railways. Transportation Research Part B, v. 40, p. 616-632, 2006.

KRUEGER et al. Simulation within the railroad environment. In: 2000 Winter Simulation Conference, 2000, Orlando, FL. Proceedings of 2000 Winter Simulation Conference. Orlando, FL: 2000. p. 1191-1200. Disponível em: < http://www.informssim.org/wsc00papers/161.PDF >. Acesso em: 04 fev. 2009.

KRUEGER, H. Parametric modeling in rail capacity planning. In: 1999 Winter Simulation Conference, 1999, Phoenix (AR). Proceedings of 1999 Winter Simulation Conference. Phoenix: 1999, p. 1194-1200. Disponível em: <http://www.informssim.org/wsc99papers/173.PDF>. Acesso em: 10 mar. 2009.

KWON, O.K.; MARTLAND, C.D.; SUSSMAN, J. M. Routing and scheduling temporal and heterogeneous freight car traffic on rail networks. Transportation Research Part E, v. 34, p. 101-115, 1998.

LACERDA, S.M. Logística Ferroviária do Porto de Santos: a integração operacional da infraestrutura compartilhada. Revista do BNDES, Rio de Janeiro, v.12, n. 24, p. 189-210, 2005.

LEILICH, R. H. Application of simulation models in capacity constrained rail corridors. In: 1998 Winter Simulation Conference, 1998, Washington, DC. Proceedings of 1998 Winter Simulation Conference. Washington: 1998. p. 1125-1133. Disponível em: < http://www.informs-sim.org/wsc98papers/153.PDF >. Acesso em: 17 fev. 2009. 
LEWELLEN, M.; TUMAY, K. Network simulation of a major railroad. In: 1998 Winter Simulation Conference, 1998, Washington, DC. Proceedings of 1998 Winter Simulation Conference. Washington: 1998. p. 1135-1138. Disponível em: < http://www.informssim.org/wsc98papers/154.PDF >. Acesso em: 17 fev. 2009.

LIU, S.O.; KOZAN, E. Scheduling trains as a blocking parallel-machine job-shop scheduling problem. Computers and Operations Research, v. 36, p. 2840-2852, 2009.

MARTIN, P. Train performance and simulation. In: 1999 Winter Simulation Conference, 1999, Phoenix (USA). Proceedings of 1999 Winter Simulation Conference. Phoenix, AZ: 1999. p. 1287-1294. Disponível em: < http://www.informs-sim.org/wsc99papers/173.PDF>. Acesso em: 18 mar. 2009.

MARTINS, R.S.; CAIXETA FILHO, J.V. O desenvolvimento dos Sistemas de Transporte: Auge, Abandono e Reativação Recente das Ferrovias. Teoria de Evidência Econômica, Passo Fundo, v. 06, n. 11, p. 67-89, 1998.

MIDDELKOOP, D.; BOUWMAN, M. SIMONE: Large scale train networks simulations. In: 2001 Winter Simulation Conference, 2001, San Diego, CA. Proceedings of 2001 Winter Simulation Conference. San Diego, CA: 2001. p. 1042-1047. Disponível em: < http://www.informs-sim.org/wsc01papers/140.PDF >. Acesso em: 17 fev. 2009.

MORLOK, E.K. Introduction to Transportation Engineering and Planning. 1st edition. New York: McGraw-Hill, 1978. 767 p.

NATIONAL AERONAUTICS AND SPACE ADMINISTRATION. Disponível em <http://www.nasa.gov/>. Acesso em: 21 mai. 2009.

NIJKAMP, P; VLEUGEL, J. M.; E. KREUTZBERGER. An assessment of capacity in infrastructure networks: a multidimensional view. Transportation Planning and Technology, v. 17, p. 301-310, 1993.

PATER, A.J.G; TEUNISSE, M.J.G. The use of template-based methodology on the simulation of a new cargo track from Rotterdan Harbor to Germany. In: 1997 Winter Simulation Conference, 1997, Atlanta, GA. Proceedings of 1997 Winter Simulation Conference. Atlanta: 1997. p. 1176-1180. Disponível em: < http://www.informssim.org/wsc97papers/1176.PDF>. Acesso em: 27 jan. 2009.

PETERSEN, E. R.; TAYLOR, A. J. A structured model for rail line simulation and optimization. Transportation Science, v. 16, p. 192-206, 1982. 
RANGARAJ, N. et al. Simulator for railway line capacity planning. In: 1997 Winter Simulation Conference, 1997, Atlanta, GA. Proceedings of the Asia-Pacific Operational Research Society (APORS) 2003. New Delhi, India: 2003.

RUMBAUGH, J.; BLAHA, M. Modelagem e projetos baseados em objetos. 1.ed. Rio de Janeiro: Campus, 1994. 576 p.

SALIDO, M. A. et al. A Topological model based on railway capacity to manage periodic train scheduling. In: Applications and Innovations in Intelligent Systems, Cambridge, 2004 Proceedings of AI-2004 - The Twenty-fourth SGAI International Conference on Innovative Techniques and Applications of Artificial Intelligence. Cambridge: 2004. p.107-120.

SCHOPPA, R. F. 150 anos do trem no Brasil. Rio de Janeiro, RJ: Ed. Autor, 2004. 196 p.

STEFANI, C.R.B. O sistema ferroviário paulista: um estudo sobre a evolução do transporte de passageiros sobre trilhos. Dissertação (Mestrando em Ciências) - Faculdade de Filosofia, Letras e Ciências Humanas, Universidade de São Paulo, São Paulo, 2007.

SZWARCFITER, J. L. Grafos e algoritmos computacionais. Rio de Janeiro: Campus, 1984. $216 \mathrm{p}$.

TEIXEIRA, K. M. Investigação de opções de transporte de carga geral em contêineres nas conexões com a região amazônica. Tese (Doutorado em Engenharia Civil) - Escola de Engenharia de São Carlos, Universidade de São Paulo, São Carlos, 2007.

. Publicação eletrônica [mensagem pessoal]. Mensagem recebida por <cassiano.isler@usp.br> em 26 jun. 2009.

VIANNA, G. O mito do rodoviarismo brasileiro. São Paulo: Ed. NTC \& Logística, 2007. $64 \mathrm{p}$. 


\section{BIBLIOGRAFIA COMPLEMENTAR}

ASSAD, A. A. A class of train-scheduling problems. Transportation Science, v. 16, n.3, p. 281-310, 1982.

CAI, X.; GOH, C.J. A fast heuristic for the train scheduling problem. Computers and Operations Research, v.21, n.5, p. 499-510, 1994.

CAREY, M. Optimizing scheduled times, allowing for behavioural response. Transportation Research Part B, v. 32, n. 5, p. 329-342, 1998.

CAREY, M.; LOCKWOOD, D. A model, algorithms and strategy for train pathing. Journal of the Operational Research Society, v.46, p. 988-1005, 1995.

CRAINIC, T.G.; FERLAND, J.; ROUSSEAU, J. A tactical planning model for rail freight transportation. Transportation Science, v. 16, n.2, p. 165-184, 1984.

CRAINIC, T.G.; FLORIAN, M.; LEAL, J. E. A model for the strategic planning of national freight transportation by rail. Transportation Science, v. 24, n.1, p. 1-23, 1990.

HIGGINS, A.; KOZAN, E. R.; FERREIRA, L. Modelling delay risks associated with train schedules. Transportation Planning and Technology, v. 19, p. 89-108, 1995.

KRAFT, E.R. Jam capacity of single track rail lines. Transportation Research Forum Proceedings, v.3, n.1, p. 461-471, 1983.

LEAL, J.E.; SOARES, A.C.; NUNES, L.S.N. Uma Abordagem Heurística para o Problema de programa de Trens em Linhas Singelas. In: XVIII CONGRESSO DE PESQUISA E ENSINO EM TRANSPORTES, 2004, Florianópolis, SC. Anais do XVIII Congresso de Pesquisa e Ensino em Transportes. Florianópolis: 2004, v.2. p.945-956.

PETERSEN, E. R. Over-the-road transit time for a single track railway. Transportation Science, v. 8, n.1, p. 65-74, 1974.

RAMOS, G.M. Análise prospectiva da capacidade de processamento de cargas pela ferrovia no Porto de Santos. Dissertação (Mestrado em Engenharia Civil) - Escola de Engenharia de São Carlos, Universidade de São Paulo, São Carlos, 2003. 
SAAD, J.A.C. Modelo para análise da operação de trechos ferroviários em linha singela. Dissertação (Mestrado em Engenharia Civil) - Escola de Engenharia de São Carlos, Universidade de São Paulo, São Carlos, 1999. 


\section{GLOSSÁRIO}

Algoritmo - conjunto de instruções ordenadas para execução de uma ação qualquer ou de um problema matemático. Em informática, é codificado explicitamente por meio de um conjunto de instruções de programação que manipulam dados.

Algoritmo branch-and-bound (Branch-and-Bound Algorithm ) - algoritmo genérico, que enumera sistematicamente todos os valores candidatos à solução de um problema, sendo uma grande quantidade desses candidatos descartada pela aplicação de limites superiores e inferiores para a variável que está sendo otimizada.

Algoritmo de Busca Global (Global Search Algoritm) - algoritmo empregado em métodos de otimização, onde todo o conjunto de valores possíveis para a solução do problema é analisado até que se encontre o valor ótimo, isto é, até que seja atingido um tempo de processamento pré-definido. Os problemas que envolvem algoritmos de busca global são mais complexos que os de busca local e alguns deles são impossíveis de serem resolvidos na prática.

Algoritmo de Busca Local (Local Search Algoritm) - algoritmo empregado em métodos de otimização, em que um conjunto de valores candidatos à solução do problema é analisado até que um valor ótimo seja encontrado ou atingido um tempo de processamento pré-definido.

Algoritmo de Busca Tabu (Tabu Search Algorithm) - método matemático de otimização, pertencente à classe de heurísticas de busca local, que funciona da seguinte maneira: a partir do momento em que o algoritmo identifica uma solução para o problema, esta é marcada como um "tabu”, de modo que esta solução não é analisada repetidas vezes.

Algoritmo Genético (Genetic Algorithm) - é uma classe particular dos algoritmos evolutivos, que utiliza técnicas baseadas na biologia evolutiva (mutação, crossover, seleção, herança), utilizada em computação para identificar soluções exatas ou aproximadas para problemas de otimização, sendo associada à categoria das heurísticas de busca global.

Algoritmo Híbrido (Hybrid Algorithm) - é resultado da aplicação de dois métodos distintos para solução de problemas de otimização, segundo restrições pré-estabelecidas, sendo exploradas as propriedades de ambos para determinação das respostas aos problemas 
propostos.

Bitola - distância entre trilhos, medida entre boletos de uma linha férrea, de 12 a $15 \mathrm{~mm}$.

Boleto - parte superior do trilho, sobre a qual deslizam as rodas dos veículos ferroviários.

Carga fracionada - carga embarcada em embalagens convencionais (ex.: caixas ou paletes), isto é, não conteinerizada.

Flow-shop scheduling - problema de otimização (geralmente no ambiente de manufatura), aplicado à ciência da computação, no qual um conjunto de processos pré-definidos para uma entidade são ordenados em uma sequência, de modo a otimizar uma medida de desempenho (espera total, makespan etc.).

Galão - unidade de volume referente ao sistema inglês de unidades (equivalente a aproximadamente 4,55 litros).

Granel líquido - todo líquido transportado sem embalagem e em grandes quantidades (ex: álcool, gasolina, suco de laranja, melaço etc.).

Granel sólido - todo sólido fragmentado ou grão vegetal transportado sem embalagem e em grandes quantidades (ex. soja, carvão, sal, trigo em grão, minério de ferro etc.).

Heurística (ou método heurístico) - método utilizado para determinação rápida de uma solução de um problema específico, próxima da melhor solução possível (ou "solução ótima").

Job-shop scheduling - problema de otimização (geralmente no ambiente de manufatura), aplicado à ciência da computação, em que os processos são ordenados de modo a otimizar uma medida de desempenho (espera total, makespan etc.), sem necessidade das entidades passarem por todos os processos.

Lastro - parte da superestrutura ferroviária que distribui na plataforma, uniformemente, os esforços transmitidos pelos trilhos através dos dormentes, oferecendo elasticidade à via, redução de impactos e adequada drenagem.

Linha singela - plataforma ferroviária com apenas uma linha férrea, que permite a circulação de trens em sentidos opostos. 
Makespan - termo empregado no ambiente de manufatura para designar a diferença de tempo entre o início e o final de uma sequência de processos.

Modelo determinístico - modelo matemático em que os resultados são precisamente determinados através de relações conhecidas entre as variáveis envolvidas, cujos valores prováveis são estimados em detrimento das variações aleatórias que podem apresentar.

Modelo estocástico - modelo matemático que utiliza um intervalo para representar o valor de uma variável, expresso sob forma de funções de distribuição de probabilidade.

Pátio - área para circulação e estacionmento de veículos, carregamento e descarregamento de produtos.

Pátio de classificação - área destinada à classificação dos vagões, quanto ao tipo de carga e destino, para formação dos trens.

Pátio de cruzamento - local onde são dispostas diversas linhas férreas paralelas, destinadas ao cruzamento de trens que circulam em diferentes sentidos no sistema.

Pátio de manobra - local onde são dispostas diversas linhas férreas paralelas, destinadas à manobra dos trens, vagões, locomotivas etc.

Pátio de triagem - área destinada à definição dos horários de partida dos trens, segundo as prioridades de chegada nos destinos e tipo de carga transportada.

Pesquisa operacional - estudo matemático de sistemas com o objetivo de otimização de funções, dadas certas restrições, com vistas a instruir a tomada de decisões, em contraposição a métodos empíricos.

Programação linear - envolve problemas de otimização (maximização/minimização), nos quais a função objetivo e as restrições são expressas na forma de equações lineares.

Programação linear inteira - envolve problemas de programação linear em que as variáveis envolvidas devem, necessariamente, assumir valores inteiros.

Programação linear inteira mista - envolve problemas de programação linear em que algumas variáveis devem, necessariamente, assumir valores inteiros e a outras podem ser atribuídos valores inteiros ou não inteiros. 
Relaxação Lagrangiana - método utilizado na solução de problemas de otimização, em que, para redução do tempo de processamento computacional as restrições utilizadas no delineamento do modelo são simplificadas.

Simulação a eventos discretos - termo empregado quando o tempo de simulação é descontínuo. Por exemplo, suponha que um evento $e_{a}$ ocorreu no instante $t_{a}$ do tempo simulado e foi sucedido pelo evento $e_{b}$ no instante $t_{b}$. Se não ocorreu nenhum evento de interesse entre $e_{a}$ e $e_{b}$, então o tempo simulado passou de $t_{a}$ diretamente para $t_{b}$.

Superestrutura - parte superior da estrutra da via férrea, que suporta diretamente os esforços dos veículos e os transmite à infraestrutura, constituída pelos trilhos e dormentes.

Teoria de filas - conjunto de regras de definições empregadas no estudo da formação e dissipação de filas, através de suas propriedades mensuráveis e de análises matemáticas. Provê modelos para demonstrar o comportamento de um sistema cuja demanda é variável e dimensioná-lo, de modo a satisfazer os clientes e ser viável economicamente para o provedor do serviço.

Terceiro trilho - trilho paralelo à via férrea, que viabiliza a circulação de trens com bitolas diferentes em um mesmo arco.

Topologia - representação das características de um terreno com a descrição minuciosa da localidade, incluindo seu relevo (o mesmo que topografia).

Trem periódico - trem de carga com origem e destino pré-definidos, formado periodicamente em um terminal de origem. Percorre a linha com horários pré-estabelecidos e segue um caminho fixo até chegar ao terminal de destino, onde é desmembrado.

Variáveis binárias - variáveis que podem assumir apenas dois valores distintos, por exemplo, variáveis inteiras binárias (0/1, Sim/Não etc.)

Via permanente - conjunto formado pelos trilhos, dormentes e lastro, que definem o traçado de uma ferrovia. 


\section{Apêndice A}

\section{CLASSIFICAÇÃO DA REDE}

São estabelecidas, a seguir, algumas definições básicas e terminologias relacionadas à Teoria dos Grafos, para que a rede abordada neste trabalho possa ser inserida na taxonomia relacionada ao assunto. Segundo Bazaraa (1977), os elementos que constituem esta Teoria podem ser utilizados para representação dos problemas associados às redes de transporte.

Os conceitos apresentados neste item referem-se aos estabelecidos por Szwarcfiter (1984), que define um grafo $\mathrm{G}(\mathrm{V}, \mathrm{E})$ como um conjunto finito não-vazio $\mathrm{V}$ e um conjunto $\mathrm{E}$ de pares não ordenados de elementos distintos de $\mathrm{V}$, tal que os elementos de $\mathrm{V}$ são os vértices e os de $\mathrm{E}$ as arestas de $\mathrm{G}$, respectivamente.

Cada aresta $\mathrm{e} \in E$ é denotada pelo par ordenado $e=(v, w)$, em que os vértices $v, w$ são denominados extremos (ou extremidades) da aresta, de modo que duas arestas com extremo comum são denominadas adjacentes. Às constantes $n$ e $m$ são atribuídos os valores de $|\mathrm{V}|$ e |E|, respectivamente.

Os grafos podem ainda ser representados geometricamente através da inserção de pontos (vértices) em posições arbitrárias do plano, que são unidos por linhas que representam cada aresta $(v, w)$ aos pontos equivalentes a $v$ e $w$.

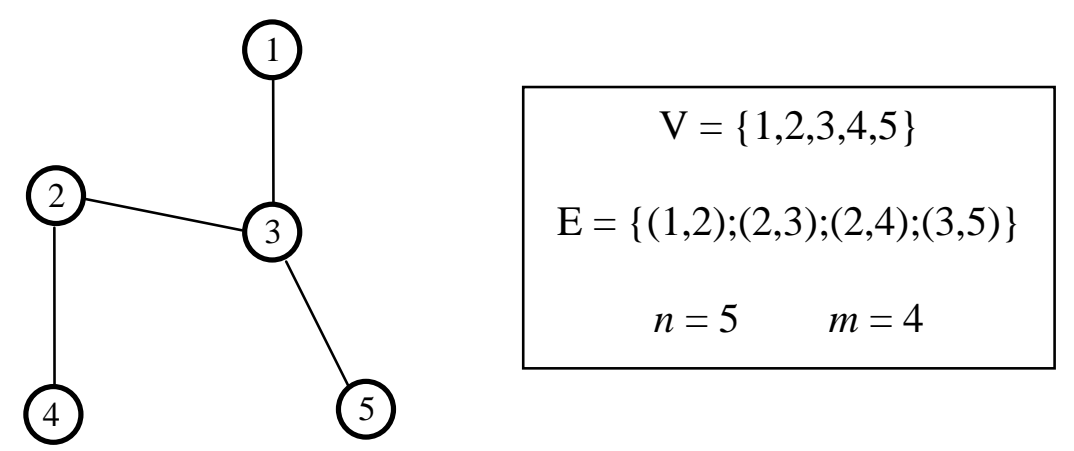

Figura A.1- Representação geométrica de um grafo.

Um laço é uma aresta formada por um par de vértices idênticos, ou seja, $e=(v, v)$. Arestas paralelas é o termo utilizado para definir a existência de mais de uma aresta entre o mesmo par de vértices, de modo que um grafo $G(V, E)$ com esta estrutura passa a ser 
denominado multigrafo.

Em um grafo $\mathrm{G}(\mathrm{V}, \mathrm{E})$, o grau de um vértice $v \in \mathrm{V}$, denotado por grau(v), é definido como o número de vértices adjacentes a $v$ e este é regular de grau $r$ quando todos os seus vértices possuem o mesmo grau $r$.

A distância $\mathrm{d}(v, w)$ entre $v$ e $w$ é o comprimento do menor caminho entre esses vértices, a excentricidade de um vértice $v \in \mathrm{V}$ é o valor da distância máxima entre $v$ e $w$ para todo $w \in \mathrm{V}$, e o centro de $\mathrm{G}$ é o subconjunto de vértices de excentricidade mínima.

$\mathrm{O}$ vértice $v_{1}$ atinge ou alcança $v_{\mathrm{k}}$ quando é estabelecido o caminho de $v_{1}$ a $v_{\mathrm{k}}$ na sequência de vértices $v_{1}, \ldots, v_{\mathrm{k}}$ com $\left(v_{\mathrm{j}}, v_{\mathrm{j}+1}\right) \in \mathrm{E}$ e $1 \leq \mathrm{j} \leq|\mathrm{k}-1|$, de modo que um caminho de $(\mathrm{k})$ vértices é formado por (k-1) arestas, sendo este último parâmetro denominado comprimento do caminho. Se todos os vértices do caminho $v_{1}, \ldots, v_{\mathrm{k}}$ forem distintos, a sequência recebe o nome de caminho simples ou elementar, e se as arestas forem distintas recebe o nome de trajeto.

Um ciclo é um caminho $v_{1}, \ldots, v_{\mathrm{k}}$ com $v_{1}=v_{\mathrm{k}+1}$ e $\mathrm{k} \geq 3$, tal que, se um caminho $v_{1}, \ldots, v_{\mathrm{k}}$ for simples, o ciclo $v_{1}, \ldots, v_{\mathrm{k}}, v_{\mathrm{k}+1}$ também é denominado simples ou elementar. Um grafo que não possui ciclo é denominado acíclico.

Um caminho que contém cada vértice do grafo exatamente uma vez é denominado hamiltoniano e, por outro lado, um caminho que contém cada aresta do grafo também exatamente uma vez é chamado euleriano. Se G é um grafo que possui caminho hamiltoniano e/ou euleriano, então G é denominado hamiltoniano e/ou euleriano, respectivamente.

Um grafo $\mathrm{G}(\mathrm{V}, \mathrm{E})$ é denominado conexo quando existe ao menos um caminho entre cada par de vértices de $\mathrm{G}$ e, caso contrário, é chamado dito desconexo. Um caso particular de grafo desconexo refere-se àquele que não possui arestas, denominado totalmente desconexo.

Um grafo é completo quando existe uma aresta entre cada par de seus vértices, com a notação $\mathrm{K}_{n}$ para um grafo completo com $n$ vértices e número máximo possível de arestas dado por $\left(n^{2}\right)$.

Um grafo $\mathrm{G}(\mathrm{V}, \mathrm{E})$ é bipartite quando o conjunto de vértices $\mathrm{V}$ pode ser particionado em dois subconjuntos $V_{1}, V_{2}$, de modo que toda aresta de $G$ une um vértice de $V_{1}$ a outro de $V_{2}$, sendo denotado por $\mathrm{G}\left(\mathrm{V}_{1} \mathrm{U} \mathrm{V}_{2}, \mathrm{E}\right)$. Um grafo bipartite completo possui uma aresta para cada par de vértices $\mathrm{v}_{1}, \mathrm{v}_{2}$, com $\mathrm{v}_{1} \in \mathrm{V}_{1}, \mathrm{v}_{2} \in \mathrm{V}_{2}, \mathrm{n}_{1}=\left|\mathrm{V}_{1}\right|$ e $\mathrm{n}_{2}=\left|\mathrm{V}_{2}\right|,\left(\mathrm{n}_{1} \cdot \mathrm{n}_{2}\right)$ arestas e denotado por $\mathrm{K}_{\mathrm{n} 1, \mathrm{n} 2}$. 
O termo árvore é utilizado para designar um grafo $\mathrm{T}(\mathrm{V}, \mathrm{E})$ acíclico e conexo, sendo um conjunto de árvores denominado floresta. Toda árvore T com $(n)$ vértices possui exatamente (n-1) arestas, e se um de seus vértices possui grau menor ou igual a 1, então ela é caracterizada como uma folha.

Um grafo é rotulado em vértices (ou arestas) quando a cada vértice (ou aresta) estiver associado um conjunto denominado rótulo, tal como apresentado na Figura A.2, por exemplo, cujos vértices das árvores estão rotulados com os conjuntos $\{1\},\{2\},\{3\},\{4\}$ e $\{5\}$.

Um árvore $\mathrm{T}(\mathrm{V}, \mathrm{E})$ é denominada enraizada quando algum vértice $v \in \mathrm{V}$ é escolhido como especial - este denominado raiz da árvore - e caso contrário é denominada árvore livre. Se v e $\mathrm{w}$ são dois vértices de uma árvore enraizada $\mathrm{T}$ no vértice $\mathrm{r}$, suponha que $\mathrm{v}$ pertença ao caminho de $\mathrm{r}$ a w, então v é ancestral de w e este é descendente daquele. Se v $\neq$ w, então v é ancestral próprio de w e este é descente próprio de v. Além disso, se (v,w) é aresta de T então v é pai de w e este é filho daquele, de modo que dois vértices com mesmo pai são irmãos.
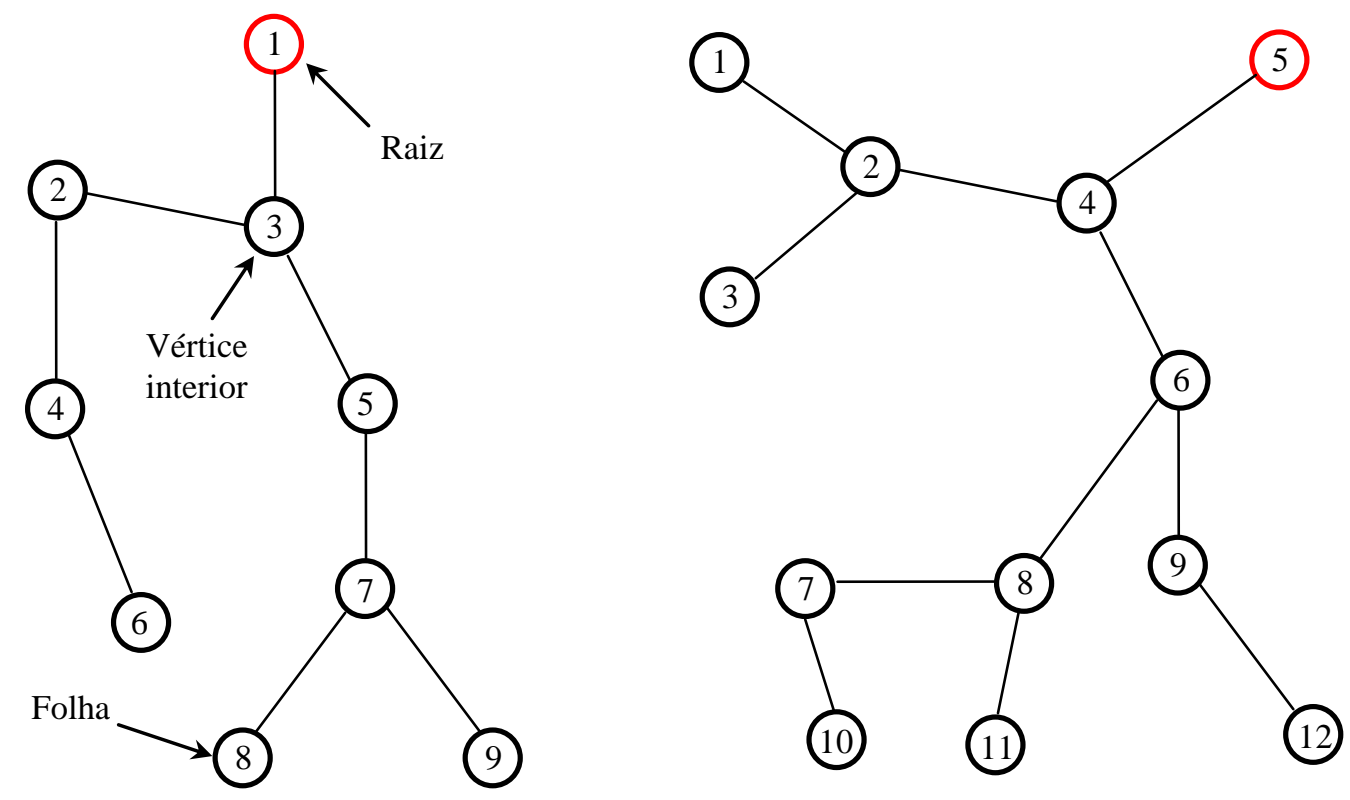

Figura A.2- Floresta composta por duas árvores enraizadas.

Todos os outros vértices de uma árvore enraizada possuem um único pai, a raiz de uma árvore naturalmente não possui nenhum e uma folha é um vértice que não possui filhos. $\mathrm{O}$ nível de um vértice $\mathrm{v}$, denotado nível(v), é o comprimento do caminho da raiz $\mathrm{r}$ a v e a altura de uma árvore $\mathrm{T}$ é igual ao valor máximo de nível v, para todo vértice $\mathrm{v}$ de $\mathrm{T}$. Caso a ordem dos filhos de cada vértice $\mathrm{v}$ for relevante, a árvore é denominada enraizada ordenada. Assim, para cada vértice $\mathrm{v}$ que possui filhos é possível identificar o $1^{\mathrm{o}}$ filho de $\mathrm{v}$ (o mais à esquerda), o $2^{\circ}$ (o 
mais à esquerda), e assim por diante.

Uma árvore estritamente m-ária $\mathrm{T}$ é aquela enraizada ordenada em que cada vértice, nãofolha, possui $\mathrm{m}$ filhos, com $\mathrm{m} \geq 1$ ( $\mathrm{m}=2$ é uma árvore estritamente binária). Quando a cada filho $\mathrm{w}$ de todo vértice não-folha $\mathrm{v}$ de $\mathrm{T}$ for atribuído um rótulo inteiro positivo $\mathrm{r}(\mathrm{w})$, $1 \leq \mathrm{r}(\mathrm{w}) \leq \mathrm{m}$, igual à posição que $\mathrm{w}$ ocupa na ordenação dos filhos de $\mathrm{v}$, a subárvore parcial de uma árvore estritamente m-ária que possui essa rotulação é chamada árvore m-ária.

Os grafos não direcionados são aqueles em que, sendo $(v, w)$ uma aresta de $\mathrm{G}(\mathrm{V}, \mathrm{E})$, tanto $v$ é adjacente a $w$ como este é adjacente a $v$. Por outro lado, um grafo direcionado, $\mathrm{D}(\mathrm{V}, \mathrm{E})$, é um conjunto finito não vazio $\mathrm{V}$ (vértices) e um conjunto $\mathrm{E}$ (arestas) de pares ordenados de vértices distintos, ou seja, cada aresta $(v, w)$ de um grafo direcionado apresenta uma única direção de $v$ para $w$.

A maioria dos conceitos (caminho simples, trajeto, ciclo simples etc.) é análoga tanto aos grafos quanto aos grafos direcionados, porém, neste o grau de entrada de $v$ é o número de arestas convergentes ao vértice $v$ e o grau de saída é o número de arestas divergentes a ele. A retirada das direções das arestas de um grafo direcionado D resulta em um multigrafo não direcionado, denominado grafo subjacente a $\mathrm{D}$.

Uma fonte é um vértice com grau de entrada nulo e um sumidouro (ou poço) é um vértice com grau de saída nulo. Uma árvore direcionada enraizada é um grafo direcionado D em que um vértice $r$ possui grau de entrada nulo e todos os seus demais vértices possuem grau de entrada igual a 1. A Figura A.3 apresenta uma árvore enraizada e um grafo direcionado subjacente.
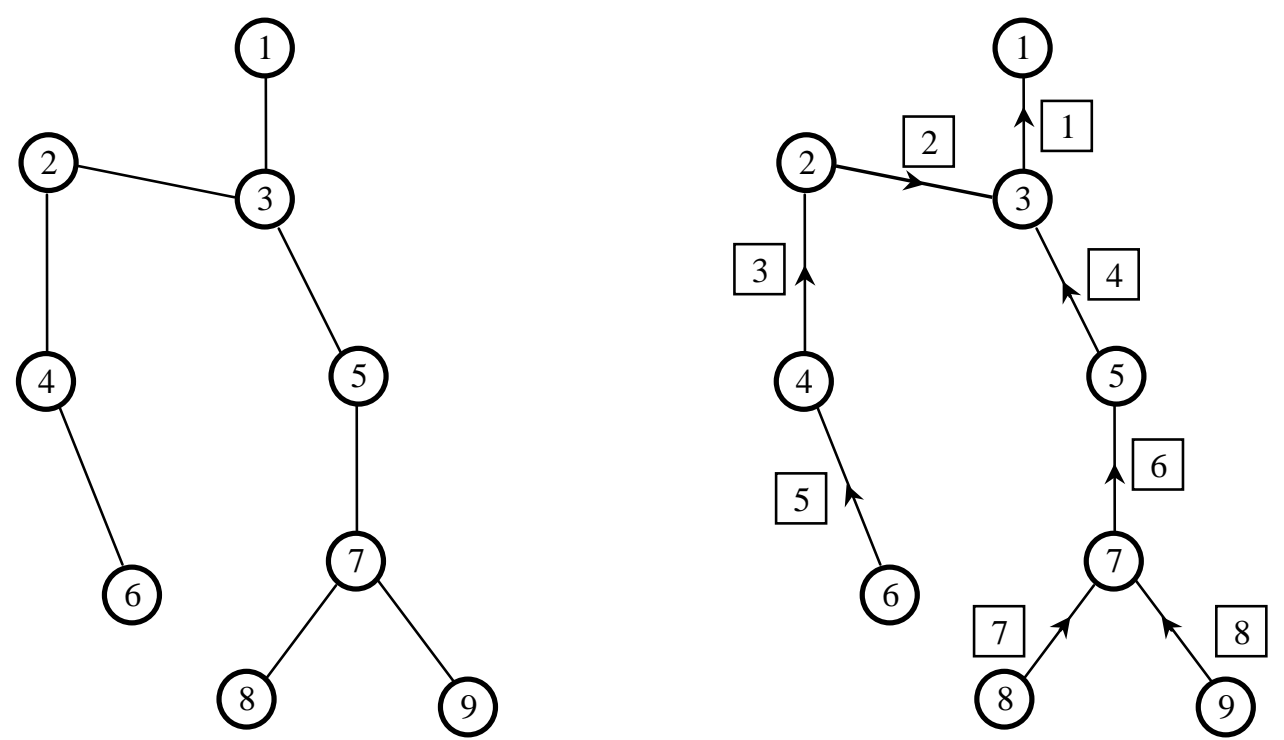

Figura A.3- Representação de um grafo e um grafo direcionado subjacente. 
Um grafo $\mathrm{G}(\mathrm{V}, \mathrm{E})$ também pode ser representado através de matrizes de adjacências, em que a matriz $\mathrm{R}=\left(r_{\mathrm{ij}}\right)$ de ordem $n$ é tal que, para grafos não direcionados, $r_{\mathrm{ij}}=1$ quando os vértices $v_{\mathrm{i}} \mathrm{e}$ $v_{\mathrm{j}}$ forem adjacentes e $r_{\mathrm{ij}}=0$ caso contrário, e para grafos direcionados, $\mathrm{r}_{\mathrm{ij}}=1$ se $\left(v_{\mathrm{i}}, v_{\mathrm{j}}\right)$ for aresta divergente de $v$ i e convergente a $v_{\mathrm{j}}$ e $r_{\mathrm{ij}}=0$ caso contrário.

Ainda sob a forma desta notação, podem ser definidas matrizes de incidências em que a matriz $\mathrm{B}=\left(b_{\mathrm{ij}}\right)$ de ordem $(n \times m)$ é tal que $b_{\mathrm{ij}}=1$ quando o vértice $v_{\mathrm{i}}$ for um extremo da aresta $e_{\mathrm{j}}$, e $b_{\mathrm{ij}}=0$ caso contrário. Através desse método é possível, em geral, representar um mesmo grafo através de diferentes matrizes.

$\begin{array}{lllllllll}1 & 2 & 3 & 4 & 5 & 6 & 7 & 8 & 9\end{array}$

$\mathbf{1}$
$\mathbf{2}$
$\mathbf{3}$
$\mathbf{4}$
$\mathbf{5}$
$\mathbf{6}$
$\mathbf{7}$
$\mathbf{8}$
$\mathbf{9}$$\left[\begin{array}{lllllllll}0 & 0 & 1 & 0 & 0 & 0 & 0 & 0 & 0 \\ 0 & 0 & 0 & 1 & 0 & 0 & 0 & 0 & 0 \\ 0 & 1 & 0 & 0 & 1 & 0 & 0 & 0 & 0 \\ 0 & 0 & 0 & 0 & 0 & 1 & 0 & 0 & 0 \\ 0 & 0 & 0 & 0 & 0 & 0 & 1 & 0 & 0 \\ 0 & 0 & 0 & 0 & 0 & 0 & 0 & 0 & 0 \\ 0 & 0 & 0 & 0 & 0 & 0 & 0 & 0 & 0 \\ 0 & 0 & 0 & 0 & 0 & 0 & 0 & 0 & 0\end{array}\right]$

$\begin{array}{lllllllll}1 & 2 & 3 & 4 & 5 & 6 & 7 & 8 & 9\end{array}$

$\mathbf{1}$
$\mathbf{2}$
$\mathbf{3}$
$\mathbf{4}$
$\mathbf{5}$
$\mathbf{6}$
$\mathbf{7}$
$\mathbf{8}$
$\mathbf{9}$$\left[\begin{array}{lllllllll}0 & 0 & 1 & 0 & 0 & 0 & 0 & 0 & 0 \\ 0 & 0 & 1 & 1 & 0 & 0 & 0 & 0 & 0 \\ 1 & 1 & 0 & 0 & 1 & 0 & 0 & 0 & 0 \\ 0 & 1 & 0 & 0 & 0 & 1 & 0 & 0 & 0 \\ 0 & 0 & 1 & 0 & 0 & 0 & 1 & 0 & 0 \\ 0 & 0 & 0 & 1 & 0 & 0 & 0 & 0 & 0 \\ 0 & 0 & 0 & 0 & 1 & 0 & 0 & 1 & 1 \\ 0 & 0 & 0 & 0 & 0 & 0 & 1 & 0 & 0 \\ 0 & 0 & 0 & 0 & 0 & 0 & 1 & 0 & 0\end{array}\right]$

Figura A.4- Matriz de adjacências do grafo direcionado e de seu grafo subjacente da Figura A.3.

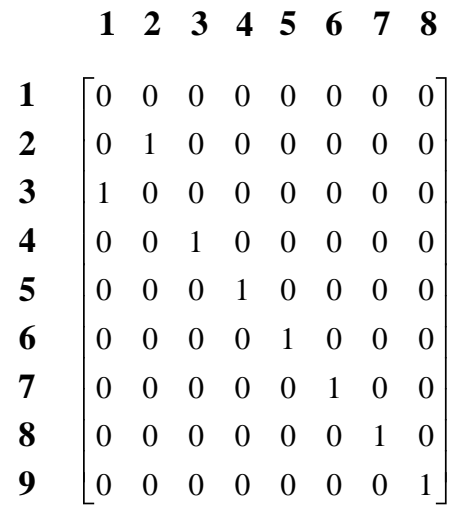

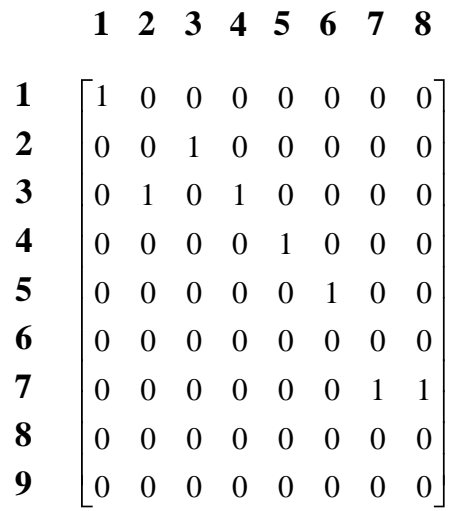

Figura A.5- Matriz de incidências do grafo direcionado e de seu grafo subjacente da Figura A.3.

Outra maneira de especificar um grafo é através de listas, que podem apresentar diferentes configurações, sendo a mais comum a estrutura de adjacências. Seja G(V,E) a estrutura de adjacências $\mathrm{A}$ de $\mathrm{G}$ é um conjunto de $n$ listas $\mathrm{A}(v)$, uma para cada $\mathrm{v} \in V$, denominadas listas de adjacências do vértice $v$, que contêm os vértices $w$ adjacentes a $v$ em G, ou seja, $\mathrm{A}(v)=\{w \mid(v, w) \in E\}$. 
No caso de um grafo, cada aresta $(v, w)$ dá origem a duas entradas na estrutura de adjacências, correspondentes a $v \in \mathrm{A}(w)$ e w $\in \mathrm{A}(v)$, então a estrutura $\mathrm{A}$ consiste de $n$ listas com um total de $2 . m$ elementos. Por outro lado, em ambos os grafos e grafos direcionados, a cada elemento $w$ de uma lista de adjacências $\mathrm{A}(v)$ associa-se um ponteiro que informa o próximo elemento se houver - após $w$ em $\mathrm{A}(v)$, sendo necessária a indicação de um vetor $\mathrm{p}$, de tamanho $n$, tal que $\mathrm{p}(v)$ indica o ponteiro inicial da lista $\mathrm{A}(v)$.

A estrutura de adjacência pode ser interpretada como uma matriz de adjacências sob a forma de matriz esparsa (sem os zeros), em que $v_{\mathrm{j}} \in \mathrm{A}\left(v_{\mathrm{i}}\right)$ corresponde a afirmar que $r_{\mathrm{ij}}=1$ naquela matriz. Além disso, a estrutura de adjacências pode ser definida para um grafo direcionado $\mathrm{D}(\mathrm{V}, \mathrm{E})$, de modo que a lista de adjacências $\mathrm{A}(v)$ é formada pelos vértices divergentes de $v$, isto é, $\mathrm{A}(v)=\{w \mid(v, w) \in E\}$.

Szwarcfiter (1984) afirma, ainda, que a estrutura de adjacência é a representação mais recorrente na abordagem dos grafos, talvez pelo fato de necessitar de um espaço de armazenagem binária de tamanho $(n+m)$, ou seja, linear em relação ao tamanho de G.

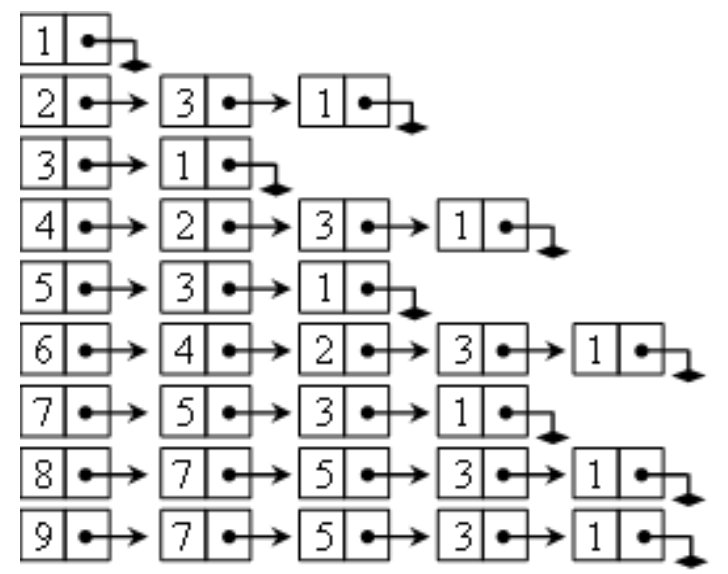

Figura A.6- Estrutura de adjacência do grafo direcionado da Figura A.3.

A partir das definições estabelecidas anteriormente são apresentados a seguir os atributos de uma rede segundo os conceitos estabelecidos na Teoria dos Grafos e a Tabela A.1 que sintetiza as caracteríticas da rede ferroviária sobre a qual é aplicado o modelo de capacidade proposto neste trabalho.

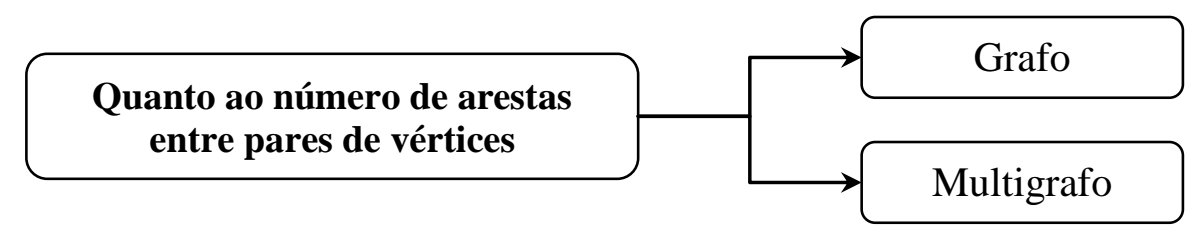




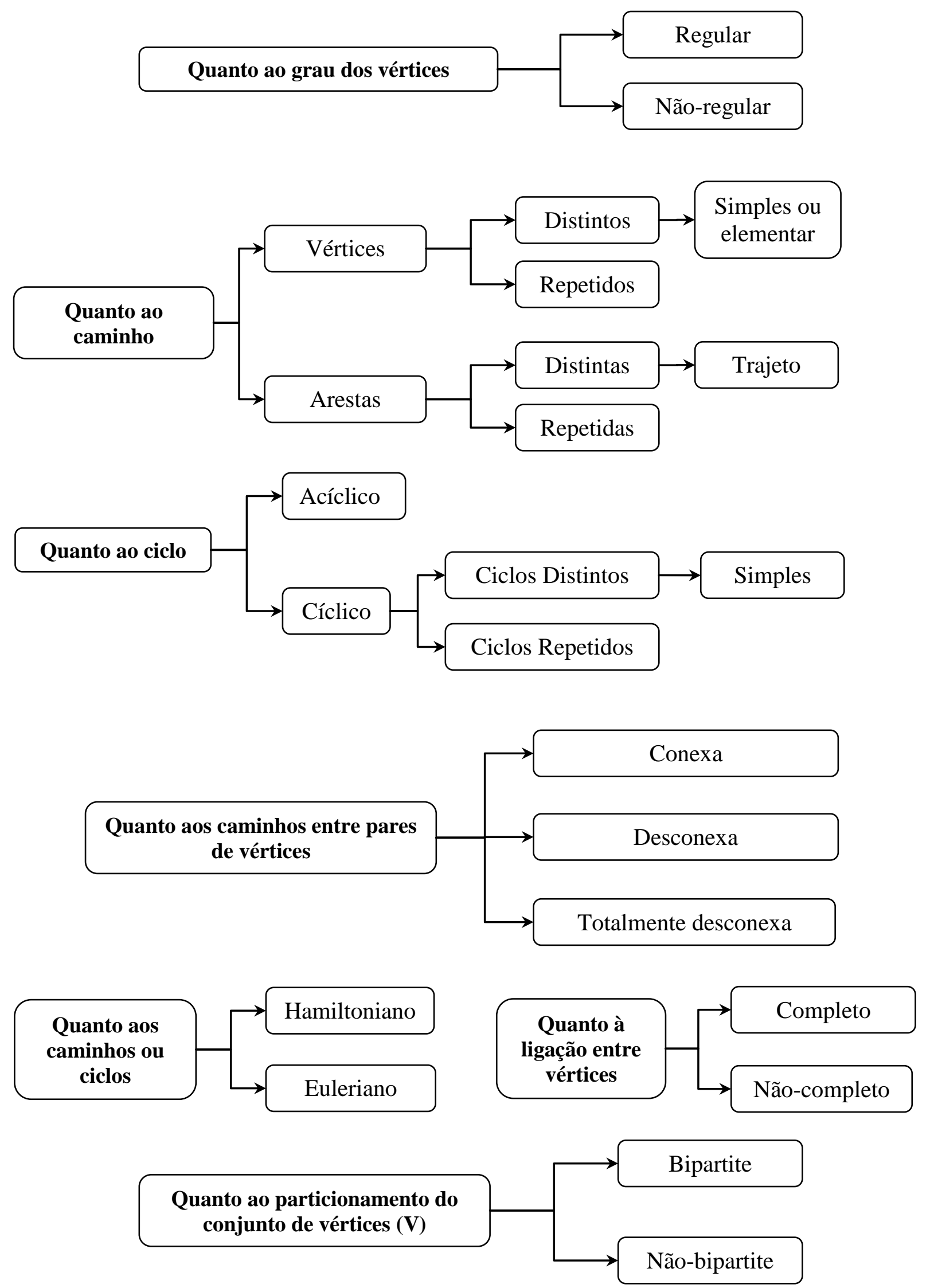



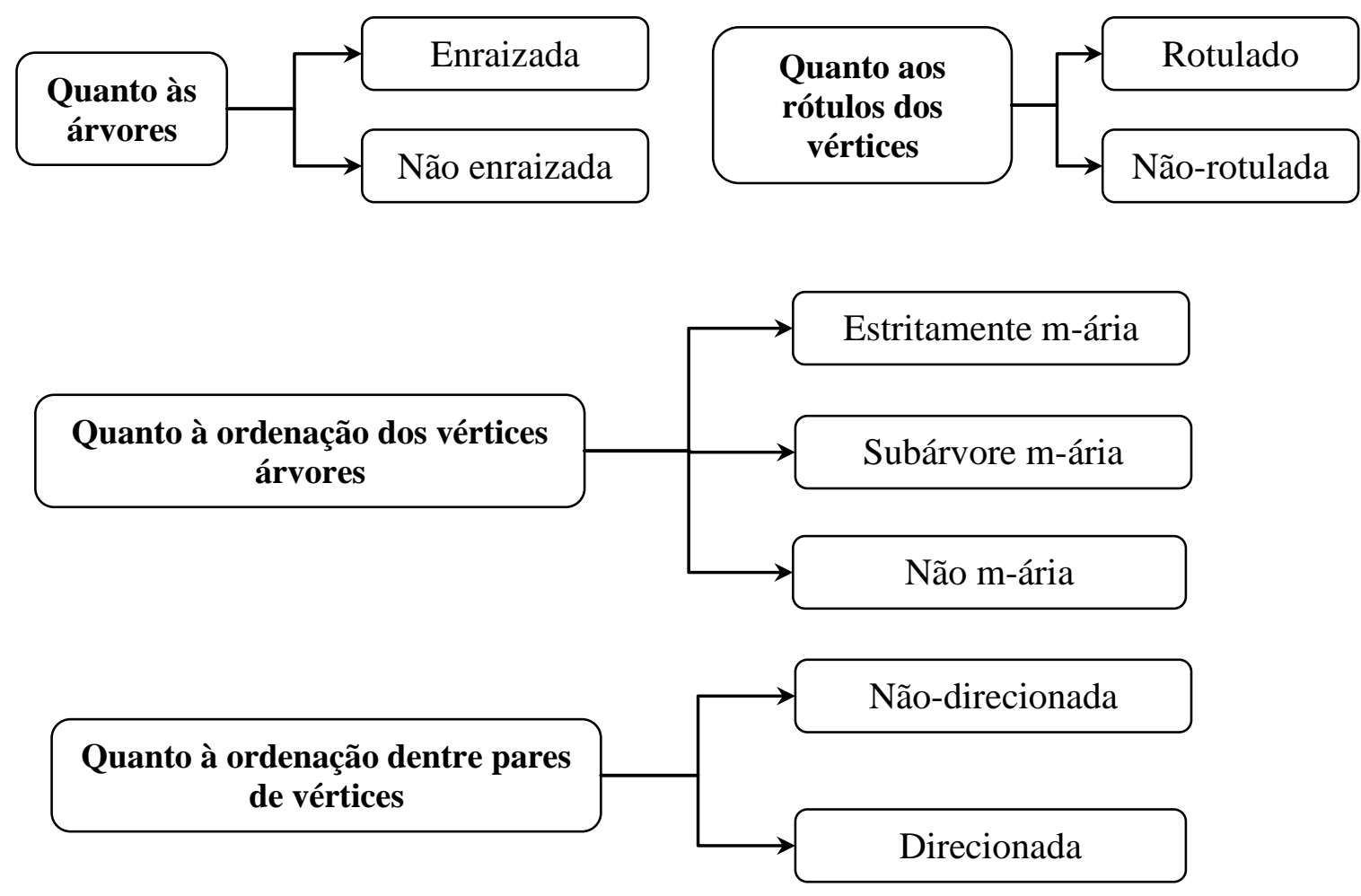

Tabela A.1 - Classificação do tipo de rede ferroviária empregada neste estudo segundo a terminologia da Teoria dos Grafos.

\begin{tabular}{|c|c|c|}
\hline \multicolumn{2}{|c|}{ Classificação } & Atributo \\
\hline \multicolumn{2}{|c|}{ Quanto ao número de arestas entre pares de vértices } & Grafo \\
\hline \multicolumn{2}{|c|}{ Quanto ao grau dos vértices } & Não-regular \\
\hline \multirow{2}{*}{ Quanto ao caminho } & Vértices & Caminho simples (ou elementar) \\
\hline & Arestas & Trajeto \\
\hline \multicolumn{2}{|c|}{ Quanto ao ciclo } & Acíclico \\
\hline \multicolumn{2}{|c|}{ Quanto aos caminhos ou ciclos } & Qualquer \\
\hline \multicolumn{2}{|c|}{ Quanto aos caminhos entre pares de vértices } & Desconexo \\
\hline \multicolumn{2}{|c|}{ Quanto à ligação entre vértices } & Não-completo \\
\hline \multicolumn{2}{|c|}{ Quanto ao particionamento do conjunto de vértices } & Bipartite \\
\hline \multicolumn{2}{|c|}{ Quanto às árvores } & Enraizada \\
\hline \multicolumn{2}{|c|}{ Quanto aos rótulos dos vértices } & Rotulado \\
\hline \multicolumn{2}{|c|}{ Quanto à ordenação dos vértices árvores } & $\begin{array}{c}\text { Não m-ária } \\
\text { ou Estritamente m-ária }\end{array}$ \\
\hline \multicolumn{2}{|c|}{ Quanto à ordenação dentre pares de vértices } & Não-direcionado \\
\hline
\end{tabular}




\section{Apêndice B}

\section{MODELO DE VIA PERMANENTE}

Este apêndice expõe o método de geração dos dados sobre a geometria da via permanente, relativos às suas características planimétricas, altimétricas, das condições de conservação da superestrutura e posição dos equipamentos nela existentes, como pontes, viadutos e passagens em nível.

Os procedimentos descritos neste item foram elaborados devido à falta de acesso aos dados sobre as características geométricas e limites operacionais de velocidade nos arcos dos ramais que compõem a rede proposta para aplicação do modelo de capacidade. Este cenário criado não corresponde às características reais dos arcos ferroviários, mas permite que os parâmetros gerados possam ser utilizados para descrição aproximada do movimento dos trens na via.

Inicialmente são descritos os procedimentos para definição dos parâmetros geométricos dos arcos em relação à altitude, inclinação da rampa, grau da curva, limite de velocidade e localização dos desvios, pontes, viadutos, passagens em nível etc.

Em seguida são quantificadas as variáveis utilizadas para caracterizar o corredor ferroviário, entre os terminais de Santa Fé do Sul e Mairinque, cujo conhecimento se deve à sua utilização em pesquisa anterior, realizada no Departamento de Transportes da Escola de Engenharia de São Carlos (BATISTA, 2006).

A validação do método é feita através da comparação das velocidades médias - obtidas através do simulador Train Energy Model versão 2.5, nesse trecho segundo as configurações da via real e daquela gerada pelo modelo. Este modelo de caracterização de linhas ferroviárias permitiu a criação de um cenário virtual para definição dos tempos de viagem nos ramais de Itirapina-Panorama e Araraquara-Colômbia, utilizados na rede aplicada ao modelo de capacidade de processamento de trens, proposto neste trabalho.

Os procedimentos foram sistematizados através de rotinas computacionais, elaboradas no Visual Basic for Applications, inserido no software Microsoft Office Excel, de modo a evitar possíveis erros nos cálculos e proporcionar maior rapidez nas operações. 


\section{B.1. Caracterização da geometria no modelo teórico da via}

A primeira etapa do processo de caracterização dos elementos geométricos dos arcos consiste na definição da trajetória que o trem descreve entre uma origem e um destino. Para isso, foi utilizada uma base de dados georeferenciada, contendo as informações sobre a infraestrutura de transporte ferroviário disponível atualmente no país (ver Figura 4.1)

$\mathrm{O}$ arquivo de linhas do software Transcad, que define o traçado em planta da via permanente, no trecho entre os terminais de Santa Fé do Sul e Mairinque (Figura B.1), foi extraído da BGTIB e exportado para uma plataforma de desenho assistido por computador (CAD Computer Aided Design).

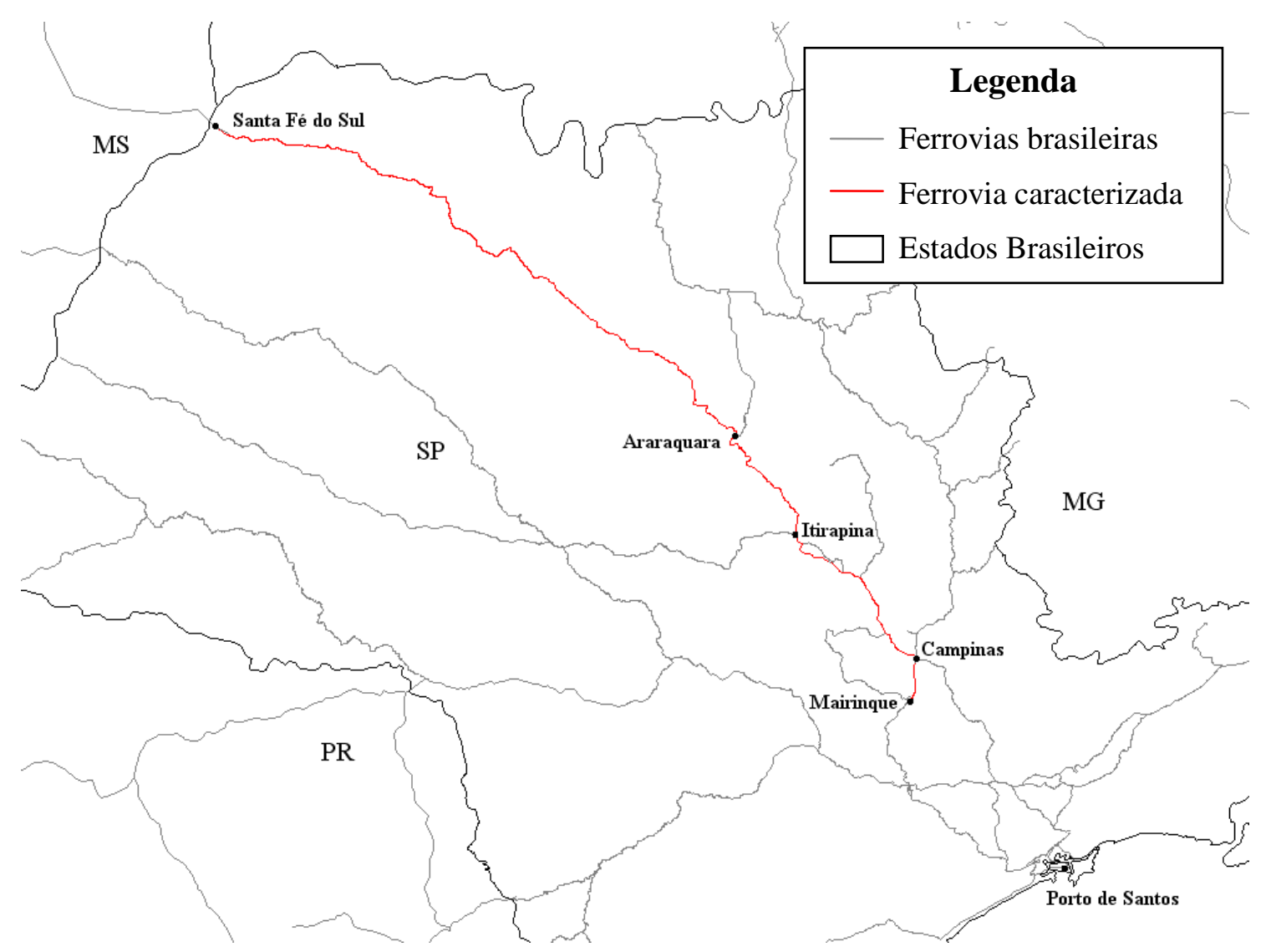

Figura B.1 - Trecho ferroviário com dados reais sobre a via permanente.

Foi constatado, entretanto, que o conjunto de linhas fornecido pelo Sistema de Informação Geográfica (SIG) apresenta trechos com mudanças bruscas de orientação da via, situações estas que impossibilitam a adequada circulação de trens na linha férrea. A solução para o problema foi a suavização do traçado da ferrovia, através da superposição de uma linha sobre o trecho original e readequação do traçado com as características citadas, como exemplificado na Figura B.2, no trecho próximo à cidade de Itirapina. 


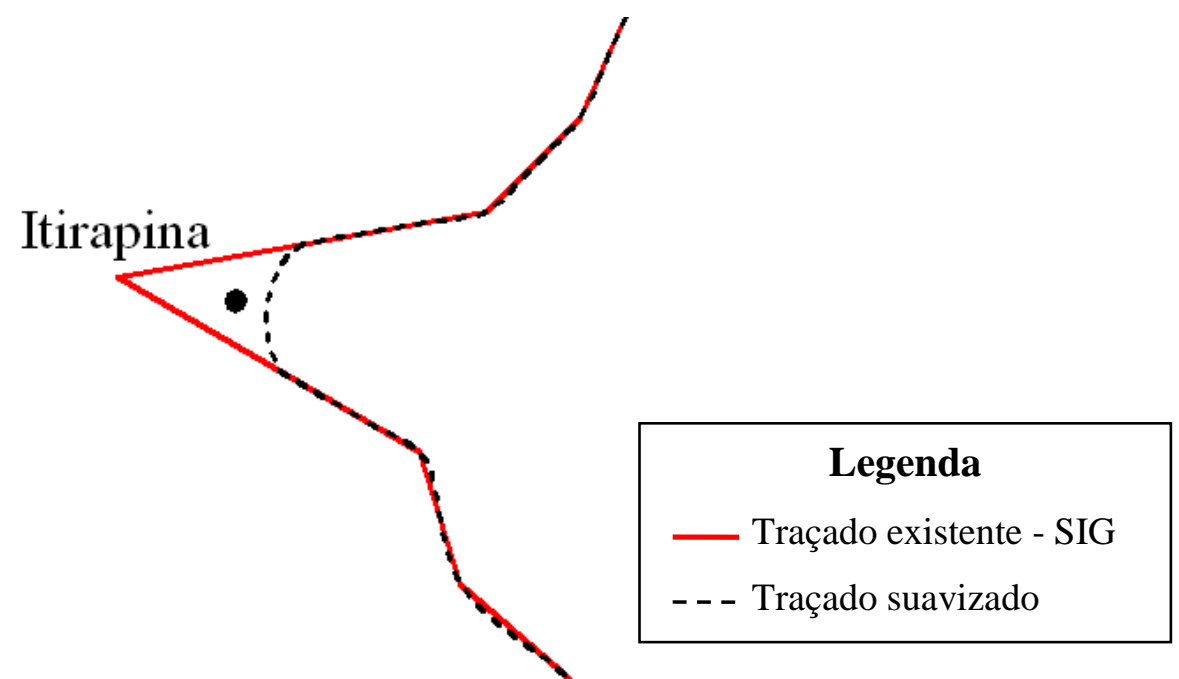

Figura B.2 - Suavização do traçado georeferenciado da ferrovia.

Uma vez realizado esse procedimento, a linha contínua que define o percurso dos trens é discretizada através da inserção de pontos igualmente espaçados. Como o arquivo de linhas é georeferenciado, as coordenadas desses pontos são extraídas e transferidas para uma planilha eletrônica. A Figura B.3 caracteriza o trecho próximo à cidade de Itirapina, com a discretização da via permanente para obtenção das coordenadas geográficas dos pontos, após a suavização do traçado original.

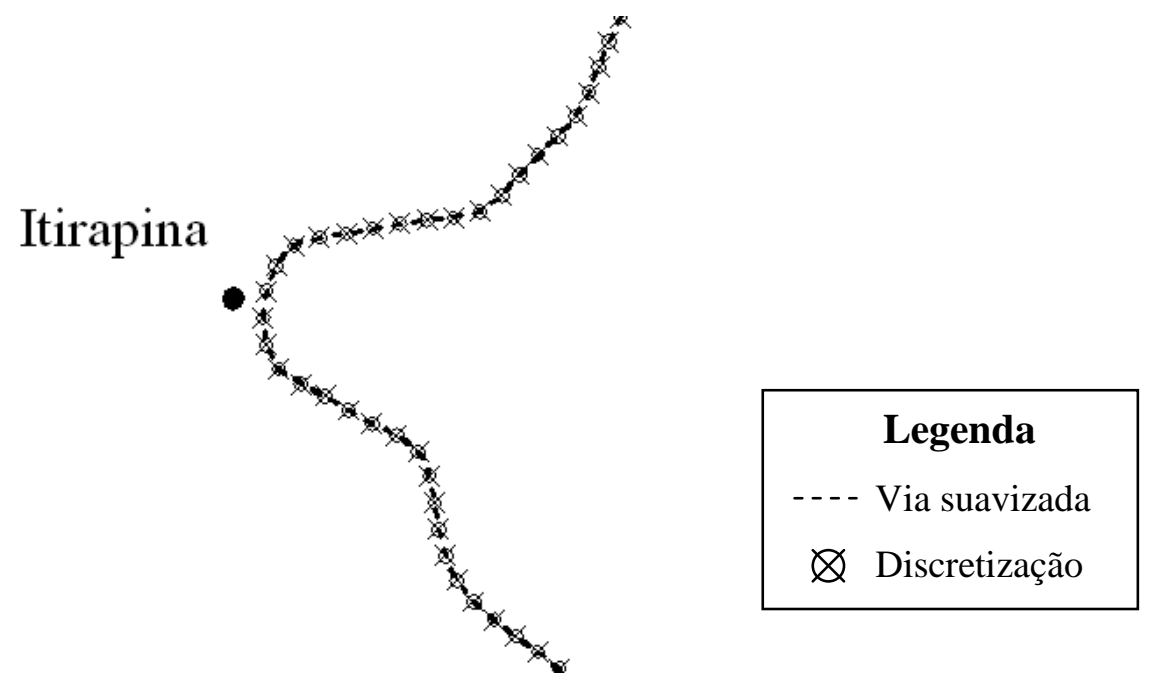

Figura B.3 - Discretização do traçado georeferenciado da ferrovia.

O procedimento descrito neste item permite a caracterização planimétrica da via permanente, com base em um arquivo georeferenciado, porém foi constatado que o comprimento total da via caracterizada pelo modelo teórico é aproximadamente $10 \%$ menor que o comprimento real, decorrente das imprecisões do processo de digitalização da malha ferroviária do país e da suavização do traçado da via na plataforma $C A D$. 
Entretanto, esse erro não inviabilizou a utilização do método apresentado, já que outras aproximações foram consideradas na definição dos parâmetros de caracterização da via permanente, cujas aproximações afetaram mais significativamente os resultados dos tempos médios de viagem nos arcos, como será demonstrado mais adiante, neste apêndice.

Em relação às características geométricas que definem a linha ferroviária, o método calcula, nessa ordem, o raio da curva circular nos pontos da via definidos anteriormente, a posição acumulada destes em relação ao início da trajetória e a rampa nesses locais.

Para o cálculo do raio da curva inscrita em um ponto da ferrovia, a rotina computacional inserida no software Microsoft Excel considera os pontos de coordenadas conhecidas à montante e à jusante desse local. Para o ponto subsequente, o algoritmo toma as coordenadas geográficas do ponto cujo raio de curva foi calculado anteriormente e o ponto imediatamente após aquele, até que toda a trajetória da ferrovia seja percorrida, como pode ser observado na Figura B.4, que ilustra o processo descrito.

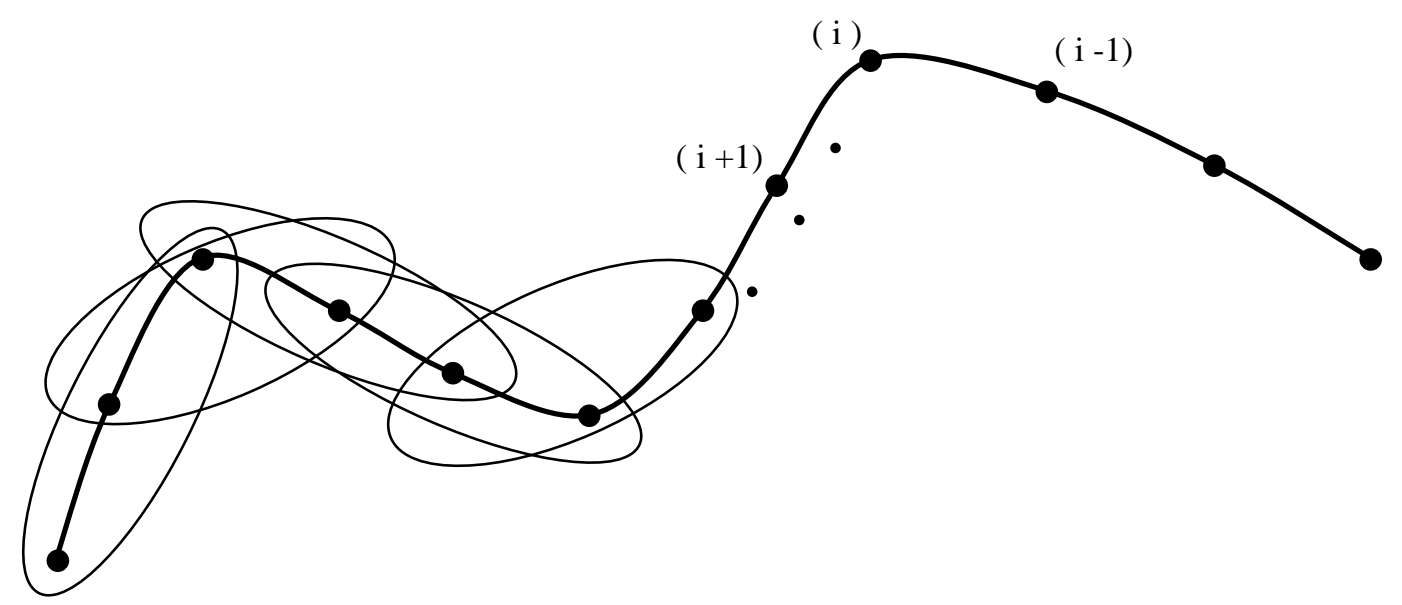

Figura B.4 - Análise dos parâmetros da via permanente através de pontos sucessivos.

O cálculo do raio de curva é feito com base nos elementos geométricos de uma circunferência, que passam por três pontos de coordenadas conhecidas (Figura B.5), analisados segundo o procedimento descrito acima. 


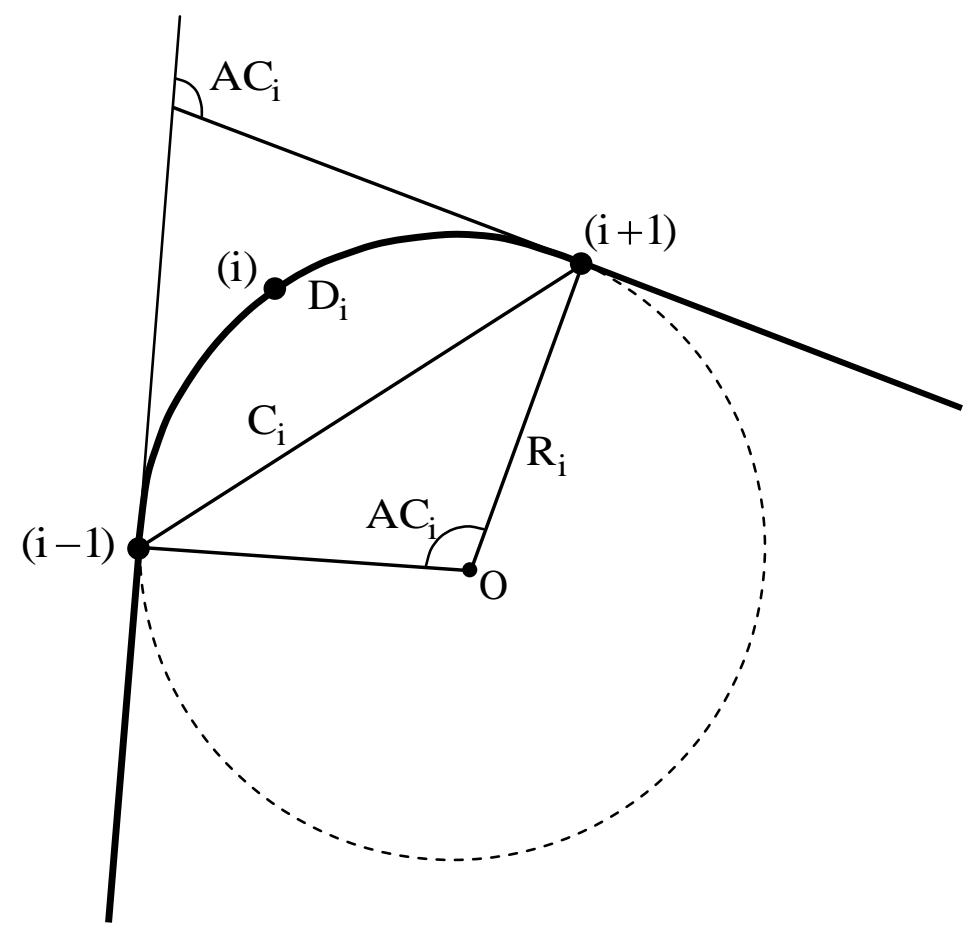

Figura B.5 - Curva circular (sem transição) inscrita em uma circunferência.

Algebricamente, o raio da curva com centro na origem $\mathrm{O}$ e que passa pelo ponto (i) é então dado pela Equação (A.1).

$$
\mathrm{R}_{\mathrm{i}}=\sqrt{\left(\mathrm{x}_{\mathrm{i}}-\mathrm{x}_{\mathrm{o}}\right)^{2}+\left(\mathrm{y}_{\mathrm{i}}-\mathrm{y}_{\mathrm{o}}\right)^{2}}
$$

Como a curva de raio $R_{i}$ passa pelos pontos $(i-1)$ e $(i+1)$ têm-se, analogamente, as Equações (A.2) e (A.3).

$$
\begin{aligned}
& R_{i}=\sqrt{\left(x_{i-1}-x_{o}\right)^{2}+\left(y_{i-1}-y_{o}\right)^{2}} \\
& R_{i}=\sqrt{\left(x_{i+1}-x_{o}\right)^{2}+\left(y_{i+1}-y_{o}\right)^{2}}
\end{aligned}
$$

A partir disso, é possível obter o sistema de equações não-lineares indicado a seguir, formado pela igualdade entre as Equações (A.1), (A.2) e (A.3).

$$
\left\{\begin{array}{l}
\sqrt{\left(x_{i}-x_{o}\right)^{2}+\left(y_{i}-y_{o}\right)^{2}}=\sqrt{\left(x_{i-1}-x_{o}\right)^{2}+\left(y_{i-1}-y_{o}\right)^{2}} \\
\sqrt{\left(x_{i}-x_{o}\right)^{2}+\left(y_{i}-y_{o}\right)^{2}}=\sqrt{\left(x_{i+1}-x_{o}\right)^{2}+\left(y_{i+1}-y_{o}\right)^{2}}
\end{array}\right.
$$


O desenvolvimento algébrico da Equação (A.4) resulta na seguinte igualdade:

$$
x_{0} \cdot\left(x_{i-1}-x_{i}\right)+y_{o} \cdot\left(y_{i-1}-y_{i}\right)=\frac{x_{i-1}^{2}+y_{i-1}^{2}-x_{i}^{2}-y_{i}^{2}}{2}
$$

Analogamente, a Equação (A.5) resulta em:

$$
x_{0} \cdot\left(x_{i}-x_{i+1}\right)+y_{o} \cdot\left(y_{i}-y_{i+1}\right)=\frac{x_{i}^{2}+y_{i}^{2}-x_{i+1}^{2}-y_{i+1}^{2}}{2}
$$

Resolvendo o sistema formado pelas Equações (A.6) e (A.7) nas incógnitas $x_{o}$ e $y_{o}$, relativas às coordenadas do centro da circunferência que passa pelos pontos $(i-1)$, (i) e $(i+1)$, é possível obter os valores numéricos destes parâmetros, tal que:

$$
\begin{gathered}
y_{0}=\left\{\left[\frac{x_{i-1}^{2}+y_{i-1}^{2}-x_{i}^{2}-y_{i}^{2}}{2 \cdot\left(x_{i-1}-x_{i}\right)}\right]-\left[\frac{x_{i}^{2}+y_{i}^{2}-x_{i+1}^{2}-y_{i+1}^{2}}{2 \cdot\left(x_{i}-x_{i+1}\right)}\right]\right\} /\left[\left(\frac{y_{i-1}-y_{i}}{x_{i-1}-x_{i}}\right)-\left(\frac{y_{i}-y_{i+1}}{x_{i}-x_{i+1}}\right)\right] \\
x_{o}=\left[\frac{x_{i-1}^{2}+y_{i-1}^{2}-x_{i}^{2}-y_{i}^{2}}{2 \cdot\left(x_{i-1}-x_{i}\right)}\right]-\left(\frac{y_{i-1}-y_{i}}{x_{i-1}-x_{i}}\right) \cdot y_{o}
\end{gathered}
$$

A aplicação desses valores na Equação (A.1) viabiliza a obtenção do valor do raio da circunferência que passa pelo ponto (i). Entretanto, o arquivo do simulador TEM de configuração da via necessita que as curvas sejam definidas segundo o seu ângulo central (em graus decimais) que, geometricamente, é dado pelo parâmetro "AC" na Figura B.5. Algebricamente, esse parâmeto é calculado como apresentado na Equação (A.8).

$$
\mathrm{AC}_{\mathrm{i}}=2 \cdot \operatorname{arcsen}\left(\frac{\mathrm{C}_{\mathrm{i}}}{2 \cdot \mathrm{R}_{\mathrm{i}}}\right)
$$

em que $\quad \mathrm{AC}_{\mathrm{i}}=$ ângulo central (ou grau) da curva.

$$
\mathrm{R}_{\mathrm{i}}=\text { raio da circunferência no ponto (i). }
$$

$$
\mathrm{C}_{\mathrm{i}}=\sqrt{\left(\mathrm{x}_{\mathrm{i}-1}-\mathrm{x}_{\mathrm{i}+1}\right)^{2}+\left(\mathrm{y}_{\mathrm{i}-1}-\mathrm{y}_{\mathrm{i}+1}\right)^{2}}=\text { corda relativa ao ponto (i), equivalente à }
$$

distância entre os pontos $(i-1)$ e $(i+1)$ de coordenadas conhecidas 
Definidos os ângulos centrais e raios das curvas que passam nos pontos que compõem a linha ferroviária, é possível obter a posição acumulada destes em relação ao início da trajetória, tal que:

$$
\mathrm{S}_{\mathrm{i}}=\mathrm{S}_{\mathrm{i}-1}+\frac{\mathrm{D}_{\mathrm{i}}}{2}
$$

em que $\quad S_{i}=$ posição do ponto (i) na trajetória.

$$
\mathrm{S}_{\mathrm{i}-1}=\text { posição do ponto à montante do ponto (i), tal que } \mathrm{S}_{0}=0 \text {. }
$$

$\mathrm{D}_{\mathrm{i}}=\mathrm{R}_{\mathrm{i}} \cdot \mathrm{AC}_{\mathrm{i}}=$ desenvolvimento, refernte ao comprimento do arco entre os pontos $(i-1)$ e $(i+1)$, indicado na Figura B.5.

O último parâmetro relativo à caracterização geométrica da via permanente, requerido pelo $T E M$, diz respeito às rampas nos pontos definidos anteriormente, as quais foram obtidas através de um levantamento topográfico internacional, comandado pela Agência Nacional de Inteligência Geoespacial (NGA - National Geospatial-Intelligence Agency) e Administração Nacional da Aeronáutica e do Espaço (National Aeronautics and Space Administration NASA) dos Estados Unidos da América, denominado SRTM (Shuttle Radar Topography Mission).

O projeto SRTM teve como objetivo realizar o levantamento sobre os dados de elevação em escala global, de modo a gerar uma base de dados sobre a topografia terrestre com a maior resolução digital possível, através de um radar projetado para esse fim, o qual sobrevoou a atmosfera do planeta durante 11 dias, no mês de fevereiro do ano 2000.

Os dados obtidos são disponibilizados a qualquer usuário da internet e podem ser adquiridos em dois formatos distintos - arquivo com extensão relacionada a um Sistema de Informação Geográfica ou em formato de planilha acessada através de um editor de texto. Como pode ser observado na Figura B.6, a superfície terrestre foi dividida em 72 fusos com 5 graus de longitude e 24 fusos com 5 graus de latitude, sendo então possível selecionar a quadrícula que contém a localidade cuja altitude se deseja conhecer. 


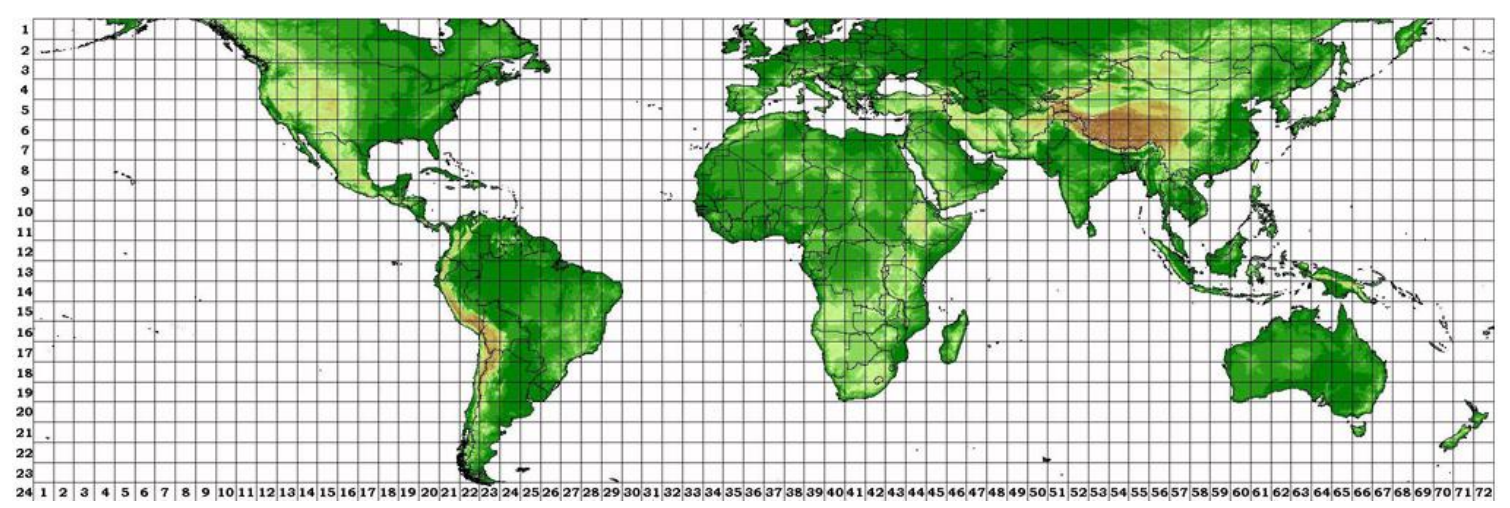

Figura B.6 - Divisão da superfície terrestre definida no projeto SRTM.

Após definição do tipo de arquivo a ser adquirido (SIG ou planilha), o usuário é direcionado para uma seção que contém a descrição da quadrícula selecionada e o seu esquema gráfico, exemplificado no conjunto de ilustrações da Figura B.7.

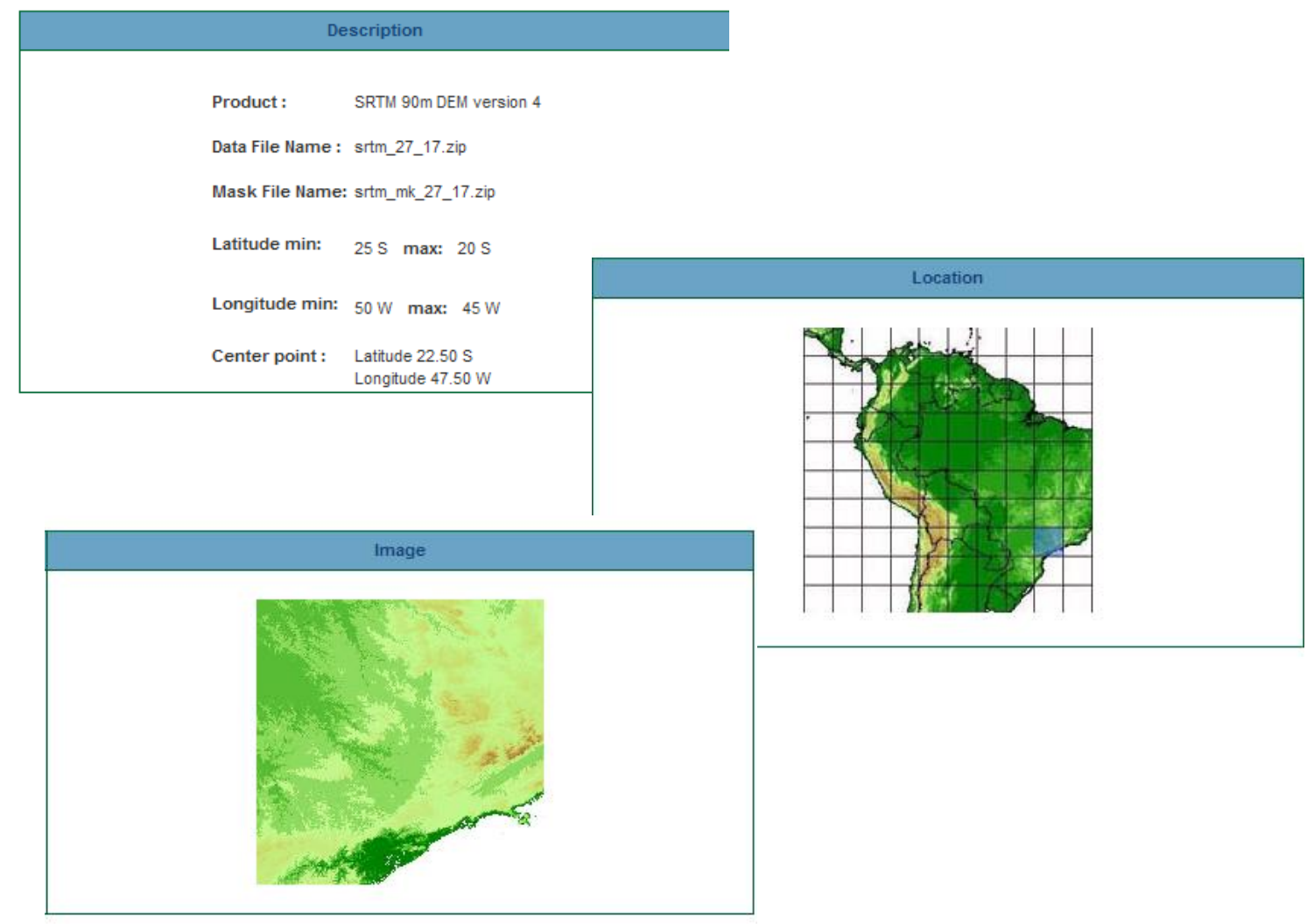

Figura B.7 - Detalhamento de uma quadrícula definida no projeto SRTM.

Cada quadrícula representada na figura acima contém 36 milhões de pontos espaçados igualmente em uma matriz quadrada de 6000 linhas e 6000 colunas, cada qual com uma altitude correspondente. Como estas possuem variação de 5 graus de latitude e 5 graus de longitude, cada ponto da matriz é espaçado $8,33_{\mathrm{x}} 10^{-4}$ graus (ou 3 segundos de arco) entre si, o equivalente a 90 metros, aproximadamente. 
A partir da aquisição dos arquivos que contêm as altitudes dos pontos sobre a ferrovia que liga as cidades de Santa Fé do Sul e Mairinque, os valores das elevações são calculados com base nas coordenadas desses pontos, através de interpolação linear.

Devido às imprecisões inerentes à localização exata da ferrovia no arquivo de linha do SIG, ao levantamento topográfico realizado e às aproximações devido ao processo de interpolação, foi verificada uma diferença expressiva entre a velocidade de um trem sobre a via caracterizada pelo arquivo real e aquela gerada através deste método.

A análise dos resultados das simulações mostrou que a velocidade na via real é significativamente maior que aquela obtida na via teórica, decorrente da elevada declividade das rampas calculadas devido à não uniformidade das altitudes apresentadas pelo levantamento topográfico.

Devido a isso, foi necessário suavizar o perfil longitudinal da ferrovia, de modo análogo ao realizado na correção das curvas horizontais do arquivo com o traçado da ferrovia. A Figura B.8 apresenta as altitudes no trecho entre as cidades de Salto e Mairinque, e também o perfil longitudinal obtido através do projeto SRTM e o suavizado.

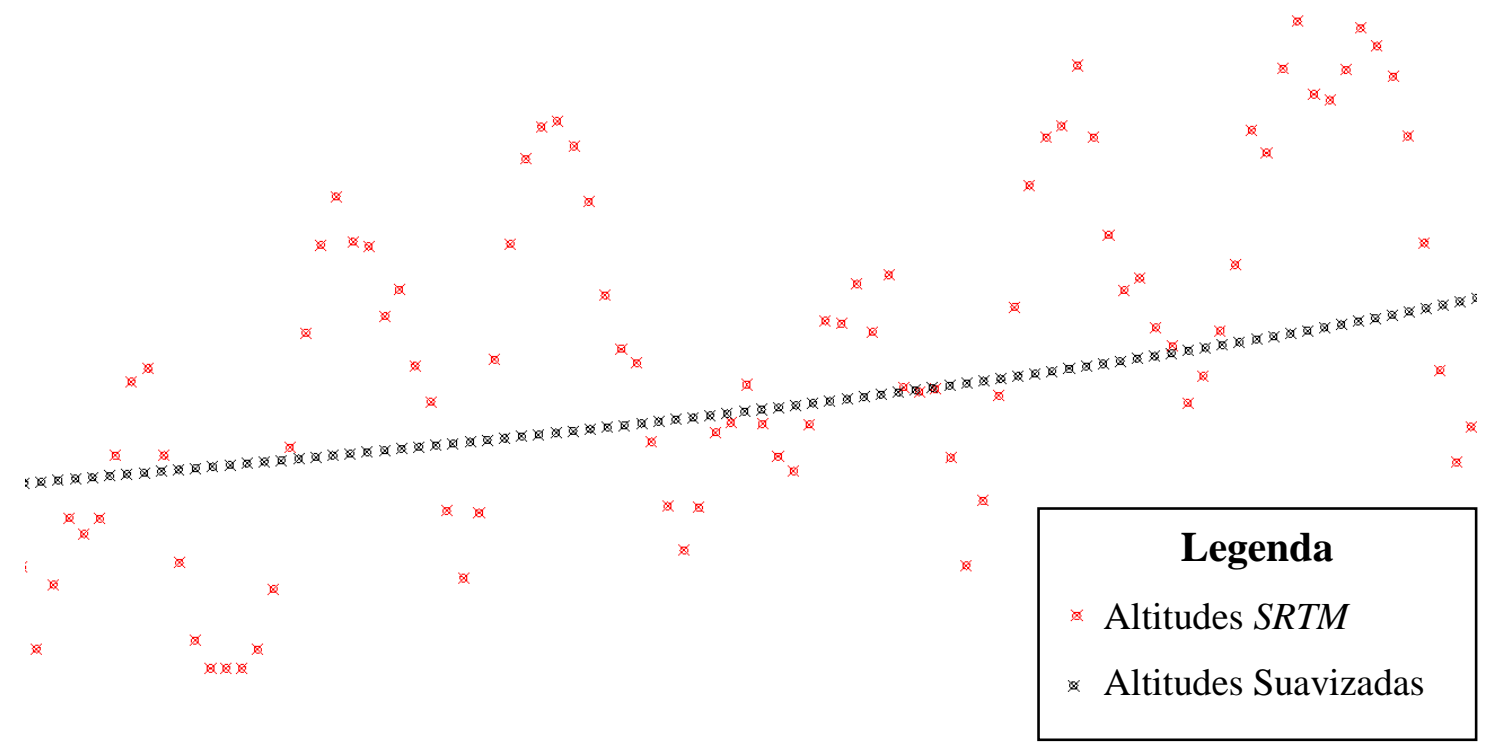

Figura B.8 - Suavização do perfil longitudinal da via permanente.

A partir das altitudes ajustadas nos pontos de coordenadas conhecidas do trecho ferroviário, é possível calcular as rampas nesses locais com base no mesmo critério de pontos sucessivos, utilizado para obtenção do raio das curvas. A partir da Figura B.9, apresentada a seguir, a rampa em um ponto de coordenadas e altitude conhecidas é calculada segundo a Equação (A.10). 


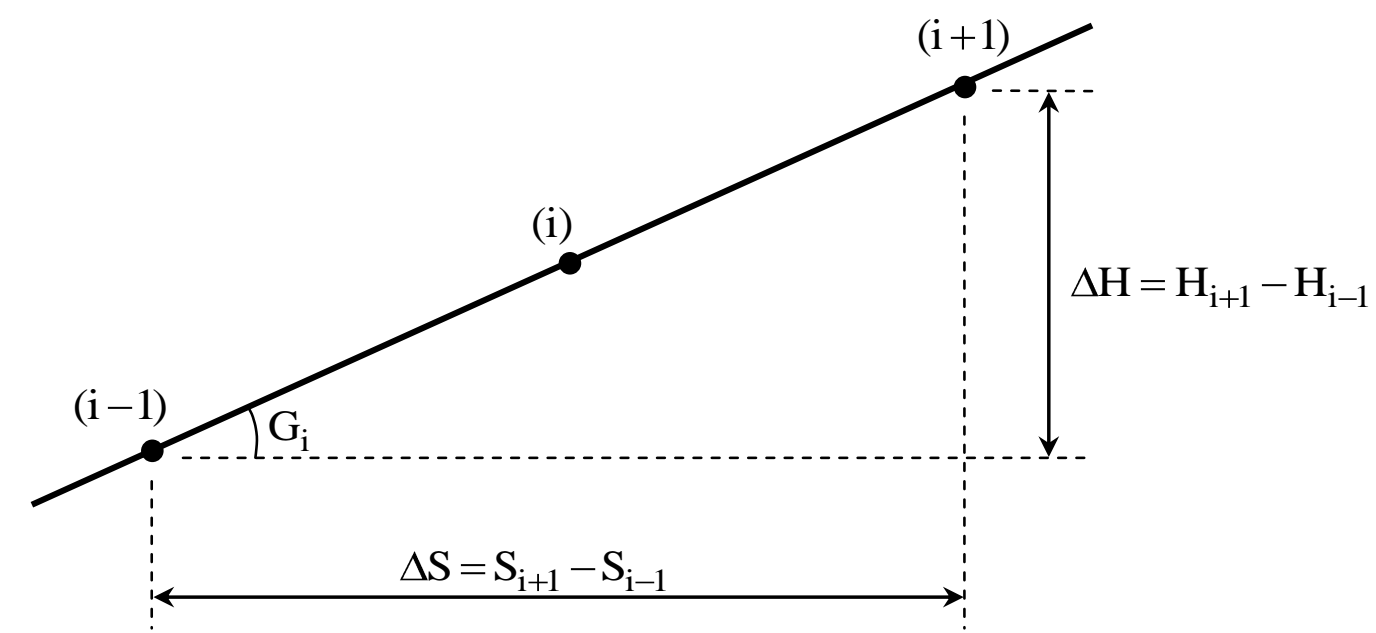

Figura B.9 - Esquemas para cálculo das rampas nos pontos da ferrovia.

$$
\mathrm{G}_{\mathrm{i}}=\frac{\Delta \mathrm{H}}{\Delta \mathrm{S}}=\frac{\mathrm{H}_{\mathrm{i}+1}-\mathrm{H}_{\mathrm{i}-1}}{\mathrm{~S}_{\mathrm{i}+1}-\mathrm{S}_{\mathrm{i}-1}}
$$

em que $G_{i}=$ rampa no ponto (i) da trajetória.

$\mathrm{S}_{\mathrm{i}-1}=$ posição do ponto à montante do ponto (i) .

$\mathrm{S}_{\mathrm{i}+1}=$ posição do ponto à jusante do ponto (i) .

$\mathrm{H}_{\mathrm{i}-1}=$ altitude do ponto à montante do ponto (i) .

$\mathrm{H}_{\mathrm{i}+1}=$ altitude do ponto à jusante do ponto (i) .

\section{B.2. Características dos elementos ferroviários da via real}

Esta etapa de obtenção dos parâmetros associados a um trecho real de linha ferroviária diz respeito à análise dos fatores que determinam as condições de circulação dos trens. Ao observar os dados de um arquivo de via existente para simulação no TEM, é possível concluir que os dados de posição, as rampas e raios de curvas são de caráter determinístico, os quais podem ser obtidos através dos métodos algébricos e geométricos apresentados no item anterior.

Existem, entretanto, fatores que exercem influência sobre os tempos de viagem nos arcos que apresentam comportamento aleatório, quando analisados sob o ponto de vista de 
caracaterização de um trecho ferroviário. Esses fatores estão relacionados às variáveis que determinam o comprimento dos desvios destinados ao cruzamento dos trens em sentidos opostos, às condições de conservação da superestrutura ferroviária e à distância entre pontes, viadutos e passagens em nível ao longo da via.

A partir do arquivo contendo as características reais do ramal entre os terminais de Santa Fé do Sul e Mairinque, foram extraídos dados sobre esses parâmetros e ajustadas funções de distribuição de probabilidade às séries de dados encontrados para que, durante a modelagem de um trecho virtual, pudessem ser escolhidos valores dessas variáveis com base no padrão de distribuição aleatório determinado para cada uma delas.

A seguir, são descritos os métodos de obtenção dos valores que caracterizam essas variáveis aleatórias e a função de distribuição de probabilidade que melhor se ajusta a elas, através do método do valor mínimo das somas dos erros quadráticos. Em cada item é exposto o procedimento de obtenção do parâmetro, seguido da descrição da função de distribuição de probabilidade que apresentou melhor ajuste no histograma construído com os dados do arquivo da via real.

Além dos parâmetros expostos a seguir, existem dois elementos ferroviários que podem ser incorporados ao modelo de simulação de marcha, que são as pontes e viadutos. Apesar de serem caracterizados no arquivo real, foi observado que essas construções não influenciam significativamente nos tempos de viagem nos arcos do sistema, de modo que o padrão de ocorrência no trecho não foi objeto de estudo nesta modelagem.

\section{B.2.1. Nós}

O primeiro passo na caracterização dos elementos que constituem uma ferrovia é a definição dos nós que permitem o cruzamento de trens que circulam em sentidos opostos. A localização dos nós nos ramais da rede em que foi aplicado o modelo de capacidade de processamento de trens foi estabelecida segundo uma base de dados fornecida pelo Ministério dos Transportes.

A seguir é exposto o método de definição do início e final dos nós, com o qual é possível determinar o comprimento dos arcos. Para análise desse parâmetro foi criada uma rotina computacional que identifica a localização da entrada e saída de um nó no arquivo real da via e calcula a diferença entre essas posições, cujos valores resultam no histograma e função de densidade de probabilidade, apresentados a seguir. 


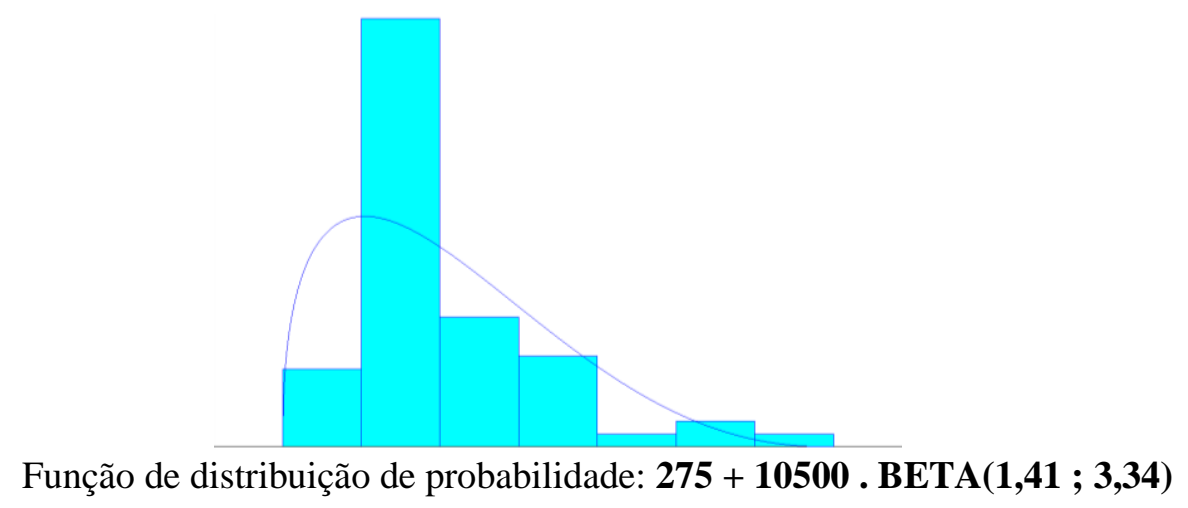

Nesses locais definidos pela distribuição da frequência apresentada acima ocorre uma redução de velocidade dos trens - na entrada e saída do nó, e esta segue um padrão representado pela função de distribuição de probabilidade e histograma a seguir, os quais serão utilizados para escolha aleatória da velocidade limite de operação nesses locais.

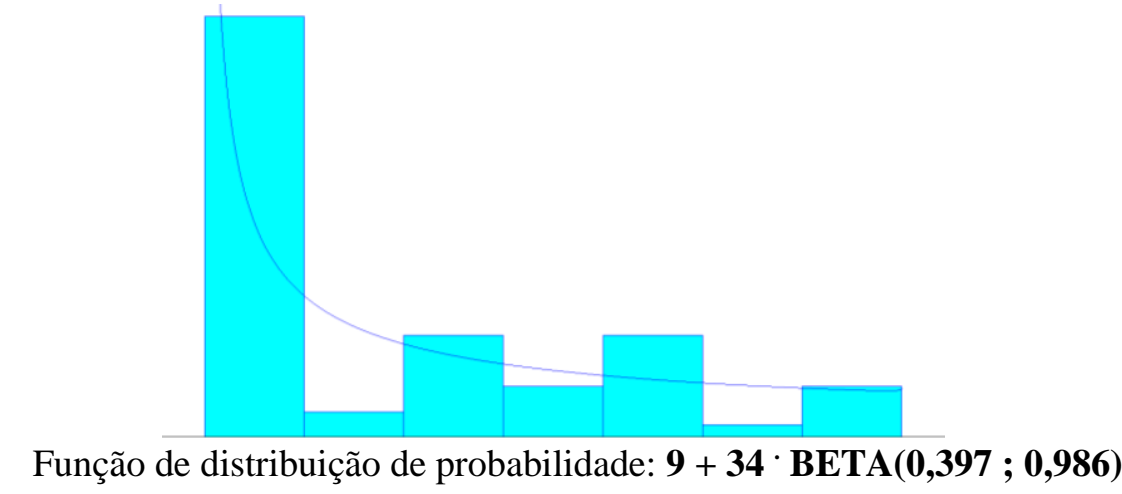

\section{B.2.2. Limites de velocidade}

A condição de conservação da linha ferroviária (trilhos, dormentes, lastro etc.) é uma variável qualitativa que reflete o desgaste da via permanente, decorrente da ação do tempo e circulação dos trens. Para que essa característica fosse incorporada ao processo de caracterização dos ramais ferroviários, esse parâmetro foi convertido em uma variável que reflete o limite de velocidade operacional nos pontos da linha, a fim de evitar acidentes que comprometam a operação do sistema.

No arquivo da via entre os terminais de Santa Fé Sul e Mairinque, as velocidades limites apresentam um comportamento aleatório, que varia em trechos com comprimento e espaçamento definidos.

Inicialmente, foram estabelecidos três intervalos de valores de velocidade limite, utilizados para classificação de um trecho nas condições BOA, MÉDIA ou RUIM. As velocidades que 
caracterizam o início e final de cada um desses intervalos são relacionadas à terça parte da velocidade máxima permitida, cujo valor é estabelecido em $70 \mathrm{~km} / \mathrm{h}$ (43 mph), de modo que a condição RUIM compreende a velocidade igual a zero e a primeira terça parte, inclusive; a condição MÉDIA, a primeira terça parte e a segunda terça parte, inclusive, e a condição BOA, a segunda terça parte e a velocidade máxima, inclusive.

Desse modo, tem-se a seguinte caracterização qualitativa das velocidades máximas possíveis em um trecho qualquer:

CONDIÇÃO RUIM: $0 \leq$ Velocidade $\leq \frac{\mathrm{V}_{\text {máx }}}{3} \cong 14 \mathrm{mph}$

CONDIÇÃO MÉDIA: $\frac{\mathrm{V}_{\text {máx }}}{3} \cong 14 \mathrm{mph}<$ Velocidade $\leq 2 \cdot \frac{\mathrm{V}_{\text {máx }}}{3} \cong 28,5 \mathrm{mph}$ CONDIÇÃO BOA: $2 \cdot \frac{\mathrm{V}_{\text {máx }}}{3} \cong 28,5 \mathrm{mph} \leq$ Velocidade $\leq \mathrm{V}_{\text {máx }}=43 \mathrm{mph}$

Após a classificação dos limites de velocidade nos pontos da via, construiu-se um gráfico de frequência ilustrado no histograma a seguir, no qual são indicados os intervalos de classificação das condições de conservação da ferrovia. Nesse histograma foi definida uma função de distribuição de probabilidade que possibilita a escolha aleatória de um valor de velocidade limite no intervalo para ser atribuído a um trecho de via teórica, cujo procedimento é descrito mais adiante.

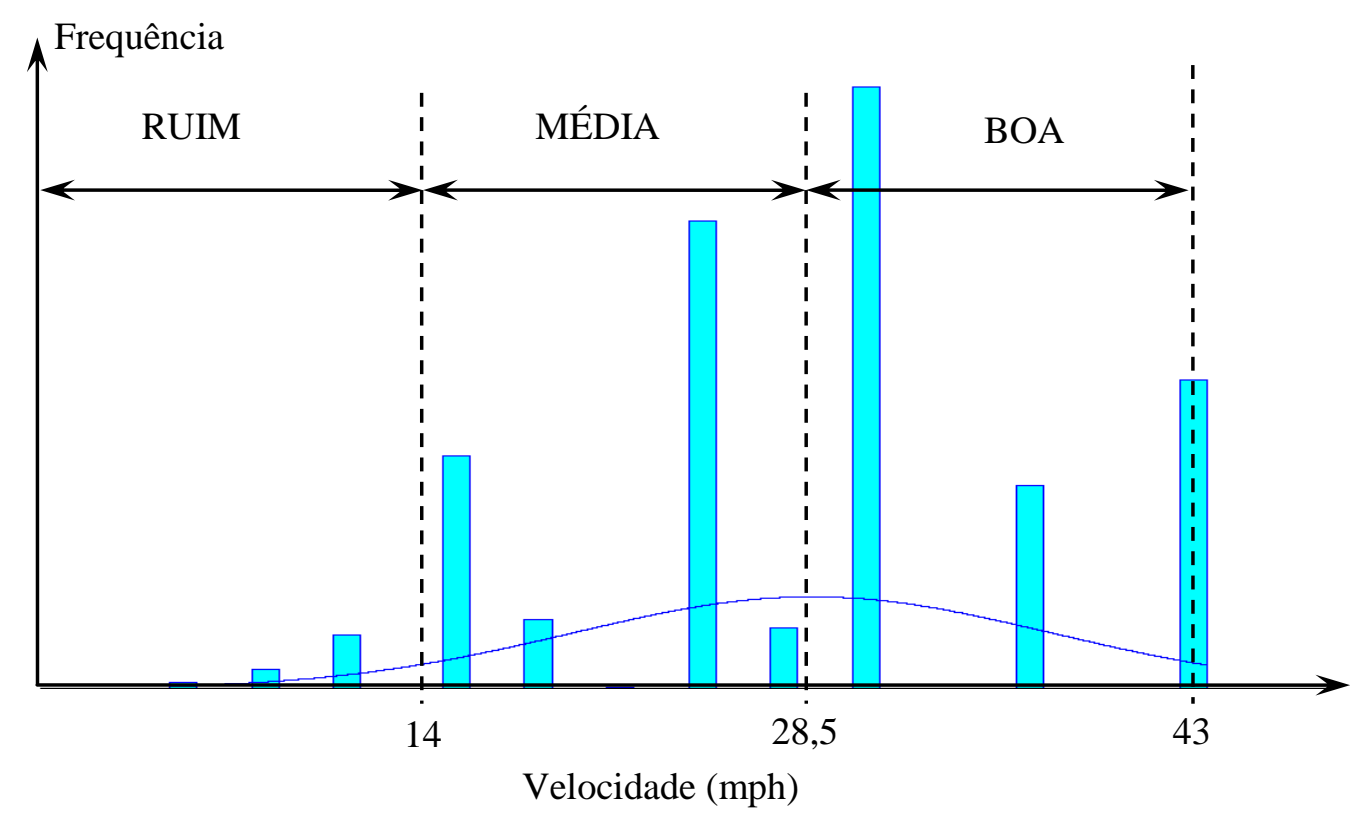

Função de distribuição de probabilidade: NORMAL (28,6 ; 8,91) 
Para atribuir limites de velocidades nos trechos da via são definidas duas variáveis, que dizem respeito ao comprimento do trecho com esse mesmo atributo, escolhido aleatoriamente na função de distribuição de probabilidade indicada no histograma anterior, e o espaçamento entre os trechos com velocidade máxima permitida, inseridas na mesma classe (BOA, MÉDIA ou RUIM).

O esquema da Figura B.10 apresenta o modo como são calculados os parâmetros referentes aos comprimentos dos trechos em um dado estado de conservação e espaçamento entre estes.

\section{CONSERVAÇÃO BOA, MÉDIA OU RUIM}

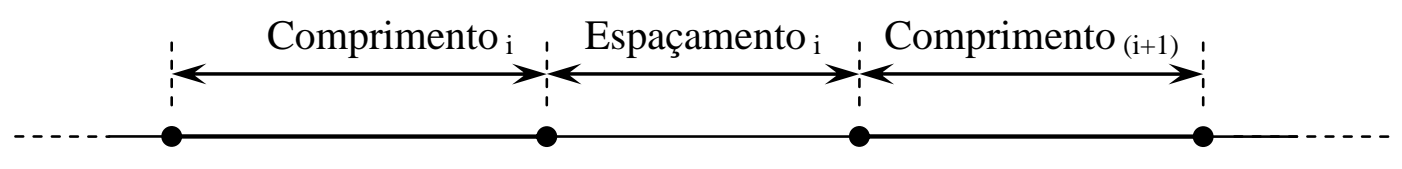

Figura B.10 - Representação do método utilizado para determinação dos parâmetros de conservação da superestrutura ferroviária.

Para cada um desses intervalos foi estabelecida uma função de distribuição de probabilidade, relacionada a essas duas variáveis (comprimento e espaçamento), baseadas nas observações do aquivo real da via, no corredor entre Santa Fé do Sul e Mairinque, que resultaram nos histogramas e funções apresentados a seguir.

$$
\text { CONDIÇÃO RUIM }\left[0 \leq \text { Velocidade } \leq \frac{\mathrm{V}_{\text {máx }}}{3} \cong 14 \mathrm{mph}\right]
$$

\section{Comprimento}

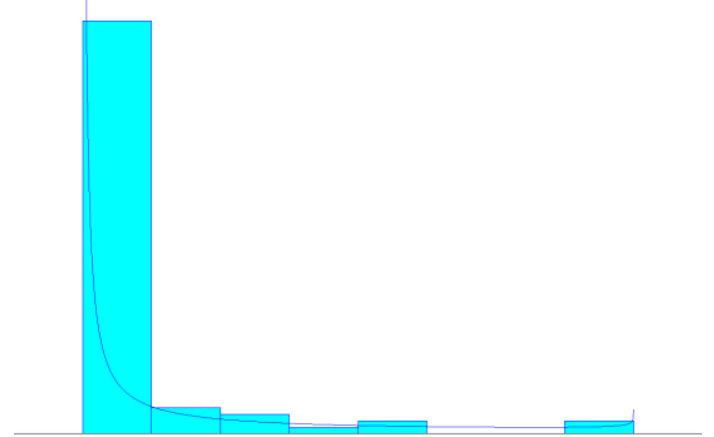

Função de distribuição de probabilidade: -0.001 + EXPONENCIAL (370) 


\section{Espaçamento}

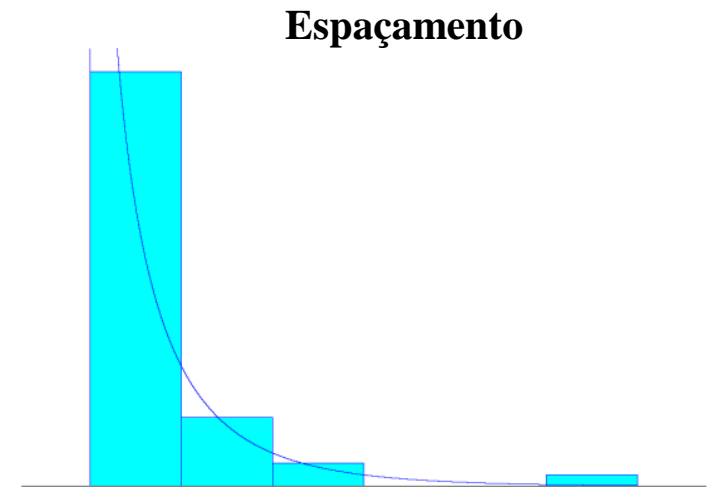

Função de distribuição de probabilidade: 275 + WEIBULL $(21700$; 0,68)

\section{CONDIÇÃO MÉDIA $\left[\frac{\mathrm{V}_{\text {máx }}}{3} \cong 14 \mathrm{mph}<\right.$ Velocidade $\left.\leq 2 \cdot \frac{\mathrm{V}_{\text {máx }}}{3} \cong 28,5 \mathrm{mph}\right]$}

\section{Comprimento}

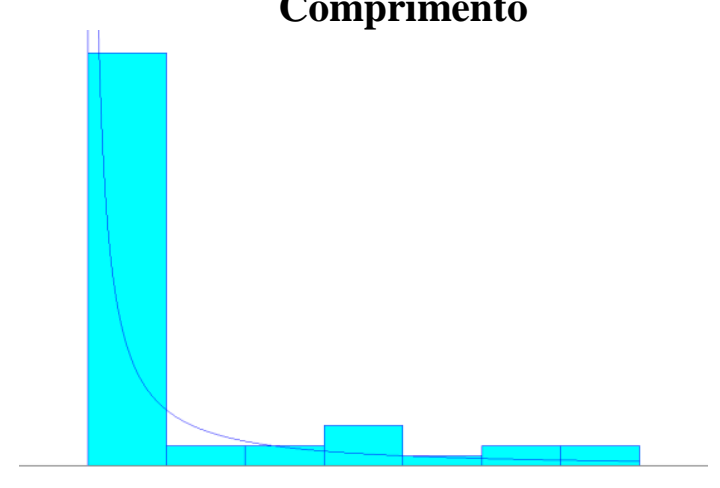

Função de distribuição de probabilidade: $-\mathbf{0 . 0 0 1}+$ WEIBULL $(\mathbf{7 6 5 0} ; \mathbf{0 , 3 7 2})$

\section{Espaçamento}

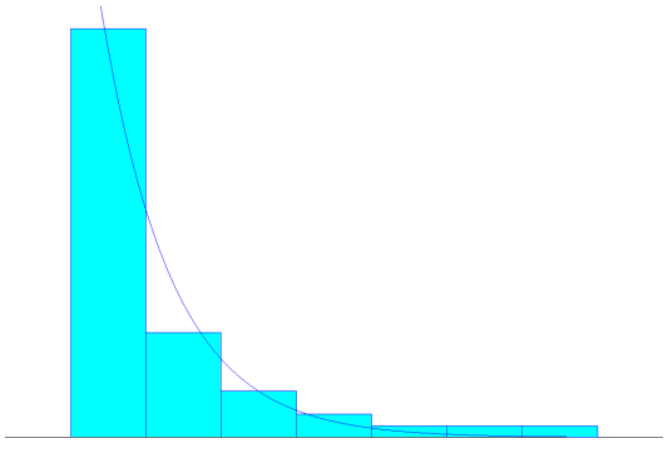

Função de distribuição de probabilidade: $124+$ EXPONENCIAL (20700) 


\section{CONDIÇÃ̃ BOA $\quad\left[2 \cdot \frac{\mathrm{V}_{\text {máx }}}{3} \cong 28,5 \mathrm{mph} \leq\right.$ Velocidade $\left.\leq \mathrm{V}_{\text {máx }}=43 \mathrm{mph}\right]$}

\section{Comprimento}

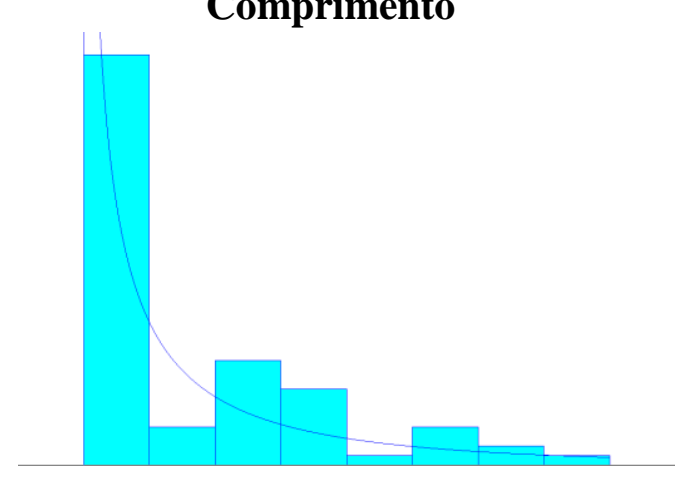

Função de distribuição de probabilidade: $-\mathbf{0 . 0 0 1}+$ WEIBULL $(9070 ; 0,519)$

\section{Espaçamento}

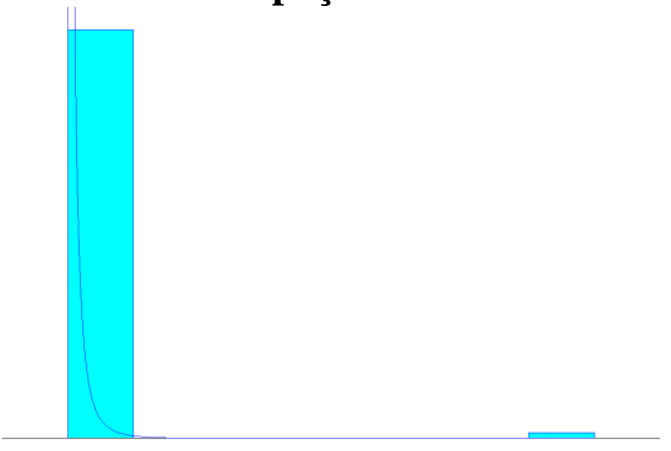

Função de distribuição de probabilidade: $69+$ WEIBULL $(2420 ; 0,457)$

\section{B.2.3. Passagens em nível}

No arquivo que caracteriza o trecho real entre os terminais de Santa Fé do Sul e Mairinque, são identificadas as passagens em nível (interseções da ferrovia com outros modos de transporte) e a posição em que estão localizadas. Um histograma referente à distância entre esses locais é construído e uma função de distribuição de probabilidade é ajustada, conforme indicado a seguir. 


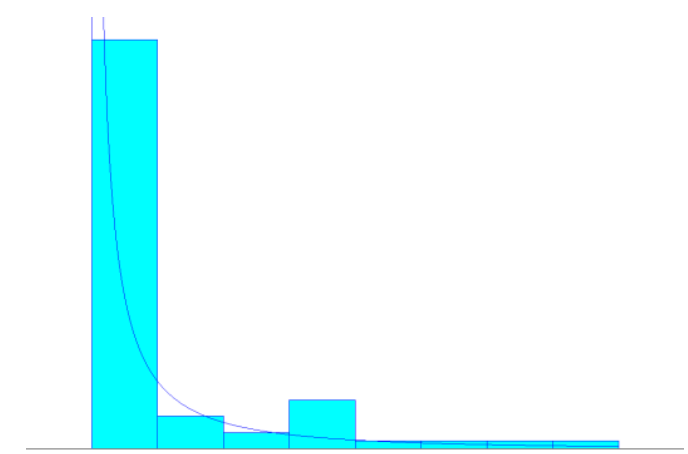

Função de distribuição de probabilidade: 3 + WEIBULL $(8860$; 0,393)

\section{B.3. Caracterização dos elementos ferroviários no modelo teórico da via}

Após a definição da posição, raio de curva, altitude e rampa nos pontos da linha ferroviária teórica, entre os terminais de Santa Fé do Sul e Mairinque, procede-se à atribuição dos parâmetros relativos aos elementos que fazem parte do sistema, cujas variáveis foram definidas no item anterior, sob a forma de funções de distribuição de probabilidade. Os itens a seguir descrevem o método de atribuição de valores a cada um desses elementos.

Os elementos físicos que caracterizam um trecho ferroviário no arquivo de via do simulador são definidos através de duas variáveis denominadas " $c_{1}$ " e " $c_{2}$ ", que recebem valores numéricos (Tabela B. 1), relativos a cada um desses componentes.

Tabela B. 1 - Códigos para caracterização da via permanente no simulador TEM.

\begin{tabular}{ccc}
\hline $\begin{array}{c}\text { Valor } \\
\text { numérico }\end{array}$ & Código 1 $\left(\mathbf{c}_{\mathbf{1}}\right)$ & Código $\mathbf{2}\left(\mathbf{c}_{\mathbf{2}}\right)$ \\
\hline 0 & Linha singela & Linha singela \\
1 & - & Linha do desvio \\
2 & Ponte & Chave direita do desvio (entrada do desvio) \\
3 & Viaduto & Chave esquerda do desvio (saída do desvio) \\
5 & Passagem em nível & - \\
8 & Estação & - \\
\hline
\end{tabular}

\section{B.3.1. Nós}

A localização das estações nos ramais da rede ferroviária, cujos dados reais não são conhecidos, foi estabelecida por meio de uma base de dados fornecida pelo Ministério dos Transportes, através da $\mathrm{Dr}^{\mathrm{a}}$. Karênina Martins Teixeira ${ }^{4}$. Após os locais de parada dos trens

\footnotetext{
${ }^{4}$ TEIXEIRA, K. M. Publicação eletrônica [mensagem pessoal]. Mensagem recebida por <cassiano.isler@ usp.br> em 26 jun. 2009.
} 
serem estabelecidos convenientemente, procedeu-se à definição do comprimento dos pátios de cruzamento, situados na mesma área das estações.

O valor desse parâmetro é escolhido aleatoriamente, segundo uma função de distribuição de probabilidade dada por [275+10500 BETA(1,41;3,34)], em pés, cujo valor deve ser maior que 3280,84 pés (1000 metros), referente à média dos comprimentos dos desvios existentes no trecho de via real. Na entrada e saída dos pátios de cruzamento é inserido um valor de velocidade limite, dada por uma função de distribuição de probabilidade expressa por $[9+34 \cdot \operatorname{BETA}(0,397 ; 0,986)]$. Assim como os demais parâmetros aleatórios envolvidos na caracterização da linha ferroviária, essas duas funções foram obtidas a partir da análise do comportamento dessas variáveis no arquivo real do trecho entre Santa Fé do Sul e Mairinque.

\section{B.3.2. Limites de velocidade}

A atribuição dos limites de velocidade em trechos da via teórica, com comprimentos e espaçamentos específicos, baseados nas classes de condições de conservação da via (BOA, MÉDIA e RUIM) e nas funções de distribuição de probabilidade apresentadas nos itens anteriores, foi realizada através do algoritmo apresentado a seguir, implementado no Microsoft Office Excel.

Passo 1 - Escolha de um valor de limite de velocidade, segundo a função de distribuição de probabilidade "Normal", com média 28,8 mph e desvio padrão $8,91 \mathrm{mph}$;

Passo 2 - Identificação da classe de condição de conservação (BOA, MÉDIA ou RUIM) em que a velocidade escolhida aleatoriamente está inserida;

Passo 3 - Escolha aleatória do comprimento do trecho ao qual será atribuída a velocidade máxima escolhida;

Passo 4 - Atribuição dessa velocidade ao conjunto de pontos do trecho que compreende a extensão definida no Passo 3.

Passo 5 - Escolha aleatória do espaçamento entre o final da velocidade máxima escolhida nessa iteração e o início do trecho com a velocidade máxima, que pertence à mesma condição de conservação da atual.

Passo 6 - Escolha aleatória de um novo valor de velocidade máxima para um novo trecho da 
via;

Passo 7 - Se o valor de velocidade escolhido pertencer a uma classe diferente da atual, verificar se a posição do último ponto ao qual foi atribuído um valor de velocidade máxima é maior que a do final do último trecho pertencente à classe do valor escolhido, somado ao espaçamento entre trechos, definido na iteração anterior para essa classe. Caso essa condição seja verificada, o algoritmo retorna ao Passo 2, até que toda a extensão do trecho de via teórica seja percorrido. Caso contrário, um novo valor de velocidade máxima é determinado e nova verificação da condição estabelecida neste passo é realizada.

\section{B.3.3. Passagens em nível}

Conforme descrito anteriormente, a localização das passagens em nível é dada por uma variável aleatória descrita por uma função de distribuição de probabilidade "Weibull". A partir da escolha aleatória da distância entre esses dispositivos, um algoritmo implementado no Visual Basic for Applications do software Microsoft Office Excel verifica se a velocidade máxima no ponto que receberá esse atributo é maior que aquela definida na etapa de definição do limite de velocidade na via.

Caso essa condição seja verdadeira, a velocidade máxima nesse ponto é substituída pelo valor de $28 \mathrm{mph}$ (aproximadamente $45 \mathrm{~km} / \mathrm{h}$ ), referente à média das velocidades nos pontos caracterizados como passagens em nível do arquivo de via real. Caso contrário, um novo número aleatório é escolhido e nova verificação é realizada. O procedimento descrito nesta etapa é realizado até que toda a extensão da linha ferroviária seja percorrida.

\section{B.4. Validação do modelo}

A validação do modelo proposto neste apêndice se deu através da comparação da velocidade média nos arcos do corredor ferroviário, entre os terminais de Santa Fé do Sul e Mairinque, considerando a circulação de um trem-tipo na via real e na linha caracterizada pelos procedimentos descritos anteriormente.

A configuração do trem é uma locomotiva principal do tipo DASH9, com massa de 160 toneladas, uma locomotiva auxiliar do tipo U20, com massa de 108 toneladas - para os trechos que necessitam de força de tração adicional para serem percorridos, e 45 vagões carregados do tipo HOOPER, com 100 toneladas cada um, semelhante ao utilizado para 
determinação da capacidade de processamento da rede apresentada no Capítulo 4.

As simulações foram realizadas no sentido "Exportação" e "Importação" de circulação dos trens, para que pudesse ser investigada a influência na modificação da orientação das rampas e curvas, que alteram significativamente as velocidades em relação a cada sentido. Foram estabelecidos cenários distintos considerando separadamente cada um dos elementos que influem sobre a velocidade média nos arcos (rampas, raios de curvas, limites de velocidade) e um cenário adicional com a união dessas três variáveis.

A Tabela B.2 mostra as variações percentuais das velocidades médias no trecho entre Santa Fé do Sul e Mairinque nos cenários propostos, segundo as porcentagens relativas aos comprimentos dos trechos em que foram calculadas as velocidades médias.

Tabela B.2 - Erros médios das velocidades nos arcos em relação a cada parâmetro da via permanente

\begin{tabular}{cccccc}
\hline & $\begin{array}{c}\text { Velocidade } \\
\text { na via }\end{array}$ & Rampas & Curvas & Superestrutura & Todas \\
\hline \multirow{2}{*}{ Sentido } & Teórica & 64 & 66 & 33 & 29 \\
Exportação & Real & 58 & 66 & 30 & 26 \\
& Erro* & $10 \%$ & $0 \%$ & $10 \%$ & $12 \%$ \\
\hline \multirow{2}{*}{ Sentido } & Teórica & 63 & 66 & 33 & 28 \\
Importação & Real & 58 & 66 & 30 & 26 \\
& Erro* & $9 \%$ & $0 \%$ & $10 \%$ & $8 \%$ \\
\hline
\end{tabular}

* Relativo à velocidade dos trens na via real, tal que ERRO $=\left(\mathrm{V}_{\text {Teórica }}-\mathrm{V}_{\mathrm{Re} \text { al }}\right) / \mathrm{V}_{\mathrm{Re} \text { al }} \cdot$

Algumas ressalvas devem ser feitas quanto ao uso do modelo de via permanente proposto nesse capítulo. Primeiramente, é possível constatar que as velocidades médias obtidas pela simulação dos cenários, com a via permanente gerada pelo modelo que considera apenas as rampas e os limites de velocidade nos arcos, divergem daquelas obtidas utilizando o arquivo real da via permanente (aproximadamente 10\%).

Esses erros, entretanto, dizem respeito à velocidade média considerando o tempo de viagem em relação ao comprimento total da via. Se forem analisadas as velocidades médias nos arcos do trecho, as variações observadas são mais expressivas, como pode ser observado no histograma da Figura B.11, e as aproximações dos tempos de viagem nesses trechos para aplicação no modelo de capacidade não representam o movimento real do trem na via. 


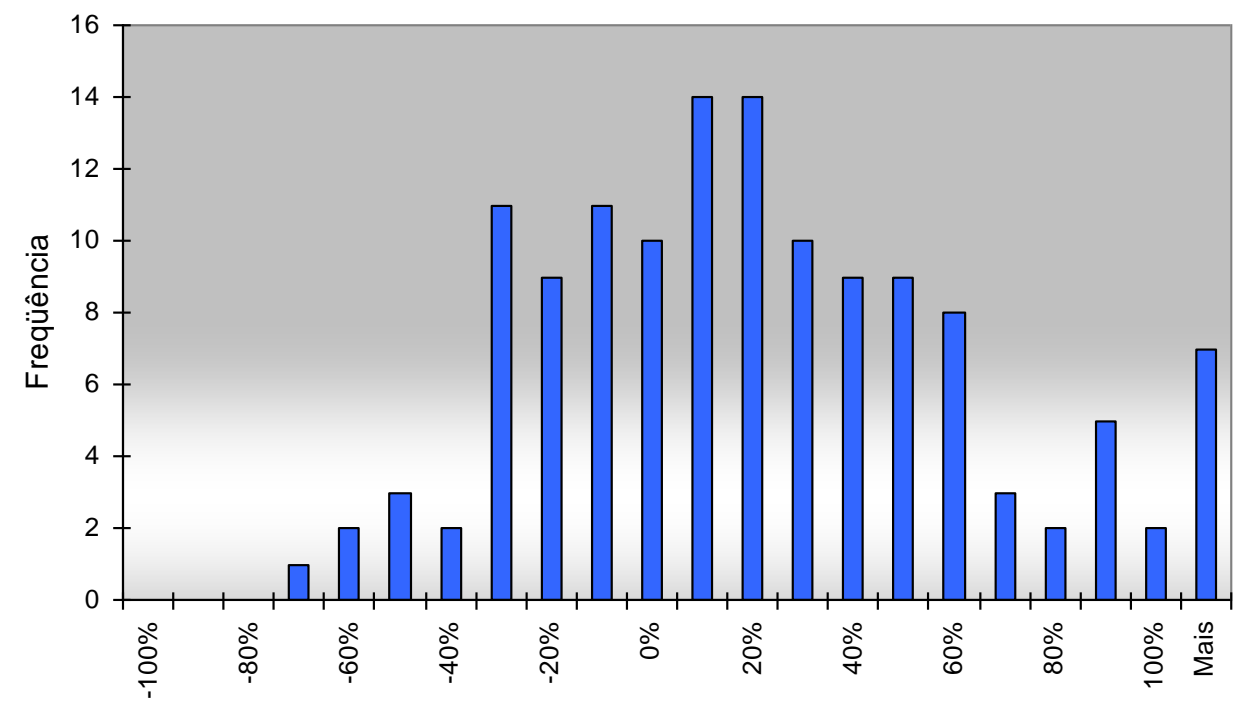

Figura B.11 - Erros percentuais das velocidades médias nos arcos.

O gráfico anterior mostra que as diferenças percentuais entre as velocidades médias nos arcos são maiores que aquelas obtidas no trecho real da via, cujas causas são devidas, igualmente, aos limites de velocidade e valores das rampas nos pontos que caracterizam a via permanente.

Os erros devido aos limites de velocidade são decorrentes do seu caráter aleatório, e podem ser excessivamente discrepantes no trecho de via teórica em relação aos valores reais. Por exemplo, em um arco com baixos valores de limite de velocidade na via real podem ser atribuídos valores mais altos a essa variável, resultando em uma velocidade média no trecho maior que a possível de ser desenvolvida pelo trem.

Os valores das rampas interferem sobre os valores de velocidade média, devido às imprecisões decorrentes do método de obtenção dos dados pelo projeto SRTM e ao fato dos pontos que definem o traçado da ferrovia não estarem localizados exatamente no seu eixo. Este último problema é devido às aproximações da base georeferenciada de ferrovias, apresentadas no SIG Transcad, e às imprecisões decorrentes do processo de interpolação para cálculo das altitudes nesses pontos.

Apesar das restrições de aplicação do modelo proposto neste apêndice, os resultados dos tempos de viagem nos arcos dos ramais entre os terminais de Itirapina-Panorama e Araraquara-Colômbia, da rede enraizada não-direcionada, indicada no Capítulo 4, foram utilizados para aplicação do modelo de capacidade de procesamento de trens, apresentado neste trabalho.

Esses valores são válidos para definição de um cenário virtual de caracaterização do 
movimento dos trens, diante da dificuldade de obtenção dos dados reais da via permanente junto aos órgãos públicos e privados, detentores das informações a respeito das características do sistema ferroviário brasileiro. 


\section{Apêndice C}

\section{RAMAIS DA REDE FERROVIÁRIA}

Neste apêndice são detalhados os ramais da rede, com a relação dos nós que os constituem, a distância entre eles, o tempo médio de viagem em ambos os sentidos de circulação - com os limites reais de velocidade e retirando as restrições de velocidade impostas pelas condições de conservação da superestrutura, dados estes obtidos através do simulador Train Energy Model.

\section{Ramal Mairinque-Itirapina (1-2)}

Tabela C.1 (continua) - Localização dos nós do ramal Mairinque-Itirapina (1-2), com marco inicial no terminal de Mairinque.

\begin{tabular}{|c|c|c|c|c|c|c|c|}
\hline \multirow{3}{*}{ Nó } & \multirow{3}{*}{ Sigla } & \multirow{3}{*}{$\begin{array}{c}\text { Localização } \\
(\mathbf{k m})\end{array}$} & \multirow{3}{*}{$\begin{array}{c}\text { Comprimento } \\
\text { do arco } \\
(\mathbf{k m})\end{array}$} & \multicolumn{4}{|c|}{ Tempo médio de viagem (min) } \\
\hline & & & & \multicolumn{2}{|c|}{$\begin{array}{l}\text { Limites reais de } \\
\text { velocidade }\end{array}$} & \multicolumn{2}{|c|}{$\begin{array}{c}\text { Limite teórico de } \\
\text { velocidade } \\
(70 \mathrm{~km} / \mathrm{h})\end{array}$} \\
\hline & & & & Exp. & Imp. & Exp. & Imp. \\
\hline $\begin{array}{l}\text { Terminal } \\
\text { Mairinque }\end{array}$ & ZME & 0 & - & - & - & - & - \\
\hline Guaiana & ZGI & 5,5 & 5,5 & 11 & 12 & 11 & 12 \\
\hline Capricórnio & $\mathrm{ZCX}$ & 17,8 & 12,3 & 23 & 30 & 19 & 17 \\
\hline Eng. Acrísio & ZER & 22,4 & 4,6 & 20 & 17 & 13 & 9 \\
\hline Pirapitingui & ZXP & 42,8 & 20,4 & 32 & 34 & 29 & 23 \\
\hline Itu & ZYU & 58,7 & 16,0 & 31 & 40 & 23 & 22 \\
\hline Salto & $\mathrm{ZST}$ & 67,3 & 8,6 & 25 & 17 & 16 & 13 \\
\hline Pimenta & ZXI & 73,9 & 6,5 & 16 & 12 & 13 & 12 \\
\hline Itaici & ZIC & 77,7 & 3,8 & 17 & 19 & 8 & 9 \\
\hline Viracopos & ZVK & 90,2 & 12,5 & 46 & 28 & 17 & 18 \\
\hline $\begin{array}{l}\text { Boa Vista } \\
\text { Velha }\end{array}$ & ZBV & 110,9 & 20,7 & 48 & 52 & 27 & 27 \\
\hline Hortolândia & $\mathrm{ZHO}$ & 116,1 & 5,1 & 15 & 11 & 11 & 11 \\
\hline Sumaré & ZSU & 123,0 & 6,9 & 26 & 27 & 12 & 13 \\
\hline
\end{tabular}


Tabela C.1 (conclusão) - Localização dos nós do ramal Mairinque-Itirapina (1-2), com marco inicial no terminal de Mairinque.

\begin{tabular}{|c|c|c|c|c|c|c|c|}
\hline \multirow{3}{*}{ Nó } & \multirow{3}{*}{ Sigla } & \multirow{3}{*}{$\begin{array}{l}\text { Localização } \\
(\mathbf{k m})\end{array}$} & \multirow{3}{*}{$\begin{array}{c}\text { Comprimento } \\
\text { do arco } \\
(\mathbf{k m})\end{array}$} & \multicolumn{4}{|c|}{ Tempo médio de viagem (min) } \\
\hline & & & & \multicolumn{2}{|c|}{$\begin{array}{l}\text { Limites reais de } \\
\text { velocidade }\end{array}$} & \multicolumn{2}{|c|}{$\begin{array}{c}\text { Limite teórico de } \\
\text { velocidade } \\
(70 \mathrm{~km} / \mathrm{h})\end{array}$} \\
\hline & & & & Exp. & Imp. & Exp. & Imp. \\
\hline Nova Odessa & $\mathrm{ZNO}$ & 128,4 & 5,4 & 11 & 12 & 11 & 11 \\
\hline Recanto & $\mathrm{ZRC}$ & 131,8 & 3,5 & 16 & 30 & 7 & 8 \\
\hline Americana & ZAC & 135,4 & 3,6 & 22 & 9 & 8 & 9 \\
\hline Tatu & ZTT & 147,2 & 11,8 & 30 & 29 & 20 & 17 \\
\hline Limeira & ZLI & 158,9 & 11,6 & 24 & 19 & 19 & 17 \\
\hline Cordeirópolis & $\mathrm{ZCD}$ & 170,5 & 11,6 & 23 & 23 & 15 & 20 \\
\hline $\begin{array}{c}\text { Santa } \\
\text { Gertrudes }\end{array}$ & ZSQ & 179,6 & 9,1 & 16 & 16 & 16 & 13 \\
\hline $\begin{array}{c}\text { Rio Claro } \\
\text { Novo }\end{array}$ & ZRX & 185,4 & 5,8 & 22 & 18 & 10 & 11 \\
\hline Batovi & ZRQ & 192,5 & 7,1 & 18 & 19 & 12 & 10 \\
\hline Camaquã & ZQX & 197,8 & 5,3 & 22 & 19 & 9 & 12 \\
\hline Graúna & $\mathrm{ZOX}$ & 210,9 & 13,2 & 19 & 29 & 13 & 18 \\
\hline $\begin{array}{l}\text { Terminal } \\
\text { Itirapina }\end{array}$ & ZIQ & 223,2 & 12,3 & 35 & 34 & 17 & 26 \\
\hline
\end{tabular}

\section{Ramal Itirapina-Panorama (2-3)}

Tabela C.2 (continua) - Localização dos nós do ramal Itirapina-Panorama (2-3), com marco inicial no terminal de Itirapina.

\begin{tabular}{cccccccc}
\hline & & & & \multicolumn{3}{c}{ Tempo médio de viagem (min) } \\
\cline { 5 - 8 } Nó & Sigla & $\begin{array}{c}\text { Localização } \\
(\mathbf{k m})\end{array}$ & $\begin{array}{c}\text { Comprimento } \\
\text { do arco } \\
\mathbf{( k m )}\end{array}$ & $\begin{array}{c}\text { Limites reais de } \\
\text { velocidade }\end{array}$ & $\begin{array}{c}\text { Limite teórico } \\
\text { de velocidade } \\
\text { (70 km/h) }\end{array}$ \\
\cline { 5 - 9 } & & & & Exp. & Imp. & Exp. & Imp. \\
\hline $\begin{array}{c}\text { Terminal } \\
\text { Itirapina }\end{array}$ & ZIQ & 0 & - & - & - & - & - \\
\hline Posto km 183 & ZPO & 7,0 & 7,0 & 12 & 15 & 11 & 14 \\
\hline Campo Alegre & ZFH & 12,9 & 5,9 & 11 & 13 & 9 & 12 \\
\hline Aterrado & ZWF & 18,3 & 5,4 & 12 & 12 & 11 & 12 \\
\hline
\end{tabular}


Tabela C.2 (continuação) - Localização dos nós do ramal Itirapina-Panorama (2-3), com marco inicial no terminal de Itirapina.

\begin{tabular}{|c|c|c|c|c|c|c|c|}
\hline \multirow{3}{*}{ Nó } & \multirow{3}{*}{ Sigla } & \multirow{3}{*}{$\begin{array}{c}\text { Localização } \\
(\mathbf{k m})\end{array}$} & \multirow{3}{*}{$\begin{array}{c}\text { Comprimento } \\
\text { do arco } \\
(\mathbf{k m})\end{array}$} & \multicolumn{4}{|c|}{ Tempo médio de viagem (min) } \\
\hline & & & & \multicolumn{2}{|c|}{$\begin{array}{l}\text { Limites reais de } \\
\text { velocidade }\end{array}$} & \multicolumn{2}{|c|}{$\begin{array}{l}\text { Limite teórico } \\
\text { de velocidade } \\
(70 \mathrm{~km} / \mathrm{h})\end{array}$} \\
\hline & & & & Exp. & Imp. & Exp. & Imp. \\
\hline Brotas & $\mathrm{ZBO}$ & 26,0 & 7,7 & 15 & 12 & 14 & 11 \\
\hline Espraiado & ZEP & 28,8 & 2,7 & 10 & 5 & 9 & 6 \\
\hline Canela & $\mathrm{ZFG}$ & 35,8 & 7,0 & 16 & 20 & 14 & 9 \\
\hline Torrinha & ZTR & 42,6 & 6,8 & 19 & 16 & 9 & 13 \\
\hline Taboleiro & ZTE & 47,7 & 5,1 & 13 & 17 & 7 & 11 \\
\hline Ventania & ZVT & 54,9 & 7,3 & 14 & 16 & 9 & 16 \\
\hline Dois Córregos & ZDK & 62,0 & 7,0 & 17 & 15 & 10 & 13 \\
\hline $\begin{array}{l}\text { Lacerda } \\
\text { Franco }\end{array}$ & ZLF & 67,9 & 5,9 & 15 & 17 & 13 & 13 \\
\hline Banharão & $\mathrm{ZDH}$ & 74,9 & 7,0 & 19 & 18 & 12 & 10 \\
\hline Jaú & ZJU & 80,6 & 5,7 & 14 & 15 & 12 & 11 \\
\hline Ave Maria & ZWM & 88,1 & 7,5 & 19 & 18 & 12 & 11 \\
\hline Airosa Galvão & ZWY & 93,4 & 5,3 & 15 & 14 & 13 & 8 \\
\hline Pederneiras & $\mathrm{ZPD}$ & 101,7 & 8,3 & 21 & 19 & 17 & 10 \\
\hline Carajás & ZFJ & 107,9 & 6,2 & 15 & 16 & 12 & 7 \\
\hline Guaianas & ZGY & 114,8 & 6,9 & 18 & 16 & 9 & 14 \\
\hline Aimorés & ZAY & 123,9 & 9,1 & 24 & 27 & 17 & 14 \\
\hline $\begin{array}{l}\text { Triagem } \\
\text { Paulista }\end{array}$ & ZTP & 129,2 & 5,4 & 16 & 18 & 11 & 9 \\
\hline Bauru & $\mathrm{ZBU}$ & 131,9 & 2,6 & 8 & 10 & 7 & 7 \\
\hline Garça & ZGR & 206,0 & 74,2 & 126 & 127 & 78 & 79 \\
\hline Jafá & $\mathrm{ZJF}$ & 211,7 & 5,7 & 10 & 12 & 8 & 12 \\
\hline $\begin{array}{l}\text { Vera Cruz } \\
\text { Paulista }\end{array}$ & ZVS & 221,5 & 9,8 & 20 & 22 & 14 & 17 \\
\hline Marilia & ZML & 232,7 & 11,2 & 20 & 20 & 13 & 19 \\
\hline $\begin{array}{l}\text { Padre } \\
\text { Nóbrega }\end{array}$ & ZUG & 240,3 & 7,6 & 17 & 28 & 14 & 14 \\
\hline Oriente & ZOR & 248,5 & 8,2 & 24 & 17 & 17 & 14 \\
\hline Pompéia & $\mathrm{ZXO}$ & 257,0 & 8,6 & 15 & 15 & 16 & 15 \\
\hline
\end{tabular}


Tabela C.2 (conclusão) - Localização dos nós do ramal Itirapina-Panorama (2-3), com marco inicial no terminal de Itirapina.

\begin{tabular}{|c|c|c|c|c|c|c|c|}
\hline \multirow{3}{*}{ Nó } & \multirow{3}{*}{ Sigla } & \multirow{3}{*}{$\begin{array}{l}\text { Localização } \\
(\mathbf{k m})\end{array}$} & \multirow{3}{*}{$\begin{array}{l}\text { Comprimento } \\
\text { do arco } \\
(\mathbf{k m})\end{array}$} & \multicolumn{4}{|c|}{ Tempo médio de viagem (min) } \\
\hline & & & & \multicolumn{2}{|c|}{$\begin{array}{l}\text { Limites reais de } \\
\text { velocidade }\end{array}$} & \multicolumn{2}{|c|}{$\begin{array}{l}\text { Limite teórico } \\
\text { de velocidade } \\
(70 \mathrm{~km} / \mathrm{h})\end{array}$} \\
\hline & & & & Exp. & Imp. & Exp. & Imp. \\
\hline Paulópolis & ZXK & 263,3 & 6,3 & 16 & 18 & 14 & 14 \\
\hline Quintana & ZQO & 268,7 & 5,5 & 20 & 14 & 12 & 11 \\
\hline Herculândia & $\mathrm{ZHE}$ & 280,0 & 11,2 & 20 & 19 & 19 & 18 \\
\hline Tupã & ZTU & 291,3 & 11,3 & 31 & 19 & 20 & 15 \\
\hline Iacri & ZIK & 309,8 & 18,5 & 24 & 46 & 20 & 24 \\
\hline Parapuã & $\mathrm{ZPJ}$ & 320,9 & 11,1 & 32 & 35 & 19 & 17 \\
\hline Oswaldo Cruz & $\mathrm{ZOS}$ & 328,6 & 7,7 & 26 & 24 & 16 & 14 \\
\hline $\begin{array}{c}\text { Inúbia } \\
\text { Paulista }\end{array}$ & ZYV & 336,8 & 8,2 & 23 & 18 & 15 & 15 \\
\hline Lucélia & ZLC & 343,0 & 6,2 & 13 & 11 & 12 & 11 \\
\hline Adamantina & ZAP & 349,1 & 6,2 & 18 & 17 & 12 & 12 \\
\hline $\begin{array}{l}\text { Flórida } \\
\text { Paulista }\end{array}$ & ZFL & 359,8 & 10,7 & 23 & 23 & 19 & 14 \\
\hline Atlântida & ZAT & 366,2 & 6,4 & 22 & 17 & 13 & 12 \\
\hline Pacaembu & ZPU & 369,7 & 3,5 & 12 & 10 & 9 & 9 \\
\hline Irapuru & ZIL & 378,2 & 8,5 & 19 & 23 & 16 & 14 \\
\hline Junqueirópolis & ZJX & 386,7 & 8,5 & 22 & 19 & 14 & 16 \\
\hline Dracena & $\mathrm{ZDN}$ & 396,1 & 9,4 & 24 & 23 & 16 & 16 \\
\hline Marrequinhas & ZNQ & 448,2 & 52,2 & 91 & 94 & 57 & 55 \\
\hline Landará & ZYK & 452,4 & 4,2 & 13 & 12 & 11 & 8 \\
\hline Arabela & ZWZ & 462,8 & 10,4 & 21 & 23 & 16 & 13 \\
\hline $\begin{array}{l}\text { Terminal } \\
\text { Panorama }\end{array}$ & $\mathrm{ZPM}$ & 473,2 & 10,4 & 23 & 19 & 21 & 18 \\
\hline
\end{tabular}




\section{Ramal Itirapina-Araraquara (2-4)}

Tabela C.3 - Localização dos nós do ramal Itirapina-Araraquara (2-4), com marco inicial no terminal de Itirapina.

\begin{tabular}{|c|c|c|c|c|c|c|c|}
\hline \multirow{3}{*}{ Nó } & \multirow{3}{*}{ Sigla } & \multirow{3}{*}{$\begin{array}{c}\text { Localização } \\
(\mathbf{k m})\end{array}$} & \multirow{3}{*}{$\begin{array}{c}\text { Comprimento } \\
\text { do arco } \\
(\mathbf{k m})\end{array}$} & \multicolumn{4}{|c|}{$\begin{array}{c}\text { Tempo médio de viagem } \\
(\text { min) }\end{array}$} \\
\hline & & & & \multicolumn{2}{|c|}{$\begin{array}{c}\text { Limites } \\
\text { reais de } \\
\text { velocidade }\end{array}$} & \multicolumn{2}{|c|}{$\begin{array}{c}\text { Limite } \\
\text { teórico de } \\
\text { velocidade } \\
(70 \mathrm{~km} / \mathrm{h})\end{array}$} \\
\hline & & & & Exp. & Imp. & Exp. & Imp. \\
\hline $\begin{array}{l}\text { Terminal } \\
\text { Itirapina }\end{array}$ & ZIQ & 0 & - & - & - & - & - \\
\hline $\begin{array}{l}\text { Visconde do } \\
\text { Rio Claro }\end{array}$ & ZVI & 13,0 & 13,0 & 29 & 26 & 20 & 18 \\
\hline $\begin{array}{l}\text { Conde do } \\
\text { Pinhal }\end{array}$ & ZFR & 20,9 & 7,9 & 20 & 16 & 14 & 12 \\
\hline São Carlos & ZSK & 31,9 & 11,0 & 30 & 34 & 14 & 20 \\
\hline Retiro & ZRS & 37,5 & 5,6 & 24 & 14 & 9 & 11 \\
\hline Ibaté & ZIZ & 46,4 & 8,9 & 22 & 19 & 18 & 15 \\
\hline Tamoio & ZTI & 53,3 & 6,9 & 16 & 20 & 12 & 11 \\
\hline Chibarro & ZFQ & 61,1 & 7,8 & 21 & 14 & 13 & 8 \\
\hline Ouro & ZOI & 69,9 & 8,8 & 15 & 26 & 15 & 16 \\
\hline $\begin{array}{l}\text { Terminal } \\
\text { Araraquara }\end{array}$ & ZAR & 79,4 & 9,5 & 19 & 21 & 14 & 13 \\
\hline
\end{tabular}

\section{Ramal Araraquara-Colômbia (4-5)}

Tabela C.4 (continua) - Localização dos nós do ramal Araraquara-Colômbia (4-5), sentido Importação, com marco inicial no terminal de Araraquara.

\begin{tabular}{|c|c|c|c|c|c|}
\hline \multirow[b]{2}{*}{ Nó } & \multirow[b]{2}{*}{ Sigla } & \multirow[b]{2}{*}{$\begin{array}{c}\text { Localização } \\
(\mathbf{k m})\end{array}$} & \multirow[b]{2}{*}{$\begin{array}{c}\text { Comprimento } \\
\text { do arco } \\
(\mathbf{k m})\end{array}$} & \multicolumn{2}{|c|}{$\begin{array}{c}\text { Tempo médio de viagem } \\
(\text { min) }\end{array}$} \\
\hline & & & & $\begin{array}{c}\text { Limites } \\
\text { reais de } \\
\text { velocidade }\end{array}$ & $\begin{array}{c}\text { Limite } \\
\text { teórico de } \\
\text { velocidade } \\
(70 \mathrm{~km} / \mathrm{h})\end{array}$ \\
\hline
\end{tabular}

Exp. Imp. Exp. Imp.

\begin{tabular}{cccccccc}
\hline $\begin{array}{c}\text { Terminal } \\
\text { Araraquara }\end{array}$ & ZAR & 0 & - & - & - & - & - \\
\hline $\begin{array}{c}\text { Américo } \\
\text { Brasiliense }\end{array}$ & ZAX & 9,1 & 9,1 & 18 & 19 & 17 & 18
\end{tabular}


Tabela C.4 (conclusão) - Localização dos nós do ramal Araraquara-Colômbia (4-5), com marco inicial no terminal de Araraquara.

\begin{tabular}{|c|c|c|c|c|c|c|c|}
\hline \multirow{3}{*}{ Nó } & \multirow{3}{*}{ Sigla } & \multirow{3}{*}{$\begin{array}{l}\text { Localização } \\
\quad(\mathbf{k m})\end{array}$} & \multirow{3}{*}{$\begin{array}{c}\text { Comprimento } \\
\text { do arco } \\
(\mathbf{k m})\end{array}$} & \multicolumn{4}{|c|}{$\begin{array}{c}\text { Tempo médio de viagem } \\
\text { (min) }\end{array}$} \\
\hline & & & & \multicolumn{2}{|c|}{$\begin{array}{c}\text { Limites } \\
\text { reais de } \\
\text { velocidade }\end{array}$} & \multicolumn{2}{|c|}{$\begin{array}{c}\text { Limite } \\
\text { teórico de } \\
\text { velocidade } \\
(70 \mathrm{~km} / \mathrm{h})\end{array}$} \\
\hline & & & & Exp. & Imp. & Exp. & Imp. \\
\hline Santa Lucia & ZSL & 15,1 & 6,0 & 13 & 16 & 11 & 7 \\
\hline Tapuia & ZTW & 23,8 & 8,7 & 24 & 22 & 16 & 11 \\
\hline Rincão & ZRI & 27,8 & 4,0 & 15 & 14 & 7 & 10 \\
\hline Guatapara & ZGT & 37,8 & 10,0 & 19 & 20 & 16 & 14 \\
\hline Guarani & ZGK & 45,9 & 8,1 & 23 & 26 & 15 & 16 \\
\hline Pradópolis & ZXE & 58,5 & 12,6 & 34 & 38 & 20 & 19 \\
\hline Barrinha & $\mathrm{ZBH}$ & 71,0 & 12,5 & 29 & 27 & 19 & 15 \\
\hline Passagem & ZPL & 90,2 & 19,2 & 40 & 38 & 22 & 23 \\
\hline Pitangueiras & $\mathrm{ZPH}$ & 95,5 & 5,3 & 12 & 13 & 8 & 11 \\
\hline Ibitiuva & ZIB & 108,0 & 12,5 & 24 & 28 & 20 & 21 \\
\hline Bebedouro & ZBD & 125,5 & 17,5 & 37 & 39 & 21 & 20 \\
\hline Colina & $\mathrm{ZCJ}$ & 151,5 & 26,0 & 44 & 45 & 34 & 33 \\
\hline Frigorífico & $\mathrm{ZFO}$ & 168,2 & 16,7 & 37 & 37 & 22 & 21 \\
\hline Barretos & ZBR & 173,3 & 5,1 & 17 & 22 & 12 & 13 \\
\hline Adolfo Pinto & ZWH & 199,1 & 25,8 & 66 & 64 & 35 & 34 \\
\hline $\begin{array}{l}\text { Terminal } \\
\text { Colômbia }\end{array}$ & $\mathrm{ZCA}$ & 220,0 & 20,9 & 42 & 43 & 30 & 25 \\
\hline
\end{tabular}




\section{Ramal Araraquara-Santa Fé do Sul (4-6)}

Tabela C.5 (continua) - Localização dos nós do ramal Araraquara-Santa Fé do Sul (4-6), com marco inicial no terminal de Araraquara.

\begin{tabular}{|c|c|c|c|c|c|c|c|}
\hline \multirow{3}{*}{ Nó } & \multirow{3}{*}{ Sigla } & \multirow{3}{*}{$\begin{array}{c}\text { Localização } \\
(\mathbf{k m})\end{array}$} & \multirow{3}{*}{$\begin{array}{c}\text { Comprimento } \\
\text { do arco } \\
(\mathbf{k m})\end{array}$} & \multicolumn{4}{|c|}{$\begin{array}{c}\text { Tempo médio de viagem } \\
\text { (min) }\end{array}$} \\
\hline & & & & \multicolumn{2}{|c|}{$\begin{array}{c}\text { Limites } \\
\text { reais de } \\
\text { velocidade }\end{array}$} & \multicolumn{2}{|c|}{$\begin{array}{c}\text { Limite } \\
\text { teórico de } \\
\text { velocidade } \\
(70 \mathrm{~km} / \mathrm{h})\end{array}$} \\
\hline & & & & Exp. & Imp. & Exp. & Imp. \\
\hline $\begin{array}{l}\text { Terminal } \\
\text { Araraquara }\end{array}$ & ZAR & 0 & - & - & - & - & - \\
\hline Tutóia & ZTO & 7,4 & 7,4 & 20 & 18 & 9 & 14 \\
\hline $\begin{array}{l}\text { Bueno de } \\
\text { Andrade }\end{array}$ & ZDZ & 25,1 & 17,7 & 35 & 35 & 25 & 21 \\
\hline Silvania & ZZL & 30,8 & 5,7 & 13 & 13 & 12 & 13 \\
\hline Matão & ZMA & 42,9 & 12,1 & 25 & 32 & 19 & 13 \\
\hline Dobrada & $\mathrm{ZDG}$ & 53,6 & 10,8 & 31 & 29 & 15 & 16 \\
\hline $\begin{array}{c}\text { Santa } \\
\text { Ernestina }\end{array}$ & $\mathrm{ZSH}$ & 59,0 & 5,4 & 18 & 15 & 12 & 10 \\
\hline Taquaritinga & ZTQ & 75,2 & 16,2 & 39 & 31 & 23 & 19 \\
\hline $\begin{array}{l}\text { Cândido } \\
\text { Rodrigues }\end{array}$ & $\mathrm{ZCZ}$ & 91,1 & 15,9 & 39 & 31 & 17 & 23 \\
\hline $\begin{array}{l}\text { Fernando } \\
\text { Prestes }\end{array}$ & ZFU & 99,3 & 8,2 & 19 & 20 & 12 & 12 \\
\hline Santa Adélia & ZSD & 115,3 & 15,9 & 33 & 35 & 20 & 21 \\
\hline Pindorama & $\mathrm{ZPN}$ & 128,0 & 12,7 & 29 & 35 & 20 & 15 \\
\hline Catanduva & $\mathrm{ZCV}$ & 138,7 & 10,7 & 33 & 31 & 16 & 15 \\
\hline Catiguá & ZCT & 152,2 & 13,5 & 30 & 29 & 22 & 19 \\
\hline Uchôa & ZUC & 169,3 & 17,1 & 63 & 60 & 24 & 24 \\
\hline Cedral & ZCG & 182,9 & 13,6 & 46 & 40 & 20 & 19 \\
\hline Eng. Schmit & $\mathrm{ZEH}$ & 188,4 & 5,5 & 17 & 14 & 13 & 7 \\
\hline $\begin{array}{l}\text { São José do } \\
\text { Rio Preto }\end{array}$ & ZSP & 199,5 & 11,0 & 21 & 31 & 17 & 14 \\
\hline $\begin{array}{l}\text { Rio Preto } \\
\text { Paulista }\end{array}$ & ZRU & 203,9 & 4,5 & 16 & 11 & 9 & 11 \\
\hline Mirassol & $\mathrm{ZMO}$ & 218,7 & 14,8 & 30 & 27 & 20 & 22 \\
\hline Bálsamo & ZVU & 231,9 & 13,2 & 35 & 38 & 20 & 19 \\
\hline
\end{tabular}


Tabela C.5 (conclusão) - Localização dos nós do ramal Araraquara-Santa Fé do Sul (4-6), com marco inicial no terminal de Araraquara.

\begin{tabular}{|c|c|c|c|c|c|c|c|}
\hline \multirow{3}{*}{ Nó } & \multirow{3}{*}{ Sigla } & \multirow{3}{*}{$\begin{array}{l}\text { Localização } \\
(\mathbf{k m})\end{array}$} & \multirow{3}{*}{$\begin{array}{c}\text { Comprimento } \\
\text { do arco } \\
(\mathbf{k m})\end{array}$} & \multicolumn{4}{|c|}{$\begin{array}{c}\text { Tempo médio de viagem } \\
(\text { min) }\end{array}$} \\
\hline & & & & \multicolumn{2}{|c|}{$\begin{array}{c}\text { Limites } \\
\text { reais de } \\
\text { velocidade }\end{array}$} & \multicolumn{2}{|c|}{$\begin{array}{c}\text { Limite } \\
\text { teórico de } \\
\text { velocidade } \\
(70 \mathrm{~km} / \mathrm{h})\end{array}$} \\
\hline & & & & Exp. & Imp. & Exp. & Imp. \\
\hline Eng. Balduíno & ZEB & 245,9 & 14,0 & 49 & 52 & 20 & 20 \\
\hline Ecatu & $\mathrm{ZEC}$ & 263,7 & 17,7 & 56 & 58 & 23 & 25 \\
\hline Cosmorama & $\mathrm{ZKY}$ & 278,2 & 14,6 & 44 & 47 & 20 & 21 \\
\hline Simonsen & $\mathrm{ZZM}$ & 292,0 & 13,8 & 40 & 48 & 20 & 21 \\
\hline Votuporanga & ZVP & 302,7 & 10,7 & 30 & 36 & 16 & 16 \\
\hline $\begin{array}{l}\text { Valentim } \\
\text { Gentil }\end{array}$ & $\mathrm{ZVG}$ & 315,4 & 12,7 & 43 & 33 & 18 & 18 \\
\hline Meridiano & ZMR & 329,1 & 13,7 & 26 & 25 & 21 & 20 \\
\hline Fernandópolis & $\mathrm{ZFN}$ & 339,6 & 10,4 & 18 & 20 & 17 & 17 \\
\hline $\begin{array}{c}\text { Estrela } \\
\text { D`Oeste }\end{array}$ & ZED & 357,0 & 17,4 & 32 & 26 & 24 & 23 \\
\hline Jales & ZJA & 373,4 & 16,5 & 33 & 38 & 25 & 23 \\
\hline Urânia & ZUR & 385,6 & 12,2 & 25 & 21 & 18 & 18 \\
\hline Santa Salete & $\mathrm{ZHL}$ & 391,0 & 5,4 & 11 & 15 & 11 & 11 \\
\hline $\begin{array}{l}\text { Pimenta } \\
\text { Bueno }\end{array}$ & ZUE & 400,9 & 10,0 & 19 & 22 & 16 & 16 \\
\hline $\begin{array}{c}\text { Três } \\
\text { Fronteiras }\end{array}$ & ZTF & 413,7 & 12,7 & 22 & 22 & 19 & 20 \\
\hline $\begin{array}{c}\text { Terminal } \\
\text { Santa Fé do } \\
\text { Sul }\end{array}$ & ZSF & 421,2 & 7,5 & 17 & 21 & 16 & 12 \\
\hline
\end{tabular}

A seguir são apresentadas as figuras com a representação da posição das estações nos ramais da rede em que foi aplicado o modelo de capacidade. 


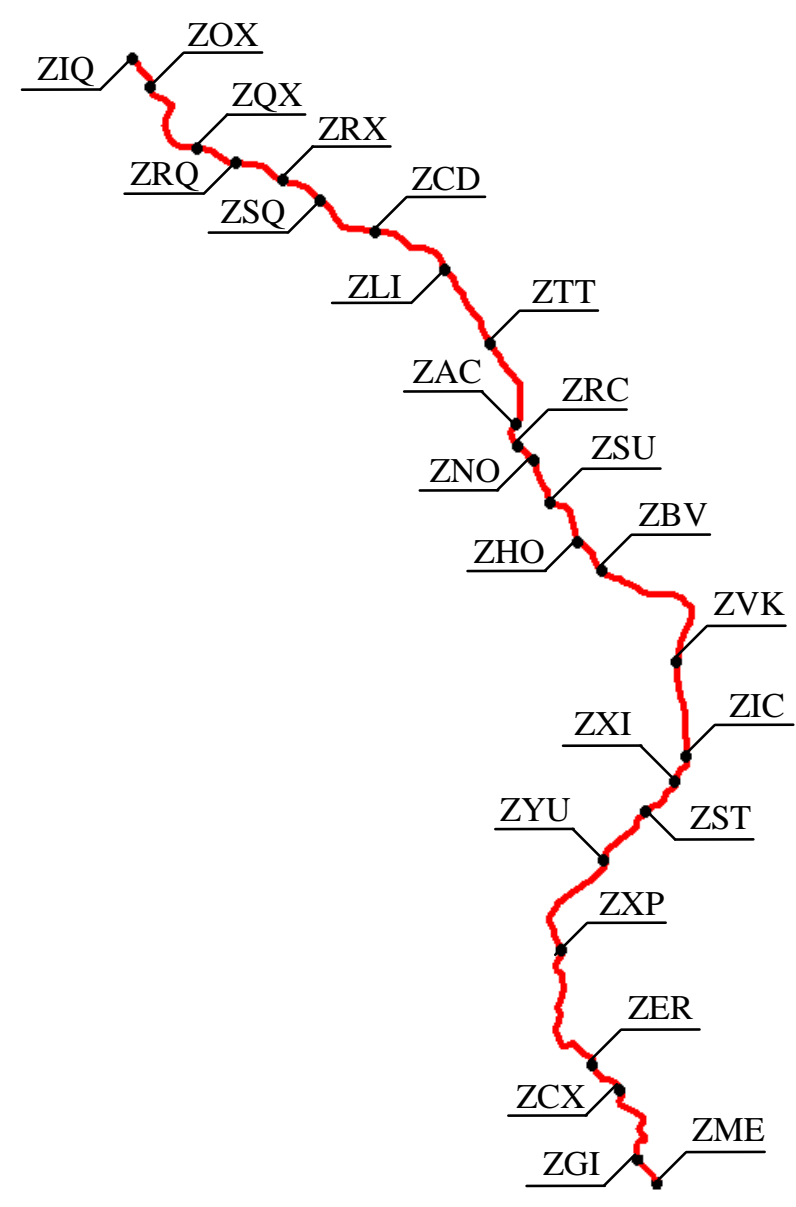

Figura C.1 - Representação esquemática da localização das estações no ramal entre os terminais de Mairinque e Itirapina (Ramal 1-2). 


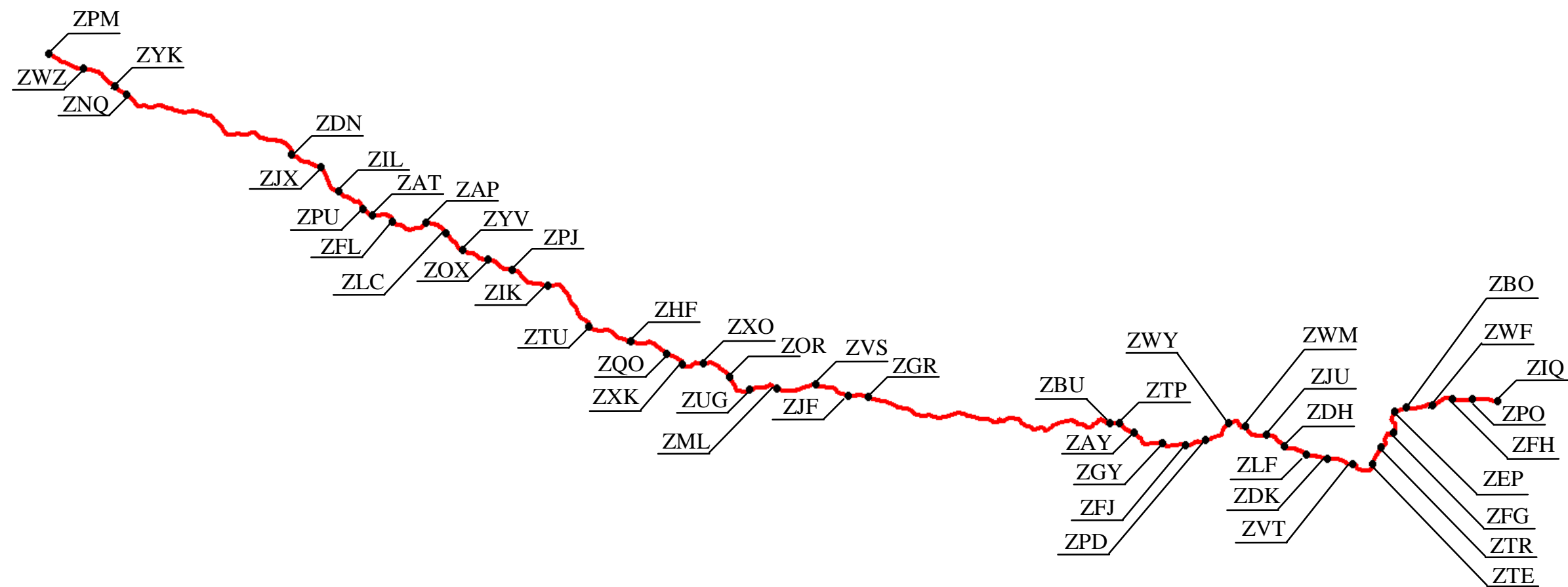

Figura C.2 - Representação esquemática da localização das estações no ramal entre os terminais de Itirapina e Panorama (Ramal 2-3). 


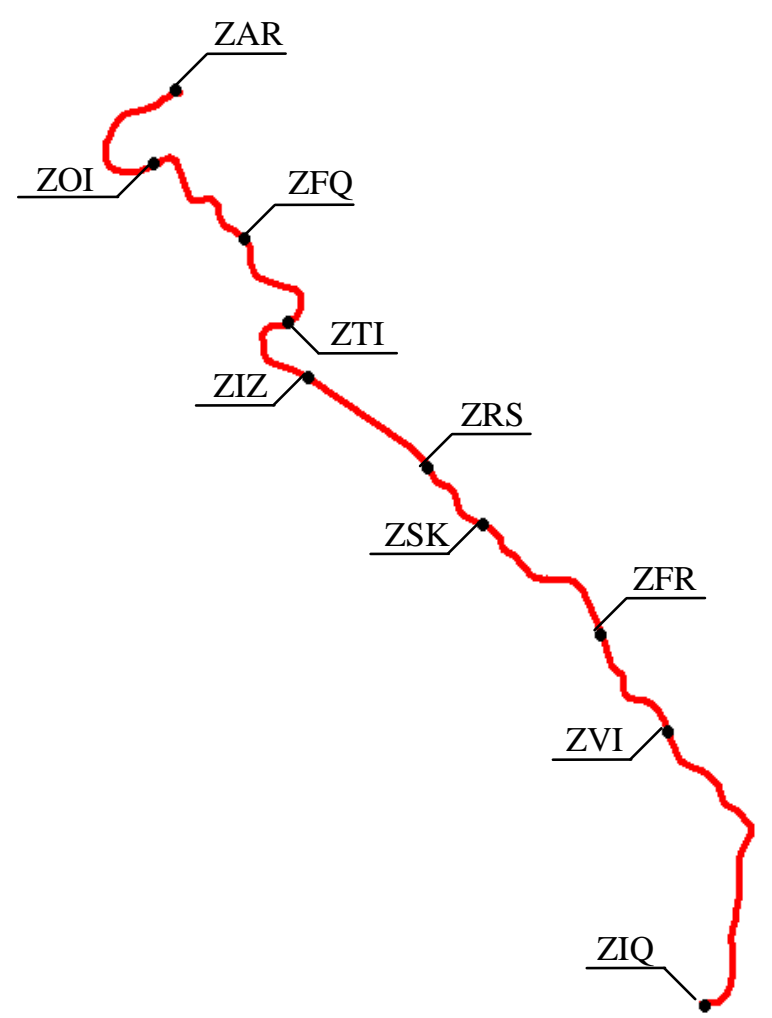

Figura C.3 - Representação esquemática da localização das estações no ramal entre os terminais de Itirapina e Araraquara (Ramal 2-4). 


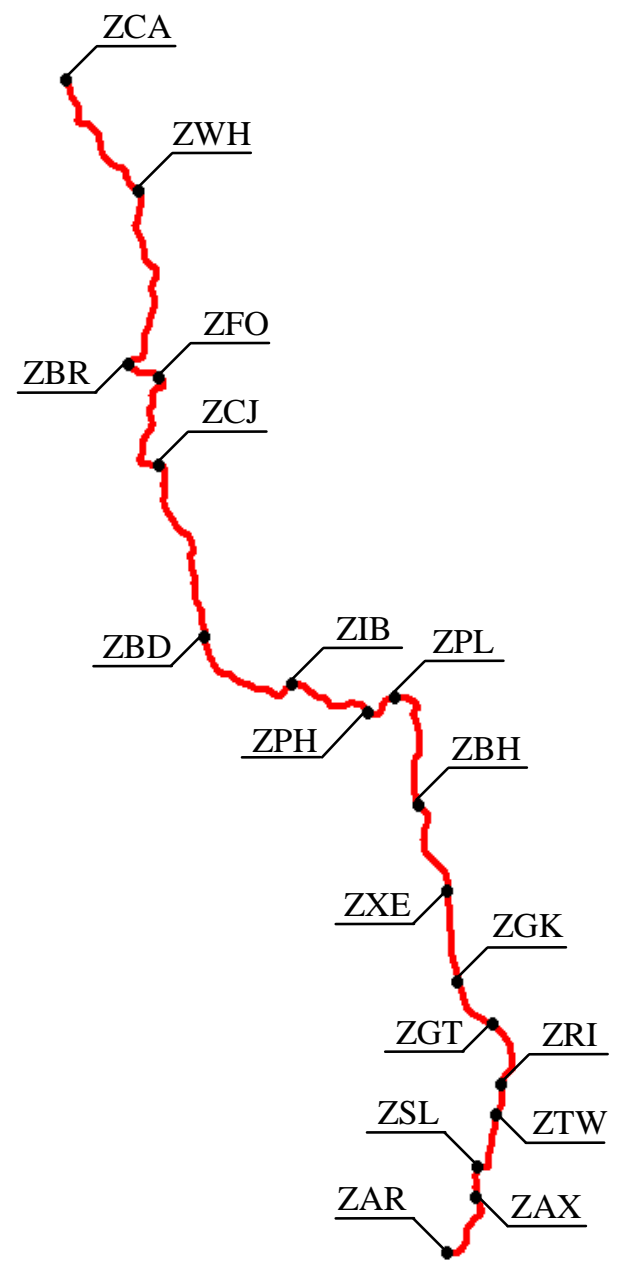

Figura C.4 - Representação esquemática da localização das estações no ramal entre os terminais de Araraquara e Colômbia (Ramal 4-5). 


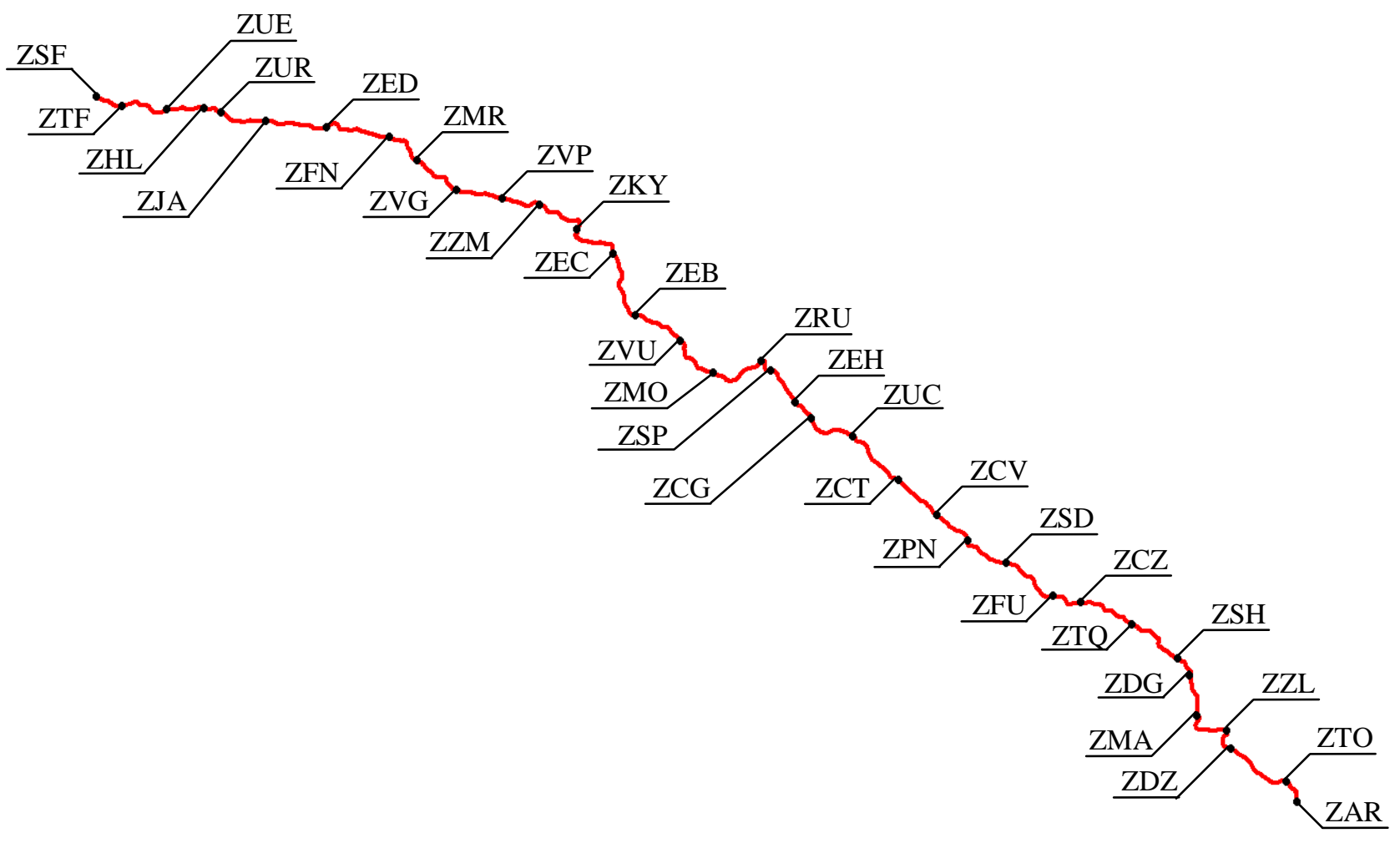

Figura C.5 - Representação esquemática da localização das estações no ramal entre os terminais de Araraquara e Santa Fé do Sul (Ramal 4-6). 


\section{Anexo A \\ MODELO DE LOCOMOÇÃO - TEM}

Os tempos de viagem nos arcos da rede ferroviária são utilizados como dados de entrada do modelo de capacidade descrito e obtidos a partir do equilíbrio entre as forças de resistência que limitam o movimento das composições e a força de propulsão disponibilizada pelas locomotivas.

O equacionamento apresentado naquele capítulo mostra simplificadamente a relação matemática proveniente do equilíbrio estabelecido entre essas forças, cuja representação gráfica é dada na Figura 2.1. Entretanto, apesar de as expressões algébricas utilizadas pelo simulador Train Energy Model versão 2.5 serem fundamentadas nas definições expostas, estas se apresentam mais complexas por considerarem outros fatores na caracterização do movimento do trem na via.

Neste anexo são apresentadas as equações e os coeficientes utilizados no simulador para análise do desempenho dos trens, os limites de operação dos motores elétricos, os limites de aderência nos vários pontos de tração das locomotivas, o modelo de cálculo da força de frenagem e da força nos engates durante o movimento.

\section{A.1. Equações do movimento}

O movimento dos veículos ferroviários é regido pelo equilíbrio das forças que neles atuam, em determinado instante, as quais podem ser traduzidas em expressões matemáticas. Entretanto, os valores de deslocamento, velocidade e aceleração dos trens são determinados através de modelos que, por vezes, podem se mostrar complexos devido à não-linearidade das equações envolvidas.

De modo geral, o desempenho dos trens pode ser modelado através de métodos embasados na segunda Lei de Newton, que define a resultante das forças aplicadas em um objeto como o produto de sua massa (M), pela aceleração (A), como indicado na Equação (A.1).

$$
\mathrm{F}=\mathrm{m} \cdot \mathrm{A}
$$


No TEM versão 2.5, a aceleração é definida pelos parâmetros de força máxima de tração fornecida pelas locomotivas, força de frenagem e forças de resistências impostas aos veículos, incluindo os efeitos das rampas (DRISH, 1992). A equação que traduz a aceleração de uma composição ferroviária é dada pela Equação (A.2).

$$
\mathrm{A}=\frac{\mathrm{F}}{\mathrm{m}}=\frac{\mathrm{F}}{\left(\frac{\mathrm{W}}{\mathrm{g}}\right)}=\frac{\mathrm{g} \cdot[\mathrm{S}-\mathrm{G}-\mathrm{R} \cdot \mathrm{sgn}(\mathrm{V})]}{\mathrm{W}}
$$

em que $\quad \mathrm{A}=$ aceleração do trem $(\mathrm{mph} / \mathrm{s})$.

$\mathrm{W}=$ peso total do trem $(l b s)$.

$\mathrm{S}=$ força total de tração disponibilizada pelas locomotivas, limitada pela aderência roda-trilho $(l b s)$.

$\mathrm{G}=$ força total de rampa $(l b s)$.

$\mathrm{R}=$ resistência total do trem $(l b s)$.

$\mathrm{V}=$ velocidade do trem $(m p h)$.

$\mathrm{g}=$ aceleração da gravidade $(21,8 \mathrm{mph} / \mathrm{s})$.

$\operatorname{sgn}(V)=$ função que determina o sinal da força de rampa, indicando se esta é a favor ou contrária ao movimento, tal que $\operatorname{sgn}(\mathrm{V})=\mathrm{V} /|\mathrm{V}|$ se $\mathrm{V} \neq 0$, e $\operatorname{sgn}(\mathrm{V})=0$ se $\mathrm{V}=0$.

Os valores da força total de tração, da resistência total e da força de rampa, que atuam no trem, são determinados através do somatório desses componentes que atuam em cada um dos veículos que o constituem, como indicado na Equação (A.3), Equação (A.4) e Equação (A.5).

$$
\begin{aligned}
& \mathrm{S}=\sum_{\mathrm{k}=1}^{\mathrm{k}=\mathrm{N}} \mathrm{S}_{\mathrm{k}} \\
& \mathrm{R}=\sum_{\mathrm{k}=1}^{\mathrm{k}=\mathrm{N}} \mathrm{R}_{\mathrm{k}} \\
& \mathrm{G}=\sum_{\mathrm{k}=1}^{\mathrm{k}=\mathrm{N}} \mathrm{G}_{\mathrm{k}}
\end{aligned}
$$

em que $\quad \mathrm{k}=$ índice relativo a cada veículo que constitui o trem. 


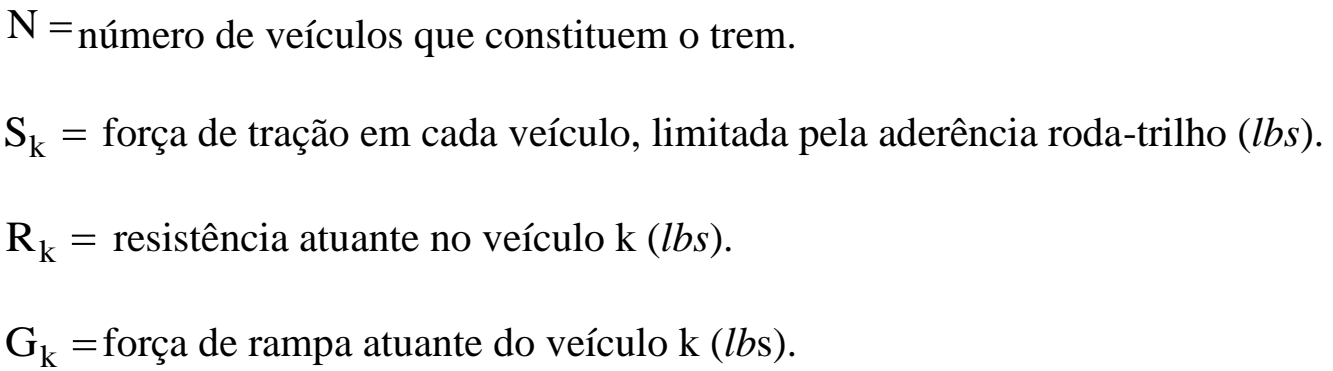

\section{A.2. Esforço trator em locomotivas diesel-elétricas}

A força de tração produzida pelas locomotivas diesel-elétricas (Figura A.7) é proveniente de um motor a combustão, que aciona um gerador elétrico e transfere a energia elétrica produzida às rodas motrizes, sob a forma de energia mecânica.

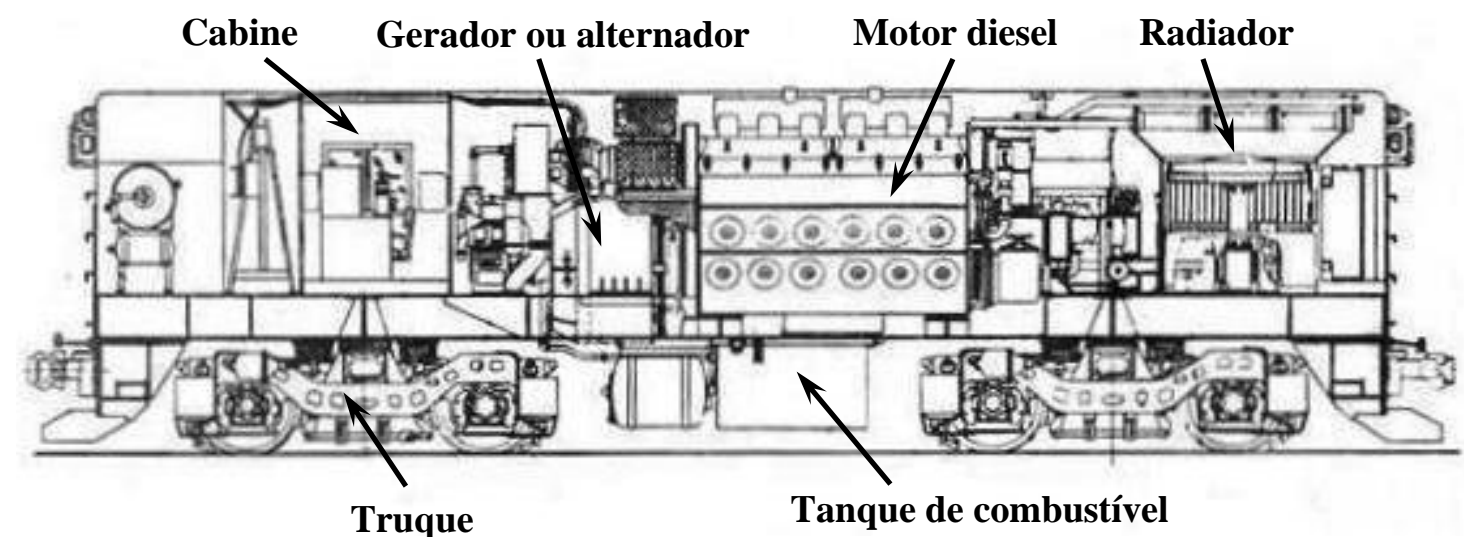

Figura A.7 - Esquema de uma locomotiva diesel-elétrica.

Segundo Morlok (1978), a força tratora ou força motriz é expressa, matematicamente, a partir do conceito de trabalho, que corresponde ao produto de uma força aplicada a um corpo pelo seu deslocamento ao longo de uma trajetória definida, como exposto na Equação (A.6).

$$
M=S \cdot d
$$

em que $\quad \mathrm{M}=$ trabalho realizado pela força $\mathrm{S}(\mathrm{N} . \mathrm{m}$ ou Joule $-J)$.

$$
\begin{aligned}
& \mathrm{S}=\text { força motriz }(\mathrm{N}) . \\
& \mathrm{d}=\text { deslocamento }(\mathrm{m}) .
\end{aligned}
$$

Como a potência de um motor corresponde à variação do trabalho realizado por uma força em relação ao tempo:

$$
\mathrm{P}=\frac{\partial \mathrm{M}}{\partial \mathrm{t}}=\mathrm{S} \cdot \frac{\partial \mathrm{d}}{\partial \mathrm{t}}=\mathrm{S} \cdot \mathrm{V}
$$


em que $\quad \mathrm{P}=$ potência do motor elétrico (N.m/s ou Watts).

$\mathrm{t}=$ tempo (segundos).

Apesar de o motor produzir uma força proporcional à sua potência, parte da energia por ele produzida é utilizada para acionar outros sistemas do trem (iluminação, ar comprimido etc.) e outra parcela é dissipada sob outras formas de energia (calor, por exemplo).

Devido a isso, é adicionado um coeficiente à equação anterior, que reflete a proporção de potência do motor, a qual, efetivamente, é convertida em força motriz. Como geralmente a velocidade de um trem é expressa em quilômetros por hora $(\mathrm{km} / \mathrm{h})$, um fator de conversão de unidades também é inserido na equação de força tratora.

$$
\mathrm{S}=\eta \cdot 3600 \cdot \frac{\mathrm{P}}{\mathrm{V}}
$$

em que $\quad \eta=$ coeficiente de eficiência da transmissão.

No sistema de unidades utilizadas pelo simulador, a força de tração é dada por:

$$
\mathrm{S}=\eta \cdot 375 \cdot \frac{\mathrm{P}}{\mathrm{V}}
$$

A Equação (A.9) representa a força de propulsão fornecida pelo motor elétrico, porém a sua potência utilizada nem sempre corresponde à máxima disponibilizada pelo motor elétrico. Os motores possuem reguladores para aplicação da força no trem, que caracterizam 10 ajustes ou "Pontos de Tração", correspondentes à máquina inativa, ociosa e outros 8 ajustes (pontos de tração 1 a 8) de injeção de combustível no motor.

Para cada ajuste a locomotiva utiliza uma parcela da potência dos motores e a converte em força tratora, proporcionalmente àquele valor e inversamente proporcional à velocidade do trem.

\section{A.2.1. Limites de operação dos motores elétricos}

O movimento dos trens depende tanto da resultante das forças que atuam sobre os veículos que os integram quanto das regras operacionais, como o sistema de controle e sinalização.

A velocidade dos veículos ferroviários é limitada por fatores de segurança, como a necessidade de redução da velocidade em trechos urbanos ou em condições precárias de 
conservação, por exemplo, ou pela voltagem máxima que pode ser aplicada aos motores elétricos das locomotivas, de modo que os seus circuitos não sejam danificados, estabelecida por um limite de velocidade imposto ao trem.

Além dessas restrições, é necessário considerar que o movimento dos veículos ferroviários ocorre devido ao atrito entre as rodas e o trilho, e a força máxima que pode ser aplicada pelas locomotivas para permitir a aderência entre esses componentes é determinada pela comparação da força tratora - ou a força de frenagem dinâmica - e a força de frenagem a ar comprimido, como produto do peso total do veículo multiplicado por um coeficiente de atrito roda-trilho.

O fator de aderência que define o limite máximo da força tratora aplicada pelas locomotivas é calculado pelo simulador, segundo a Equação (A.10), cujo valor varia de acordo com o tipo de locomotiva. Para veículos não tracionados, é admitido valor constante e igual a 0,235.

$$
\mathrm{a}_{\mathrm{k}}(\mathrm{V})=\mathrm{a}_{0 \mathrm{k}}-\Delta \mathrm{a} \cdot\left(1-\mathrm{e}^{-\mathrm{V} / 10}\right)
$$

em que $\quad a_{k}(V)=$ coeficiente de aderência do veículo $\mathrm{k}$.

$\mathrm{a}_{0 \mathrm{k}}=$ máximo coeficiente de aderência do veículo $\mathrm{k}$, quando $\mathrm{V}=0$.

$\Delta \mathrm{a}=$ variação total no coeficiente de aderência $(0,05)$.

A força máxima que pode ser aplicada por uma locomotiva é dada pelas condições estabelecidas a seguir.

Se $\left|S_{k}\right| \leq W_{k} \cdot a_{k}(V)$, então: $\quad S_{k}=E_{k}-B_{k} \cdot \operatorname{sgn}(V)$

Caso contrário:

$$
\mathrm{S}_{\mathrm{k}}=\mathrm{s} \cdot \mathrm{W}_{\mathrm{k}} \cdot \mathrm{a}_{\mathrm{k}}(\mathrm{V})
$$

em que $\quad \mathrm{B}_{\mathrm{k}}=$ força de frenagem dinâmica $(l b s)$.

$\mathrm{s}=$ função binária $($ positivo/negativo $)=\operatorname{sgn}\left(\mathrm{E}_{\mathrm{k}}-\mathrm{B}_{\mathrm{k}} \cdot \operatorname{sgn}(\mathrm{V})\right)$

A Figura A.8 apresenta o gráfico de força tratora de uma locomotiva do tipo DASH 9, limitado pela velocidade máxima de $70 \mathrm{mph}$ (aproximadamente $112 \mathrm{~km} / \mathrm{h}$ ) e pelo coeficiente de aderência obtido segundo as equações indicadas anteriormente. 


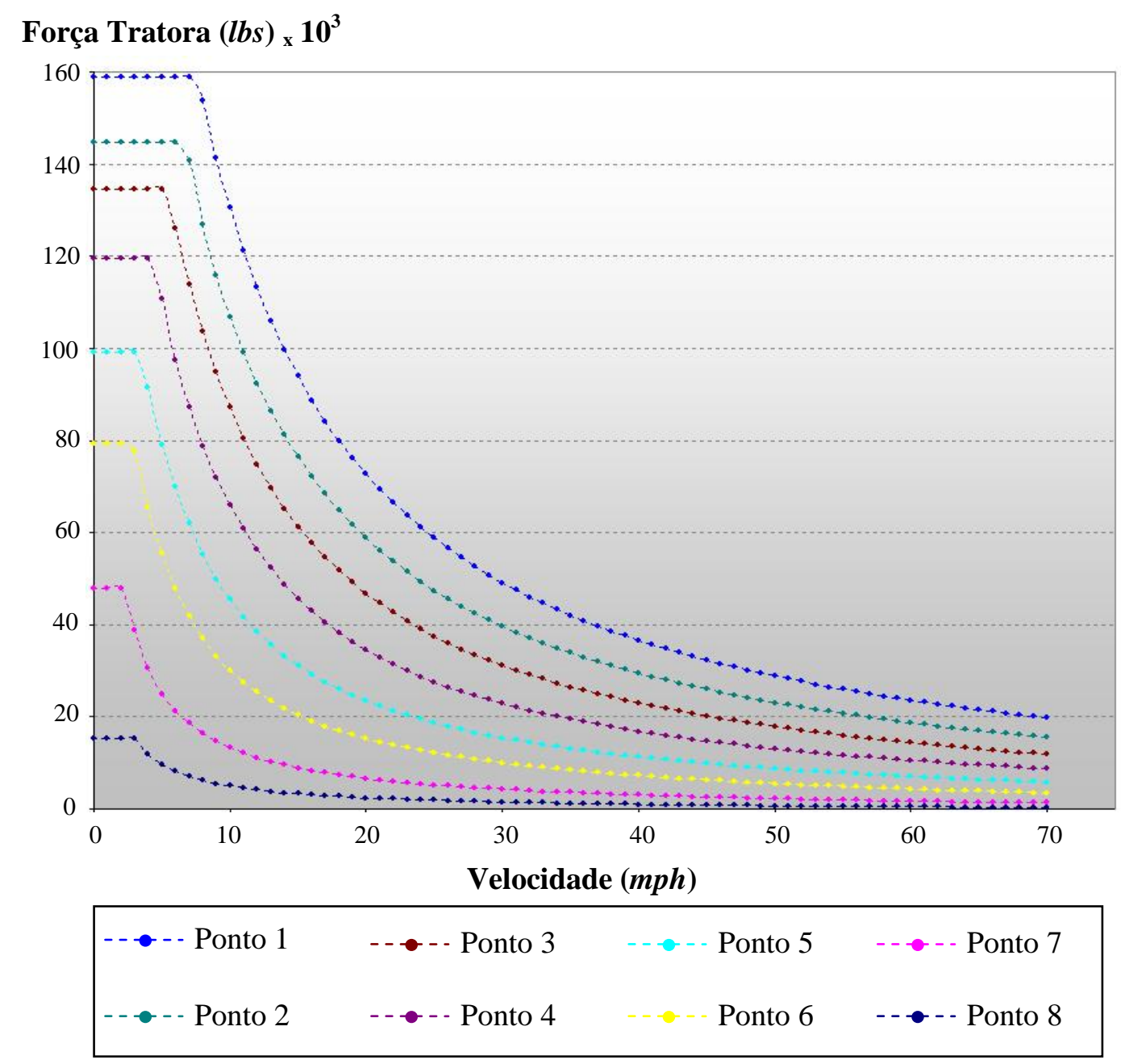

Figura A.8 - Curvas de tração de uma locomotiva diesel-elétrica DASH 9.

\section{A.3. Resistência ao movimento}

As forças que retardam o movimento dos trens são denominadas "resistência" e classificadas em quatro componentes distintos: resistência dos mancais, resistência de rolamento, resistência aerodinâmica e resistência de curva.

A força de rampa é classificada em uma categoria à parte, pelo fato de contribuir para o movimento dos veículos nos declives e oferecer resistência à sua movimentação nos trechos ascendentes. Em geral, a força de rampa apresenta sinal positivo quando favorece a locomoção do trem e sinal negativo em caso desfavorável.

A resistência total em cada um dos veículos que compõem a composição ferroviária é dada pela Equação (A.12). 


$$
\mathrm{R}_{\mathrm{Tk}_{\mathrm{k}}}=\mathrm{R}_{\mathrm{Mk}_{\mathrm{k}}}+\mathrm{R}_{\mathrm{R}_{\mathrm{k}}}+\mathrm{R}_{\mathrm{Ak}_{\mathrm{k}}}+\mathrm{R}_{\mathrm{Ck}_{\mathrm{k}}}+\left|\mathrm{R}_{\mathrm{G}_{\mathrm{k}}}\right|
$$

em que $\quad \mathrm{R}_{\mathrm{M}_{\mathrm{k}}}=$ resistência dos mancais do veículo $\mathrm{k}(l b s)$.

$$
\begin{aligned}
& \mathrm{R}_{\mathrm{R}_{\mathrm{k}}}=\text { resistência de rolamento do veículo } \mathrm{k}(l b s) . \\
& \mathrm{R}_{\mathrm{Ak}_{\mathrm{k}}}=\text { resistência aerodinâmica do veículo } \mathrm{k}(l b s) . \\
& \mathrm{R}_{\mathrm{C}_{\mathrm{k}}}=\text { resistência de curva do veículo } \mathrm{k}(l b s) . \\
& \mathrm{R}_{\mathrm{G}_{\mathrm{k}}}=\mathrm{G}_{\mathrm{k}}=\text { resistência do veículo k em rampas ascendentes }(l b s), \text { se } \mathrm{G}_{\mathrm{k}}<0 .
\end{aligned}
$$

\section{A.3.1. Resistência dos mancais}

A resistência dos mancais resulta da interação entre os componentes físicos dos veículos ferroviários e é definida matematicamente pelo produto do número de eixos, pelo coeficiente de resistência dos mancais, o qual depende do tipo de truque do veículo ferroviário, da temperatura ambiente e do carregamento dos veículos.

Seja $\quad \mathrm{R}_{\mathrm{M}_{\mathrm{k}}}=$ resistência dos mancais do veículo $\mathrm{k}(l b s)$.

$$
\begin{aligned}
& \mathrm{n}_{\mathrm{k}}=\text { número de eixos do veículo } \mathrm{k} \text {. } \\
& \mathrm{C}_{\mathrm{Mk}}=\text { coeficiente de resistência dos mancais do veículo } \mathrm{k} \text { (lbs/eixo). }
\end{aligned}
$$

então

$$
\mathrm{R}_{\mathrm{M}_{\mathrm{k}}}=\mathrm{n}_{\mathrm{k}} \cdot \mathrm{C}_{\mathrm{M}_{\mathrm{k}}}
$$

O coeficiente $C_{M_{k}}$ é obtido através da Equação (A.14):

$$
\mathrm{C}_{\mathrm{Mk}_{\mathrm{k}}}=\delta_{\mathrm{k}} \cdot \mathrm{M}_{\mathrm{k}}{ }_{\mathrm{k}}
$$

em que $\quad \delta_{\mathrm{k}}=$ multiplicador empírico para o veículo $\mathrm{k}$.

$$
\psi_{\mathrm{k}}=\text { expoente empírico para o veículo } \mathrm{k} \text {. }
$$

O expoente e o multiplicador empírico para cada veículo da composição ferroviária são dados respectivamente pela Equação (A.15) e Equação (A.16). 


$$
\begin{aligned}
& \delta_{\mathrm{k}}=\mathrm{b}_{1}\left(i_{\mathrm{M}_{\mathrm{k}}}\right)+\mathrm{b}_{2}\left(i_{\mathrm{M}_{\mathrm{k}}}\right) \cdot \mathrm{T}+\mathrm{b}_{3}\left(i_{\mathrm{M}_{\mathrm{k}}}\right) \cdot \mathrm{T}^{2} \\
& \psi_{\mathrm{k}}=\mathrm{b}_{4}\left(i_{\mathrm{M}_{\mathrm{k}}}\right)+\mathrm{b}_{5}\left(i_{\mathrm{M}_{\mathrm{k}}}\right) \cdot \mathrm{T}+\mathrm{b}_{6}\left(i_{\mathrm{M}_{\mathrm{k}}}\right) \cdot \mathrm{T}^{2}
\end{aligned}
$$

em que $\quad \mathrm{T}=$ temperatura ambiente (graus Fahrenheit).

$$
\begin{aligned}
& \left(i_{\mathrm{m} k}\right)=\text { índice relativo ao tipo de mancal. } \\
& \mathrm{b}_{1}\left(i_{\mathrm{m}_{\mathrm{k}}}\right), \ldots, \mathrm{b}_{6}\left(i_{\mathrm{m}_{\mathrm{k}}}\right)=\text { coeficientes dos multiplicadores empíricos para o veículo }
\end{aligned}
$$
k, apresentados na Tabela C.15 do item C.1.16, no Anexo C.

\section{A.3.2. Resistência de rolamento}

A resistência de rolamento é inerente ao movimento dos trens e resulta do atrito existente entre as suas rodas e os trilhos. A fórmula empírica é dada pelo produto do peso da massa do veículo pelo coeficiente de rolamento, como indicado na Equação (A.17):

$$
\mathrm{R}_{\mathrm{Rk}}=0,0005 \cdot \mathrm{M}_{\mathrm{k}} \cdot \mathrm{C}_{\mathrm{Rk}}
$$

em que $\quad \mathrm{R}_{\mathrm{R}_{\mathrm{k}}}=$ resistência de rolamento do veículo $\mathrm{k}(l b s)$.

$$
\mathrm{C}_{\mathrm{R}_{\mathrm{k}}}=\text { coeficiente de resistência de rolamento do veículo } \mathrm{k} \text { (lbs/ton). }
$$

O coeficiente de resistência de rolamento é definido segundo as expressões e condições dadas pela Equação (A.18) e Equação (A.19).

$$
\begin{gathered}
\mathrm{C}_{\mathrm{R}_{\mathrm{k}}}=\varepsilon\left(i_{\mathrm{T}_{\mathrm{k}}}\right)-\left[\varepsilon\left(i_{\mathrm{T}_{\mathrm{k}}}\right)-\lambda\left(i_{\mathrm{T}_{\mathrm{k}}}\right)\right] \cdot\left[\frac{\mathrm{M}_{\mathrm{k}}-\tau_{\mathrm{k}}}{\gamma_{\mathrm{k}}-\tau_{\mathrm{k}}}\right], \text { se } \mathrm{W}_{\mathrm{k}}<\gamma_{\mathrm{k}} \\
\mathrm{C}_{\mathrm{R}_{\mathrm{k}}}=\lambda\left(i_{\mathrm{T}_{\mathrm{k}}}\right), \text { se } \mathrm{W}_{\mathrm{k}} \geq \gamma_{\mathrm{k}}
\end{gathered}
$$

em que $\quad \gamma_{\mathrm{k}}=$ peso da carga do veículo $\mathrm{k}(l b s)$.

$\tau_{\mathrm{k}}=$ tara do veículo $\mathrm{k}(l b s)$.

$i_{\mathrm{t}}=$ tipo de truque do veículo $\mathrm{k}$.

$\varepsilon\left(i_{\mathrm{t}_{\mathrm{k}}}\right)=$ coeficiente empírico relativo ao veículo vazio (lbs/ton) em função do tipo de truque do veículo, indicado na Tabela C.16 do item C.1.16, no Anexo C. 
$\lambda\left(i_{\mathrm{t}_{\mathrm{k}}}\right)=$ coeficiente empírico relativo ao veículo carregado (lbs/ton), em função do tipo de truque do veículo, indicado na Tabela C.16 do item C.1.16, no Anexo C.

\section{A.3.3. Resistência aerodinâmica}

A resistência aerodinâmica de um veículo ferroviário depende da forma e tamanho de sua área frontal, e é expressa algebricamente pelo produto da velocidade relativa do vento, elevada ao quadrado, e pelo coeficiente de resistência aerodinâmico, como indicado na Equação (A.20).

$$
\mathrm{R}_{\mathrm{Ak}}=v_{k}^{2} \cdot \mathrm{C}_{\mathrm{Ak}}
$$

em que $\quad \mathrm{R}_{\mathrm{A}_{\mathrm{k}}}=$ resistência aerodinâmica do veículo $\mathrm{k}(l b s)$.

$$
\begin{aligned}
& v_{\mathrm{k}}=\text { velocidade relativa do vento no veículo } \mathrm{k}(m p h) \\
& \mathrm{C}_{\mathrm{A}_{\mathrm{k}}}=\text { coeficiente de resistência aerodinâmica do veículo } \mathrm{k}\left(\mathrm{l} \mathrm{bs} / m p h^{2}\right) \text {. }
\end{aligned}
$$

O coeficiente de resistência aerodinâmico é, por sua vez, definido como o produto do fator de densidade, que depende da pressão e temperatura ambiente, e da área de arrasto, que depende das características aerodinâmicas do veículo, sua posição e orientação em relação ao vento, conforme exposto nas Equações (A.21) e (A.22).

$$
\mathrm{C}_{\mathrm{Ak}_{\mathrm{k}}}=0,5 \cdot r(\mathrm{P}, \mathrm{T}) \cdot \mathrm{A}_{\mathrm{k}}\left(\mathrm{Y}_{\mathrm{k}}\right)
$$

em que

$$
r(\mathrm{P}, \mathrm{T})=0,04114 \cdot \frac{\mathrm{P}}{(\mathrm{T}+460)}
$$

e $\quad r(\mathrm{P}, \mathrm{T})=$ fator de densidade do ar.

$\mathrm{P}=$ pressão barométrica (polegadas de mercúrio - inch).

$\mathrm{A}_{\mathrm{k}}=$ área de arrasto do veículo $\mathrm{k}\left(f t^{2}\right)$.

$\mathrm{Y}_{\mathrm{k}}=$ ângulo de direção do veículo $\mathrm{k}$.

O coeficiente $A_{k}\left(Y_{k}\right)$ depende das características aerodinâmicas do veículo e varia entre veículos dependendo da sua posição no trem. O simulador disponibiliza os 10 tipos de veículos ferroviários listados na Tabela C.3 do item C.1.4, no Anexo C, para análise do desempenho aerodinâmico. 


\section{A.3.4. Resistência de curva}

A resistência de curva ocorre devido ao atrito lateral entre o friso das rodas dos veículos e os trilhos. A formulação utilizada pelo simulador, para cálculo desta parcela da resistência total do trem, é dada pelo produto da massa do veículo por um coeficiente de resistência de curva, que depende do tipo de truque e do coeficiente empírico de resistência de curva, conforme indicado na Equação (A.23).

$$
\mathrm{R}_{\mathrm{Ck}_{\mathrm{k}}}=\mathrm{M}_{\mathrm{k}} \cdot \mathrm{C}_{\mathrm{C}_{\mathrm{k}}}\left(i_{\mathrm{t}_{\mathrm{k}}}, \mathrm{c}_{\mathrm{k}}\right)
$$

em que $\quad \mathrm{R}_{\mathrm{C}_{\mathrm{k}}}=$ resistência de curva do veículo $\mathrm{k}(l b s)$.

$i_{\mathrm{t}}=$ tipo de truque do veículo $\mathrm{k}$.

$\mathrm{c}_{\mathrm{k}}=$ ângulo entre o centro de gravidade (C.G.) do veículo $\mathrm{k}$ e a reta tangente à curva em dado instante (graus decimais).

$\mathrm{C}_{\mathrm{C}_{\mathrm{k}}}=$ coeficiente de resistência de curva do veículo $\mathrm{k}$ (lbs/ton), que depende do tipo de truque do veículo e do ângulo central da curva, cujos valores são apresentados na Tabela C.13 e Tabela C.14 do item C.1.15, no Anexo C.

\section{A.4. Força de rampa}

O termo "força de rampa" é utilizado para designar os efeitos da diferença de nível entre dois pontos da via e é empregado dessa forma por não ser caracterizado como resistência ao movimento em rampas descendentes.

Segundo Drish (1992), a força de rampa é determinada pelo produto da massa do veículo, do grau (instantâneo) da rampa e uma constante de ajuste de unidades, como indicado na Equação (A.24).

$$
\mathrm{G}_{\mathrm{k}}=0,01 \cdot\left(\mathrm{M}_{\mathrm{k}} \cdot g\right) \cdot \theta_{\mathrm{k}}
$$

em que $\quad \mathrm{G}_{\mathrm{k}}=$ força de rampa atuante no veículo $\mathrm{k}(l b s)$.

$\theta_{\mathrm{k}}=$ grau instantâneo da rampa relativo ao centro de gravidade (C.G.) do veículo $\mathrm{k}(\%)$. 


\section{A.5. Frenagem de composições ferroviárias}

\section{A.5.1. Frenagem dinâmica}

A força de frenagem dinâmica é utilizada para reduzir a velocidade do trem. Assim como a força de tração, durante a frenagem dinâmica o controle dos freios varia continuamente entre o Ponto 0 (nenhuma desaceleração para qualquer velocidade do trem) e o Ponto 8 (força máxima de desaceleração, que depende da velocidade do trem), a exemplo da Figura A.9, relativa a uma locomotiva diesel-elétrica DASH 9.

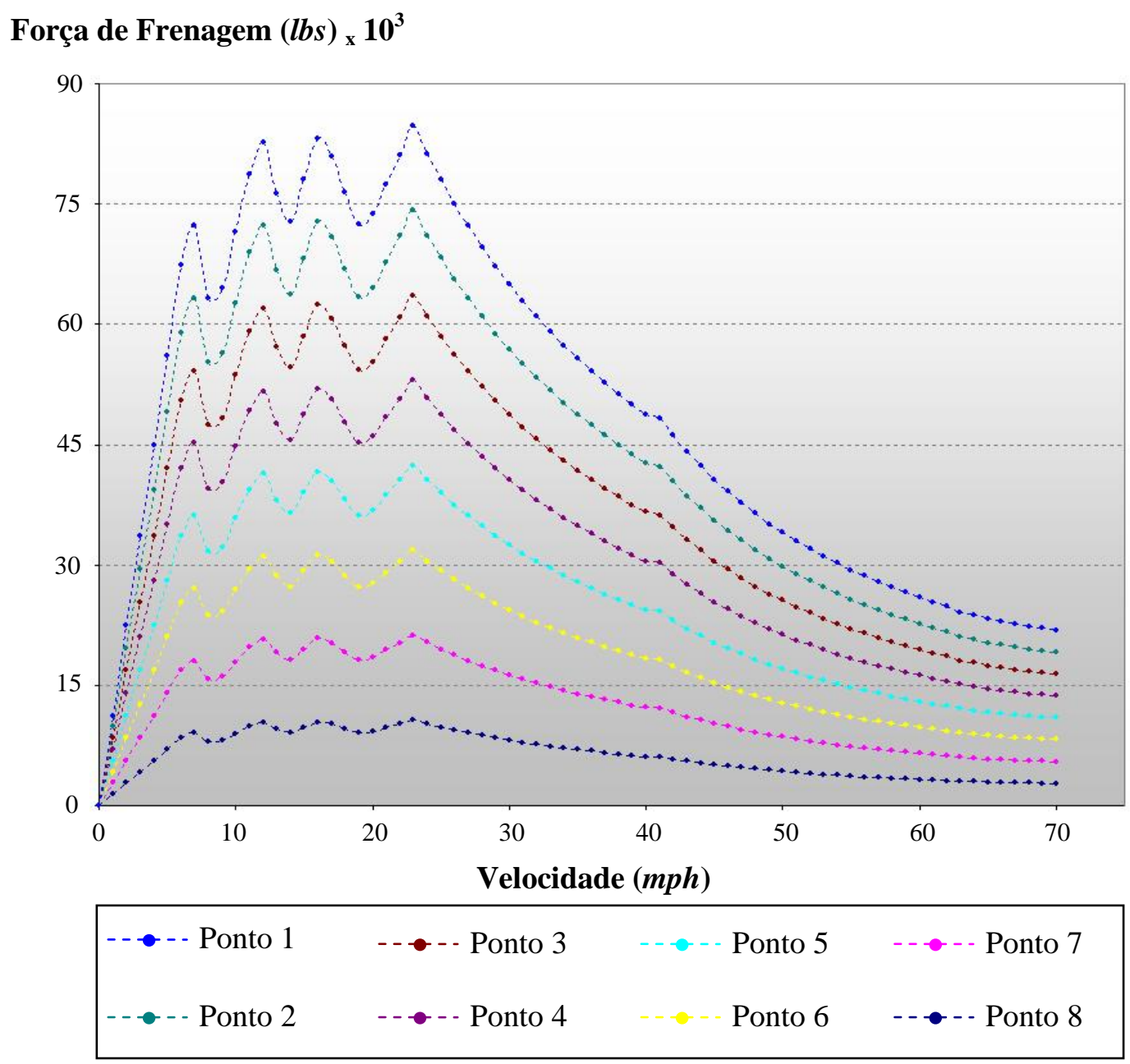

Figura A.9 - Curvas de frenagem de uma locomotiva diesel-elétrica DASH 9.

Existem quatro tipos de circuitos de frenagem dinâmica que, em semelhança com as taxas de consumo de combustível e características da força de tração das locomotivas, são especificados pelos fabricantes das locomotivas como: tapered extended (cônico estendido $\mathrm{TE}$ ), tapered nonextended (cônico não estendido - TN), flat extended (plano estendido - FE) e flat nonextended (plano não estendido - FN). 
Como as características de frenagem dinâmica têm, em geral, comportamento não-linear, o simulador utiliza tabelas para caracterização das curvas em cada um dos pontos de frenagem e interpola estes valores para as velocidades intermediárias.

Se uma locomotiva estiver em um dos Pontos de Tração, como especificado no item A.2, então:

$$
\mathrm{E}_{\mathrm{k}}=\mathrm{T}_{\mathrm{k}}\left(\mathrm{n}_{\mathrm{T}}, \mathrm{V}\right)
$$

Por outro lado, se esse veículo estiver sob o efeito de uma força de frenagem dinâmica:

$$
\mathrm{E}_{\mathrm{k}}=-\mathrm{D}_{\mathrm{k}}\left(\mathrm{n}_{\mathrm{D}}, \mathrm{V}\right)
$$

Se o veículo não é tracionado ou se diz respeito a uma locomotiva com o motor elétrico inativo, então:

$$
\mathrm{E}_{\mathrm{k}}=0
$$

em que $\mathrm{n}_{\mathrm{T}}=$ "Ponto de Tração" da locomotiva diesel-elétrica (número inteiro variando entre 0 - inativo - e 8).

$\mathrm{n}_{\mathrm{D}}=$ Ponto de Frenagem Dinâmica da locomotiva diesel-elétrica (número inteiro variando entre 0 - inativo - e 8)

$\mathrm{T}_{\mathrm{k}}=$ força de tração atuando no veículo $\mathrm{k}(l b s)$.

$\mathrm{D}_{\mathrm{k}}=$ força de frenagem atuando no veículo $\mathrm{k}(l b \mathrm{~s})$, expressa como um valor positivo.

$\mathrm{E}_{\mathrm{k}}=$ força de tração ou de frenagem dinâmica atuando no veículo $\mathrm{k}(l b s)$.

Como a frenagem dinâmica não é expressa por uma equação linear, em função dos pontos de frenagem e velocidade dos veículos, o simulador interpola valores em uma curva de modo análogo à força de tração aplicada pelas locomotivas.

\section{A.5.2. Frenagem a ar comprimido}

O sistema de frenagem a ar comprimido é acionado quando o de frenagem dinâmica é ineficiente ou quando seu uso não é recomendado. Esse sistema opera com dois tipos distintos de controle, o independente e o automático.

O controle automático de frenagem a ar comprimido permite que o operador do trem reduza a pressão interna da tubulação de frenagem (denominada "aplicação"), que é propagada para os 
demais veículos da composição e causa o aumento da força de frenagem (devido ao aumento da pressão no cilindro de frenagem). O efeito contrário é obtido quando a pressão interna da tubulação de frenagem é aumentada (denominada "relaxação") e a força de frenagem do trem é diminuída.

Como o procedimento inverso ao exposto também pode ser efetuado para diminuição da força de frenagem, diz-se que o controle automático de frenagem opera com uma "lógica negativa", ou seja, a diminuição da pressão nos tubos dos freios causa um aumento na força de frenagem (devido ao aumento da pressão no cilindro dos freios), ao passo que o aumento da pressão nos tubos dos freios provoca a diminuição na força de frenagem (devido à diminuição da pressão no cilindro dos freios).

Por outro lado, o controle independente é utilizado para, além de reduzir a velocidade, parar o trem, especialmente em trechos com declividades acentuadas. A frenagem automática, ao contrário, é aplicada somente às locomotivas, com ação quase instantânea da força de frenagem. Ao contrário da frenagem dinâmica, a independente opera com uma "lógica positiva", ou seja, o aumento da pressão nos cilindros de frenagem acarreta o aumento da força que atua para redução da velocidade e o contrário também ocorre.

As equações a seguir são utilizadas para representar matematicamente o sistema de frenagem a ar comprimido das composições ferroviárias.

$$
F_{k}=\frac{f \cdot e_{k} \cdot W_{k}}{P_{R}}
$$

em que $\quad \mathrm{F}_{\mathrm{k}}=$ força de frenagem por unidade de pressão para o veículo $\mathrm{k}$ (lbs/psi).

$\mathrm{f}=$ pressão de referência nos cilindros dos freios (psi).

$\mathrm{P}_{\mathrm{R}}=$ taxa de frenagem do veículo vazio $(0,3)$.

tal que

$$
\mathrm{e}_{\mathrm{k}}=\varepsilon-[\varepsilon-\lambda] \cdot\left[\frac{\mathrm{W}_{\mathrm{k}}-\tau_{\mathrm{k}}}{\gamma_{\mathrm{k}}-\tau_{\mathrm{k}}}\right] \text {, se } \gamma_{\mathrm{k}}>\tau_{\mathrm{k}}
$$

$\mathrm{e}$

$$
\mathrm{e}_{\mathrm{k}}=\lambda, \text { se } \mathrm{W}_{\mathrm{k}}>\tau_{\mathrm{k}}
$$

em que $\quad \gamma_{\mathrm{k}}=$ peso da carga do veículo $(l b s)$.

$\tau_{\mathrm{k}}=$ tara do veículo $(l b s)$. 


$$
\begin{aligned}
& \varepsilon=\text { taxa de frenagem do veículo vazio }(0,3) . \\
& \lambda=\text { taxa de frenagem do veículo carregado }(0,1) . \\
& \mathrm{e}_{\mathrm{k}}=\text { taxa de frenagem do veículo. }
\end{aligned}
$$

Em relação ao tempo entre a aplicação da força de frenagem e o atraso dessa aplicação sobre as rodas dos veículos ferroviárias, são aplicadas as equações que se seguem.

$$
\delta_{\mathrm{k}}=0, \text { se } \mathrm{L}_{\mathrm{k}} \leq \mathrm{L}_{0}
$$

$\mathrm{e}$

$$
\delta_{\mathrm{k}}=\log _{2}\left(\frac{\mathrm{L}_{\mathrm{k}}^{7}}{\mathrm{~L}_{0}}\right) \text {, se } \mathrm{L}_{\mathrm{k}}>\mathrm{L}_{0}
$$

Para uma "aplicação": $\mathrm{d}_{\mathrm{Ak}}=\mathrm{T}_{\mathrm{A}} \cdot \delta_{\mathrm{k}}$

Para uma "relaxação": $\mathrm{d}_{\mathrm{Rk}}=\mathrm{T}_{\mathrm{R}} \cdot \delta_{\mathrm{k}}$

em que $\quad \mathrm{L}_{0}=$ comprimento de referência da tubulação de frenagem $(64 \mathrm{ft})$.

$\mathrm{L}_{\mathrm{k}}=$ comprimento da tubulação de frenagem do veículo $\mathrm{k}(l b s)$.

$\delta_{\mathrm{k}}=$ fator de atraso da frenagem automática para o veículo $\mathrm{k}$.

$\mathrm{T}_{\mathrm{A}}=$ tempo de atraso característico para "aplicação" (3,0 segundos).

$\mathrm{T}_{\mathrm{R}}=$ tempo de atraso característico para "relaxação" (1,0 segundos).

$\mathrm{d}_{\mathrm{Ak}}=$ tempo de atraso de "aplicação" para o veículo k (segundos).

$\mathrm{d}_{\mathrm{Rk}}=$ tempo de atraso de "relaxação" para o veículo k (segundos).

A força de frenagem efetiva é dada por:

$$
\mathrm{B}_{\mathrm{k}}=\mathrm{q}_{\mathrm{k}} \cdot \mathrm{F}_{\mathrm{k}}
$$

De modo que, para uma "aplicação":

$$
\mathrm{q}_{\mathrm{k}}=0, \text { se } \mathrm{t}_{\mathrm{A}}<\mathrm{d}_{\mathrm{Ak}}
$$

$\mathrm{e}$

$$
\mathrm{q}_{\mathrm{k}}=\mathrm{v} \cdot \mathrm{b}, \text { se } \mathrm{t}_{\mathrm{A}} \geq \mathrm{d}_{\mathrm{Ak}}
$$

Para uma "relaxação":

$\mathrm{e}$

$$
\mathrm{q}_{\mathrm{k}}=0 \text {, se } \mathrm{t}_{\mathrm{R}}<\mathrm{d}_{\mathrm{Rk}}
$$

$$
\mathrm{q}_{\mathrm{k}}=\mathrm{v} \cdot \mathrm{b}, \text { se } \mathrm{t}_{\mathrm{R}}<\mathrm{d}_{\mathrm{Rk}}
$$


em que $\quad b=$ redução da frenagem automática $(p s i)$.

$\mathrm{v}=$ fator de volume de frenagem a ar (2,5).

$\mathrm{q}_{\mathrm{k}}=$ pressão efetiva no cilindro de frenagem a ar do veículo $\mathrm{k}$ ( $p s i$ ).

$\mathrm{t}_{\mathrm{A}}=$ tempo transcorrido a partir da "aplicação" (segundos).

$\mathrm{t}_{\mathrm{R}}=$ tempo transcorrido a partir da "relaxação" (segundos).

$\mathrm{B}_{\mathrm{k}}=$ força de frenagem efetiva aplicada no veículo $\mathrm{k}(l b s)$.

Para uma locomotiva utilizando a frenagem independente, a expressão para determinação da pressão do cilindro é dada por:

$$
\mathrm{q}_{\mathrm{k}}=0,6 \cdot \mathrm{I}+\mathrm{v} \cdot \mathrm{b}, \text { se } \mathrm{I}<\mathrm{v} \cdot \mathrm{b}-2
$$

$\mathrm{e}$

$$
\mathrm{q}_{\mathrm{k}}=1,6 \cdot \mathrm{I}, \text { se } \mathrm{I}>\mathrm{v} \cdot \mathrm{b}+2
$$

em que $\quad \mathrm{I}=$ ajuste da frenagem a ar independente $(p s i)$.

Para os limites fora do intervalo definido em (A.34.a) e (A.34.b), são utilizadas as Equações (A.33.a) e (A.33.b), respectivamente, e a Equação (A.34.b) também pode ser utilizada para locomotivas ligadas, mas inoperantes.

\section{A.6. Estimativa da força no engate}

O simulador TEM versão 2.5 faz uma estimativa da força no engate dos veículos que constituem a composição ferroviária, cujos valores são apresentados no arquivo de texto descrito no item "C.2.1 - Histórico de distribuição da força nos engates no tempo (.ACT)", do Anexo C.

Para cada intervalo de simulação, o cálculo da força nos engates é dado pelas condições a seguir.

Se $A=0$, então: $\quad \mathrm{E}_{\mathrm{k}}=\mathrm{S}_{\mathrm{k}}-\mathrm{G}_{\mathrm{k}}-\mathrm{R}_{\mathrm{k}} \cdot \operatorname{sgn}(\mathrm{V})-\mathrm{M}_{\mathrm{k}} \cdot\left(\frac{\mathrm{A}}{g}\right)$

Caso contrário: $\quad \mathrm{E}_{\mathrm{k}}=0$

em que $\quad \mathrm{E}_{\mathrm{k}}=$ força no engate traseiro do veículo $\mathrm{k}(l b s)$. 
Anexo B

\section{MODELO DE SIMULAÇÃO - TEM}

O simulador Train Energy Model versão 2.5 é resultado de um projeto desenvolvido pela Association of American Railroads (AAR), no Programa de Pesquisas em Energia (Energy Research Program), iniciado no ano de 1982 para estudo do consumo de combustível de composições ferroviárias.

Atualmente, a $A A R$ é responsável pelos estudos de planos de operação (segurança e eficiência) do sistema ferroviário norte-americano e sua Divisão de Comunicações e Sinalizações fundiu-se, em 1997, com a American Railway Bridge and Building Association, a American Railway Engineering Association (AREA) e a Roadmaster's and Maintenace of Way Association, formando a American Railway Engineering and Maintenance-of-Way Association (AREMA), responsável pela pesquisas sobre técnicas construtivas e de manutenção ferroviária.

As versões posteriores ao lançamento do software foram aperfeiçoadas pela inserção de parâmetros complementares, relativos aos coeficientes de resistência obtidos através de métodos empíricos e às características aerodinâmicas dos veículos, e pelo cálculo de outras variáveis, como a força nos engates dos vagões e locomotivas.

O simulador é organizado em três estruturas distintas, que viabilizam a representação do movimento de um trem na linha férrea.

\section{Modelo Matemático (Mathematical Model)}

Abrange as equações de força propulsora, as relações empíricas empregadas na modelagem da resistência ao movimento, a caracterização do sistema de frenagem etc., e os métodos numéricos utilizados para integrar essas equações.

\section{Lógica de Controle do Trem (Train Control Logic)}

É o conjunto de comandos internos pré-definidos no software, para inicialização e controle do trem, capaz de representar adequadamente os seus movimentos no nível de detalhamento 
disponibilizado pelo simulador.

Algoritmo de Manobra do Trem (Automatic Train-handling Algorithm-ATA)

É uma espécie de inteligência artificial, que busca atingir alguns objetivos pré-estabelecidos em relação ao trem durante a sua movimentação na linha. Os usuários podem empregar o ATA em uma grande variedade de estudos como, por exemplo, na análise paramétrica do consumo de combustível. No processo de validação do modelo de simulação, ficou constatado que o ATA representa adequadamente as manobras da composição ferroviária e que os erros constatados geralmente não afetam os resultados globais das análises.

\section{B.1. Estrutura Básica}

A integração do modelo é dada através de cinco programas principais, alguns dos quais constituídos de subprogramas que auxiliam no preparo e execução de uma simulação. Os arquivos gerados por esses programas e seu conteúdo são descritos no Anexo C.

1. Programa Editor $(E D I)$

1.1. Compilador de Arquivos (Batch File Editor - BIF)

1.2. Gerador e Editor de Arquivos (File Editor and Builder Program - FEB)

1.3. Processador de Dados relativos à via e ao trem (Track/Train Utility Processor ProgramTUP)

2. Programa Pré-processador Aerodinâmico (Aerodinamic Preprocessor Program-DRAG)

3. Programa Pré-processador dos Dados do trem (Consist Preprocessor Program-PRE)

4. Programa Simulador (Simulator Program - TEM)

5. Programa Avaliador de Resultados (EVA)

5.1. Tabulador do Relatório de Simulação (TEM Report Tabulator Program - TAB)

5.2. Verificador das Condições de Contorno (Stall Checker Program - STLCHK) 


\section{B.1.1. Programa Editor (EDI)}

É um arquivo executável, que permite ao usuário acessar as opções de configuração do conjunto de arquivos necessários para compilar o Programa de Pré-processamento Aerodinâmico $(D R A G)$, o Programa Pré-processador dos Dados do trem (PRE) e o Programa Simulador (TEM).

Dentro do programa EDI são disponibilizados três subprogramas - Editor dos Grupos de Arquivos $(B I F)$, Gerador e Editor de Arquivos $(F E B)$ e Processador de Dados relativos à via e ao trem (TUP), todos utilizados no preparo dos arquivos de simulação.

\section{B.1.2. Compilador de Arquivos (Batch File Editor - BIF)}

O objetivo do subprograma $B I F$ é permitir que o usuário crie arquivos auxiliares para a execução dos programas $D R A G, P R E$ e TEM. As funções nele inseridas são:

Função 1: Editar os arquivos requeridos pelo programa $D R A G$

(Function 1: Edit DRAG Batch File)

Função 2: Editar os arquivos requeridos pelo programa $P R E$

(Function 2: Edit PRE Batch File)

Função 3: Editar os arquivos requeridos pelo programa TEM

(Function 3: Edit TEM Batch File)

Os arquivos gerados pelas funções do programa $B I F$ são, respectivamente:

GOAIR.BAT - Possui os comandos que copiam informações para o arquivo de inicialização do programa $D R A G$, o AIR.BIF.

GOPRE.BAT - Possui os comandos que copiam informações para o arquivo de inicialização do programa PRE, o PRE.BIF.

GOTEM.BAT -Possui comandos que copiam informações para o arquivo de inicialização do programa TEM, o TEM.BIF. 


\section{B.1.3. Gerador e Editor de Arquivos (File Editor and Builder Program-FEB)}

O propósito do subprograma $F E B$, acessado através do programa $E D I$, é permitir que o usuário configure os arquivos requeridos pelos programas DRAG, PRE e TEM. As suas funções são:

Função 1: Criar Novo Arquivo de Composição

$(. \mathrm{CON})$

(Function 1: Build New Train Consist File)

Função 2: Criar Novo Arquivo de Parâmetros dos Veículos

(Function 2: Build New Vehicle Parameter File)

Função 3: Criar Novo Arquivo de Configuração da Via

(Function 3: Build New Track Chart File)

Função 4: Criar Novo Arquivo de Condições Ambientais

(Function 4: Build New Wind Chart File)

Função 5: Criar Novo Arquivo de Paradas

(Function 5: Build New Destination File)

Função 6: Criar ou Editar Arquivo de Parâmetro ATA

(Function 6: Build or Edit ATA Parameter File)

Função 7: Criar ou Editar Arquivo de Inicialização

(Function 7: Build or Edit Initializtion File)

Função 8: Criar Novo Arquivo de Comando

(Function 8: Build New Command File)

Função 9: Criar Novo Arquivo de Tipo de Carregamento

(Function 9: Build New Intermodal Cargo File)

B.1.3.1. Processador de Dados relativos à Via e ao Trem (Track/Train Utility Processor Program - TUP)

O objetivo deste programa é auxiliar o usuário na edição dos arquivos que contêm os dados de entrada do simulador e na elaboração de gráficos com os dados de saída, através das funções: 
Função 1: Inverter o sentido da via do Arquivo de Configuração da Via (.TRK)

(Function 1: Reverse existing TEM Track Chart File)

Função 2: Calcular as rampas em função das elevações

(Function 2: Compute grades from known elevations)

Função 3: Calcular as elevações em função das rampas

(Function 3: Compute elevations from known grades)

Função 4: Adicionar seções no Arquivo de Configuração da Via

(Function 4: Add constant position to Track Chart File)

Função 5: Editar arquivo de força tratora das locomotivas

(Function 5: De-rate existing tractive effort file)

\section{B.1.3.2. Programa Pré-processador Aerodinâmico (Aerodinamic Preprocessor Program - $D R A G)$}

Este programa cria a área de arrasto para cada veículo do trem, que varia com o seu ângulo de desvio de direção durante o movimento e depende da posição do veículo na composição, e insere esses dados em um arquivo específico (.DRG).

O programa DRAG necessita dos arquivos de Parâmetros dos Veículos (.PAR) e de Parâmetros da Composição (.CON), e do Tipo de Carregamento (.CGO), quando a composição inclui veículos com diferentes tipos de cargas (contêiner ou trailer).

Quando o programa é executado, após o usuário executar corretamente a Função 1 do programa $B I F$, um arquivo com extensão “.DRG” é criado, o qual será utilizado pelo programa $P R E$ para gerar o arquivo de dados com as características do trem (.DAT), incluindo aí as configurações de controle do movimento do trem.

\section{B.1.3.3. Programa Pré-processador dos Dados do Trem (Consist Preprocessor Program - PRE)}

Este programa organiza os parâmetros relativos ao trem, com o objetivo de minimizar o tempo de simulação necessário para obtenção dos resultados de desempenho da composição. 
O correto funcionamento do programa exige a criação dos arquivos de Área de Arrasto (.DRG), da Composição (.CON), de Parâmetros dos Veículos (.PAR), dos Valores de Força Tratora (.THL) para cada uma das locomotivas, dos Valores de Força de Frenagem Dinâmica (.DYN), dos Parâmetros do Sistema Automático de Frenagem a Ar (TEM.AIR) e do arquivo de Inicialização (.INI), gerado pelo programa GOPRE.BAT (PRE.BIF).

Após preparação desses arquivos, o usuário deve acessar o programa executável PRE para que sejam criados o arquivo de Dados Pré-processados pelo programa DRAG (.DAT), o de Informações sobre o Desempenho dos Trens (.FYI), o da Tabela de Velocidades de Equilíbrio (.TES), o da Tabela de Configurações de Frenagem Dinâmica (.DES) e o da Tabela de Reduções dos Freios no Equilíbrio (.AER).

Se ao trem forem incluídas locomotivas auxiliares para realização do movimento, são gerados os arquivos adicionais de Informações sobre o Desempenho dos Trens (.FY2), o da Tabela de Velocidades de Equilíbrio (.TE2) e o da Tabela de Configurações de Frenagem Dinâmica (.DE2), referentes a esses veículos.

\section{B.1.3.4. Programa Simulador (Simulator Program - TEM)}

Os arquivos de entrada exigidos por esse programa - responsável pela exibição da simulação e geração dos dados de desempenho do trem - são o de Dados Pré-processados pelo programa DRAG (.DAT), o de Configuração da Via (.TRK), o de Configuração Aerodinâmica (.WND), o de Paradas (.STP), o de Comando (.CMD), o de Parâmetro ATA - Automatic Trainhandling Algorithm (.ATA), o de Inicialização (.INI) e o de Inicialização gerado pelo programa GOTEM.BAT (TEM.BIF).

Após exibição da simulação, os arquivos resultantes da execução desse programa são o de Relatório de Simulação (.RPT) e o de Saída dos Dados de Desempenho (.OUT). O arquivo com o histórico de distribuição de forças nos engates (.ACT) também é criado se o usuário indicar essa opção no Arquivo de Inicialização (.INI).

\section{B.1.3.5. Programa Avaliador de Resultados (EVA)}

O programa EVA disponibiliza ao usuário ferramentas para avaliação dos resultados de uma simulação e é dividido em dois subprogramas - Tabulador do Relatório de Simulação (TAB) e Verificador das Condições de Contorno (STLCHK). 


\section{B.1.3.6. Tabulador do Relatório de Simulação (TEM Report Tabulator Program - TAB)}

Como parte do programa que permite a análise das simulações, esse subprograma organiza os seus resultados e exibe graficamente o conteúdo do arquivo de Relatório de Simulação (.RPT). Os parâmetros que podem ser visualizados através do programa $T A B$ estão descritos no item C.2.7, do Anexo C.

\section{B.1.3.7. Verificador das Condições de Contorno (Stall Checker Program - STLCHK)}

O arquivo GOTEM.BAT, criado através da Função 3 (Editar os arquivos requeridos pelo programa TEM) do Compilador de Arquivos (Batch File Editor - BIF), pode ser verificado em relação à existência de erros na configuração da linha ferroviária.

Se algum erro for detectado pelo subprograma Verificador das Condições de Contorno (Stall Checker Program - STLCHK), uma mensagem indica a posição aproximada na via, para que este possa ser reparado com acesso àquela Função ou intervenção direta do usuário no arquivo, através de um editor de texto.

\section{B.2. Relação entre os programas}

A Figura B.1 ilustra a relação entre os programas e os conjuntos de arquivos destinados à criação, execução e avaliação das simulações no Train Energy Model, versão 2.5. 
1. Definição dos conjuntos de arquivos

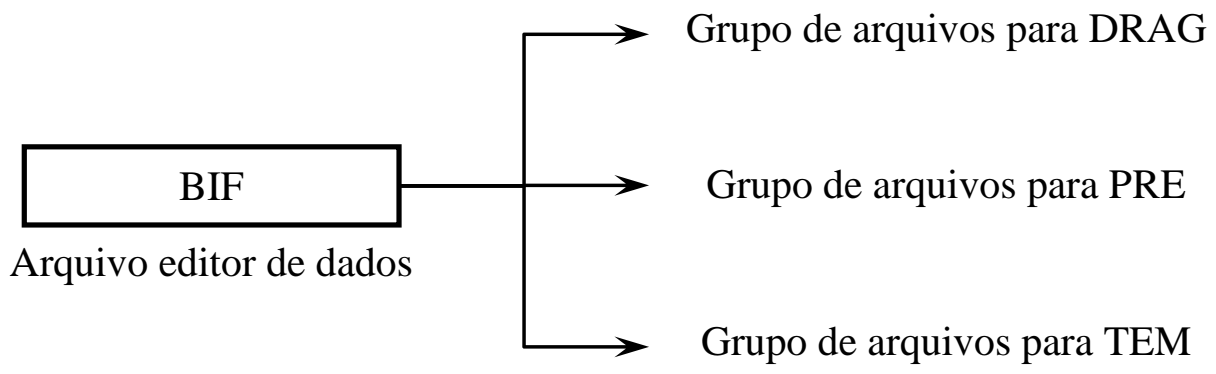

\section{Pré-processamento}

Grupo de arquivos para DRAG

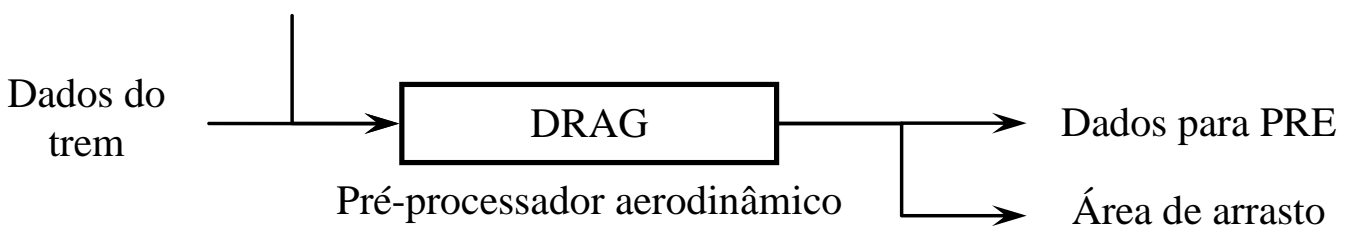

Grupo de arquivos para PRE

Dados do trem e da Área de Arrasto

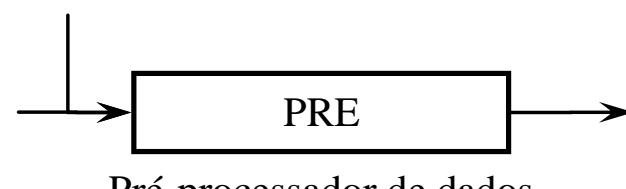

Pré-processador de dados
Dados pré-processados para TEM

\section{Simulação}

Grupo de arquivos para TEM

Dados do trem e da via pré-processados

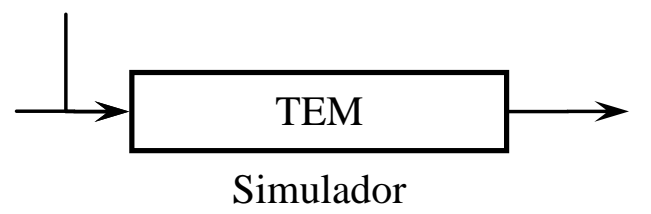

Resultados da simulação

\section{Análise dos relatórios de simulação}

$$
\begin{aligned}
& \text { Resultados da } \\
& \text { simulação }
\end{aligned}
$$

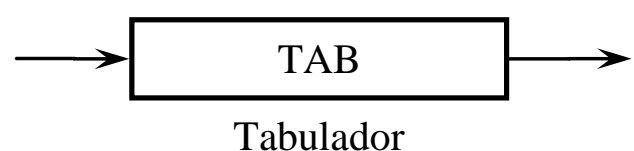

Tabelas de relatórios de simulação 


\section{Anexo C}

\section{ARQUIVOS DO SIMULADOR TEM}

Neste anexo são descritos os arquivos que contêm os dados de entrada do modelo de locomoção, apresentado no Anexo A, e os arquivos contendo os parâmetros calculados após a execução do modelo de simulação.

\section{C.1. Arquivos de entrada de dados}

\section{C.1.1. Arquivo de Carregamento (.CGO)}

A função "Criar um Novo Arquivo de Carregamento" (Build a New Intermodal Cargo File), do subprograma $F E B$, permite a criação de um arquivo que contém os parâmetros de carregamento dos veículos, no formato adequado para ser processado pelo programa $D R A G$. Cada tipo de veículo é caracterizado em um Arquivo da Composição (.CON), com um Arquivo de Carregamento (.CGO) correspondente.

Tabela C.1 - Conteúdo do arquivo ".CGO".

Tipo de Carga - 1: reboque; 2: contêiner (Cargo Type - 1: trailer; 2: container)

Comprimento do Vagão, em Pés (Cargo Lenght in Feet)

Indicador de Aresta Externa do Vagão - 0: inexistente; 1: existente (Cargo External Ribs Indicator - 0: absent; 1: present)

Distância da Face Frontal do Vagão ao Pino Rei, em Pés (Trailer Front to Kingpin Distance in Feet)

Tipo de Geometria da Face Frontal do Vagão (Type of Trailer Frontal Geometry)

1 Topo suavizado e laterais arredondadas (Streamlined top corner and rounded side corners)

2 Topo reto e laterais arredondadas (Square top corner and rounded side corners)

3 Todas as laterais retas (All square corners)

\section{C.1.2. Arquivo de Área de Arrasto (.DRG)}

O arquivo ".DRG” apresenta a Área de Arrasto de cada veículo do trem, definida como um polinômio de sétima ordem, em função do ângulo de desvio de direção do movimento (yaw angle). Cada linha do arquivo de Área de Arrasto contém os setes coeficientes do polinômio, 
relacionados aos correspondentes veículos da composição ferroviária.

\section{C.1.3. Arquivo da Composição (.CON)}

A função "Criar um Arquivo da Composição" (Build a New Train Consist File), do subprograma $F E B$, permite a criação do arquivo que especifica as partes constituintes do trem, utilizado posteriormente durante a execução do programa $D R A G$ para criação do arquivo “.DRG” e do programa PRE para criação do arquivo “.DAT”. O simulador é capaz de analisar o movimento de um trem com, no máximo, 250 veículos, com as locomotivas e vagões caracterizados em seis campos distintos, em cada linha do arquivo ".CON", cujo conteúdo pode ser editado a qualquer instante com o auxílio de um editor de texto.

Tabela C. 2 - Conteúdo de cada linha do arquivo ".CON".

Código da Locomotiva - 1 a 5: tipo de locomotiva - máximo de 5 tipos; 0: veículo não tracionado (Locomotive Code - 1 through 5 for locomotives - up to 5 different locomotive types; 0 for unpowered vehicles)

Identificador do Veículo - seis caracteres para todos os tipos de veículos (Vehicle Identifier - six characters for all vehicles)

Tipo de Frenagem Dinâmica - dois caracteres para locomotivas ou dois espaços vazios para veículos não tracionados (Dynamic Brake Type - two characters for locomotives or two blanks for unpowered vehicles)

Peso do Combustível, ou da Carga, em Toneladas (Weight of Fuel or Landing in Tons)

Indicador da Orientação da Locomotiva - 0: cabine na parte dianteira - frente; 1 : cabine na parte traseira -ré (Locomotive Orientation Indicator - 0: short hood facing forward; 1: short hood facing backward)

Identificação do Vagão à Montante - seis caracteres para vagão com carregamento ou seis espaços vazios para vagão sem carregamento (Identifier for Upstream Trailer or Container - six characters for intermodal cargo or six blanks for no intermodal cargo)

Identificação do Vagão à Jusante - seis caracteres para vagão com carregamento ou seis espaços vazios para vagão sem carregamento (Identifier for Downstream Trailer or Container - six characters for intermodal cargo or six blanks for no intermodal cargo)

Indicação da Condição das Portas do vagão tipo BOXCAR - 0: aberto; 1: fechado (BOXCAR Door Status Indicator - 0: open; 1: closed)

Tipo de Mancal do Veículo - 1: T gasto; 2: T novo; 3: B gasto; 4: B novo (Vehicle Bearing Type - 1: worn T; 2: new T; 3: worn B; 4: new B)

Tipo de Truck do Veículo - 1: 3 eixos gasto; 2: 3 eixos novo; 3: radial; 4: estrutura reforçada; 5: 2 eixos; 6: 1 eixo (Vehicle Truck Type - 1: 3-piece (3P) worn; 2: 3-piece $(3 P)$ new; 3: radial $(R)$; 4: frame-braced $(F R)$; 5: premium 2-axle $(P 2 A)$; 6: singleaxle $(1 A))$ 


\section{C.1.4. Parâmetros dos Veículos (.PAR)}

Este arquivo permite especificar os parâmetros físicos de um veículo e é produzido através da função "Build New Vehicle Parameter File", para posterior processamento nos programas $D R A G$ e $P R E$. Cada tipo de veículo listado no Arquivo de Composição (.CON) deve possuir um Arquivo de Parâmetros dos Veículos (.PAR) correspondentes.

Os parâmetros das locomotivas e veículos não tracionados são definidos nessa função através de um menu padrão, que depende do tipo de veículo definido pelo usuário. A Tabela C.3 apresenta os tipos de veículos disponíveis para escolha e a Tabela C.4 mostra os dados contidos nos arquivos que caracterizam os veículos.

Tabela C.3 (continua) - Tipos e subtipos de veículos ferroviários.

\section{LOCOMOTIVAS}

1. EMD 2 GE

\section{VAGÃO HOOPER}
1. Open Coal
4. Covered Conventional
2. Open Aggregate
5. Covered Center Flow
3. Open Woodchip
6. Covered Airslide

VAGÃO GÔNDOLA (GONDOLA)
1. Rotary Dump
3. Coil Steel Car
2. Mill car
4. Woodchip

VAGÃO BOXCAR

VAGÃO REFRIGERADOR (REFRIGERATOR CAR)

VAGÃO TANQUE (TANK CAR)

VAGÃO INDEPENDENTE ( $A U T O T R A C K C A R$ )

VAGÃO CONTÊINER (INTERMODAL CAR)

1. Double Stack Car (Well)

2. Double Stack Car (Bulkhead)

3. Road Railer (Mark IV)

4. Road Railer (Mark V)

5. Flat Car (Plain)

6. Flat Car (89-Foot)

7. Flat Car (Skeletonized) 
Tabela C.3 (conclusão) - Tipos e subtipos de veículos ferroviários.

\section{CABOOSE}

VAGÃO DE PASSAGEIROS (PASSENGER CAR)

1. Um nível (Single Level) 2. Dois níveis (Double Level)

Tabela C.4 (continua) - Conteúdo do arquivo “.PAR”.

\section{LINHA 1}

Número de eixos (Number of axles)

Peso Bruto da Carga, em Libras (Gross Rail Load in Lbs)

Massa do Veículo Vazio, em Toneladas (Empty Weight of Vehicle in Tons)

Distância entre Engates, em Pés (Coupler-to-Coupler Lenght in Feet)

Área Frontal de Arrasto, em Pés Quadrados (Stand-Alone Drag Area in Square Feet)

\section{LINHA 2}

Taxa de Consumo de Combustível para Frenagem Dinâmica, em Galões/Hora (Fuel Consumption Rate for Dynamica Braking in Gal/hr)

Taxa de Consumo de Combustível para Locomotivas Ociosas, em Galóes/Hora (Fuel Consumption Rate for Idle in Gal/hr)

Taxa de Consumo de Combustível por Ponto de Tração (1 a 8), em Galões/Hora (Fuel Consumption Rate for Notches in Gal/hr)

\section{LINHA 3}

Coeficiente de Aderência Máximo (Maximum Adhesion Coefficient)

Velocidade Mínima da Locomotiva, em Milhas por Hora (Minimum Continuous Locomotive Speed in MPH)

\section{LINHA 4}

Código do Tipo de Veículo - 0 a 25 (Rail Vehicle Aerodynamic. Type Code - 0 thru 25)

Indicador do Reservatório de Freio a Ar e da Barra de Tração - 0: existente; 1: inexistente (Air Brake Tank and Roll Bar Indicator $-0=$ absent; $1=$ present)

Tipo de cobertura - 0: aberto; 1: coberto; 2: fechado (Top Type - 0: open; 1: covered; 2: complex)

Tipo de Fundo - 0: plano; 1: alçapão (Bottom Type - 0: flat;1: drop)

Divisões Internas - 0: ausente; 1: presente (Interior Crossties - 0: absent; 1: present) Estrutura Interior - 0: Inexistente; 1: circular; 2: elipsoidal (Interior Strcture - 0: absent; 1: circular; 2: elliptical)

Modelo da cabine - 1: padrão; 2 : CN/aerodinâmica; 3: CN/ não aerodinâmica ( $C a b$ Design-1: standard; 2: CN/cowl; 3: CN/no cowl) 
Tabela C.4 (conclusão) - Conteúdo do arquivo ".PAR”.

\section{LINHA 5}

Porcentagem de Modificação Aerodinâmica Externa (Percentage of External Aerodynamic Modification)

Porcentagem de Modificação Aerodinâmica Interna (Percentage of Internal Aerodynamic Modification)

Distância do Pino Rei ao Engate Frontal, em Pés (Front Coupler to KingPin Distance in Feet)

Distância do Pino Rei ao Engate Traseiro, em Pés (Rear Coupler to KingPin Distance in Feet)

Distância da Face do Contêiner ao Engate Frontal, em Pés (Front Coupler to Container Face Distance in Feet)

Distância da Face do Contêiner ao Engate Traseiro, em Pés (Rear Coupler to Container Face Distance in Feet)

LINHA 6

Altura do Veículo, em Pés (Car Height in Feet)

Distância da Face do Veículo ao Engate, em Pés (Coupler to Car Face Distance in Feet)

Altura da extremidade superior acima da plataforma do vagão HOOPER, em Pés (Hooper End Upper Vertical Portion Lenght in Feet)

Coeficiente de Ponderação relativo às Arestas do Veículo - 0: sem arestas; 1: arestas máximas (Rib Weighting Factor - 0: no ribs; 1: full sized ribs)

Incremento da Área Externa de Arrasto, em Pés Quadrados (External Drag Area Increment in Square Feet)

Incremento da Área Interna de Arrasto, em Pés Quadrados (Internal Drag Area Increment in Square Feet)

\section{LINHA 7}

Incremento da Área de Arrasto devido a Fixações Externas, em Pés Quadrados (External Fixture Drag Area Increment in Square Feet)

Tipo de Vagão CABOOSE - 0: aberto; 1: domo (Caboose Type - 0: bay window;1: cupola)

Número da Plataforma do Truck - 1: intermediário; 1.5: final; 2: independente (Plataform Truck Number - 1: middle; 1.5: end; 2: stand alone)

O pacote de instalação do simulador Train Energy Model versão 2.5 possui os arquivos de Parâmetros dos Veículos “.PAR”, Valores de força tratora da locomotiva “.THL” e Valores da Força de frenagem Dinâmica “.DYN”, configurados para dez tipos de locomotivas EMD. 


\section{C.1.5. Dados de Pré-processamento do trem (.DAT)}

O .DAT possui os dados pré-processados de configuração do comboio ferroviário, incluindo as definições de controle do trem, geradas após execução do programa PRE, e requer as informações do Arquivo da Composição (.CON), dos Arquivos de Parâmetros dos Veículos (locomotivas e veículos não tracionados - .PAR), do Arquivo de Valores de Força Tratora das Locomotivas (.THL), do Arquivo de Valores da Frenagem Dinâmica (.DYN) e daquele que define os parâmetros para o sistema de frenagem dinâmica (TEM.AIR).

\section{C.1.6. Arquivo de Inicialização (.INI)}

É criado pela função "Criar ou Editar o Arquivo de Inicialização" (Build or Edit Initialization File) do subprograma FEB e contém as informações indicadas na Tabela C.5, necessárias para inicialização de uma simulação.

Tabela C.5 (continua) - Conteúdo do arquivo ".INI".

Nome do Arquivo dos Dados do Trem “.DAT" (Train Data “.DAT” File Name)

Nome do Arquivo da Via ".TRK" (Track Chart “.TRK” File Name)

Nome do Arquivo das Condições Ambientais “.WND” (Wind Chart “.WND” File Name)

Intervalo de Tempo do Arquivo de Saída “.OUT", em Segundos (File Output time Interval in Seconds)

Mostrar intervalo de Saída de Dados em Segundos - (sinal negativo): sem figura; 0: não mostrar (Display Output Time Interval in Seconds - (minus): no picture; 0: no display)

Orientação Inicial do Veículo Condutor, em Graus Decimais (Initial Heading of Leading Vehicle in Degrees)

Posição Inicial do Veículo Condutor, em Milhas mais valor em Pés (Initial Position of Leading Vehicle - Number of Miles plus Number of Feet)

Lubrificação das Engrenagens dos Veículos - 0: desativada; 1: ativada (Status of Vehicle-Mounted Lubricators - 0:off; 1: on)

Lubrificação dos Equipamentos da Via - 0: desativada; 1: ativada (Status of Trackside Lubricators - 0: off; 1: on)

Distância de Efetividade da Lubrificação dos Equipamentos da Via, em Pés (Effective Lubrication Distance in Feet)

Redução da Resistência de Rolamento, em Libras por Tonelada (Reduction of Rolling Resistance in Lbs/Ton) 
Tabela C.5 (conclusão) - Conteúdo do arquivo “.INI”.

Intervalo de Tempo para Interrupção Manual da Simulação, em Segundos (Manual Command Interupt Time Interval in Seconds)

Orientação Inicial - E_; NE; N_; NW; W-; SW; S_; SE (Initial Compass Heading $\left.-E_{-} ; N E ; N_{-} ; N W ; W-; S W ; S_{-} ; S E\right)$

Intervalo de Tempo no Arquivo de Saída de Dados da Distribuição de Forças nos Engates, em Segundos (Coupler Force Distribution Output File Interval in Seconds)

\section{PARÂMETROS GRÁFICOS}

Efeitos Sonoros - 0: desligado; 1: ligado ( Status of Sound Effects - 0: off; 1:on)

Distância entre mudança de tela durante a simulação, em Milhas (Display Scene Distance in Miles)

Condições Inicias do período do dia - 1: noite; 0: crepúsculo; -1:dia (Initial Scene Time-of-Day - := night; 0: twilight; -1: day)

Tempo Restante até o Início do Crepúsculo, em Horas (Time Until Twilight in Hours)

Duração das Condições Iniciais do período do dia, em Horas (Duration of Initial Time-of-Day in Hours)

Apresentação da Distribuição de Forças nos Engates - 0: desligada; 1: ligada (Status of Coupler Force Distribution Display - 0: off; 1: on)

Força Máxima no Engate exibida durante a Simulação, em Libras (Maximum Display Coupler Force in Lbs)

\section{C.1.7. Configuração das Condições Ambientais (.WND)}

A função "Criar um Novo Arquivo de Condições Ambientais" (Build New Wind Chart File), do subprograma $F E B$, é acessada para a criação de uma tabela que diz respeito às condições ambientais em que o trem opera, sendo utilizada, posteriormente, pelo programa TEM. Os valores de referência são 32 graus Fahrenheit (32 $\operatorname{deg} F$ ) para temperatura ambiente e 30 polegadas de mercúrio (30 inches $\mathrm{Hg}$ ), padrões ao nível do mar.

Tabela C.6 (continua) - Conteúdo das linhas do arquivo ".WND”.

Especificação da Posição na Via, em Pés (Specified Track Position in Feet)

Direção do Vento na posição especificada - e no entorno - em Graus (Wind Direction at - and following - especified poisiton in Degrees)

Velocidade do Vento na posição especificada - e no entorno - em Milhas por Hora (Wind Speed at - and following - specified psition in MPH)

Temperatura Ambiente na posição especificada - e no entorno - em graus Fahrenheit (Ambient Temperatura at - and following - specified position in degrees Fahrenheit) 
Tabela C.6 (conclusão) - Conteúdo das linhas do arquivo “.WND”.

Pressão Barométrica não corrigida na posição especificada - e no entorno - em Polegadas de Mercúrio (Uncorrected Barometric Pressure at - and following specified psition in Inches of Mercury)

\section{C.1.8. Arquivo de Parâmetro ATA (.ATA)}

O subprograma FEB possui a função "Criar ou editar o Arquivo de Controle Automático de Trem - ATA" (Build or Edit ATA Parameter File), que permite ao usuário editar os valores dos parâmetros indicados na Tabela C.7, relativos ao Algoritmo Automático de Manobra do Trem (Automatic Train-handling Algorithm - ATA).

Tabela C.7 - Conteúdo das linhas do arquivo ".ATA".

Indicador do Uso de Freios Dinâmicos - 0: proibido o uso de freios dinâmicos; 1: permitido o uso de freios dinâmicos (Dynamic Break Use Indicator - 0: use of dynamic brakes not allowed; 1: use of dynamic brakes allowed)

Tolerância do Desvio da Velocidade no Controle Automático da Velocidade Limite do Trem, em Milhas por Hora (Offset Speed Margin for automatic speed limit control of train speed in MPH)

Velocidade Máxima Permitida no Controle Automático da Velocidade Limite do Trem, em Milhas por Hora (Maximum Speed Allowed for automatic speed limit control of train speed in $M P H$ )

\section{C.1.9. Parâmetros do Sistema de Frenagem Dinâmica (TEM.AIR)}

O Arquivo TEM.AIR é criado a partir de uma função do subprograma $F E B$ e contém os parâmetros para o sistema de frenagem automática a ar comprimido.

Tabela C. 8 - Conteúdos das linhas do arquivo TEM.AIR.

Pressão Máxima nos Tubos de Frenagem, em Libras por Polegada Quadrada (Maximum Break Pipe Pressure in PSI) $=\mathbf{9 0}$

Tempo de Atraso para Aplicação da Força de Frenagem, em Segundos (Characteristic Delay time fo Application in Seconds) $=3.0$

Tempo de Atraso para Resposta dos Freios, em Segundos (Characteristic Delay Time for Release in Seconds) $=1.0$

Taxa de Frenagem para Veículos Vazios (Net Braking Ratio For Empty Vehicles) = 0.3

Taxa de Frenagem para Veículos Totalmente Carregados (Net Braking Ratio For Fully Loaded Vehicles) $=0.1$

Coeficiente de Atrito das Sapatas dos Freios (Coefficient of Friction for Brake Shoes) $=0.3$ 


\section{C.1.10. Valores de Força Tratora (.THL)}

Este arquivo diz respeito aos valores das forças de tração, disponibilizadas pelas locomotivas em cada ponto de tração ( 1 a 8), sendo que para cada veículo tracionado descrito no Arquivo da Composição (.CON) deve haver um arquivo de Valores de Força Tratora (.THL) correspondente.

$\mathrm{O}$ arquivo pode ser editado pelo usuário a partir das informações de uma locomotiva específica ou pode ser utilizado um veículo do tipo EMD, cujo arquivo correspondente está inserido no pacote de instalação do Train Energy Model versão 2.5.

\section{C.1.11. Valores da Força de Frenagem Dinâmica (.DYN)}

Correspondem aos valores da força de frenagem dinâmica disponibilizada pelas locomotivas quando esse sistema é acionado. Assim como o arquivo de Valores de Força Tratora (.THL), o arquivo de Valores da Força de Frenagem Dinâmica (.DYN), relativo a cada uma das locomotivas descritas no Arquivo da Composição (.CON), pode ser configurado pelo usuário ou referir-se a um daqueles disponibilizados no pacote de instalação do simulador.

\section{C.1.12.Arquivo da Via (.TRK)}

Este arquivo é utilizado para caracterizar a via e seus equipamentos, sendo gerado a partir da função "Criar Novo Arquivo de Via" (Build New Track Chart File) do subprograma FEB e utilizado pelo programa TEM durante a simulação.

Tabela C.9 (continua) - Conteúdo do arquivo “.TRK”.

Especificação da Posição da Via, em Pés (Specified Track Position in Feet)

Elevação da Via na posição especificada, em Pés (Track Elevation at specified position in Feet)

Porcentagem da Rampa na posição especificada - e no entorno (Percent Grade at - and following - specified position)

Curva da posição especificada em relação à próxima posição, em Graus (Curve from specified position to the next in Degrees)

Velocidade Limitada na posição especificada - e no entorno - em Milhas por Hora (Speed Limita at - and following - especified position in MPH)

Marco Quilométrico na posição especificada (Milepost at specified position) 
Tabela C.9 (conclusão) - Conteúdo do arquivo “.TRK”.

Nome do local na posição especificada - se houver (Place Name at specified position - if any)

CÓDIGO DE CARACTERIZAÇÃO DO ENTORNO DA VIA

1 Componentes da Via Lubrificados (Trackside Lubricator)

2 Ponte (Bridge)

3 Viaduto (Trestle or Viaduct)

4 Sinalização de Aparelho de Mudança de Via (Mainline Switch Signal)

5 Sinalização de Cruzamento (Crossing Signal)

6 Limite de Pátio (Yard Limit)

7 Túnel (Tunnel)

8 Estação ou Pequeno Edifício (Station or Small Building)

9 Torre ou Grande Edifício (Tower or Large Building)

“CÓDIGO DE CARACTERIZAÇÃO DE DESVIOS”

1 Desvio (Siding Track)

2 Chave de Mudança de Via à esquerda (Left-hand Switch)

3 Chave de Mudança de Via à direita (Right-hand Switch)

4 Proteção Lateral - para-choque - à esquerda (Left-hand Bumper)

5 Proteção Lateral - para-choque - à direita (Right-hand Bumper)

\section{C.1.13. Arquivo de Comando (.CMD)}

O arquivo ".CMD" resulta da execução da função "Construir Novo Arquivo de Comando", (Build New Command File) do subprograma FEB, e possui os comandos para o controle do trem e da simulação durante a execução do programa TEM.

Existem dois tipos de comandos no simulador: o Comando Direto ou "Mestre" e o Comando Indireto ou “Auxiliar”. O Comando Direto é dividido em duas categorias:

1) Comandos que correspondem às configurações atuais de controle da locomotiva condutora do trem;

2) Comandos de simulação que determinam a operação do simulador.

Um Comando Direto é dividido em quatro partes: 
1. MODO de controle ou operação

2. ATRIBUIÇÃO para o modo especificado.

3. TIPO DE AÇÃO que deve ser executada antes da finalização do comando, com um intervalo de tempo decorrido, uma distância percorrida ou uma velocidade a ser atingida.

4. PARÂMETRO (ou MÉTODO) de especificação da ação, como o tempo em minutos ou segundos, distância em milhas ou pés, ou velocidade em milhas por hora.

Analogamente, um Comando Auxiliar é dividido em quatro partes.

1. Identificador da utilização de um Comando Auxiliar, definido pela palavra "HELper".

2. MODO AUXILIAR de controle (controle de regulador de pressão do sistema de frenagem a ar comprimido ou controle de frenagem dinâmica).

3. CONFIGURAÇÕES AUXILIARES para o MODO AUXILIAR especificado.

4. PARÂMETRO (ou MÉTODO) de controle da locomotiva (controle auxiliar sincronizado, controle auxiliar autônomo ou controle auxiliar fixo).

A Tabela C.10 apresenta as palavras-chave para os tipos de comandos e os seus parâmetros (ou métodos) e a Tabela C.11 mostra o conteúdo de cada linha do Arquivo de Comando. As três primeiras letras das palavras-chave, em inglês, correspondem a padrões numéricos que são utilizados para controlar o trem durante a simulação.

Tabela C.10 (continua) - Palavras-chave para criação do arquivo ".CMD”.

\begin{tabular}{|c|c|c||c|c|}
\hline $\begin{array}{c}\text { TIPO de } \\
\begin{array}{c}\text { Comando } \\
(\text { Command } \\
M O D E)\end{array}\end{array}$ & $\begin{array}{c}\text { ATRIBUIÇÃO } \\
\text { (Special } \\
\text { SETTING })\end{array}$ & $\begin{array}{c}\text { PALAVRA- } \\
\text { CHAVE } \\
(\text { KEY WORD })\end{array}$ & $\begin{array}{c}\text { MÉTODO } \\
\text { Command } \\
\text { METHOD })\end{array}$ & $\begin{array}{c}\text { PALAVRA- } \\
\text { CHAVE } \\
(\text { KEY WORD })\end{array}$ \\
\hline \multicolumn{3}{|c|}{ Regulador de Pressão (Throttle $)$} & $\begin{array}{c}\text { Intervalo de tempo que deve } \\
\text { ser decorrido }\end{array}$ \\
\hline 1 & -1 & $\begin{array}{c}\text { Ativado } \\
(\text { RUN })\end{array}$ & 1 & $\begin{array}{c}\text { Minuto } \\
\text { (MINute })\end{array}$ \\
\hline 1 & $\begin{array}{c}\text { Desativado } \\
(\text { SHUtdown })\end{array}$ & 2 & $\begin{array}{c}\text { Segundo } \\
(\text { SECond })\end{array}$ \\
\hline
\end{tabular}


Tabela C.10 (conclusão) - Palavras-chave para criação do arquivo ".CMD".

\begin{tabular}{|c|c|c|c|c|}
\hline $\begin{array}{l}\text { TIPO de } \\
\text { Comando } \\
\text { (Command } \\
\text { MODE) } \\
\end{array}$ & $\begin{array}{l}\text { ATRIBUIÇÃO } \\
\text { (Special } \\
\text { SETTING) }\end{array}$ & $\begin{array}{l}\text { PALAVRA- } \\
\text { CHAVE } \\
(K E Y W O R D)\end{array}$ & $\begin{array}{l}\text { MÉTODO } \\
\text { (Command } \\
\text { METHOD) }\end{array}$ & $\begin{array}{l}\text { PALAVRA- } \\
\text { CHAVE } \\
(K E Y W O R D)\end{array}$ \\
\hline \multicolumn{3}{|c|}{ Frenagem Dinâmica (Dynamic Brake) } & \multicolumn{2}{|c|}{$\begin{array}{l}\text { Distância que deve ser } \\
\text { percorrida }\end{array}$} \\
\hline 2 & & $\begin{array}{l}\text { Dinâmica } \\
(\text { DYNamic })\end{array}$ & 3 & Milhas (MILes) \\
\hline \multicolumn{3}{|c|}{ Frenagem a Ar Automática (Automatic Air Brake) } & 4 & Pés $(F E E t)$ \\
\hline 3 & & $\begin{array}{c}\text { Reduzida } \\
\text { (REDuction) }\end{array}$ & \multicolumn{2}{|c|}{$\begin{array}{l}\text { Velocidade que deve ser } \\
\text { atingida }\end{array}$} \\
\hline 3 & -1 & $\begin{array}{c}\text { Livre } \\
\text { (RELease) } \\
\end{array}$ & 5 & $\begin{array}{c}\text { Milhas por } \\
\text { Horas }(M P H) \\
\end{array}$ \\
\hline \multicolumn{3}{|c|}{ Frenagem a $\operatorname{Ar}($ Independent Air Brake $)$} & \multicolumn{2}{|c|}{ Tipo de Controle Auxiliar } \\
\hline 4 & & $\begin{array}{c}\text { Quando } \\
\text { solicitado } \\
\text { (INDependent) }\end{array}$ & 7 & $\begin{array}{l}\text { Sincronizado } \\
(\text { SYNchronous })\end{array}$ \\
\hline 4 & -1 & $\begin{array}{c}\text { Sempre } \\
\text { utilizado } \\
(\text { BAIloff }) \\
\end{array}$ & 8 & $\begin{array}{c}\text { Autônomo } \\
\text { (AUTonomous) }\end{array}$ \\
\hline \multicolumn{3}{|c|}{$\begin{array}{l}\text { Controle de Comando ATA (ATA Command } \\
\text { Control) }\end{array}$} & 9 & Fixo $(F I X e d)$ \\
\hline 6 & & $\begin{array}{l}\text { Constante } \\
(\text { CONstant })\end{array}$ & & \\
\hline 6 & -1 & $\begin{array}{l}\text { Limitado } \\
(\text { LIMit })\end{array}$ & & \\
\hline \multicolumn{3}{|c|}{ Controle Manual (Manual Control) } & & \\
\hline 7 & & $\begin{array}{c}\text { Manual } \\
(\text { MANual })\end{array}$ & & \\
\hline \multicolumn{3}{|c|}{ Controle Auxiliar (Helper Control) } & & \\
\hline 9 & & $\begin{array}{l}\text { Auxiliar } \\
\text { (HELper) }\end{array}$ & & \\
\hline \multicolumn{3}{|c|}{ Fim da Simulação (End Simulation) } & & \\
\hline 0 & & $\begin{array}{l}\text { Final } \\
(E N D)\end{array}$ & & \\
\hline
\end{tabular}


Tabela C.11 - Conteúdo das linhas de um arquivo “.CMD”.

Modo de Controle (Mode of control)

Atribuições do modo de controle (Setting appropriate for control mode)

Extensão (ou Alcance) do comando (Range of command)

Parâmetro (ou Método) do tipo de ação especificada (Method of specifying range)

Se o trem estiver sob o controle do ATA, durante a simulação, o Arquivo de Comando (.CMD) é gerado automaticamente após a criação do Arquivo de Paradas (.STP). Entretanto, aquele arquivo pode ser criado através do subprograma $F E B$, através da inserção dos comandos e métodos exibidos na Tabela C.10.

\section{C.1.14. Arquivo de Paradas (.STP)}

A função "Construir Novo Arquivo de Paradas" (Build New Destination File), do subprograma $F E B$, é utilizada para criar o arquivo que define os locais de parada do trem durante a simulação, locais estes caracterizados pela posição do desvio na via e o tempo de parada nesses locais. O Train Energy Model versão 2.5 estabelece um número máximo de 20 desvios em um trecho de via singela.

Tabela C.12 - Conteúdo do arquivo ".STP”.

Posição da Parada na Via, em Milhas mais o valor em Pés (Track Position of Stop - Number of Miles plus Number of Feet)

Tempo de Parada, em Minutos (Dwell Time in Minutes)

Condição da locomotiva durante o tempo de parada - 0: ociosa; -1 : desligada (Locomotive Status During Dwell Time - 0: idle; -1: shutdown)

\section{C.1.15. Coeficientes de Resistência de Curva (TEM.CRC)}

O software permite que o usuário acesse e edite um arquivo no formato de texto, o qual contém uma tabela de coeficientes de resistência de curva para seis tipos de eixos e suas condições de lubrificação.

A Tabela C.13 indica os valores numéricos de referência para cada tipo de truque e sua condição de lubrificação, utilizados para consulta à Tabela C.14, que apresenta os valores dos coeficientes empíricos - para curvas com ângulos centrais entre 0 e 15 graus, inseridos nas equações de resistência de curva, utilizadas no modelo de locomoção do simulador descrito no Anexo A. 
Tabela C.13 - Valores numéricos relativos ao tipo de truque.

\begin{tabular}{ccc}
\hline Truque & Lubrificado & Não lubrificado \\
\hline 3 eixos gastos - 3P worn & 1 & 2 \\
3 eixos novos - 3P new & 1 & 2 \\
Radial - R & 3 & 4 \\
Estrutura reforçada - FR & 5 & 5 \\
2 eixos - P2A & 6 & 6 \\
1 eixo - $1^{\text {a }}$ & 7 & 7 \\
\hline
\end{tabular}

Tabela C.14 - Coeficientes de Resistência de Curva de diferentes eixos (lbs/ton).

\begin{tabular}{cccccccccc}
\hline $\begin{array}{c}\text { Curva } \\
\text { (grau) }\end{array}$ & 1 & 2 & 3 & 4 & 5 & 6 & 7 & 8 & 9 \\
\hline 0 & 0.000 & 0.000 & 0.000 & 0.000 & 0.000 & 0.000 & 0.000 & 0.000 & 0.000 \\
1 & 0.090 & 0.056 & 0.013 & 0.017 & 0.010 & 0.015 & 0.015 & 0.000 & 0.000 \\
2 & 0.731 & 0.339 & 0.018 & 0.020 & 0.055 & 0.120 & 0.055 & 0.000 & 0.000 \\
3 & 1.548 & 0.791 & 0.206 & 0.173 & 0.200 & 0.430 & 0.110 & 0.000 & 0.000 \\
4 & 2.465 & 1.335 & 0.624 & 0.448 & 0.320 & 0.800 & 0.220 & 0.000 & 0.000 \\
5 & 3.325 & 1.907 & 1.020 & 0.747 & 0.470 & 1.130 & 0.365 & 0.000 & 0.000 \\
6 & 4.106 & 2.468 & 1.315 & 1.073 & 0.760 & 1.520 & 0.675 & 0.000 & 0.000 \\
7 & 4.767 & 3.046 & 1.505 & 1.445 & 1.120 & 1.895 & 1.235 & 0.000 & 0.000 \\
8 & 5.816 & 3.664 & 2.016 & 1.824 & 1.555 & 2.375 & 2.135 & 0.000 & 0.000 \\
9 & 6.686 & 4.298 & 2.478 & 2.206 & 1.770 & 2.915 & 5.555 & 0.000 & 0.000 \\
10 & 7.557 & 4.933 & 2.926 & 2.588 & 2.410 & 3.560 & 11.625 & 0.000 & 0.000 \\
11 & 8.427 & 5.563 & 3.376 & 2.968 & 2.705 & 4.260 & 14.170 & 0.000 & 0.000 \\
12 & 9.297 & 6.193 & 3.826 & 3.348 & 3.330 & 5.020 & 16.905 & 0.000 & 0.000 \\
13 & 10.167 & 6.823 & 4.276 & 3.728 & 4.050 & 5.865 & 19.425 & 0.000 & 0.000 \\
14 & 11.037 & 7.453 & 4.726 & 4.108 & 4.815 & 6.755 & 22.310 & 0.000 & 0.000 \\
15 & 11.907 & 8.803 & 5.176 & 4.488 & 5.695 & 7.665 & 27.685 & 0.000 & 0.000 \\
\hline
\end{tabular}

NOTA 1: Valores médios relativos aos trens vazios e carregados;

NOTA 2: Para graus de curva não exatos os valores podem ser interpolados;

O valor da última linha da coluna correspondente ao tipo de eixo deve ser utilizado para curvas com ângulos maiores que 15 graus. As duas últimas colunas do arquivo podem ser preenchidas com os coeficientes de resistência de eixos personalizados pelo usuário.

\section{C.1.16. Coeficientes de Resistência de Rolamento e dos Mancais (TEM.ROB)}

O pacote de instalação do simulador Train Energy Model versão 2.5 contém o arquivo TEM.ROB com os coeficientes utilizados no cálculo das resistências ao movimento do trem, segundo as equações descritas no Anexo A, cujos valores em relação ao tipo de mancal do veículo ferroviário são apresentados na Tabela C.15 e Tabela C.16, respectivamente. 
Tabela C.15 - Valores dos coeficientes $\mathrm{b}\left(i_{\mathrm{mk}}\right)$, de resistência dos mancais.

\begin{tabular}{cccccccc}
\hline$i_{\mathrm{M}_{\mathrm{k}}}$ & Mancal & $\mathrm{b}_{1}$ & $\mathrm{~b}_{2}$ & $\mathrm{~b}_{3}$ & $\mathrm{~b}_{4}$ & $\mathrm{~b}_{5}$ & $\mathrm{~b}_{6}$ \\
\hline 1 & "T" gasto & 0,137 & 0,00282 & $-0,0000275$ & 8,70 & $-0,1120$ & 0,001000 \\
2 & “T” novo & 0,280 & $-0,00343$ & 0,0000169 & 4,47 & 0,0208 & 0,000893 \\
3 & "B” gasto & 0,106 & 0,00518 & $-0,0000595$ & 10,90 & $-0,2290$ & 0,002420 \\
4 & “T” novo & 0,291 & $-0,00207$ & 0,0000267 & 4,55 & 0,0271 & $-0,000452$ \\
\hline
\end{tabular}

Tabela C.16 - Valores dos coeficientes $\varepsilon($ itk) e $\lambda($ itk), de resistência de rolamento.

\begin{tabular}{cccc}
\hline$i_{\mathrm{t}_{\mathrm{k}}}$ & Truque & $\varepsilon$ & $\lambda$ \\
\hline 1 & 3 eixos gastos - 3P worn & 2,25 & 2,13 \\
2 & 3 eixos novos - 3P new & 2,25 & 1,57 \\
3 & Radial - R & 1,48 & 1,43 \\
4 & Estrutura reforçada - FR & 1,48 & 1,35 \\
5 & 2 eixos - P2A & 1,47 & 1,02 \\
6 & 1 eixo - 1A & 4,25 & 1,89 \\
\hline
\end{tabular}

\section{C.2. Arquivos de saída}

\section{C.2.1. Histórico de Distribuição da Força nos Engates (.ACT)}

$\mathrm{O}$ arquivo opcional de saída de dados ".ACT" contém os valores da força nos $(n-1)$ engates dos $(n)$ veículos da composição para cada intervalo de tempo especificado no Arquivo de Inicialização “.INI”.

A primeira linha do arquivo apresenta o número $(n-1)$ de engates do trem - uma vez que a força no engate do último vagão é igual a zero e as linhas subsequentes correspondem aos parâmetros da Tabela C.17. Os valores resultantes do desempenho do trem, indicados no arquivo “.OUT”, podem ser comparados com os de força nos engates se os intervalos de saída definidos no arquivo “.INI” forem múltiplos.

Tabela C.17 - Conteúdo das linhas de um arquivo ".ACT”.

Fração das Horas do Tempo Simulado (Integral Number of Hours of Elapsed Time)

Fração dos Minutos do Tempo Simulado (Number of Minutes of Elapsed Time)

Fração dos Segundos do Tempo Simulado (Number of Seconds of Elapsed Time)

Distribuição de Forças em Libras - uma linha para cada 10 veículos, da esquerda para a direita (Force Distribution in Lbs - one line for each tem vehicles from left to right) 


\section{C.2.2. Configurações de Frenagem Dinâmica (.DES e .DE2)}

Esses arquivos apresentam uma tabela com as configurações do sistema de frenagem dinâmica, necessárias para manter os trens nas velocidades de equilíbrio entre 0 e 70 MPH, a incrementos de $5 \mathrm{MPH}$, em rampas entre 0 e -3\%, com decréscimos de 0,2\%.

As informações contidas nos arquivos “.DES" e ".DE2" diferem no fato de que este último considera que as locomotivas auxiliares, caso existam, estão em operação durante a execução da simulação, enquanto o arquivo do tipo “.DES” considera-as inativas ou inexistentes.

$\mathrm{O}$ arquivo “.DE2" só é gerado se o Arquivo da Composição (.CON) possuir em sua caracterização locomotivas auxiliares ou locomotivas principais inoperantes, durante um intervalo de simulação, e recebe o mesmo nome do Arquivo da Composição (.CON) ao ser criado.

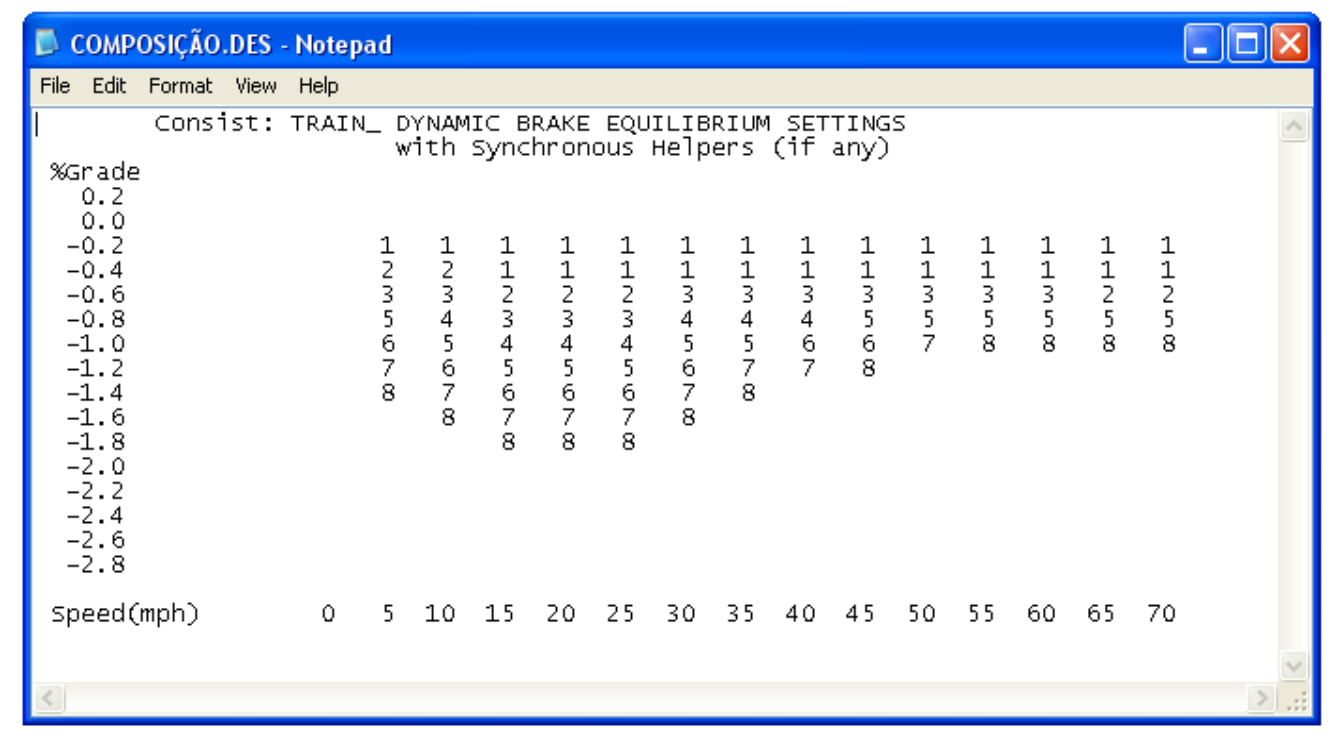

Figura C.1 - Arquivo de saída do simulador ".DES".

\section{C.2.3. Velocidades de Equilíbrio (.TES e .TE2)}

Esses arquivos contêm uma tabela com as velocidades de equilíbrio do trem, em Milhas por Hora (MPH), em pontos de tração distintos (entre 1 e 8 ) e rampas entre 0 e 3\%, com incrementos de $0,2 \%$.

A criação dos arquivos “.TES” e ".TE2" está sujeita às mesmas condições que os arquivos de Configuração de Frenagem Dinâmica (“.DES” e “.DE2”), respectivamente, em relação à existência de locomotivas auxiliares e o funcionamento das locomotivas principais. 


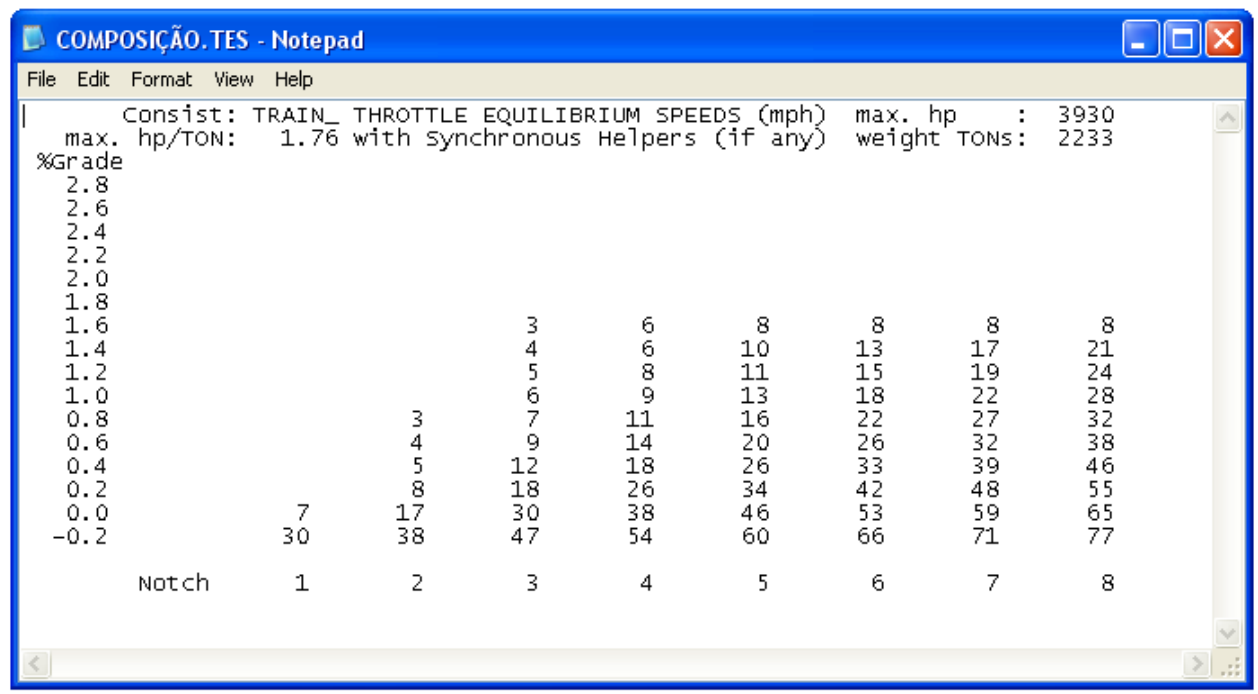

Figura C.2 - Arquivo de saída do simulador “.TES”.

\section{C.2.4. Informações sobre o Trem (.FYI e .FY2)}

Os arquivos com extensão ".FYI" e ".FY2" dizem respeito às características dos veículos do trem (Tabela C.18) e de seu desempenho durante o movimento, e estão sujeitos às mesmas condições de criação estabelecidas em relação aos arquivos com extensão “.DES”, “.DE2”, respectivamente, sobre a existência de locomotivas auxiliares e o funcionamento das locomotivas principais.

Tabela C.18 - Conteúdo de um arquivo “.FYI” (e “.FY2”).

Identificador da Composição (Consist Identifier)

Número Total de Veículos na Composição: (Total Number of Vehicles in Consist:)

Número de Locomotivas (Number of Locomotives)

Número de Locomotivas Principais em Operação (Number of Operating Leading Locomotives)

Número de Locomotivas Inoperantes e Vagões (Number of Cars and Nonoperating Locomotives)

Número de Locomotivas Auxiliares Operantes (Number of Operating Helpers) Comprimento Total do Trem, em Pés (Total Train Lenght in Feet)

Potência Total - utilizada - do Trem, em Horse-Power (Total Train Power - at the rail - in HP)

Massa Total do Trem, em Toneladas (Total Train Weight in Tons)

Massa de Combustível, em Toneladas (Weight of Fue in Tonsl)

Massa da Carga, em Toneladas (Weight of Lading in Tons)

Massa do Trem Vazio, em Toneladas (Empty Train Weigh in Tonst)

Máxima Relação Potência/Massa, em Horse-Power/Toneladas (Maximum

Power/Weight Ratio in HP/Ton) 
A Figura C.3 ilustra um arquivo de saída com extensão “.FYI”, em uma simulação sem utilização de locomotivas auxiliares.

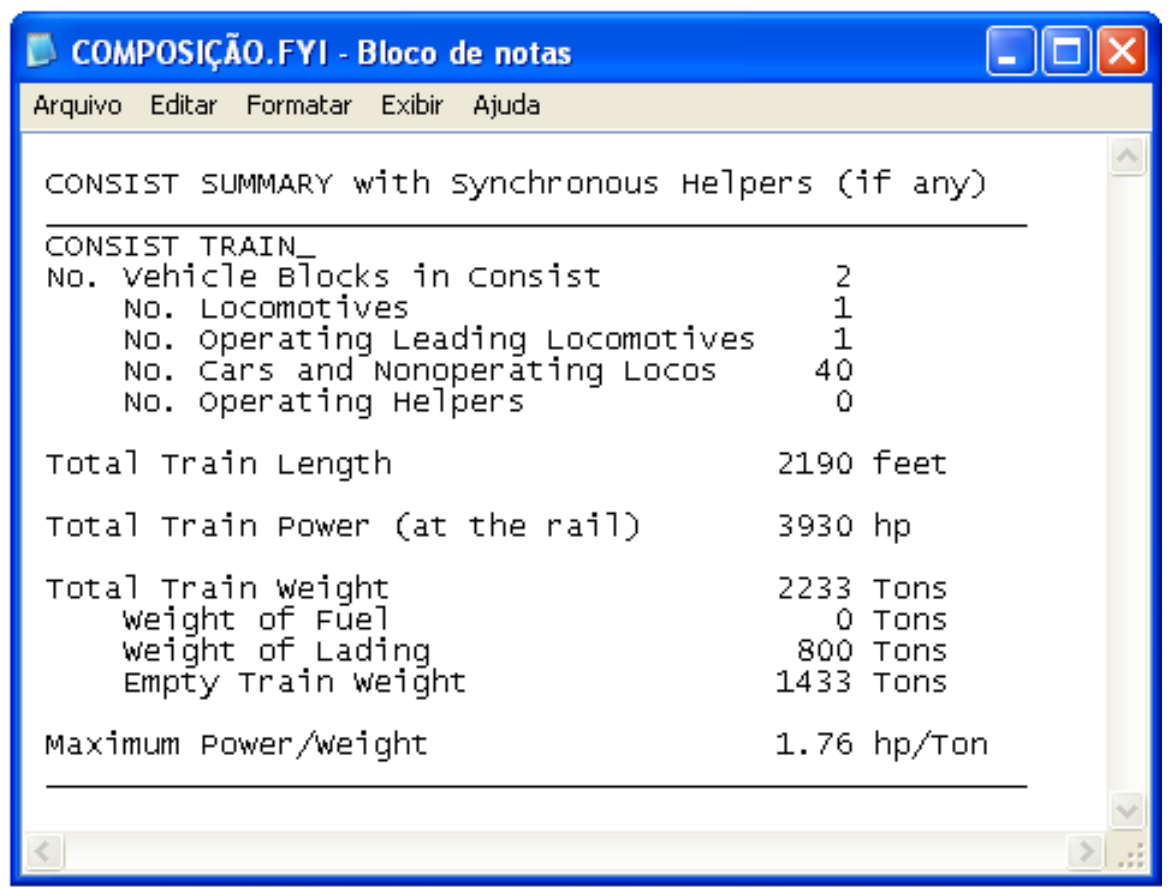

Figura C.3 - Exemplo de arquivo de saída “.FYI”.

\section{C.2.5. Reduções do Sistema de Frenagem Dinâmica no Equilíbrio (.AER)}

Este arquivo contém uma tabela com as reduções de pressão nos tubos dos freios (de 5 a 25 PSI), necessárias para manter os trens nas velocidades de equilíbrio entre 0 e $70 \mathrm{MPH}$, a incrementos de $5 \mathrm{MPH}$, e rampas entre 0 e $-3 \%$, com decréscimos de $0,2 \%$, cujo nome é igual ao do Arquivo da Composição (.CON).

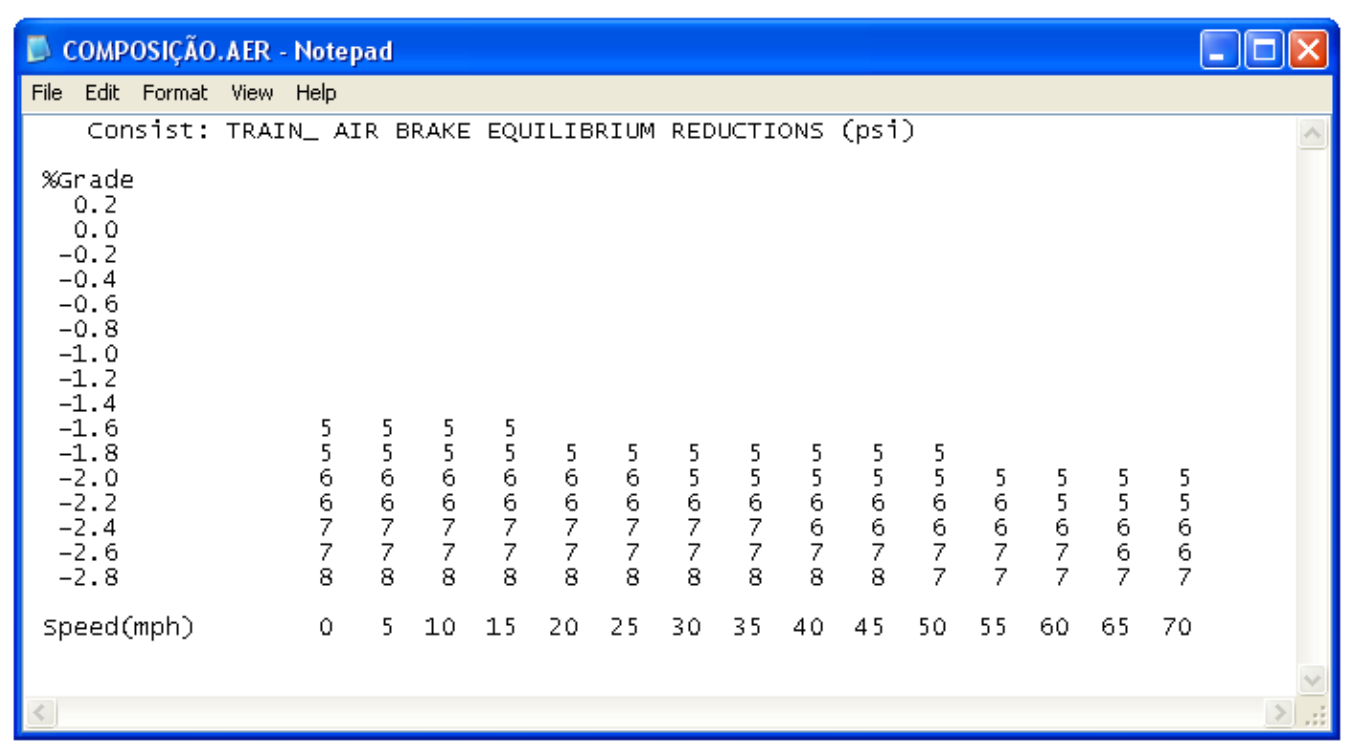

Figura C. 4 - Exemplo de arquivo do tipo “.AER”. 


\section{C.2.6. Arquivo de Saída do Simulador (.OUT)}

O arquivo ".OUT" contém os dados resultantes da simulação no intervalo de tempo definido no Arquivo de Inicialização “.INI”. Algumas de suas informações são utilizadas como dados de entrada do modelo de capacidade apresentado no Capítulo 3, uma vez que podem ser empregadas na análise do desempenho do trem na via, em função do tempo e de sua posição na via. A Tabela C.19 apresenta as informações exibidas em cada linha do arquivo ".OUT", para um intervalo de tempo especificado, cuja formatação é exemplificada na Figura C.5.

Tabela C.19 (continua) - Conteúdo das colunas em cada linha do arquivo ".OUT".

Fração das Horas de Tempo Simulado (Integral Number of Hours of Elapsed Time) Fração dos Minutos de Tempo Simulado (Integral Number of Minutes of Elapsed Time)

Fração dos Segundos de Tempo Simulado (Integral Number of Seconds of Elapsed Time)

Fração da Posição no instante definido em Milhas (Integral Number of Miles of Current Position)

Fração da Posição no instante definido em Pés (Integral Number of Feet of Current Position)

Velocidade do Trem, em Milhas por Hora (Speed of Train in MPH)

Aceleração do Trem, em Milhas por Hora por Minuto (Acceleration of Train in MPH/Min)

Consumo de Combustível Acumulado, em Galões (Cumulative Fuel Consumption in Gallons)

Valor de Tração da Locomotiva Condutora (Throttle Notch Setting: Leading Locomotive Consist)

Valor da Frenagem Dinâmica da Locomotiva Condutora (Dynamic Break Setting: Leading Locomotive Consist)

Pressão nos Tubos do Freio Automático, em Libras por Polegada Quadrada (Automatic Brake Pipe Pressure in PSI)

Pressão no Cilindro dos Freios Independentes, em Libras por Polegada Quadrada (Independent Brake Cylinder Pressure in PSI)

Configuração do Interruptor de Mudança de Sentido do Trem - Não Implementado (Reverser Switch Setting - Not Implemented)

Elevação do Veículo Condutor do Trem, em Pés (Elevation of Leading Vehicle in Train in Feet)

Velocidade Máxima Permitida, em Milhas por Hora (Current Speed Limit in $M P H)$ 
Tabela C.19 (conclusão) - Conteúdo das colunas em cada linha do arquivo ".OUT".

Força no Engate na Locomotiva Condutora, em Libras (Drawbar Force: Leading Locomotive Consist in Lbs)

Valor de Tração da Locomotiva Auxiliar (Throttle Notch Setting: Helper Locomotive Consist)

Valor da Frenagem Dinâmica da Locomotiva Auxiliar (Dynamic Break Setting: helper Locomotive Consist)

Coeficiente de Resistência de Rolamento em Libras por Tonelada - Não Implementado (Rolling Resistance Coefficient in Lbs/Ton - Not Implemented)

Ângulo de Direção do Veículo Condutor do Trem, em Graus (Direction Angle of leading Vehicle in Train in Degrees)

Projeção da Posição - em uma Tangente - da Parte Frontal do Trem, em Milhas (Tangent Position Projection in Miles)

Projeção da Posição - em uma Normal - da Parte Frontal do Trem, em Milhas (Normal Position Projection in Miles)

Indicação da Tração do Motor na Velocidade Operada - 0: acima da velocidade mínima minimorum da locomotiva; 1: abaixo da velocidade mínima minimorum da locomotiva (Traction Motor Operation Speed Indicator - 0: above greatest minimum locomotive speed; 1: below greatest minimum locomotive speed)

Direção da Parte Frontal do Veículo Condutor do Trem (Compass Heading of Leading Vehicle in Train)

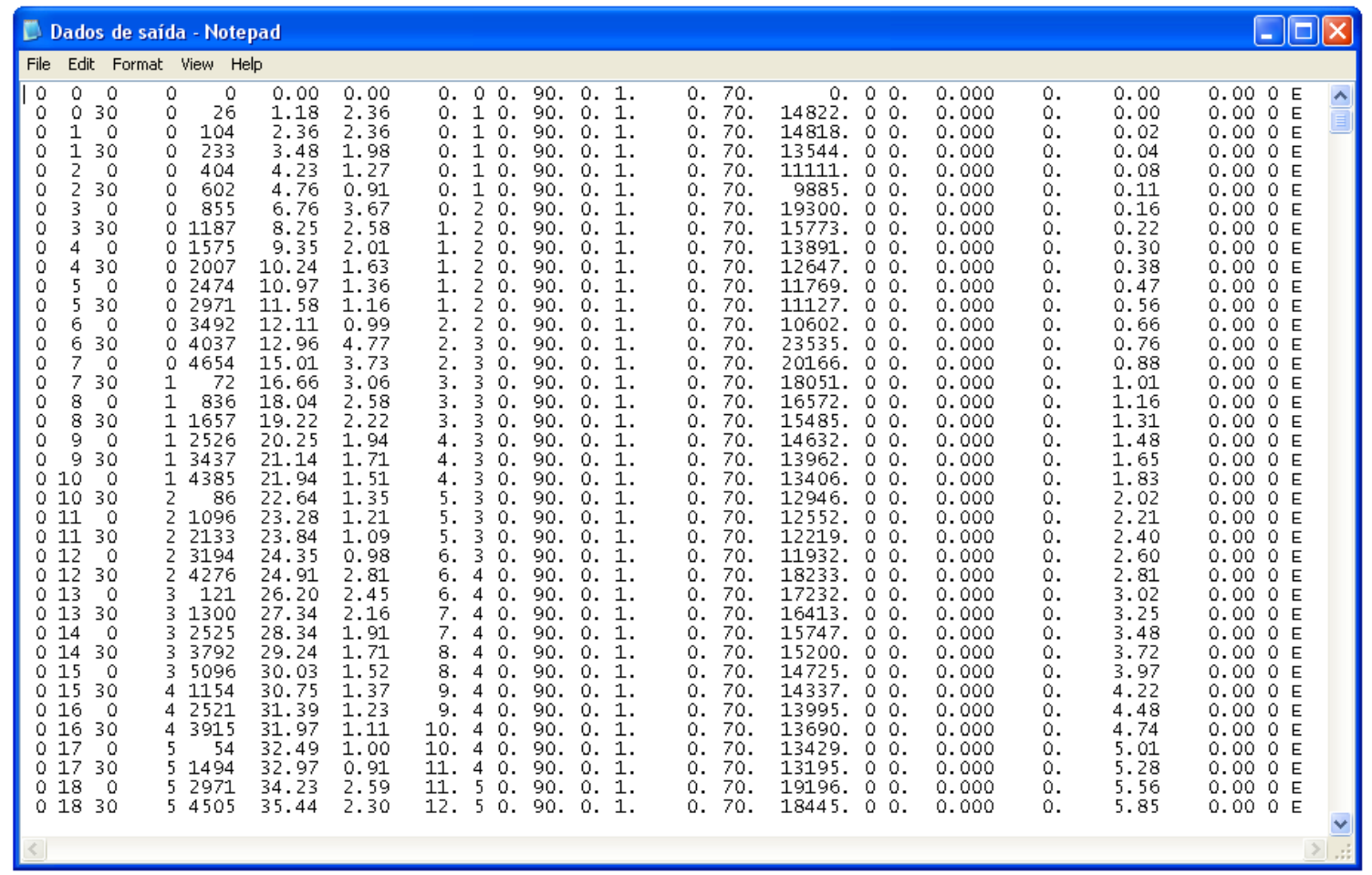

Figura C.5 - Exemplo de saída de dados do simulador. 


\section{C.2.7. Arquivo de Relatório de Simulação (.RPT)}

Os resultados finais de uma simulação são impressos em um arquivo com extensão ".RPT”, o qual pode ser acessado pelo usuário através de um editor de texto ou visualizado na forma gráfica, em conjunto com os dados do arquivo “.OUT”, pelo programa TAB. Este arquivo de relatório apresenta tabelas com os seguintes parâmetros:

\section{Configuração do Trem (Consist Summary)}

\section{Resumo da simulação (Operations Summary)}

3. Consumo de combustível nos pontos de tração (Fuel Consumption fot Throttle Settings)

4. Relação dos Pontos de Tração acionados durante a simulação (Duty Cycle)

5. Consumo de Combustível em Intervalos de Velocidade (Fuel Consumption for Speed Ranges)

6. Consumo de combustível para cada tipo de resistência - rolamento, dos mancais, curva, aerodinâmica e em rampas ascendentes (Fuel Consumption for Each Type of Resistance)

7. Trabalho realizado por cada força - resistências, freios dinâmicos e a ar comprimido e tração das locomotivas (Work Done by Each Force)

8. Tração nos motores para velocidades abaixo da mínima minimorum: $11 \mathrm{MPH}$ (Traction Motor Operation for Speeds Below Greatest Minimum Continuous Speed)

\section{C.3. Relação entre os arquivos}

A Figura C.6 exibe a relação entre os arquivos envolvidos no processo de simulação e os programas que constituem o simulador, apresentados na Figura B.1 do Anexo B. Os arquivos são identificados pela sua extensão, com três caracteres precedidos do nome do arquivo geralmente definido pelo usuário - e o caractere “.” separando-os. 


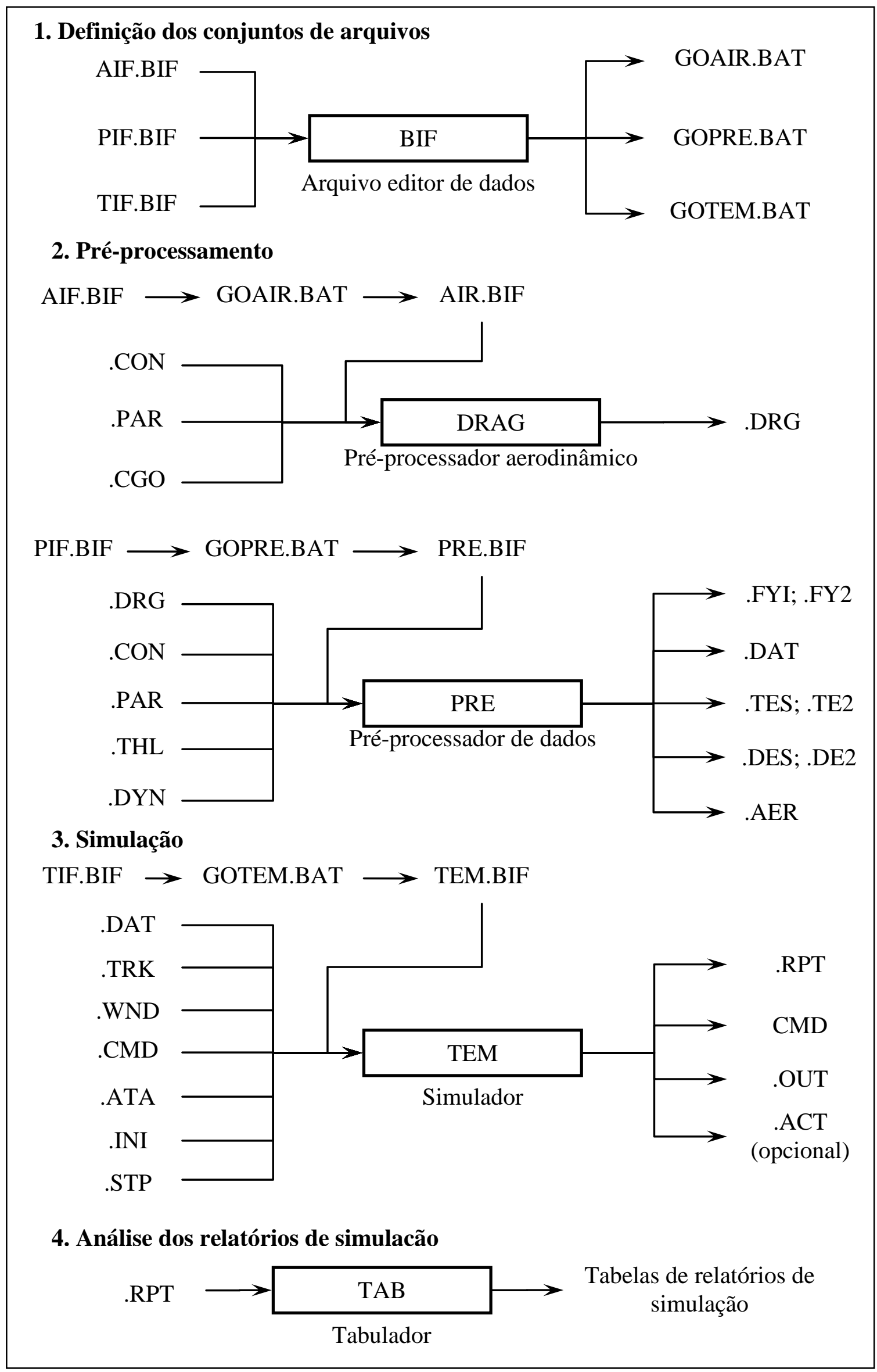

Figura C.6 - Arquivos necessários para execução das simulações. 


\section{Anexo D}

\section{EXECUTANDO O SIMULADOR TEM}

Os procedimentos descritos neste anexo tratam da sequência de comandos que deve ser executada para início de uma simulação no Train Energy Model versão 2.5, após aquisição dos dados sobre as características da via permanente, caracterização do material rodante e criação dos arquivos apresentados no Anexo C.

1. Criar um diretório específico destinado aos programas e arquivos do simulador;

2. Inserir os programas que constituem o simulador no diretório;

3. Configurar os seguintes arquivos de dados de entrada descritos no Anexo $\mathrm{C}$ e inseri-los no diretório:

- Arquivo de Carregamento (.CGO)

- Arquivo da Composição (.CON)

- Arquivo de Parâmetros dos Veículos (.PAR)

- Arquivo de Inicialização (.INI)

- Arquivo de Configuração das Condições Ambientais (.WND)

- Arquivo de Parâmetro ATA - Automatic Train-handling Algorithm (.ATA)

- Arquivo de Valores de Força Tratora (.THL)

- Arquivo de Valores da Força de Frenagem Dinâmica (.DYN)

- Arquivo de Configuração da Via (.TRK)

- Arquivo de Comando (.CMD)

- Arquivo de Paradas (.STP)

4. Inserir o Arquivo de Parâmetros de Veículos (.PAR), o Arquivo da Composição (.CON) e 
o Arquivo de Carregamento (.CGO), se este existir, no diretório;

5. Inserir o arquivo "AIF.BIF" no diretório, com o nome do Arquivo da Composição (.CON) na $2^{\mathrm{a}}$ linha;

6. Se for de interesse que seja computada a área de arrasto do trem, executar o programa $D R A G$, que resultará na criação do arquivo auxiliar "FILES";

7. Seja qual for a ação definida no item 6, executar o programa $E D I$, selecionar a opção "BATCH FILE EDITOR", em seguida a opção "Create new program DRAG batch file: GOAIR.BAT”, e digitar o nome do Arquivo da Composição (.CON);

8. Executar o arquivo GOAIR, que resultará na criação dos arquivos auxiliares "AIR.ACN", “AIR.DRG”, “AIR.TEM”, “STRINGS4” e “AIR.BIF”,

9. Inserir os arquivos "PIF.BIF" no diretório do simulador, com o nome do Arquivo da Composição (.CON) na $3^{\mathrm{a}}$ linha;

10. Inserir o arquivo "TEM.AIR" no diretório;

11. Inserir no diretório o Arquivo de Valores de Força Tratora (.THL), referente a cada uma das locomotivas, com o nome Arquivo de Parâmetros dos Veículos (.PAR);

12. Inserir no diretório o Arquivo de Valores de Força de Frenagem Dinâmica (.DYN), referente a cada uma das locomotivas, cujos nomes devem ser iguais aos do Arquivo de Parâmetros dos Veículos (.PAR), seguidos do tipo de frenagem (ar comprimido ou dinâmica);

13. Executar o programa EDI, selecionar a opção “BATCH FILE EDITOR” e, em seguida, a opção “Create new program PRE batch file: GOPRE.BAT”. Definir se é desejado que o lote de arquivos seja criado a partir do programa $P R E$, cuja opção é dada pela sentença "Criar o lote de arquivos PRE - 1: Sim; 0: Não" (PRE batch indicator - 1: Batch; 0: Reset).

Ainda durante a execução do programa EDI, digitar o nome do Arquivo da Composição (.CON), definir o número de locomotivas principais da composição (maior ou igual a 1) e optar pela utilização ou não do arquivo de área de arrasto, definido pela sentença "Utilizar o arquivo (.DRG) criado a partir do programa DRAG? Y: Sim; N: Não (Bypass DRAG file? Y: Yes; N: No)"; 
14. Executar o programa GOPRE, que resulta na criação dos arquivos auxiliares ".AER", “.DES”, “.FYI”, “.TES”, “.DAT” - e “.DE2”, “.FY2”, “.TE2”, caso sejam utilizadas locomotivas auxiliares, cujos nomes são iguais aos do Arquivo de Composição (.CON);

15. Inserir no diretório do simulador o arquivo "TIF.BIF", com o nome do Arquivo da Composição (.CON) na $3^{\mathrm{a}}$ linha;

16. Inserir no diretório do simulador o Arquivo de Parâmetros de Inicialização (.INI), de Configuração das Condições Ambientais (.WND), de Parâmetro ATA - Automatic Trainhandling Algorithm (.ATA), e Configuração da Via (.TRK), de Comando (.CMD) e o de Paradas (.STP). O Arquivo de Parâmetros de Inicialização (.INI), de Parâmetro ATA Automatic Train-handling Algorithm (.ATA), de Comando (.CMD) e o de Paradas (.STP) devem ter o mesmo nome para o correto funcionamento da simulação.

17. Inserir os Arquivos dos Coeficientes de Resistência de Curva (.CRC), o Arquivo dos Coeficientes de Resistência de Rolamento e dos Mancais (TEM.ROB) e os arquivos auxiliares "EGAVGA.BGI" e "FF7L.ERR", necessários à visualização do movimento do trem e identificação de possíveis erros durante a simulação, respectivamente.

18. Executar o programa EDI, selecionar a opção "BATCH FILE EDITOR”, a opção "Create new program TEM batch file: GOTEM.BAT”, e digitar o nome do Arquivo de Inicialização (.INI);

19. Executar o programa GOTEM para início da simulação, que resulta na criação dos arquivos “.OUT”, “.RPT”, cujos nomes são iguais aos do Arquivo de Inicialização (.INI);

20. Executar o programa $E V A$, selecionar a opção "REPORT TABULATOR" para visualização dos dados dos arquivos de saída na forma de tabelas e gráficos padronizados;

21. Executar o programa EVA, selecionar a opção "OUTPUT DATA PLOTTER" para visualização gráfica dos resultados de desempenho do trem na via em relação à força tratora utilizada, força de frenagem, consumo de combustível etc. 